\title{
FERRAMENTAL DE GESTÃO DE ÁGUAS SUBTERRÂNEAS PARA A CIDADE DE SÃO JOSÉ DO RIO PRETO, SP
}

\author{
Jefferson Nascimento de Oliveira
}

Tese apresentada à Escola de Engenharia de São Carlos, da Universidade de São Paulo, como parte dos requisitos para obtenção do título de Doutor em Hidráulica e Saneamento

ORIENTADOR: Prof. Dr. Edson Wendland 
À minha esposa Edna, incentivadora e colaboradora em todos os momentos.

À minha filha Ana Carolina, que por meio de seu sorriso sempre demonstrou seu amor e transmitiu a força de que eu necessitava para continuar. 
"Experiência é o nome que damos aos nossos próprios erros" Oscar Wilde 


\section{AGRADECIMENTOS}

Ao Prof. Dr. Edson Wendland, meu orientador, pela confiança depositada em mim, por ter acreditado neste trabalho e pela valiosa e inigualável ajuda durante a execução do mesmo.

Ao Prof. Dr. Fazal Hussain Chaudhry, pela orientação, amizade e pelo incentivo e auxílio que me permitiram a realização do estágio na Stanford University.

Aos professores do Departamento de Hidráulica e Saneamento da EESC, USP, pelo apoio e ensinamentos.

A Profa. Dra. Maria do Carmo Calijuri, por sua valorosa ajuda e senso de humanidade.

Ao Prof. Dr. Peter K. Kitanidis, do Departamento de Engenharia Civil e Ambiental da Stanford University, e ao Dr. Paul Hsieh, do USGS - Menlo Park, pelos ensinamentos.

Ao amigo Prof. Dr. Evaldo Luiz Gaeta Espíndola, pela cobrança nos momentos certos e apoio incondicional.

Aos colegas da área de Hidráulica e Saneamento da Unesp, campus de Ilha Solteira, Dib, Tsunao, Milton, Edson e Geraldo, pelo apoio e incentivo.

Ao SeMAE de São José do Rio Preto, na pessoa do Eng. Rosemiro, ao DAEE de Araraquara, por intermédio de todo seu corpo técnico, pelo fornecimento dos dados, e à Secretaria de Planejamento de São José do Rio Preto, pela disponibilização dos mapas da cidade.

Ao Prof. Dr. Renato Bertolino Júnior, pelo auxílio no uso da programação para AutoCad.

Aos técnicos da Unesp, campus de Ilha Solteira, por sua colaboração na confecção dos mapas, visita aos poços estudados e trabalhos computacionais: Aldir, Ozias, Cavassano e Renato.

À Sá e Pavi, secretárias do Departamento de Hidráulica e Saneamento, EESC, USP, pela atenção e força demostradas em diversos momentos.

Ao Valdeci, desenhista do Departamento de Hidráulica e Saneamento da EESC, USP, pela plotagem da versão final dos mapas.

Aos colegas do SHS, Jorge, Giovanni, Selma e Quaresma; e à Cíntia e ao Filipe, alunos de Engenharia Civil da Unesp, campus de Ilha Solteira, pela preciosa colaboração com os dados.

Às famílias Batistelle-Espíndola, Sé, Ribeiro-Martins, Folz e Lobos-Pozo, pela amizade.

À Unesp, campus de Ilha Solteira, pela concessão dos afastamentos no Brasil e exterior.

À Capes, pela concessão das bolsas de estudos dos programas PICD e PDEE. 


\section{SUMÁRIO}

$\begin{array}{lr}\text { LISTA DE FIGURAS } & \text { i }\end{array}$

$\begin{array}{ll}\text { RESUMO } & \text { iii }\end{array}$

ABSTRACT

1. Introdução 1

2. Revisão de literatura 4

2.1 Modelos matemáticos $\quad 4$

2.1.1 Tipos e usos de modelos matemáticos 5

2.1.2 Equações básicas $\quad 6$

$\begin{array}{ll}\text { 2.1.3 Condições auxiliares } & 7\end{array}$

$\begin{array}{ll}\text { 2.1.3.1 Condições iniciais } & 7\end{array}$

2.1.3.2 Condições de fronteira

2.1.4 Caso bi-dimensional para aqüífero freático $\quad 8$

$\begin{array}{ll}2.1 .5 \text { Métodos numéricos } & 10\end{array}$

2.1.6 Os programas MODFLOW e SICK100 13

$\begin{array}{ll}2.2 \text { Calibração do modelo } & 16\end{array}$

$\begin{array}{ll}\text { 2.2.1 Conceitos básicos } & 18\end{array}$

2.2.2 Tipos de solução para problema inverso 19

2.2.2.1 Método de tentativa e erro $\quad 20$

$\begin{array}{ll}\text { 2.2.2.2 Solução indireta } & 20\end{array}$

2.2.2.3 Solução direta $\quad 21$

2.2.3 Aproximação geoestatística 22

2.2.3.1 Conceitos básicos de geoestatística 23

2.2.3.2 Geoestatística linear $\quad 25$

2.2.3.3 Krigagem simples $\quad 26$

$\begin{array}{ll}\text { 2.2.3.4 Krigagem ordinária } & 27\end{array}$

$\begin{array}{ll}2.2 .4 \text { Aplicações práticas } & 28\end{array}$

$\begin{array}{lr}\text { 3. Metodologia } & 30\end{array}$

3.1 Planejamento do modelo conceitual 30

3.2 Caracterização da área de estudo $\quad 30$ 
3.2.2 Caracterização física

3.2.2.1 Geologia e Hidrologia

3.2.2.2 Geomorfologia

3.2.2.3 Pedologia e uso do solo

3.2.3 Características climáticas

3.2.4 Fluviometria

3.3 Catalogação dos poços existentes

3.4 Concepção do modelo

3.4.1 Determinação das fronteiras

3.4.2 Determinação das condições de contorno

3.4.3 Geração de malha

3.4.4 Determinação dos parâmetros geométricos

3.4.5 Parâmetros de entrada

3.5 Balanço hídrico

4. Resultados e discussão

4.1 Ajuste do modelo base

4.1.1 Cargas hidráulicas

4.1.2 Espessura da zona saturada

4.1.3 Estimativa do nível dinâmico

4.1.4 Velocidade

4.2 Análise de cenários

4.2.1 Ampliação da área urbanizada 75

4.2.2 Redução de precipitação

5. Conclusões e recomendações

ANEXO 1 - Temperatura - São José do Rio Preto. Médias de 1996 a 2000 
ANEXO 4 - Dados referentes aos poços registrados no SeMAE - São José do Rio

Preto

ANEXO 5 - Dados referentes aos poços registrados no Comitê de Bacia do Turvo/Grande 


\section{LISTA DE FIGURAS}

FIGURA 1 (a) Fluxo da água normal num aqüífero; (b) aproximação de Dupuit.

FIGURA 2 Representação do método das diferenças finitas e elementos finitos. (a) Mapa da área de estudo e condições de contorno; (b) mapa de diferenças finitas; (c) discretização nos vértices malha de elementos finitos.

FIGURA 3

Características que podem ser simuladas com o uso do MODFLOW.

FIGURA 4

Discretização espacial de um sistema aqüífero multicamada.

FIGURA 5

Fluxograma do método de Tentativa e Erro.

FIGURA 6

Fluxograma do método indireto.

FIGURA 7

Fluxograma do método direto.

FIGURA 8

Representação gráfica de um variograma experimental com modelo ajustado.

FIGURA 9 Vista aérea parcial da área urbana de São José do Rio Preto.

FIGURA 10 (a) Visualização da bacia do Turvo/Grande em cor laranja (sem escala); (b) localização da sub-bacia do Rio Preto em amarelo (sem escala); (c) detalhe do município de São José do Rio Preto e seus limites.

FIGURA 11 Mapa topográfico da região de estudo.

FIGURA 12 Mapa geológico da região.

FIGURA 13 Relações geométricas e de fluxo das águas nos aqǘferos da Bacia Hidrográfica do Turvo/Grande.

FIGURA 14 Geomorfologia da região de estudo.

FIGURA $15 \quad$ Mapa dos solos da região de estudo.

FIGURA 16

Mapa de uso do solo na região.

FIGURA 17

(A) Seção transversal; (B) curva-chave do posto 6B-011.

FIGURA 18

Distribuição de vazões (m³/s) para o Rio Preto em 1992.

FIGURA 19 Rede hidrográfica da região de estudo.

FIGURA 20

Distribuição dos poços na região de estudo.

FIGURA 21

Malha gerada pelo SICK100.

FIGURA 22 Detalhe da malha na região central do modelo. 
FIGURA $23 \quad$ Taxas de recarga.

$\begin{array}{lll}\text { FIGURA } 24 & \text { Condutividades inferidas ao modelo. } & 58\end{array}$

FIGURA 25 (a) Foto de satélite das duas represas; (b) foto aérea mostrando represa assoreada (anos 60); (c) foto aérea mostrando represa nova (anos 80). 59

FIGURA 26 Foto aérea mostrando detalhe do assoreamento ocorrido na represa. $\quad 60$

FIGURA 27 Esquema da hipótese sobre a colmatação do leito do lago. 61

FIGURA $28 \quad$ Mapa de isolinhas do potencial de carga subsuperficial. 66

$\begin{array}{lll}\text { FIGURA } 29 & \text { Mapa de isovalores do topo da Fm. Serra Geral. }\end{array}$

$\begin{array}{lll}\text { FIGURA } 30 & \text { Mapa de isovalores de espessura da zona saturada. } & 69\end{array}$

$\begin{array}{lll}\text { FIGURA } 31 \quad \text { Níveis estáticos estimados para a década de } 70 . & 70\end{array}$

FIGURA $32 \quad$ Níveis estáticos gerados por krigagem para a década de 90.

FIGURA $33 \quad$ Mapa de isovalores de N.D.

$\begin{array}{lll}\text { FIGURA } 34 & \text { Mapa de vetores de velocidade de escoamento. } & 74\end{array}$

FIGURA $35 \quad$ Mapa de taxas de recarga para o crescimento da periferia. $\quad 77$

FIGURA $36 \quad$ Mapa de isolinhas do potencial para a zona urbanizada expandida. $\quad 78$

FIGURA $37 \quad$ Mapa de isovalores de espessura da zona saturada (crescimento da zona 79 urbanizada).

FIGURA $38 \quad$ Mapa de taxas de recarga (chuva reduzida). $\quad 81$

FIGURA $39 \quad$ Mapa de cargas hidráulicas (chuva reduzida). $\quad 82$

FIGURA $40 \quad$ Mapa de espessura da zona saturada (chuva reduzida). 83

FIGURA $41 \quad$ Mapa de isovalores de profundidade do N.D. (chuva reduzida). $\quad 84$ 


\section{RESUMO}

OLIVEIRA, J. N. (2002). Ferramental de gestão de águas subterrâneas para a cidade de São José do Rio Preto, SP. São Carlos, 2002. 117p. Tese (Doutorado) - Escola de Engenharia de São Carlos, Universidade de São Paulo.

Tendo em vista a crescente utilização de mananciais subterrâneos para o abastecimento público, a modelação numérica do fluxo de água subterrânea vem continuamente ganhando importância como ferramenta imprescindível de suporte a decisões inerentes ao gerenciamento desse recurso hídrico. Nesse contexto, o meio acadêmico representa o ambiente ideal para o desenvolvimento e a avaliação de ferramentas e metodologias adequadas ao gerenciamento de águas subterrâneas, sob a ótica específica de problemas com características nacionais. Neste trabalho foi desenvolvida uma metodologia de gerenciamento, visando a sua possível utilização pelos órgãos gestores dos recursos hídricos subterrâneos. O ferramental desenvolvido enfocou a descrição, a catalogação e a extrapolação dos dados necessários à representação de todas as características físicas e hidrogeológicas da área de estudo. Posteriormente foi sistematizada a disponibilização em formato adequado à sua utilização no ambiente de trabalho do pacote SICK100, desenvolvido na Faculdade de Engenharia Civil da Ruhr-Universität Bochum. Esse pacote computacional, com base no Método de Elementos Finitos, permite a construção de modelos de fluxo de alta complexidade. A área urbana da cidade de São José do Rio Preto, abastecida principalmente por poços tubulares que captam água do Aqüífero Bauru, foi selecionada para a aplicação prática da metodologia desenvolvida. A região tem mais de 600 poços produtores cadastrados e 3500 poços clandestinos, que retiram aproximadamente $5000 \mathrm{~m}^{3} / \mathrm{h}$ do aqüífero livre. Com base nessas informações e dados climáticos, foi construído um modelo numérico que permitiu simular toda a complexidade hidrogeológica da área. Também foram feitos prognósticos para dois cenários: um com diminuição da precipitação e outro com o aumento da área urbanizada e conseqüente impermeabilização. Os reflexos dessas hipóteses na dinâmica atual foram avaliados, sendo possível notar um colapso do sistema de captação, na região central da cidade, caso um dos prognósticos venha a ocorrer. O ferramental desenvolvido demonstrou ser útil ao gerenciamento de recursos hídricos, tendo ampliado o conhecimento das condições do fluxo na região.

Palavras-chave: água subterrânea; Aqüífero Bauru; São José do Rio Preto; gerenciamento de recursos hídricos; modelação numérica; método de elementos finitos. 


\section{ABSTRACT}

OLIVEIRA, J. N. (2002). A groundwater management tool for São José do Rio Preto, SP, Brazil. São Carlos, 2002. 117p. Tese (Doutorado) - Escola de Engenharia de São Carlos, Universidade de São Paulo.

Considering the growing use of groundwater sources for public supply, numerical modeling of groundwater flow becomes an indispensable tool for decision support and adequate management of this natural resource. In this context, the academic circle represents, under the specific optics of problems with national characteristics, the ideal environment for the development and evaluation of tools and methodologies adapted to groundwater management. In this work, it was developed a management methodology which aims at its possible systematization and use by the water resources management agencies. The developed tool focused the description, cataloguing and extrapolation of all hydrogeological and physical characteristics of the study area, as it is necessary for the definition of a conceptual model. Furthermore, the data were in order to be used within the package SICK100 developed by the School of Civil Engineering at the Ruhr-University Bochum. This computational package, based on the Finite Element Method, allows the construction of highly complex flow models, and it is executed under LINUX platform. The urban area of São José do Rio Preto, mainly provisioned by deep wells which capture water from the Bauru Aquifer, was selected for the practical application of the developed methodology. The area is exploited by more than 600 registered and 3500 clandestine wells which remove approximately $5000 \mathrm{~m}^{3} / \mathrm{h}$ from the free aquifer. Based on these information and regional climatic data, it was developed a numerical flow model which allowed to simulate the entire hydrogeological complexity of the area. Prognostics were made for two different sceneries: one presented decrease of the precipitation, and another the increase of the urbanized area and consequent impermeabilization. The reflexes of those hypotheses in the current dynamics were appraised, indicating a possible collapse of the aquifer in the central area of the city, if one of the prognostics occurs. The methodology demonstrated to be useful for groundwater resources management, improving the understanding of the flow conditions in the model area.

Key words: groundwater; Bauru Aquifer; São José do Rio Preto; water resources management, numerical modelling; finite element method. 


\section{INTRODUÇÃO}

Os recursos hídricos subterrâneos constituem aproximadamente $97 \%$ de toda a água doce disponível no planeta. Sua utilização pelo ser humano é remota, havendo indícios de seu uso, pelos chineses, no ano 5000 a.C., segundo REBOUÇAS (1999), LEAP (1999) e FEITOSA \& MANUEL FILHO (2000). O Brasil dispõe de um volume de 112.000 quilômetros cúbicos de água em suas reservas subterrâneas, de acordo com FEITOSA \& MANUEL FILHO (2000). Conforme dados do DAEE (1999), 61\% da população brasileira é abastecida por água subterrânea: $43 \%$ por poços tubulares, $12 \%$ por fontes ou nascentes e $6 \%$ por poços escavados (tipo Amazonas).

No Estado de São Paulo, segundo CETESB (1997a), 72\% das cidades utilizam-se de água subterrânea no sistema de abastecimento, sendo $48 \%$ abastecidas exclusivamente por esse manancial. Além disso, $90 \%$ das indústrias também usam o recurso hídrico subterrâneo. De acordo com o DAEE (2000), no Balanço Hídrico do Estado de São Paulo, dos 100 bilhões de $\mathrm{m}^{3} /$ ano correspondentes ao escoamento total, 41 bilhões, ou $1.285 \mathrm{~m}^{3} / \mathrm{s}$, são oriundos do escoamento básico, parcela responsável pela regularização dos rios.

A importância do recurso hídrico subterrâneo na Bacia do Rio Turvo/Grande, onde se localiza a região de estudo do presente trabalho, pode ser verificada pelo índice de utilização da disponibilidade hídrica subterrânea da bacia, que é de $62,17 \%$, o segundo maior do Estado de São Paulo, de acordo com DAEE (2000). Deve-se salientar que, dentre as solicitações de outorga para uso de recursos hídricos, os pedidos de licença para construção de novos poços aparecem em primeiro lugar, principalmente na cidade de São José do Rio Preto, SP.

A importância de criar um modelo conceitual para a área urbana da cidade de São José do Rio Preto advém da necessidade de um ferramental adequado para o gerenciamento, tendo em vista a superexplotação existente na região e o rebaixamento do nível estático do Aqüífero Bauru, aliado ao consumo crescente, onde $70 \%$ do abastecimento público é garantido pela água subterrânea.

Nesse contexto, uma preocupação dos órgãos responsáveis pelo gerenciamento da água no Estado de São Paulo refere-se à proteção e ao uso racional da água subterrânea, principalmente no que tange às áreas de recarga dos aqüíferos. Para que isso ocorra 
efetivamente, já existem leis e decretos que visam proteger e recuperar os mananciais subterrâneos, podendo-se destacar a Lei 7663/91, que estabeleceu a Política Estadual de Recursos Hídricos, e o Decreto 3255/91, que se aplica à preservação dos depósitos naturais de água subterrânea.

Mais recentemente, o Conselho Nacional de Recursos Hídricos - CNRH, com base na resolução $\mathrm{n}^{\mathrm{o}}$ 22, de 24 de maio de 2002, estabeleceu diretrizes complementares para a elaboração dos planos de recursos hídricos das bacias hidrográficas, as quais devem considerar a caracterização dos aqǘferos envolvidos, bem como definir as inter-relações de cada aqüífero com os cursos d'água superficiais, promovendo assim uma gestão integrada das informações disponíveis dos recursos hídricos.

Nos Estados Unidos, o USGS (United States Geological Survey), órgão gestor dos recursos hídricos, está implementando um sistema de avaliação quanti e qualitativa da água subterrânea, incluindo a utilização de SIG (Sistema de Informações Geográficas), a fim de que se possa monitorar esse recurso hídrico. Como enfatizaram ENGEL \& NAVULUR (1999) e GOGU et al. (2001), a disponibilidade dos dados de um sistema aqüífero em um modelo conceitual torna mais viável o estudo da variabilidade espacial e temporal desse sistema, podendo ser acoplado a programas de modelação numérica para estimativa de cenários futuros.

No entanto, dispor apenas de dados tabulados e/ou distribuídos espacialmente não gera prognósticos sobre o comportamento futuro da água subterrânea em determinado local. Por isso, há na comunidade científica mundial grande interesse em modelar dados referentes ao escoamento em águas subterrâneas, obtendo bons resultados, ou seja, que o erro entre a estimativa e o dado real seja mínimo. Modelar numericamente aqüíferos e analisar a variabilidade espacial do fluxo vem sendo alvo de muitos estudos nas últimas décadas, quando uma grande quantidade de modelos matemáticos foi criada e simulações foram propostas (KRESIC, 1997).

No presente trabalho buscou-se criar um ferramental de suporte para gestão dos dados hidrogeológicos disponíveis nos órgãos oficiais que administram a água subterrânea de São José do Rio Preto. Para tal, foi elaborado um modelo determinístico, baseado em elementos finitos e incluindo as medidas de campo realizadas pelo SeMAE (Serviço Municipal de Abastecimento de Água e Esgoto de São José do Rio Preto) e pelo DAEE (Departamento de Águas e Energia Elétrica), visando analisar o comportamento do aqǘ́fero na região de estudo e indicar os possíveis direcionamentos para uma ação futura no que tange à utilização da água subterrânea.

O trabalho teve por objetivo, ainda, a comprovação do decaimento dos níveis estáticos dos poços na região de estudo, relatado pelo DAEE (1990), no Plano Estadual de 
Recursos Hídricos. Para isso, compararam-se dados coletados na década de 70 com outros mais recentes, dos anos 90 .

Também foram organizados os dados hídricos e hidrogeológicos disponíveis, a fim de elaborar um estudo do balanço hídrico regional do aqüífero em relação às demandas atuais, com estimativa das recarga e descarga, naturais e artificiais.

Finalmente, foram gerados cenários hipotéticos do comportamento da água subterrânea em São José do Rio Preto. Foram efetuados prognósticos de crescimento da área urbana a fim de visualizar possíveis reações do sistema aqüífero às mudanças inseridas no modelo.

De posse das ferramentas computacionais já citadas, foi realizada uma caracterização detalhada da área urbana da cidade de São José do Rio Preto, SP, que utiliza o sistema aqüífero Bauru para a captação de água subterrânea para o abastecimento público. Dessa forma, uma análise de fluxo foi executada, visando configurar o comportamento geral do Aqüífero Bauru e ampliar o conhecimento sobre esse manancial subterrâneo.

O ferramental desenvolvido por este estudo permite que, no futuro, novas características da região, como uso do solo, aumento do número de poços produtores e variações dos níveis estáticos e dinâmicos, possam ser incorporadas. Dessa forma, possíveis imprecisões no modelo proposto podem ser corrigidas por meio de modelagens futuras, com adequação dos resultados às condições reais. 


\section{REVISÃO DE LITERATURA}

O presente trabalho teve por enfoque principal a construção de um modelo matemático computacional que reproduzisse o comportamento hidráulico do aqüífero Bauru na área urbana, arredores e zona rural da cidade de São José do Rio Preto. Assim, são expostos a seguir trabalhos relacionados aos modelos matemáticos e suas aplicações em água subterrânea.

\subsection{Modelos matemáticos}

Os modelos matemáticos computacionais constituem uma ferramenta que vem sendo utilizada há muitas décadas para representar a realidade de uma maneira simplificada. Nos últimos anos, a modelação matemática da água subterrânea tem se destacado no planejamento e/ou no gerenciamento dos recursos hídricos subterrâneos, visando à proteção, à exploração e, quando necessário, à recuperação ou à descontaminação de aqüíferos.

Deve-se ter em mente que a necessidade de quantificar e analisar os fenômenos que envolvem o fluxo e o transporte nesses sistemas é de suma importância para garantir a proteção de um manancial subterrâneo. A quantificação pode ser feita por intermédio da modelação matemática, uma vez que um inventário completo da situação, por meio de levantamentos de campo, é difícil e oneroso para ser realizado. Assim, faz-se uso dos modelos matemáticos para representar uma aproximação da realidade física existente.

O uso dos modelos matemáticos, aplicados ao fluxo da água subterrânea, pode ter por objetivos, segundo CLEARY (1989):

1. locação de poços para abastecimento;

2. análise de alternativas para a descontaminação;

3. previsão dos fenômenos de fluxo e de transporte em sistemas aqǘferos heterogêneos, anisotrópicos e estratificados;

4. delineamento de áreas de proteção e contribuição de poços sob condições de anisotropia e heterogeneidade; 
5. rastreamento de contaminantes;

6. otimização dos recursos hídricos subsuperficiais.

Muitas vezes, porém, os resultados fornecidos pelos modelos são imperfeitos, pois, na tentativa de simplificação, tende-se a incorrer em erros. É necessário comparar os resultados com os dados obtidos em campo, se possível. De acordo com KRESIC (1997), muitas vezes o usuário dos modelos matemáticos computacionais não está atento às limitações técnicas destes, além de não perceber algumas "verdades":

- os modelos estão baseados em várias suposições referentes ao sistema real que está sendo modelado;

- os parâmetros hidrológicos e hidrogeológicos são simplesmente uma aproximação da distribuição real e nunca são determinados com total precisão;

- as equações diferenciais teóricas que descrevem o fluxo de água subterrânea são substituídas por sistemas de equações algébricas razoavelmente precisas.

Apesar do exposto, os modelos são válidos, pois garantem uma perspectiva de comparação e de extrapolação de resultados. Bons resultados de sua aplicação foram recentemente relatados nos trabalhos de OLSTHOORN (1999) e RAYNE et al. (2001).

\subsubsection{Tipos e usos de modelos matemáticos}

Os modelos matemáticos tentam descrever, por meio de equações, todos os processos físicos ligados ao fluxo da água subterrânea. $\mathrm{O}$ tipo de modelo depende dos fundamentos teóricos envolvidos e pode ser classificado em: empírico ou experimental, probabilístico ou estocástico e determinístico.

Os modelos empíricos são derivados do ajuste de funções matemáticas a dados experimentais. Um exemplo típico de modelo empírico é a Lei de Darcy, desenvolvida em meados do século XIX, que estabelece o fluxo em meio poroso como uma equação em que a velocidade varia diretamente com o gradiente hidráulico.

Já os modelos estocásticos são baseados nas leis estatísticas e de probabilidade. As aproximações estocásticas têm fornecido significativos avanços na caracterização da heterogeneidade subterrânea e em situações de incerteza, o que é claramente apresentado no livro de GELHAR (1993). Porém, como cita KRESIC (1997), os modelos deste tipo apresentam como limitação a necessidade de um grande número de dados de entrada e de parâmetros de identificação.

No caso dos modelos determinísticos, assume-se que as possíveis reações do aqüífero às entradas atuais e futuras no sistema são geridas pelas leis que descrevem o fluxo da água 
subterrânea. Muitos problemas podem ser resolvidos usando este tipo de modelo, desde a determinação do rebaixamento de um poço, como foi apresentado por MENDONÇA et al. (1999), até o fluxo multifásico em um sistema aqüífero anisotrópico e heterogêneo. Um exemplo clássico de modelo determinístico, citado por ANDERSON \& WOESSNER (1992), é a equação de Theis.

Segundo KRESIC (1997), são três os principais propósitos para criação de modelos de escoamento subterrâneo:

1. descrever o sistema aqüífero para que se possa analisar as várias hipóteses a respeito de sua natureza e dinâmica. Isso ajuda a entender melhor o sistema e a planejar futuras análises deste;

2. prever mudanças naturais ou artificiais no sistema aqüífero estudado;

3. gerar um sistema hipotético, no qual possam ser estudados os princípios do fluxo de água subterrânea.

KONIKOW \& REILLY (1999) afirmam que, desde meados da década de 60, pesquisadores em simulação da água subterrânea, como WANG \& ANDERSON (1982), VAN DER HEIJDE et al. (1985) e VIESSMAN \& LEWIS (1996), vêm optando pela utilização de modelos computacionais determinísticos, com parâmetros distribuídos, o que aumentou as opções de uso de ferramentas computacionais para simulação e análise do comportamento de aqüíferos. KRESIC (1997) e ANDERSON \& WOESSNER (1992) citam o MODFLOW como o programa de domínio público mais utilizado em trabalhos científicos, até o momento.

\subsubsection{Equações básicas}

As equações matemáticas do fluxo da água subterrânea têm por base a equação da continuidade ou o princípio da conservação de massa aplicado a um volume elementar representativo do aqüífero, ou seja:

Taxa de entrada - taxa de saída \pm taxa de produção elou de consumo = taxa de acumulação

Aplicando o princípio da conservação de massa e a Lei de Darcy num volume elementar de um aqüífero, pode-se derivar a equação parcial tridimensional, heterogênea, anisotrópica num estado não estacionário, para a distribuição de carga:

$$
\frac{\partial}{\partial X}\left[K_{x x} \frac{\partial H}{\partial X}\right]+\frac{\partial}{\partial Y}\left[K_{y y} \frac{\partial H}{\partial Y}\right]+\frac{\partial}{\partial Z}\left[K_{z z} \frac{\partial H}{\partial Z}\right]+W(X, Y, Z, t)=S_{s} \frac{\partial H}{\partial t}
$$


em que:

$\mathrm{H}$ = carga hidráulica;

$\mathrm{K}_{\mathrm{xx}}, \mathrm{K}_{\mathrm{yy}}$ e $\mathrm{K}_{\mathrm{zz}}=$ componentes do tensor da condutividade hidráulica;

$\mathrm{S}_{\mathrm{s}}=$ coeficiente de armazenamento específico;

$\mathrm{W}=$ fontes e sumidouros do aqüífero (poço e drenos), podendo ser expressos, como poços pontuais, por meio de 3 funções delta de Dirac:

$\mathrm{W}=\sum_{\mathrm{i}=1}^{\mathrm{N}} \mathrm{Q}_{\mathrm{i}} \delta\left(\mathrm{X}-\mathrm{X}_{\mathrm{i}}\right) \delta\left(\mathrm{Y}-\mathrm{Y}_{\mathrm{i}}\right) \delta\left(\mathrm{Z}-\mathrm{Z}_{\mathrm{i}}\right)$

em que:

$\mathrm{Q}_{\mathrm{i}}=$ taxa de bombeamento ou de injeção, adotando respectivamente o sinal (- ou +);

$\mathrm{i}=$ índice do poço;

$\mathrm{X}_{\mathrm{i}}, \mathrm{Y}_{\mathrm{i}}$ e $\mathrm{Z}_{\mathrm{i}}=$ coordenadas tridimensionais do poço;

$\mathrm{N}=$ número de poços.

A eq. (1) é chamada de Equação Fundamental do Fluxo da Água Subterrânea.

\subsubsection{Condições auxiliares}

Muitas vezes, as equações diferenciais parciais têm um conjunto de possíveis soluções. Isso faz com que seja necessário, para caracterizar especificamente a situação modelada, adicionar condições auxiliares, denominadas, dependendo do caso, de condições iniciais e condições de fronteira. Se as condições auxiliares forem prescritas em excesso, pode haver incompatibilidade entre elas e o problema não terá solução. Se, por outro lado, tais condições forem insuficientes, o problema será indefinido, podendo ter infinitas soluções. Assim, somente na medida certa se terá o que se pode chamar de problema bem posto.

\subsubsection{Condições iniciais}

As condições iniciais servem para descrever a distribuição da carga hidráulica num aqüífero, no instante inicial do processo de simulação. Geralmente, define-se uma condição inicial por:

$\mathrm{H}=\mathrm{H}(\mathrm{X}, \mathrm{Y}, \mathrm{Z}, 0)$ no instante $\mathrm{t}=0$ 
De acordo com CLEARY (1989), a eq. (3) descreve a variação tridimensional da carga hidráulica do aqüífero no instante $t=0$. No entanto, muitos pesquisadores usam uma carga constante média, já existente, como a carga inicial.

\subsubsection{Condições de fronteira}

As condições de fronteira que descrevem as interações do aqüífero com o meio podem ser de três tipos, dependendo basicamente da carga hidráulica e do fluxo nos limites externos do domínio:

Tipo 1: Dirichlet -a carga hidráulica é especificada no contorno:

$$
\mathrm{H}=\mathrm{H}(\mathrm{X}, \mathrm{Y}, \mathrm{Z}, \mathrm{v}, \mathrm{t}) \mathrm{em} \mathrm{t}>0
$$

A carga hidráulica pode ser uma constante ou uma função do tempo e/ou do espaço. Os níveis d'água de rios e lagos são um exemplo, quando há conexão entre o aqüífero e as águas superficiais.

Tipo 2: Neumann - o fluxo da água é especificado no contorno:

$$
-\mathrm{K}_{\eta} \frac{\partial \mathrm{H}}{\partial \eta}=\mathrm{f}(\mathrm{X}, \mathrm{Y}, \mathrm{Z}, \mathrm{t})
$$

em que $\mathrm{f}$ representa o fluxo definido como a taxa volumétrica de fluxo por unidade de área normal à fronteira, ou seja $\left(\mathrm{m}^{3} / \mathrm{m}^{2} / \mathrm{dia}\right)$. Um caso especial desta condição é o fluxo nulo, que ocorre nos divisores de água subterrânea e nos contornos impermeáveis, como, por exemplo, num embasamento cristalino não fraturado.

Tipo 3: Mista ou Robin (ou Cauchy) - combina linearmente os tipos Dirichlet e Neumann:

$$
-\mathrm{K}_{\mathrm{z}} \frac{\partial \mathrm{H}}{\partial \mathrm{Z}}=\frac{\mathrm{K}^{\prime}}{\mathrm{b}^{\prime}}\left(\mathrm{H}_{\mathrm{o}}-\mathrm{H}\right)
$$

ou

$$
-\mathrm{K}_{\mathrm{z}} \frac{\partial \mathrm{H}}{\partial \mathrm{Z}}+\frac{\mathrm{K}^{\prime}}{\mathrm{b}^{\prime}} \mathrm{H}=\frac{\mathrm{K}^{\prime}}{\mathrm{b}^{\prime}} \mathrm{H}_{\mathrm{o}}
$$

De maneira geral, a condição de Robin é usada para modelar situações em que o fluxo atravessa a fronteira, dependendo linearmente da carga hidráulica. Normalmente, essa situação ocorre quando se tem drenança através de contornos semipermeáveis. 


\subsubsection{Caso bidimensional para aqüífero freático}

Em razão das características de contorno móvel do aqüífero freático, é necessário que se utilize as suposições de Dupuit, desenvolvidas em 1863, e a equação de Boussinesq. Assim, o fluxo é considerado horizontal, com linhas eqüipotenciais verticais, velocidade uniforme e carga constante ao longo da dimensão vertical. A hipótese de Dupuit está esquematizada na Figura 1.

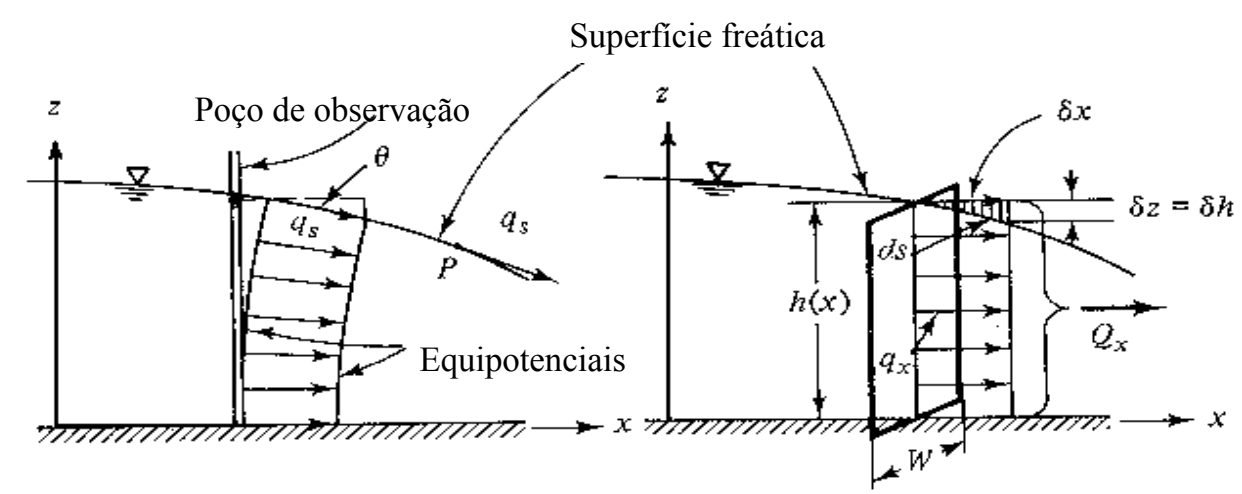

(a)

(b)

FIGURA 1 - (a) Fluxo da água normal num aqǘfero freático; (b) aproximação de Dupuit. Fonte: BEAR (1979).

Usando tais suposições e o princípio da conservação de massa, chega-se à seguinte equação não linear (Equação de Boussinesq):

$\frac{\partial}{\partial X}\left[K_{x} H \frac{\partial H}{\partial X}\right]+\frac{\partial}{\partial Y}\left[K_{y} H \frac{\partial H}{\partial Y}\right]+W(X, Y, t)=S_{y} \frac{\partial H}{\partial t}$

em que a capacidade específica (Sy) leva em consideração os efeitos de armazenamento nos aqüíferos freáticos.

O produto das cargas por suas respectivas derivadas torna a equação não linear, porém pode-se contornar a situação linearizando-se a equação, fazendo $\mathrm{H}=\mathrm{b}=\mathrm{H}_{0}=$ espessura saturada inicial. Segundo HANTUSH (1964), isso ocorre quando o rebaixamento máximo é menor que $25 \%$ da espessura saturada. Assim, substituindo alguns itens, tem-se:

$\mathrm{S}=\mathrm{S}_{\mathrm{y}} ; \quad \mathrm{T}_{\mathrm{xx}}=\mathrm{K}_{\mathrm{x}} \mathrm{H} ; \quad \mathrm{T}_{\mathrm{yy}}=\mathrm{K}_{\mathrm{y}} \mathrm{H}$

Diante do exposto, pode-se resolver as equações diferenciais parciais por meio de soluções analíticas ou numéricas, com iterações sucessivas, como citam KRESIC (1997) e 
KONIKOW \& REILLY (1999). Porém, vale a pena salientar que, segundo VAN DER HEIJDE et al. (1985), já haviam sido catalogados pelo Internacional Ground Water Modeling Center (IGWMC) 399 diferentes modelos, sendo mais de 50\% modelos de fluxo baseados na eq. (1).

\subsubsection{Métodos numéricos}

Modelos numéricos analisam todo o campo de fluxo, num determinado instante, fornecendo soluções para tantos pontos quantos forem solicitados. A área de interesse (Figura 2a) deve ser subdividida em áreas menores chamadas de células ou elementos, e a equação básica do fluxo da água subterrânea é calculada para cada célula pelo balanço de fluxo (entrada-saída). Assim, a solução apresentada é uma distribuição de cargas hidráulicas nos pontos predeterminados.

Esses pontos podem estar locados nos centros das células (Figura $2 b$ ) ou nos vértices dos elementos (Figura 2c). A equação diferencial básica do fluxo é substituída por uma equação algébrica, de forma que todo o campo por onde passa o fluxo seja representado por $n$ equações com $n$ incógnitas, em que $n$ é o número de células. Esse sistema de equações algébricas é resolvido numericamente por meio de processos iterativos ou diretos. Os principais tipos de modelos numéricos são o Método de Diferenças Finitas (MDF) e o Método de Elementos Finitos (MEF).

Ambos os métodos apresentam vantagens e desvantagens, dependendo do caso a ser aplicado. Contudo, por ser mais fácil de ser esboçado e entendido e por exigir menor esforço matemático, os modelos de diferenças finitas prevalecem na prática da hidrogeologia. Como exemplo bem-sucedido de aplicação do MDF pode-se citar o trabalho de OLSTHOORN (1999), que apresenta inclusive uma comparação feita entre modelos de diferenças finitas e modelos analíticos usados no acompanhamento do fluxo da água subterrânea na cidade de Amsterdã, Holanda.

No Brasil, o uso do MDF vem se popularizando. Pode-se citar recentemente NOBRE \& NOBRE (2001), que utilizaram essa ferramenta para simular o comportamento do aqüífero que abastece a cidade de Maceió, AL. A mesma técnica foi usada por LAZARIM \& LOUREIRO (2000) no desenvolvimento de um modelo hidrogeológico computacional no Quadrilátero Ferrífero de Minas Gerais. Em outro artigo, MENDONÇA et al. (2001) simularam o fluxo subterrâneo dos aqüíferos da Chapada do Araripe, em Pernambuco, utilizando o método das diferenças finitas.

Os modelos de elementos finitos, segundo FETTER (1994), oferecem uma alternativa aos modelos numéricos de fluxo de água subterrânea, pois não utilizam malha 
retangular com nós, como em diferenças finitas, mas sim malha em triângulos e quadrados ou tetraedros. Nos pontos de interseção dos triângulos irregulares encontram-se os nós que serão calculados para estimar o fluxo de cada elemento.

Os modelos de elementos finitos são mais adaptáveis que os de diferenças finitas principalmente quando é necessário ter maior semelhança com a geometria do aqüífero. $\mathrm{O}$ tamanho e a forma dos elementos são selecionados aleatoriamente, com isso podem se adaptar facilmente aos limites próximos. Assim pode-se tornar os elementos menores e mais próximos e removê-los onde não há tantas zonas de influência.

PINDER \& GRAY (1977) e KAZDA (1990) constituem algumas das referências básicas sobre a teoria e a aplicação dos métodos de elementos finitos nos estudos de águas subterrâneas. Os trabalhos de ALBERTSON \& HENNINGTON (1996) e LARABI \& DE SMEDT (1997) são exemplos da utilização de métodos de elementos finitos aplicados ao fluxo de água subterrânea permanente em aqüíferos livres.

Outro exemplo de utilização do método de elementos finitos foi apresentado por VIVES et al. (2000), no qual se gerou um modelo preliminar do fluxo de água subterrânea do Aqüífero Guarani, que permitiu a integração de diversas informações hidrogeológicas. 


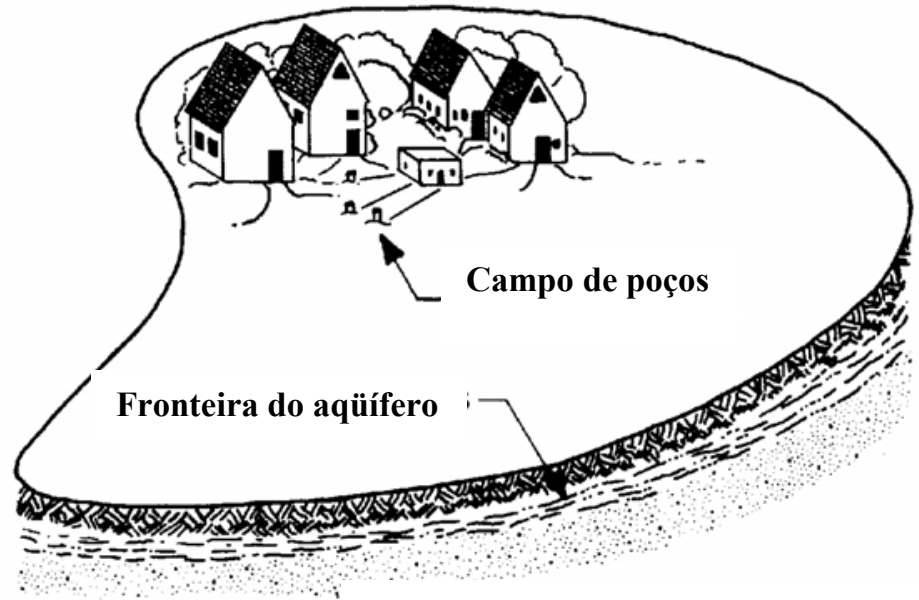

(a)

(b)
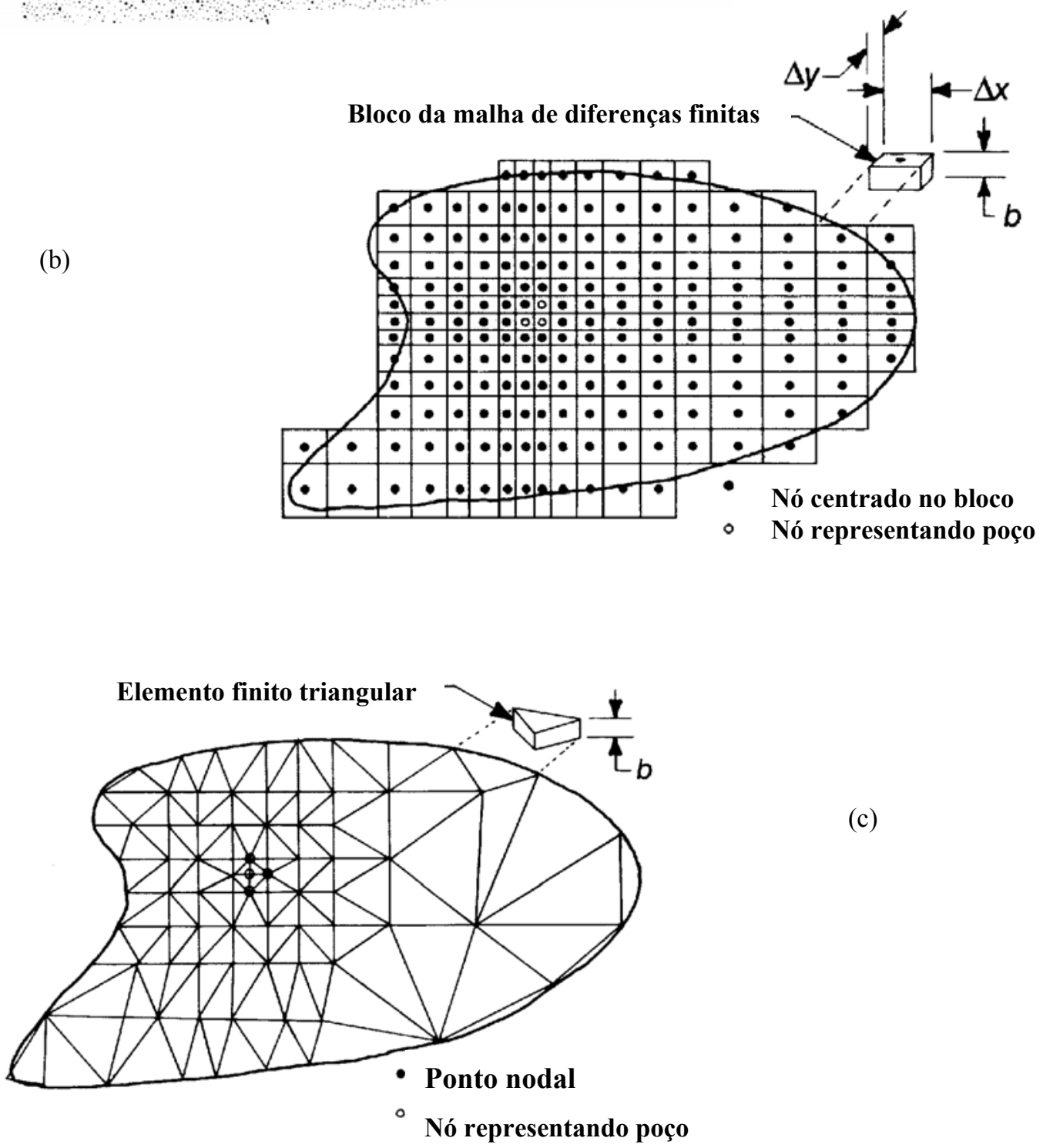

(c)

FIGURA 2 - Representação do método das diferenças finitas e elementos finitos. (a) Mapa da área de estudo e condições de contorno; (b) malha de diferenças finitas; (c) discretização nos vértices malha de elementos finitos. Fonte: Modificado de DRISCOLL (1982). 


\subsubsection{Os programas MODFLOW e SICK100}

Um dos programas computacionais mais utilizados na modelação numérica do fluxo da água subterrânea é o modelo de diferenças MODFLOW, o qual foi desenvolvido pelo United States Geological Survey (USGS), na forma de um programa de simulação. McDONALD \& HARBAUGH (1988) e HARBAUGH \& McDONALD (1996) publicaram os manuais e alguns exemplos de aplicação.

Segundo WINSTON (1999), o programa começou a ser elaborado no final dos anos oitenta e vem sendo aprimorado continuamente desde então, com a inclusão de diversos pacotes relacionados ao estudo da água subterrânea.

O programa MODFLOW foi concebido para simular sistemas aqǘferos sob as seguintes condições:

1. Existência de fluxo no meio saturado;

2. Aplicação de lei de Darcy;

3. Densidade constante da água subterrânea;

4. Não variação da direção principal da condutividade hidráulica horizontal ou da transmissividade, no sistema.

De acordo com WINSTON (1999) e KONIKOW \& REILLY (1999), o programa MODFLOW é provavelmente o mais utilizado no mundo, para modelação em água subterrânea, sendo sua popularidade alavancada pelos seguintes fatores:

- O método de diferenças finitas é relativamente fácil de ser entendido e aplicado nas mais variadas situações reais.

- O programa pode ser utilizado em diversos tipos de computadores pessoais (PC), não requerendo grandes máquinas para sua execução, além de estar disponível em várias versões compatíveis com máquinas distintas.

- Pode ser aplicado para problemas em sistemas uni, bi ou tridimensionais.

- Cada um dos recursos existentes no programa foi exaustivamente testado.

- As informações sobre os dados de entrada e a teoria computacional envolvidas no processo de simulação estão bem documentadas.

- O programa permite que sejam implementadas novas situações, em adição às existentes.

- Existe, disponível na Internet, uma grande variedade de programas escritos pelo USGS e por outros órgãos e companhias públicas e privados, que permitem construir os arquivos de entrada para o MODFLOW. 
- Existe uma gama de programas disponíveis para a leitura e confecção dos gráficos, a partir dos dados de saída do MODFLOW.

WINSTON (1999) descreveu um grande número de sites relacionados ao programa MODFLOW, bem como uma vasta documentação disponível na Internet a respeito de aplicações do modelo.

A Figura 3 mostra algumas características de sistemas aqüíferos que podem ser simuladas pelo MODFLOW.

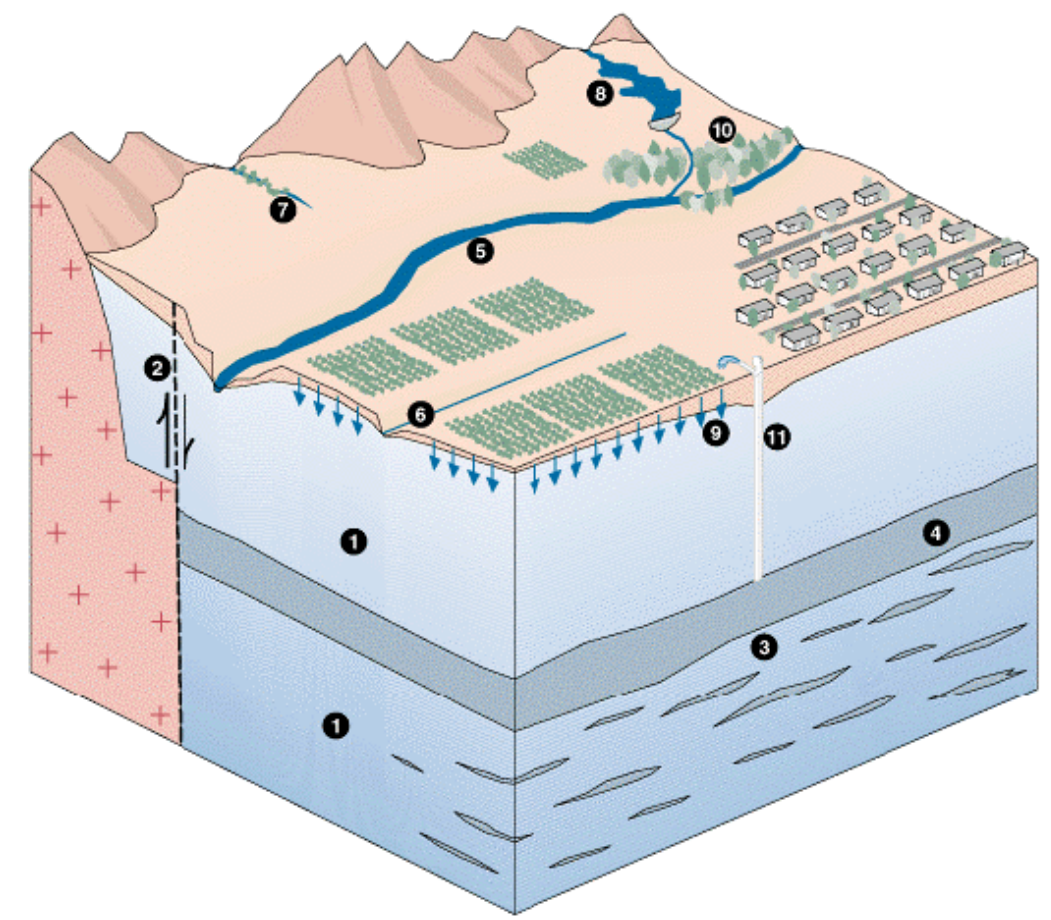

\section{LEGENDA}
1. Aqüíferos livres e confinados
7. Rios efêmeros
2. Falhas ou barreiras naturais
8. Reservatórios
3. Lentes de grãos finos
9. Recarga de precipitação e irrigação
4. Camadas confinantes
10. Evapotranspiração
5. Rios
11. Poços
6. Drenos e fontes

FIGURA 3 - Características que podem ser simuladas com o uso do MODFLOW. Fonte: USGS (1997)

A versatilidade do programa faz com que se possa incluir muitos aspectos hidrológicos na simulação, tais como: evaporação, drenagem, poços, etc. Essa característica torna o sistema mais próximo da realidade. 
O programa simula o fluxo da água subterrânea em sistemas aqǘferos usando diferenças finitas. Cria-se uma rede de blocos organizados em linhas, colunas e camadas, onde cada bloco é chamado de célula. A Figura 4 mostra como é feita esta discretização espacial.

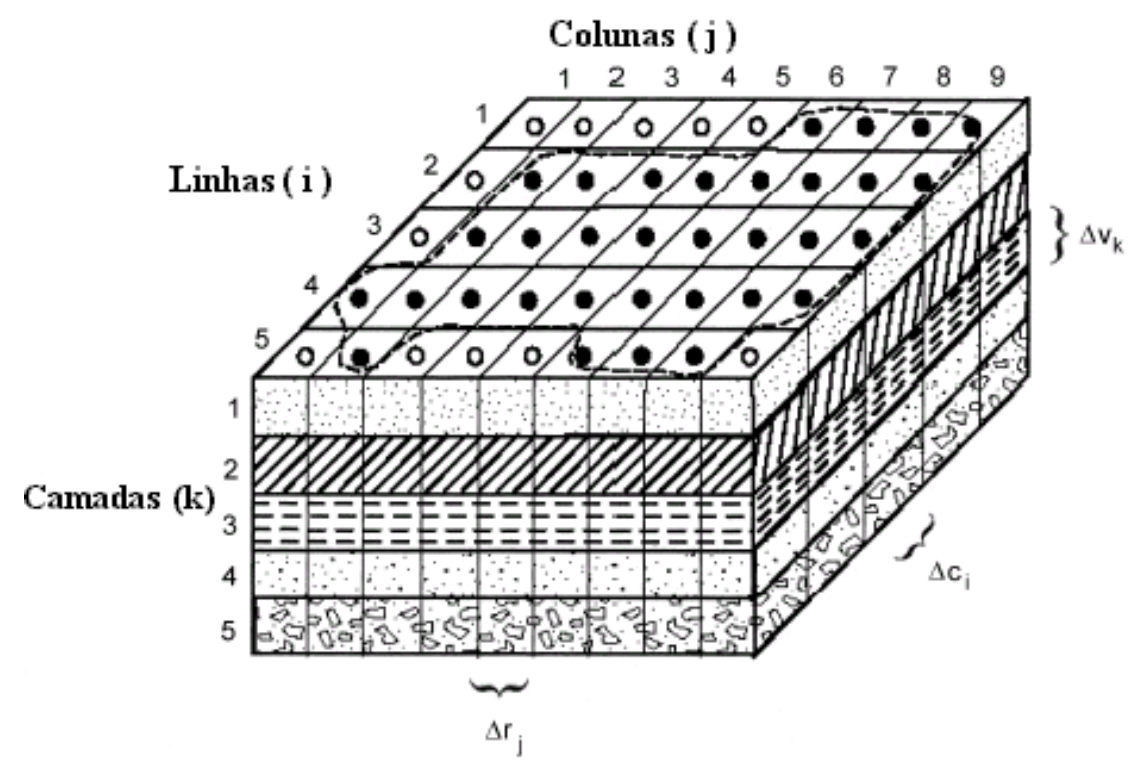

FIGURA 4 - Discretização espacial de um sistema aqüífero multicamada. Fonte: McDONALD \& HARBAUGH (1988)

onde:

--- $\quad$ Fronteira do aqüífero

- Células ativas

O Célula inativa;

$\Delta \mathrm{r}_{\mathrm{j}} \quad$ Dimensão da célula ao longo da direção da linha. O índice $\mathrm{j}$ refere-se a linha;

$\Delta \mathrm{c}_{\mathrm{i}} \quad$ Dimensão da célula ao longo da direção da coluna. O índice i refere-se a coluna;

$\Delta \mathrm{v}_{\mathrm{k}} \quad$ Dimensão da célula ao longo da direção vertical. O índice $\mathrm{k}$ indica a camada.

Como entrada, deve-se analisar cada célula, com suas propriedades específicas. Também é necessário especificar todas as informações relativas ao sistema, como poços existentes e rios, além das influências das características sob cada uma das células nas várias camadas que porventura existam.

Como exemplo de uma situação pode-se citar a influência de um rio sobre um aqüífero. Deve-se saber todas as informações sobre o rio, sua vazão, forma da calha e a influência deste sobre o aqüífero. Com estes dados analisa-se como o rio interfere sobre cada célula a ser simulada no domínio. 
Quando são montados os arquivos com os dados de entrada, o MODFLOW resolve as equações de fluxo da água subterrânea e calcula a carga hidráulica (nível d'água) em cada uma das células do sistema aqüífero em intervalos de tempo especificados. Outros resultados produzidos pelo programa são referentes ao armazenamento de água em cada célula e às velocidades de fluxo envolvidas na passagem da água de uma célula para a outra.

Apesar do MODFLOW ser difundido mundialmente no meio científico para modelação em água subterrânea, sua utilização, no presente estudo, mostrou-se incapaz de representar a complexidade da região de estudo devido a grande quantidade de poços e os corpos d'água superficiais (córregos, rios e lagos) existentes. Nessa situação optou-se pela análise da aplicabilidade de outro modelo: o modelo de elementos finitos SICK100.

O programa original SICK100 (SCHMID et al, 1992) foi desenvolvido na Faculdade de Engenharia Civil da Ruhr-Universität Bochum, baseado na plataforma LINUX e permite a simulação do problemas de fluxo de água subterrânea e transporte de poluentes dissolvidos em um domínio bi e tridimensional.

As características principais do software são:

- Método de elementos finitos;

- Modelos em 2D, 3D e combinação de ambos;

- Problemas estacionários e transientes;

- Meios porosos e/ou fraturados saturados e não-saturados;

- Transporte de poluentes sob consideração dos processos de advecção, dispersão, adsorção e decaimento.

O programa dispõe de algoritmos de pré-processamento que garantem a geração de redes não-estruturadas em meios heterogêneos baseados em Delaunay-triangulation e advancing front. Para a solução dos sistemas de equações resultantes foram implementados técnicas avançadas para armazenagem de matrizes (sparse) e algoritmos iterativos (PCG) e diretos (SUPER-LU) otimizados para solução de sistemas simétricos e não-simétricos.

\subsection{Calibração do modelo}

Cada aqüífero tem suas características próprias representadas por parâmetros distribuídos espacialmente, sendo a transmissividade, o coeficiente de armazenamento e as condições de contorno, os mais importantes a serem analisados.

Após a construção de um modelo matemático, deve-se procurar calibrá-lo por meio de informações obtidas em campo, sendo normalmente utilizados para a calibração a carga hidráulica e o balanço hídrico, segundo BEAR \& VERRRUIJT (1994). Com isso, busca-se ajustar os parâmetros de modo que o modelo reproduza os dados observados. 
Os valores ou as configurações dos parâmetros envolvidos no sistema, como condutividade hidráulica e recarga, são modificados paulatinamente, até que se obtenha o menor erro possível. Este método necessita apenas, segundo SUN (1994), de alguns dados observados, uma subrotina para resolver o problema avançado e um hidrogeólogo experiente que esteja familiarizado com o aqǘf́ro.

CLEARY (1989) salientou que nesse tipo de abordagem deve-se estimar os parâmetros iniciais mais próximos da realidade para acelerar o processo de calibração. Segundo SUN (1994), este é o método da tentativa e erro. Observa-se que a possibilidade de erro é muito alta, pois a precisão dos resultados obtidos varia de acordo com o especialista envolvido no problema. Mesmo assim, este método continua a ser amplamente utilizado e foi utilizado neste trabalho.

A identificação de parâmetros envolvidos em sistemas aqüíferos vem sendo abordada por pesquisadores desde a década de sessenta, quando YEH (1975) descreveu a formulação analítica para um aqǘfero com fluxo governado por uma equação diferencial parcial parabólica não linear. O sistema, na época, foi simplificado para uma condição unidimensional de fluxo.

Deste modo, como salientaram BEAR \& VERRRUIJT (1994), a tentativa de se chegar ao melhor conjunto de coeficientes passa a ser encarada como um problema de identificação de parâmetros, também chamado de "problema inverso", que resultará numa solução única. Muitos métodos têm sido propostos e a literatura sobre este assunto é vasta, incluindo-se algumas revisões como as apresentadas por YEH (1986), CARRERA (1988) e GINN \& CUSHMAN (1990). O problema inverso e sua importância para a calibração de modelos foi também tema de um livro (SUN, 1994).

Geralmente, o objetivo da calibração é comparar os diversos ajustes de parâmetros, verificando se estes estão compatíveis com os dados observados e como as alterações dos parâmetros interferem nas respostas do modelo (análise de sensibilidade). Isto é salientado nos trabalhos de CARRERA \& NEUMAN (1986) e COOLEY et al. (1986), que apresentam o que convencionou-se chamar de histórico comparativo.

Um item importante da calibração de um modelo é a análise de sensibilidade, processo no qual os parâmetros de entrada do modelo sofrem uma variação, dentro de uma faixa plausível, e mudanças relativas que ocorrem nas respostas do modelo são analisados. Podese citar como exemplo as mudanças que ocorrem na taxa de fluxo quando a carga hidráulica sofre alguma modificação.

A finalidade da análise de sensibilidade é demonstrar qual o comportamento das simulações do modelo diante das incertezas dos valores de entrada. Também é analisada a sensibilidade de um parâmetro do modelo em relação a outros parâmetros. Tal análise pode 
ainda ser útil para definir os dados adicionais a serem coletados para a calibração final do modelo. Assim, dados que têm interferência maior sobre o modelo devem ser melhor caracterizados no.

KOHNKE (2001) sugeriu que pode-se analisar a sensibilidade de modelos de fluxo de água de duas formas. A primeira é a análise das variações causadas nas respostas do modelo decorrentes de modificações nos parâmetros. A outra forma consiste na observação dos efeitos causados pelas modificações sobre os resultados da calibração.

A calibração é sem dúvida a etapa que demanda mais tempo e exige mais cautela na análise dos resultados, pois sem isto pode-se obter resultados fictícios, como salientam WANG \& ANDERSON (1982), HAITJEMA (1995), KRESIC (1997) e KONIKOW \& REILLY (1999).

\subsubsection{Conceitos básicos}

Em um modelo de simulação do tipo inverso pode-se desejar determinar apenas alguns parâmetros, tais como: parâmetros físicos (r), fontes e sumidouros (q), condições iniciais ou de contorno (f), ou identificar simultaneamente $r$, q, f.

Durante anos os hidrogeólogos estudaram o problema inverso com as dificuldades inerentes ao fato de o mesmo ser considerado como "mal posto", ou seja, não satisfazer alguma das condições relacionadas a seguir, discutidas nos trabalhos de CARRERA (1988) e SUN (1994):

EXISTÊNCIA - estabelece que existe uma função que satisfaz as equações governantes e as condições impostas. Na prática, não se pode evitar os erros nas observações e, com isso, uma solução precisa para o problema pode não existir.

UNICIDADE - impõe que exista apenas uma única solução válida para um sistema de equações. Deve-se lembrar que diferentes combinações hidrogeológicas podem levar a observações similares do nível de água. Sendo assim, é impossível determinar as características de um aqüífero somente pela observação de variáveis de estado. Por isso, comumente observa-se solução "não única". Em situações de "não unicidade" de solução do problema inverso deve-se acrescentar mais medições de determinadas variáveis..

ESTABILIDADE - a variação da solução encontrada deverá ser a menor possível. Geralmente isto ocorre devido às variações dos dados de entrada (por exemplo: parâmetros físicos, variáveis de controle, condições iniciais e de fronteira) serem suficientemente pequenas. Pode-se considerar que pequenas mudanças nas condições de contorno e/ou nos 
parâmetros hidráulicos implicam em alterações no nível d'água, o que torna esta solução instável.

Para iniciar um estudo mais aprofundado do problema inverso alguns passos são necessários: (1) descrever uma variabilidade espacial (a "parametrização" é adotada para isso); (2) formular um equacionamento para relacionar parâmetros e medidas de campo; (3) adotar um critério de performance para definir parâmetros estimados de boa qualidade.

Todos os fatores expostos acima são importantes, sendo que os diferentes algoritmos encontrados na literatura para resolver o problema inverso têm uma influência muito forte da parametrização. Esta influência interfere na obtenção de um problema inverso "bem posto" e assim com uma solução físicamente plausível.

\subsubsection{Tipos de solução para o problema inverso}

Para CARRERA \& NEUMAN (1986a) e CARRERA \& GLORIOSO (1991), existem dois tipos de métodos para se determinar os parâmetros envolvidos em um aqüífero: o método direto e o método indireto. A aproximação direta tem como critério minimizar os erros gerados na resolução das equações de uma maneira não iterativa. No método indireto busca-se minimizar o erro residual existente entre o dado calculado e observado.

Já SUN (1994) cita uma terceira forma de resolução chamada de método da tentativa e erro, a qual considera a mais antiga.

\subsubsection{Método de tentativa e erro}

Alguns autores CLEARY (1989) e SUN (1994), já demonstraram os aspectos positivos e negativos da utilização do método de tentativa e erro, incluindo a necessidade de uma série histórica de dados e a experiência de um profissional familiarizado com o aqüífero, além de não ser necessária a criação de um programa computacional mais sofisticado.

Apesar das inúmeras facilidades que o método apresenta a possibilidade de erro, quando não se tem uma base de dados confiáveis é elevada, estando a precisão do método sujeita a habilidade do profissional envolvido na análise do problema. Porém esse método continua ser amplamente utilizado, principalmente pelo aspecto econômico.

A Figura 5 apresenta um fluxograma do método de tentativa e erro. 


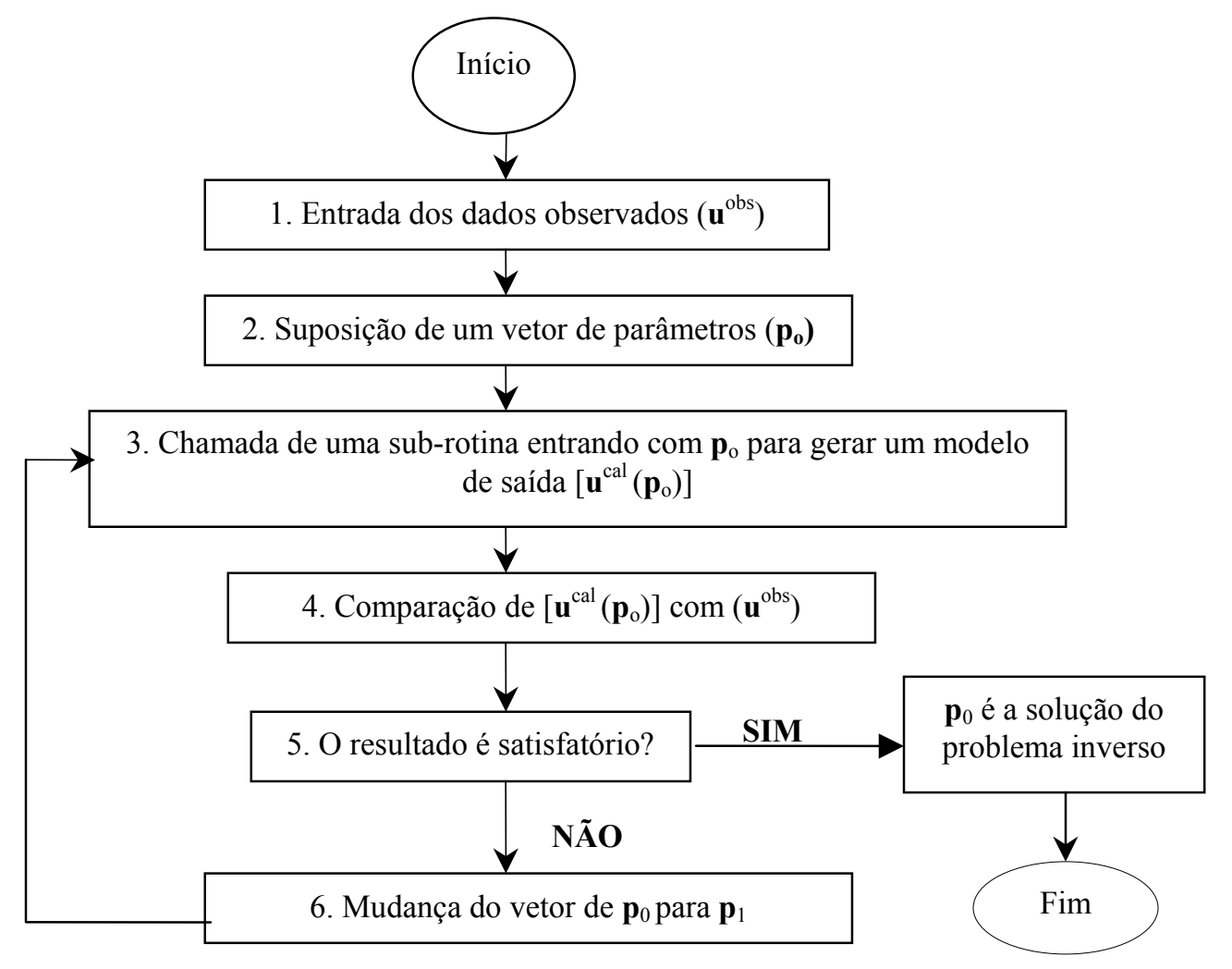

FIGURA 5 - Fluxograma do método de Tentativa e Erro. Fonte: modificado de SUN (1994).

\subsubsection{Solução indireta}

Para SUN (1994), o método indireto, cujo fluxograma é apresentado na Figura 6, tenta retirar a participação do homem na decisão final de escolha.

A solução indireta ajusta-se melhor, segundo YEH (1986), a situações onde o número de observações é limitado, baseando-se no critério de erro, onde uma estimativa dos parâmetros de interesse sofre várias iterações visando minimizar esse erro.

CARRERA \& NEUMAN (1986b) salientam ainda que a solução indireta destina-se a problemas não lineares e que o método é uma versão automatizada do método de tentativa e erro. 


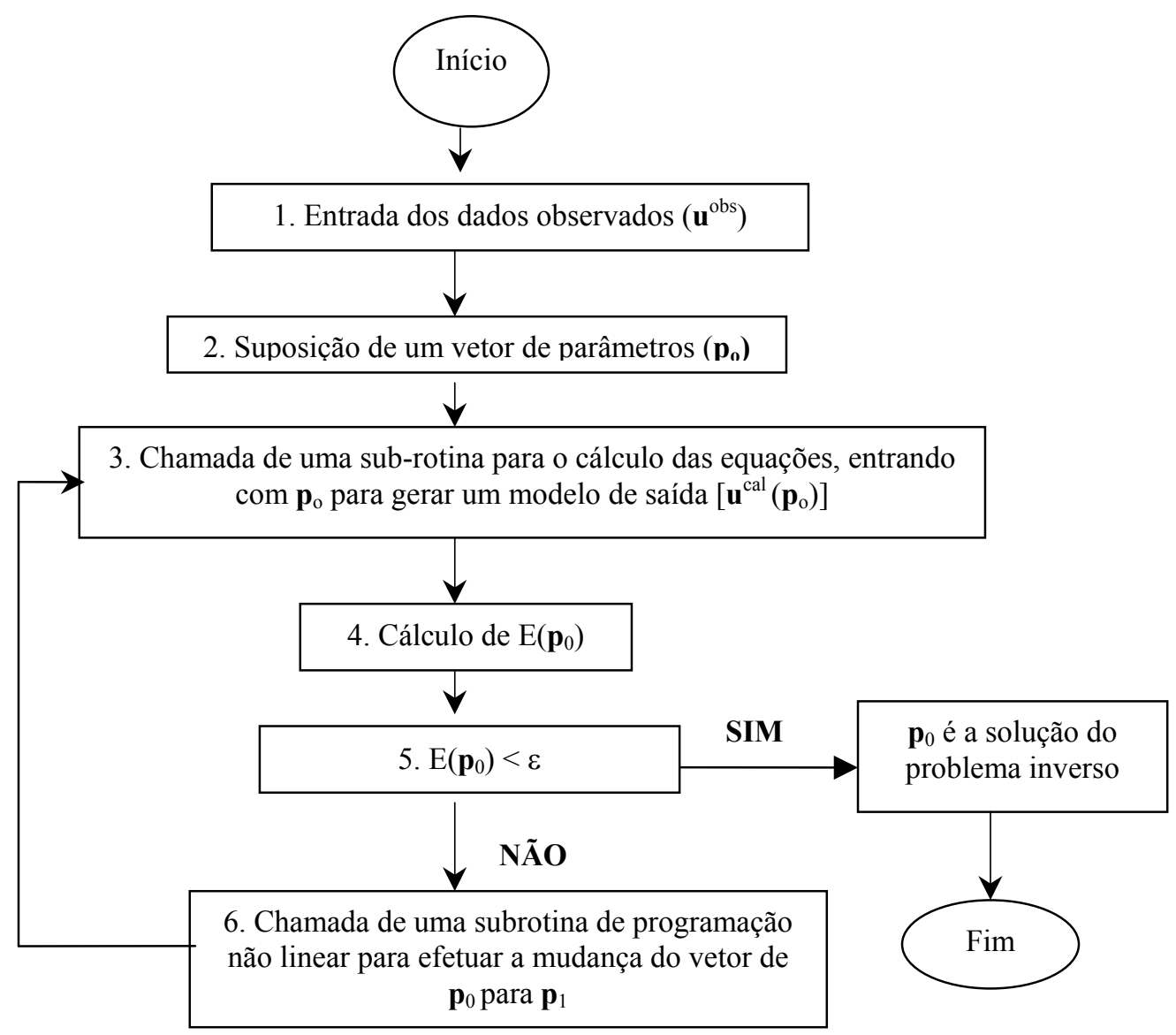

FIGURA 6 - Fluxograma do método indireto.Fonte: modificado de SUN (1994)

\subsubsection{Solução direta}

O método direto, segundo KITANIDIS \& VOMVOROVIS (1983), considera os parâmetros como sendo constantes conhecidas para todo o espaço, quando os mesmos podem ter uma variação segundo as condições de contorno existentes na região. Assim, o número de equações é maior que o número de parâmetros desconhecidos.

A maioria dos métodos diretos existentes foi concebida a partir de testes de bombeamento, sendo baseada em soluções analíticas que modelam o aqüífero como sendo homogêneo e isotrópico. Para isto levam em consideração que não há distribuição espacial dos parâmetros.

TANG \& PINDER (1979) sugeriram, em seu trabalho, uma aproximação direta para resolver um problema inverso, cujo parâmetro estimado era a transmissividade, tendo encontrado um erro "aceitável" de 10\%. 
O problema inverso pode ser resolvido de uma maneira não iterativa, usando-se um critério de minimização, porém isto não garante que este torne-se "bem posto", como citam CARRERA \& NEUMAN (1986a).

A Figura 7 apresenta os passos necessários no método direto.

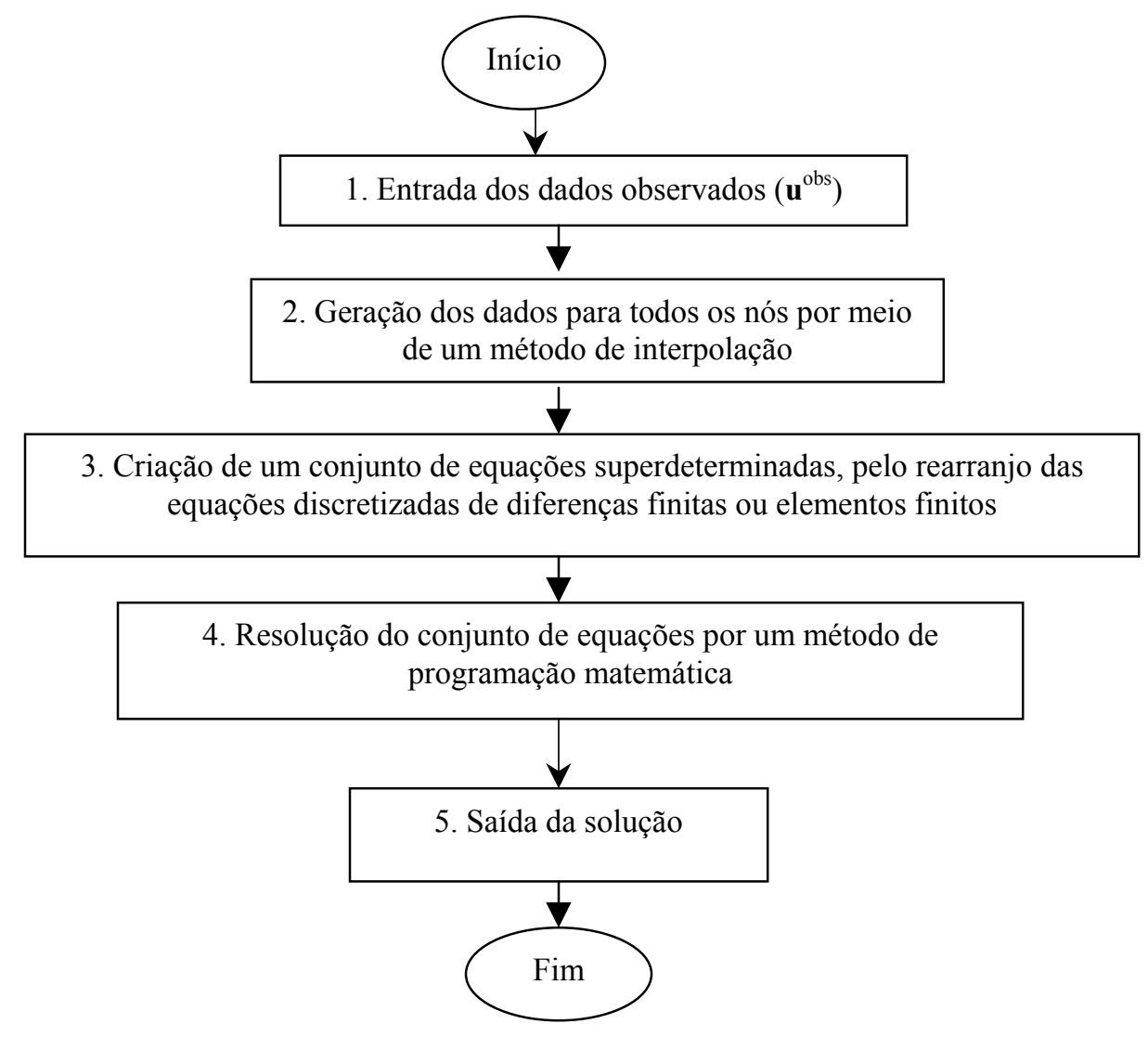

FIGURA 7 - Fluxograma do método direto. Fonte: Modificado de SUN (1994)

\subsubsection{Aproximação geoestatística}

Aproximar um problema inverso por meio de geoestatística consiste em utilizar métodos que são explicitamente baseados na caracterização estatística da variabilidade espacial dos parâmetros pertinentes. A idéia é que a continuidade espacial, que está implícita na função de covariância ou no variograma, seja usada favoravelmente na estimativa de dados.

Com a dificuldade enfrentada em coletar medidas para a determinação de parâmetros hidrogeológicos no campo, COOLEY (1977) propôs uma nova solução não-linear por mínimos quadrados, onde era utilizado o conceito de zoneamento (que subdivide a área em regiões de características semelhantes). 
NEUMAN \& YAKOWITZ (1979) sugeriram uma aproximação estatística para o problema inverso, cujo objetivo era analisar a variabilidade espacial da transmissividade de um aqüífero tendo por base dados de nível d'água. Neste trabalho foi utilizada a conceituação geoestatística trazida por DELHOME (1978) da geologia para as hidrociências.

No fim da década de setenta e início dos anos oitenta difundiu-se largamente a geoestatística no meio acadêmico internacional, sendo utilizada em diversos campos da ciência, desde a geologia, tendo como exemplo a avaliação quantitativa de uma jazida, até a estimativa da distribuição espacial das características hidráulicas de um aqüífero.

O uso dos métodos geoestatísticos em problemas inversos em águas subterrâneas ocorreu quando CLIFTON \& NEUMAN (1982) introduziram a técnica geoestatística kriging, para estimar a variabilidade espacial da transmissividade do aqǘfero Avra Valley no sudeste do estado do Arizona, nos Estados Unidos.

Um bom exemplo da utilização da vasta gama de métodos geoestatísticos é o trabalho de ZIMMERMAN et al. (1998), que testaram em um campo sintético, em quatro cenários diferentes, com a transmissividade variando numa magnitude de 10 vezes, sete métodos (transformada rápida de Fourier (R-F), simulação fractal (SF), cokrigagem linearizada(CL), simulação de máxima verossimilhança (MV), linearização semianalítica (LS), pilot-point (PP), autocalibração seqüencial (AS). Vale salientar que destes métodos somente quatro apresentaram resultados semelhantes (LS, MV, PP, AS).

\subsubsection{Conceitos básicos de geoestatística}

Quando um parâmetro distribuído é considerado como uma função estocástica $\mathrm{Z}(\mathrm{x})$, pode-se decompor esta função em duas partes: o valor médio de $\mathrm{Z}(\mathrm{x})$, representado por $\mathrm{m}(\mathrm{x})$, que descreve a variabilidade em larga escala do parâmetro estudado, também chamado de tendência, e a flutuação $\xi(x)$, que representa a variabilidade de pequena escala em torno da tendência, também conhecido como resíduo. Dessa forma pode-se definir Z(x)

Pode-se montar a função como é mostrado na eq. (9):

$$
\mathrm{Z}(\mathrm{x})=\mathrm{m}(\mathrm{x})+\xi(\mathrm{x})
$$

Assume-se, ainda, que existem pequenas variações na função determinística, que dependem de vários coeficientes indeterminados $(\beta)$, relacionados a $\mathrm{m}(\mathrm{x})$ e de parâmetros estatísticos $(\psi)$ ligados à flutuação $\xi(\mathrm{x})$.

Assim, a eq. 9 pode ser reescrita da seguinte forma: 


$$
\mathrm{Z}(\mathrm{x})=\mathrm{m}(\mathrm{x}, \beta)+\xi(\mathrm{x}, \psi)
$$

O pré-requisito básico para a utilização de métodos geoestatísticos está fundamentado na obtenção do variograma ou semivariograma (para alguns autores), que representa graficamente a estrutura estatística do conjunto de dados observados em campo. A Figura 8 mostra um variograma experimental, onde os pontos foram calculados a partir da eq. (11):

$$
\gamma(\mathrm{h})=\frac{1}{2 \mathrm{~N}} \sum_{\mathrm{i}=1}^{\mathrm{N}}\left[\mathrm{z}\left(\mathrm{x}_{\mathrm{i}}+\mathrm{h}\right)-\mathrm{z}\left(\mathrm{x}_{\mathrm{i}}\right)\right]^{2}
$$

onde $\mathrm{h}$ representa a distância entre dois pontos $\mathrm{z}\left(\mathrm{x}_{\mathrm{i}}+\mathrm{h}\right)$ e $\mathrm{z}\left(\mathrm{x}_{\mathrm{i}}\right)$ e $\mathrm{N}$ é o número de pares existentes com a mesma distância.

A Figura 8 apresenta também algumas características do variograma, tais como: o efeito pepita $\left(\mathrm{C}_{0}\right)$, que mostra a falta de continuidade da variável em estudo, observada pela existência de um valor para $\gamma(\mathrm{h})$, quando a distância é zero; o alcance $(\alpha)$, que é a distância na qual $\gamma(\mathrm{h})$ atinge a soleira $(\mathrm{C})$, sendo esta igual à variância dos dados.

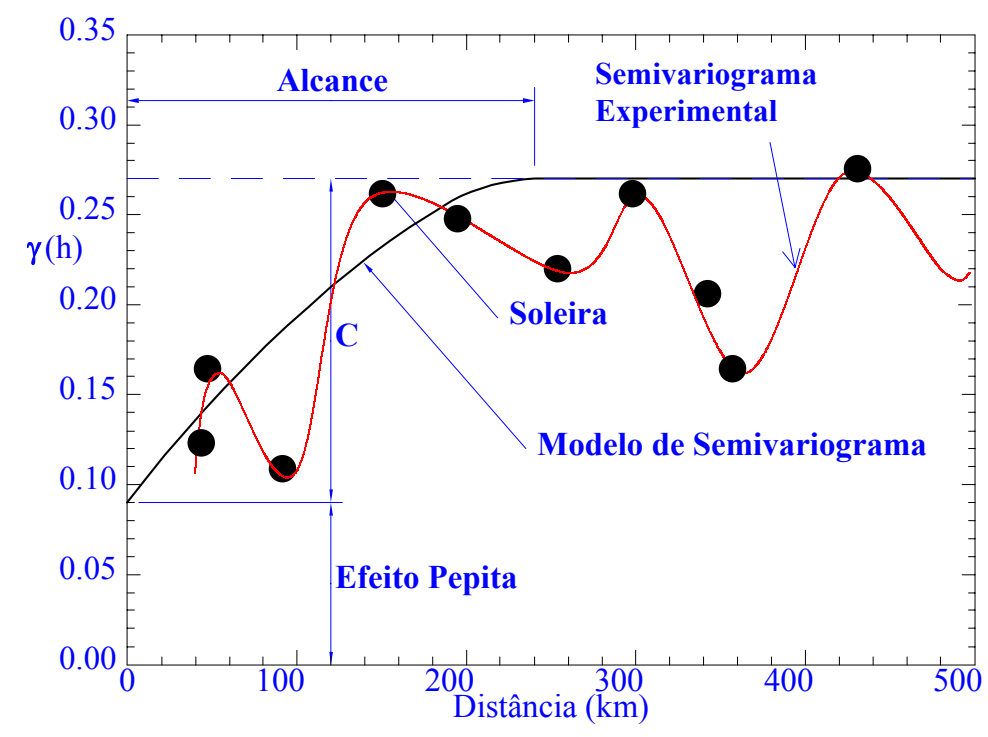

FIGURA 8 - Representação gráfica de um variograma experimental com modelo ajustado. Fonte: Modificado de LANDIM (1998).

Obtendo-se o variograma experimental faz-se necessário ajustá-lo a um modelo teórico, como frisa LANDIM (1998). Inicialmente, o ajuste era manual e sujeito a erros de interpretação, dependendo muito da experiência de quem analisava o gráfico. Hoje, dispõe- 
se de algoritmos, como o apresentado por PANNATIER (1996), que minimizam bastante a possibilidade de erro. A Tabela 1 apresenta os principais modelos teóricos utilizados para ajustar um variograma experimental, conforme KITANIDIS (1999). Uma análise mais detalhada de cada modelo teóricos pode ser encontrada em CLARK (1980), ISAAKS \& SRIVASTAVA (1989) e LANDIN (1998).

TABELA 1 - Principais modelos teóricos, com patamar, adotados na aproximação geoestatística.

\begin{tabular}{|l|c|}
\hline MODELO & $\gamma(\mathrm{h})=$ \\
\hline Linear & $\mathrm{C}_{\mathrm{O}}+\mathrm{C}(\mathrm{h} / \alpha) \quad$ para $0<\mathrm{h} \leq \alpha$ \\
Circular & $\mathrm{C}_{\mathrm{O}}+\mathrm{C}\left\{1-2 / \pi \cos ^{-1}(\mathrm{~h} / \alpha)+2 \mathrm{~h} / \pi \alpha\left(1-\mathrm{h}^{2} / \alpha^{2}\right)^{1 / 2}\right\}$ \\
Esférico & $\mathrm{C}_{\mathrm{O}}+\mathrm{C}\left\{3 \mathrm{~h} / 2 \alpha-0.5(\mathrm{~h} / \alpha)^{3}\right\}$ \\
Exponencial & $\mathrm{C}_{\mathrm{O}}+\mathrm{C}\{1-\exp (-\mathrm{h} / \alpha)\}$ \\
Gaussiano & $\mathrm{C}_{\mathrm{O}}+\mathrm{C}\left\{1-\exp \left(-\mathrm{h}^{2} / \alpha^{2}\right)\right\}$ \\
\hline
\end{tabular}

\subsubsection{Geoestatística linear}

$\mathrm{Na}$ estatística linear pode-se estimar o valor esperado de $\mathrm{Z}$ no local $\mathrm{x}_{0}$, como uma soma ponderada dos dados medidos em $\mathrm{z}\left(\mathrm{x}_{1}\right), \mathrm{z}\left(\mathrm{x}_{2}\right), \ldots, \mathrm{z}\left(\mathrm{x}_{\mathrm{n}}\right)$, como é apresentado na eq. (12).

$$
\mathrm{Z}^{*}\left(\mathrm{x}_{0}\right)=\sum_{i=1}^{n} \lambda_{\mathrm{i}} \mathrm{z}\left(\mathrm{x}_{\mathrm{i}}\right)
$$

Onde $Z^{*}$ é o valor estimado; $\lambda_{i}$ são os pesos escolhidos para satisfazer a contento as condições estatísticas.

Duas condições são impostas neste caso. A primeira impõe que $Z^{*}\left(x_{0}\right)$ não seja viciado, satisfazendo a eq. (13).

$$
\mathrm{E}\left[\mathrm{Z}^{*}\left(\mathrm{x}_{0}\right)-\mathrm{Z}\left(\mathrm{x}_{0}\right)\right]=0
$$

Combinando as eqs. (12) e (13), chega-se a eq. (14): 


$$
\mathrm{E}\left\{\left[\sum_{\mathrm{i}=1}^{\mathrm{n}} \lambda_{\mathrm{i}} \mathrm{Z}\left(\mathrm{x}_{\mathrm{i}}\right)\right]-\mathrm{Z}\left(\mathrm{x}_{0}\right)\right\}=0
$$

Pode-se, ainda, manipulando a eq. (14), obter a eq. (15) e assumir que o valor esperado é igual à média $\mathrm{m}$, a qual é considerada constante.

$$
\sum_{\mathrm{i}=1}^{\mathrm{n}} \lambda_{\mathrm{i}} \mathrm{E}\left[\mathrm{Z}\left(\mathrm{x}_{\mathrm{i}}\right)\right]-\mathrm{E}\left[\mathrm{Z}\left(\mathrm{x}_{0}\right)\right]=\sum_{\mathrm{i}=1}^{\mathrm{n}} \lambda_{\mathrm{i}} \mathrm{m}-\mathrm{m}=0
$$

Nesse caso, é necessário que seja satisfeita a eq. (16) para se legitimar a eq. (15).

$$
\sum_{\mathrm{i}=1}^{\mathrm{n}} \lambda_{\mathrm{i}}=0
$$

A segunda condição imposta é que o estimador $Z^{*}\left(\mathrm{x}_{0}\right)$ tenha o valor da variância (Var) mínimo, como é dado na eq. (17):

$$
\begin{aligned}
& \operatorname{Var}\left[Z^{*}\left(x_{0}\right)-Z\left(x_{0}\right)\right]=2 \sum_{\mathrm{i}=1}^{\mathrm{n}} \lambda_{\mathrm{i}} \gamma_{\mathrm{i} 0}-\sum_{\mathrm{i}=1}^{\mathrm{n}} \sum_{\mathrm{j}=1}^{\mathrm{n}} \lambda_{\mathrm{i}} \lambda_{\mathrm{ji}} \gamma_{\mathrm{ij}} \\
& \text { onde } \gamma_{i j}=\gamma\left(\left|x_{i}-x_{j}\right|\right)
\end{aligned}
$$

\subsubsection{Krigagem simples}

Neste método, de acordo com ASCE (1990a), assume-se que o valor médio, m, é conhecido a priori, sendo o estimador $\mathrm{Z}^{*}\left(\mathrm{x}_{0}\right)$ definido por:

$$
\mathrm{Z}^{*}\left(\mathrm{x}_{0}\right)=\mathrm{m}+\sum_{\mathrm{i}=1}^{\mathrm{n}} \lambda_{\mathrm{i}}\left[\mathrm{z}\left(\mathrm{x}_{\mathrm{i}}\right)-\mathrm{m}\right]
$$

Onde $\mathrm{Z}\left(\mathrm{x}_{\mathrm{i}}\right)$ é a medida em $\mathrm{x}_{\mathrm{i}} ; \lambda_{\mathrm{i}}$ é o peso atribuído pelo método ao valor medido em $\mathrm{x}_{\mathrm{i}}$, que será determinado; $\mathrm{n}$ é o número total de valores amostrados.

Pode-se, a partir da minimização da variância, dada pela eq. (17), encontrar a matriz que representa as $\mathrm{n}$ equações derivadas de cada $\lambda_{\mathrm{i}}$ e igualadas a zero, como é mostrado a seguir, na forma matricial. 


$$
\left[\begin{array}{ccccc}
\gamma \gamma_{11} & \gamma \gamma_{12} & \gamma \gamma_{13} & \cdots & \gamma \gamma_{1 n} \\
\gamma \gamma_{21} & & & & \gamma \gamma_{2 n} \\
\gamma \gamma_{31} & & & & \gamma \gamma_{3 n} \\
\vdots & & & & \vdots \\
\gamma \gamma_{n 1} & \gamma \gamma_{n 2} & \gamma \gamma_{n 3} & \cdots & \gamma \gamma_{n n}
\end{array}\right]\left[\begin{array}{c}
\lambda_{1} \\
\lambda_{2} \\
\lambda_{3} \\
\vdots \\
\lambda_{n}
\end{array}\right]=\left[\begin{array}{c}
\gamma_{01} \\
\gamma_{02} \\
\gamma_{03} \\
\vdots \\
\gamma_{0 n}
\end{array}\right]
$$

A variância mínima estimada é:

$$
\sigma_{S K}^{2}=\sum_{\mathrm{i}=1}^{\mathrm{n}} \lambda_{\mathrm{i}} \gamma_{0 \mathrm{i}}-\gamma_{00}
$$

onde $\gamma_{00}$ representa o efeito pepita.

O Kriging simples é considerado um interpolador exato, apresentando como desvantagem a necessidade de se obter a média a priori.

\subsubsection{Krigagem ordinária}

Caso o valor da média seja desconhecido, porém constante, pode-se introduzir o multiplicador Lagrange $\mu$, afim de se satisfazer as condições que implicam na soma dos pesos ser igual a 1 (eq. 16). Assim, o processo de minimização é descrito pela eq. (21).

$$
\frac{\partial \operatorname{Var}\left[\mathrm{Z}\left(\mathrm{x}_{0}\right)-\mathrm{Z}^{*}\left(\mathrm{x}_{0}\right)\right]}{\partial \lambda_{\mathrm{i}}}-2 \mu=0 \quad \text { para } \mathrm{i}=1,2, \ldots, \mathrm{n}
$$

O sistema de $n$ equações resultantes da eq. (21) pode ser montado da forma matricial mostrada a seguir.

$$
\left[\begin{array}{cccccc}
\gamma_{11} & \gamma_{12} & \gamma_{13} & \cdots & \gamma_{1 \mathrm{n}} & 1 \\
\gamma_{21} & & & & \gamma_{2 \mathrm{n}} & 1 \\
\gamma_{31} & & & & \gamma_{3 \mathrm{n}} & 1 \\
\vdots & & & & \vdots & \vdots \\
\gamma_{\mathrm{n} 1} & \gamma_{\mathrm{n} 2} & \gamma_{\mathrm{n} 3} & & \gamma_{\mathrm{nn}} & 1 \\
1 & 1 & 1 & \ldots & 1 & 0
\end{array}\right]\left[\begin{array}{c}
\lambda_{1} \\
\lambda_{2} \\
\lambda_{3} \\
\vdots \\
\lambda_{\mathrm{n}} \\
\mu
\end{array}\right]=\left[\begin{array}{c}
\gamma_{01} \\
\gamma_{02} \\
\gamma_{03} \\
\vdots \\
\gamma_{0 \mathrm{n}} \\
1
\end{array}\right]
$$

A variância mínima de estimação é:

$$
\sigma_{0 K}^{2}=\sum_{\mathrm{i}=1}^{\mathrm{n}} \lambda_{\mathrm{i}} \gamma_{0 \mathrm{i}}+\mu-\gamma_{00}
$$


No trabalho de DELHOMME (1978) foi levantada a possibilidade de utilização do método kriging para parâmetros ligados ao fluxo de águas subterrâneas, tendo sido apontada a importância da adequação do modelo à realidade, tentando minimizar o erro de calibração. O critério sugerido para o erro está exposto na eq. (24) e refere-se a zonas onde os valores foram padronizados:

$$
\max _{i} \frac{\left|z_{i}^{*}-z_{i}^{c}\right|}{\sigma_{k_{i}}} \leq 2
$$

onde $z_{i}^{*}$ representa o valor obtido com o modelo, $z_{i}^{c}$ representa o valor encontrado pelo método kriging e $\sigma_{\mathrm{ki}}$ é o desvio padrão da krigagem.

\subsubsection{Aplicações práticas}

Neste item são apresentados alguns exemplos de utilização de métodos geoestatísticos em problemas inversos, em situações reais de campo. Vale salientar que em conjunto com os problemas aqui expostos existe uma série de trabalhos publicados, com experimentos sintéticos.

GAILEY et al. (1991) analisaram a contaminação da água subterrânea em Ottawa no Canadá, proveniente de um depósito de resíduos tóxicos a base de cloro e a partir da estimação dos parâmetros do aqǘfero puderam inferir sobre o fluxo migratório do contaminante.

Na Dinamarca, SONNENBORG et al.(1996) utilizaram métodos geoestatísticos para encontrar os parâmetros de fluxo de um aqüífero contaminado por um depósito de resíduos de incineradores, podendo posteriormente simular as plumas de dispersão do contaminante.

$\mathrm{O}$ aqǘ́fero não confinado de Avra Valley, no sudeste do estado do Arizona nos Estados Unidos, no qual existem 169 medidas de transmissividades distribuídos numa área de aproximadamente $750 \mathrm{~km}^{2}$, vem sendo alvo de muitos estudos envolvendo métodos geoestatísticos.

CLIFTON \& NEUMAN (1982) estudaram a distribuição da transmissividade em Avra Valley e posteriormente RUBIN \& DAGAN (1987) adotaram uma metodologia semelhante, porém com resultados muito discrepantes devido à análise estrutural dos dados existentes feita pelos autores. 
Este aqüífero foi estudado novamente por YEH \& MOCK (1996), agora utilizando a variabilidade espacial da carga hidráulica como apoio à estimativa de parâmetros hidrogeológicos. Os autores comentam que, para se aplicar um modelo numérico, existe a necessidade de se conhecer a distribuição espacial da transmissividade e as condições de contorno, além das taxas de recarga do aqüífero. Isso é muito difícil, pois as condições de contorno e as taxas de recargas são ligadas às complexidades da geologia do aqüífero. Assim, os modelos numéricos são freqüentemente calibrados com os valores já mensurados obtidos a partir de medidas de carga hidráulica, o que implica na continuidade de erros caso os dados não sejam confiáveis.

MACKAY et al. (1996) estudaram, usando técnicas geoestatísticas aplicadas, a taxa de risco à contaminação de aqǘf́eros com a implantação de aterros sanitários na Inglaterra.

ROTH et al. (1998) propuseram um método híbrido combinando a técnica geoestatística com simuladores de fluxo numérico determinísticos, afim de encontrar um campo de transmissividades. O método geoestatístico utilizado foi o cokriging, por incorporar a influência da carga piezométrica na estimação da transmissividade.

CAPILLA et al. (1998) aplicaram uma simulação estocástica para analisar o fluxo da água subterrânea e o transporte de massa em uma área destinada a receber um depósito de lixo radioativo, nos Estados Unidos, onde deveria ser disposto $170.000 \mathrm{~m}^{3}$ de resíduo de urânio.

No presente trabalho optou-se pela calibração determinística, por tentativa e erro. Isso se justifica no sentido de que o profissional em hidrogeologia detém conhecimento fundamentado suficiente para avaliar a viabilidade e as conseqüências de alteração nos parâmetros físicos do modelo. Dessa forma a calibração torna-se uma questão de sensibilidade física e não fica a cargo de algoritmos matemáticos, cuja a fundamentação teórica não é necessariamente baseada em leis naturais. 


\section{METODOLOGIA}

Serão detalhadas as atividades executadas no desenvolvimento de um modelo de fluxo de água subterrânea do Aqüífero Bauru, na área urbana da cidade de São José do Rio Preto. As etapas podem ser condensadas em dois aspectos de gerenciamento do estudo: o primeiro diz respeito à coleta de dados referentes à área de estudo e o segundo envolve a escolha da ferramenta computacional a ser utilizada. Um dos principais itens será descrever detalhadamente a região a ser estudada, de modo que se possa verificar a adequação do modelo ao problema em questão.

\subsection{Planejamento do modelo conceitual}

O primeiro passo na modelagem de um aqüífero é a idealização de um modelo conceitual, que servirá de base para o desenvolvimento de todas as etapas inerentes à formulação do modelo matemático. Nesse sentido, as seguintes etapas serão cumpridas:

- descrição do propósito e escopo de aplicação do modelo;

- compreensão dos conceitos físicos mais importantes inter-relacionados ao problema proposto;

- apresentação dos dados hidrogeológicos usados para caracterizar o local;

- documentação da origem de todos os dados utilizados no modelo, se foram oriundos de publicações, medições de campo, cálculos ou de ensaios laboratoriais;

- descrição da conceituação do modelo;

- identificação dos limites do modelo;

- avaliação das possíveis condições de contorno existentes na região de estudo;

- estimativa dos valores de entradas e saídas hídricas, que ocorrem na área a ser modelada.

\subsection{Caracterização da área de estudo}

Esta etapa consiste na simplificação e idealização dos processos físicos mais relevantes do problema em questão. Isso requer um conhecimento prévio da hidrogeologia, da 
hidrologia e da dinâmica do fluxo de água subterrânea existente na área de interesse. Com a coleta de dados referentes à área de estudo visou-se montar um conjunto de arquivos computacionais, capazes de representar conceitualmente a região de interesse, podendo ser atualizados em trabalhos futuros.

O conhecimento do fluxo da água é imperativo para a caracterização de todo o local a ser estudado. A seguir está relacionado um conjunto mínimo de informações hidrogeológicas que devem ser disponibilizadas para essa caracterização:

1. dados topográficos;

2. dados geológicos regionais que descrevam a geologia de subsuperfície;

3. dados hidrológicos referentes aos corpos d'água superficiais existentes;

4. perfis estratigráficos ou litológicos de poços perfurados;

5. diagramas dos poços construídos e registros de perfuração;

6. medidas de carga hidráulica;

7. estimativa da condutividade hidráulica derivada dos testes de bombeamento e de recuperação;

8. locação e estimativa da taxa de fluxo das fontes e sumidouros da água subterrânea.

De posse desses dados preliminares, pode-se montar um modelo conceitual realmente representativo da área referente ao presente trabalho. A seguir serão apresentados os delineamentos propostos para servir de arcabouço ao problema proposto.

\subsubsection{Aspectos gerais}

A cidade de São José do Rio Preto, onde se localiza a área de estudo do presente trabalho, situa-se nas coordenadas $20^{\circ} 45^{\prime}$ e $20^{\circ} 50^{\prime}$ de latitude Sul e $49^{\circ} 20^{\prime}$ e $49^{\circ} 25^{\prime}$ de longitude Oeste. A área total do município é de $437.587 \mathrm{~km}^{2}$, sendo a área urbana de 80.59 $\mathrm{km}^{2}$. Assim, a região urbanizada corresponde a $18,4 \%$ da área do município. A população é de 358.523 habitantes, com 94\% residindo na área urbana, segundo o Censo 2000 do IBGE (http://www.ibge.gov.br/home/estatistica/populacao/censo2000/). A Figura 9 apresenta uma foto panorâmica da área urbana da cidade. 


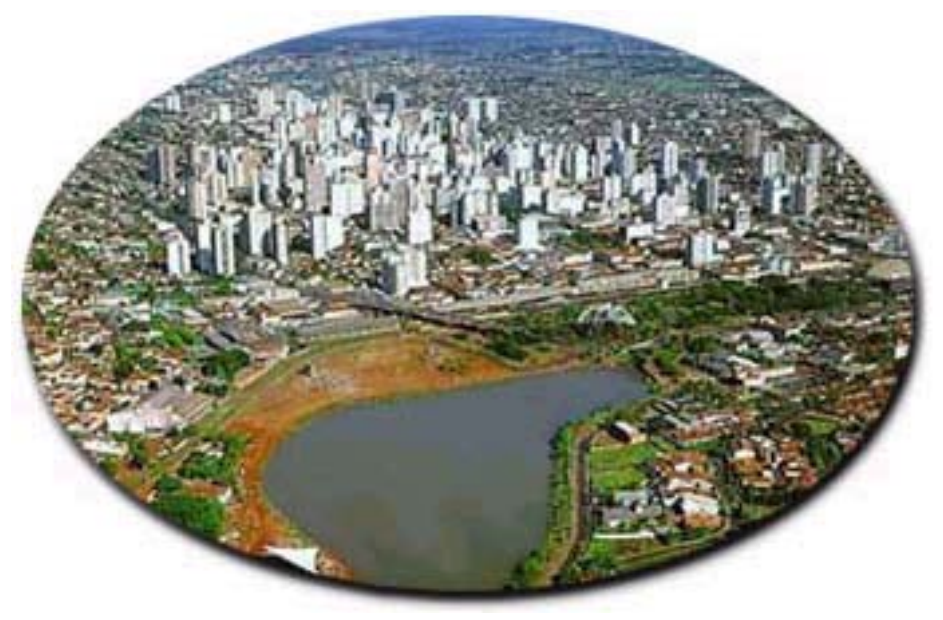

Figura 9 - Vista aérea parcial da área urbana de São José do Rio Preto. Fonte: Prefeitura Municipal de São José do Rio Preto.

O município de São José do Rio Preto localiza-se na sub-bacia do Rio Preto, que faz parte da bacia hidrográfica do Turvo/Grande (BTG), definida como Unidade Hidrográfica de Gerenciamento de Recursos Hídricos 15 (UGRHI-15). Segundo o DAEE (2000), a BTG possui $15.975 \mathrm{~km}^{2}$ de extensão territorial, sendo a $4^{\mathrm{a}}$ UGRHI em área de drenagem no Estado de São Paulo. A bacia do Rio Preto tem $2.866,6 \mathrm{~km}^{2}$ e é a maior das 12 sub-bacias que compõem a BTG. A Figura 10 apresenta a distribuição e localização das sub-bacias no Estado de São Paulo, das sub-bacias do Turvo Grande e situa também o município de São José do Rio Preto que faz divisa ao norte com Ipiguá e Onda Verde, ao sul com Cedral e Bady Bassit, a leste com Guapiaçu e a oeste com Mirassol.

Esses mapas foram obtidos com o Relatório Zero da Bacia do Turvo Grande DAEE (2000). Tais mapas, bem como os apresentados no item 3.2.2 foram confeccionados pelo IPT, usando originalmente a escala 1:250.0000.

Para a confecção do mapa da Figura 11, que apresenta maior nível de detalhamento, foram utilizadas as cartas planialtimétricas do Instituto Brasileiro de Geografia e Estatística IBGE, folhas de São José do Rio Preto SF-22-X-B-IV-3 e Nova Granada SF-22-X-B-IV-1, ambas na escala 1:50.000. Para obter melhor definição do mapa foram usadas as folhas SF22-X-B-IV-3-A, B, C e D de São José do Rio Preto na escala 1:20.000.

A região urbana tem uma vasta rede de drenagem, sendo a bacia hidrográfica do município composta pelo Rio Preto e seus principais afluentes: Córrego do Macaco, Córrego da Lagoa, Córrego do Canela, Córrego do Borá, Córrego da Piedade, Córrego da Felicidade, Córrego São Pedro e Córrego do Talhado. Além da rede de drenagem natural, a cidade conta com dois lagos artificiais formados pelo Rio Preto, que atendem o abastecimento público.. 


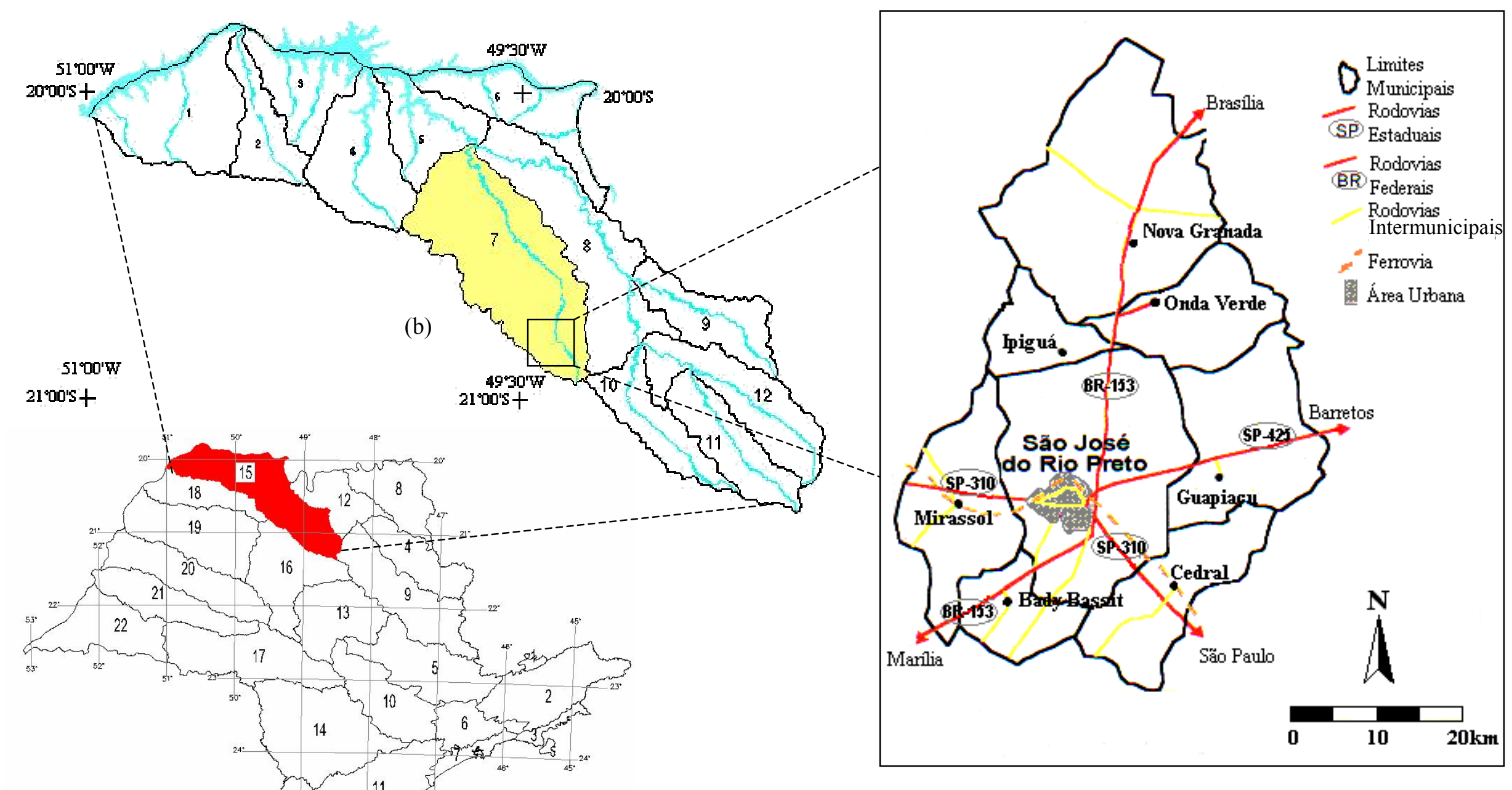

(a)

(c)

FIGURA 10 - ( a) Visualização da Bacia do Turvo/Grande em destaque (sem escala); (b) localização da sub-bacia do Rio Preto em amarelo (sem escala); (c) detalhe do município de São José do Rio Preto e seus limites. Fonte: Modificado de DAEE (2000) e LIMA (2000). 


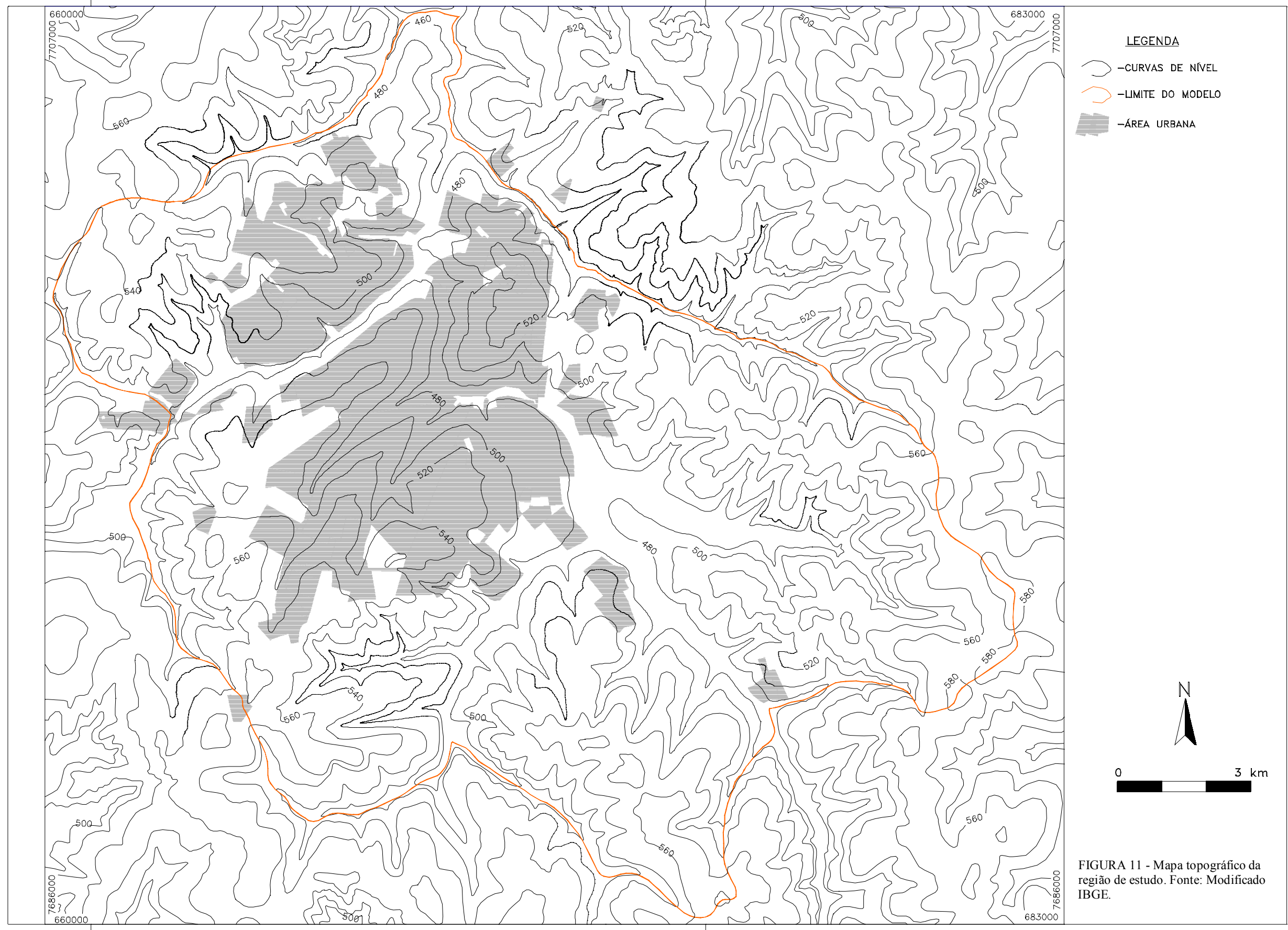




\subsubsection{Caracterização Física}

Neste item estão descritos aspectos regionais referentes a geologia, hidrogeologia, geomorfologia, pedologia e hidrometeorologia. A principal fonte de referência para a elaboração deste item foi o Relatório ZERO da BTG (DAEE, 2000).

\subsubsection{Geologia e hidrogeologia}

Segundo IPT (1981a) e BARCHA (1998), a área urbana situa-se sobre as rochas do Grupo Bauru (K), ocorrendo na superfície apenas a Formação Adamantina e em profundidade, a Formação Santo Anastácio.

O Grupo Bauru é composto pelas formações Vale do Rio do Peixe, Araçatuba, Uberaba, São José do Rio Preto, Presidente Prudente e Marília (FERNANDES, 1998). Foram consideradas apenas as unidades que ocorrem na área de estudo, como as formações Vale do Rio do Peixe e São José do Rio Preto.

A Formação Vale do Rio do Peixe ocupa uma grande parte da região de estudo, predominantemente situada nos vales dos rios da região, como exposto na Figura 12. Essa Formação apresenta estratos de arenitos com espessura inferior a um metro, maciços ou estratificados, aos quais se intercalam, subordinadamente, lamitos arenosos de aspecto maciço.

Os arenitos que ocorrem nessa Formação são de cor marrom-claro, rosado a alaranjado, muito finos a finos, com seleção moderada a boa e apresentam-se em estratos tabulares de aspecto maciço com estratificação ou laminação plano-paralela grosseira e outros com estratificação cruzada tabular e acanalada de médio a pequeno porte.

A Formação Vale do Rio do Peixe apresenta um ambiente deposicional predominantemente eólico, com a acumulação, em extensas áreas planas, de depósitos de lençóis de areia com campos de dunas baixas, alternados com depósitos de lamitos com estratificação ondulada em razão da ação do vento.

Para o topo, os sedimentos dessa Formação têm contato marcado por diastemas com os sedimentos da Formação São José do Rio Preto. Sobre a Formação ocorre cobertura arenosa colúvio-eluvial ou depósitos aluviais de idade quaternária.

Já a Formação São José do Rio Preto é composta por uma sucessão de bancos arenosos com estratificação cruzada acanalada a tabular tangencial na base e intercalações subordinadas de bancos tabulares de arenitos a siltitos, com estratificação plano-paralela e estruturas de fluxo aquoso, e lamitos argilosos, em geral maciços. 


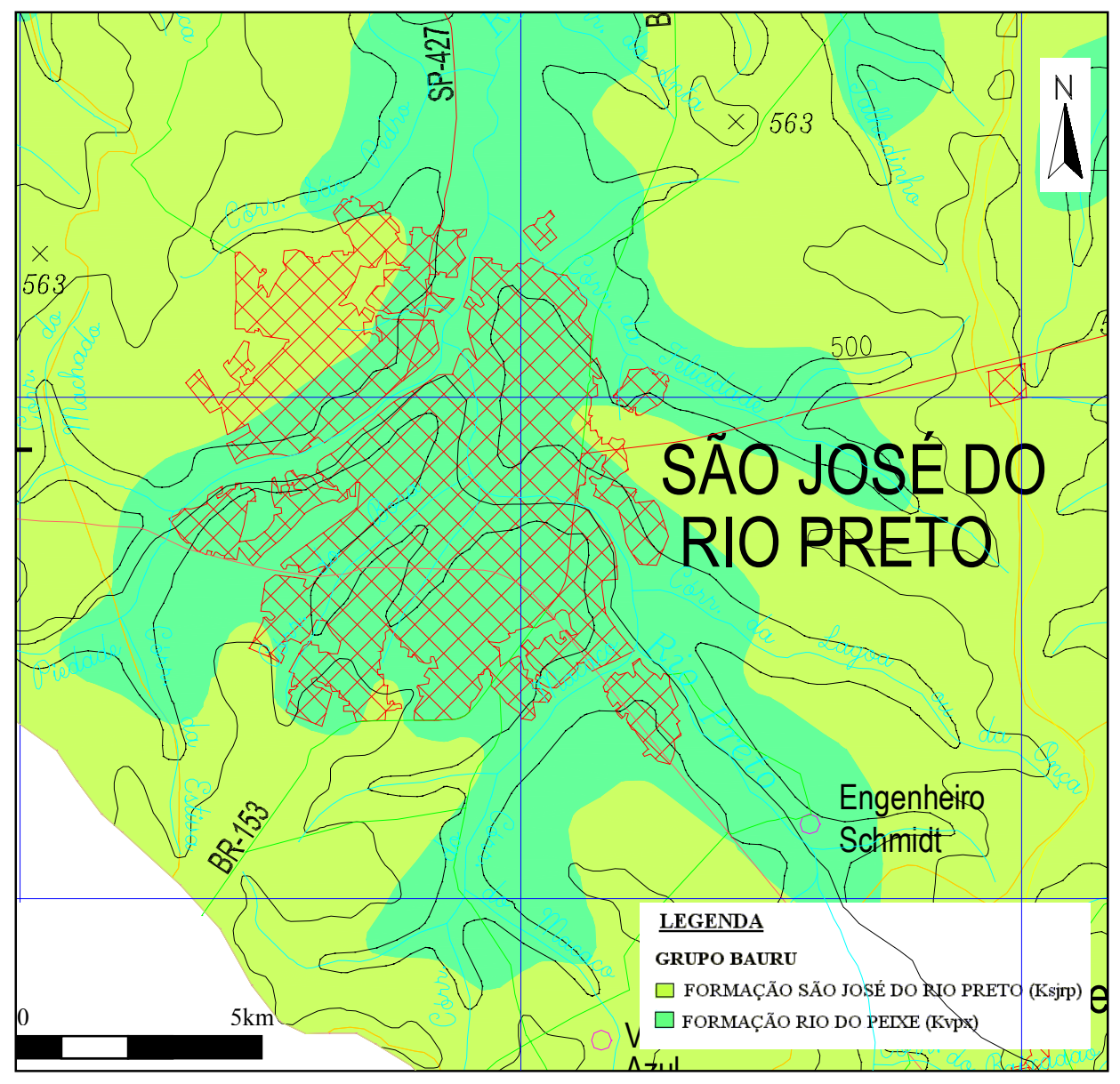

FIGURA 12 - Mapa geológico da região. Fonte: Modificado de DAEE (2000).

Os arenitos da Formação São José do Rio Preto são de cor marrom-claro a bege, finos a muito finos, moderado a mal selecionados, freqüentemente conglomeráticos (frações areia média e grossa secundárias), com seixos silicosos, de nódulos carbonáticos, de lamitos e argilitos.

Predomina, para os arenitos da Formação São José do Rio Preto, um ambiente deposicional de barras fluviais, em sistemas de amplos e rasos canais entrelaçados, nos quais teria predominado um regime de fluxos intempestivos. A escassez de depósitos pelíticos sugere relativa proximidade das áreas-fonte, predominância de intemperismo físico e clima semi-árido.

O Sistema Aqüífero Bauru, apresentado na Figura 13, é conhecido como uma unidade hidrogeológica sedimentar, permeável por porosidade granular, destacando-se por sua extensa área de afloramento no Estado de São Paulo, e que corresponde aos sedimentos da Bacia Bauru.

Segundo CETESB (1997b), a área aflorante do aqǘfero Bauru, na Bacia do Turvo Grande, corresponde a $90 \%$ do total da área da bacia. 


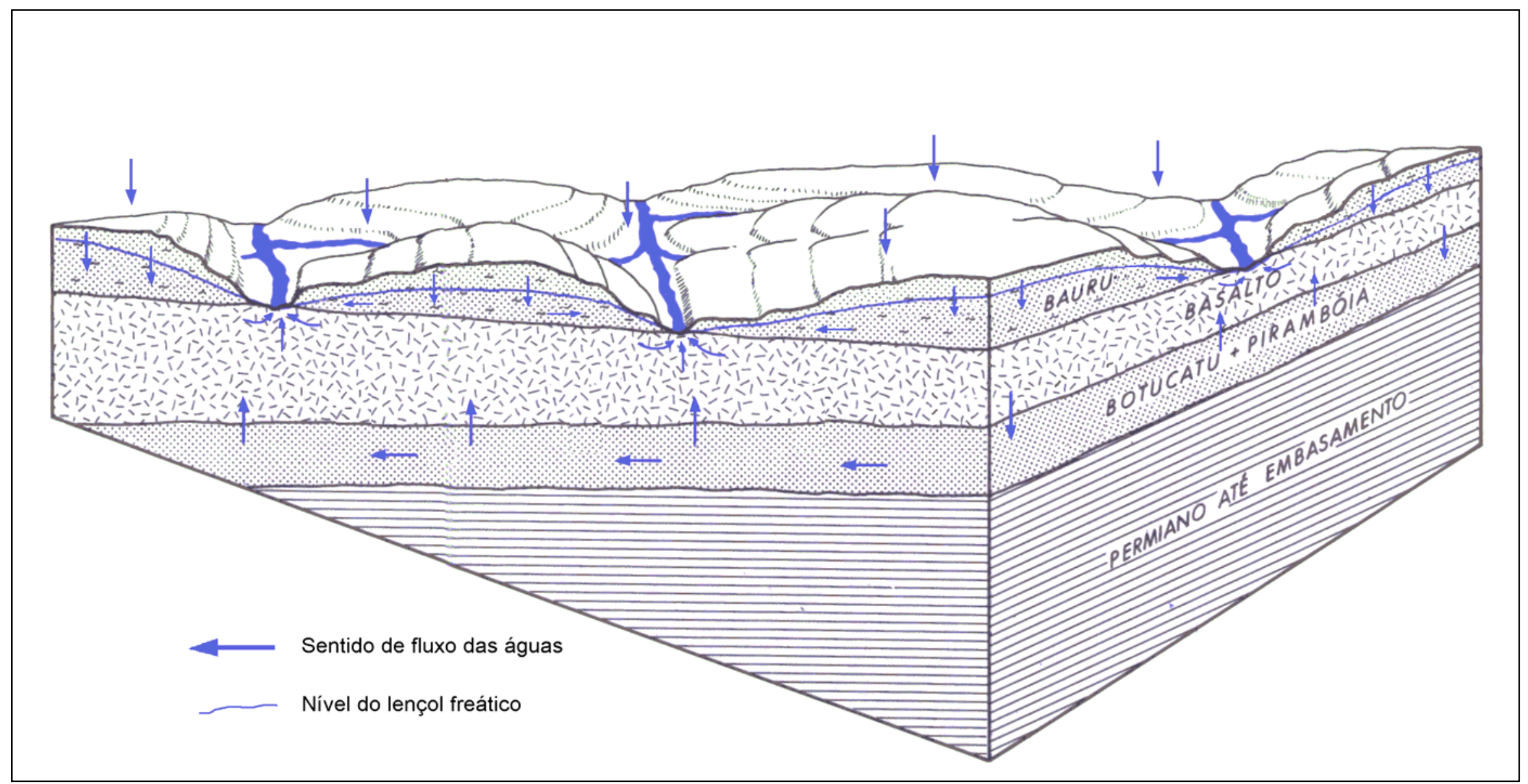

FIGURA 13 - Relações geométricas e de fluxo das águas nos aqüíferos da bacia hidrográfica do Turvo/Grande. Fonte: Modificado de DAEE (1976). 
De acordo com FERNANDES (1998), o aqüífero na região apresenta comportamento de aqüífero livre, com recarga natural diretamente de infiltração da pluviometria. Os níveis d'água são relativamente rasos, acompanhando o relevo e com sentidos de fluxo principais rumo às drenagens, como mostra a Figura 13.

Estudos realizados pelo DAEE (1976) nas regiões administrativas de Bauru, São José do Rio Preto e Araçatuba apresentam a espessura saturada do aqüífero variável entre $100 \mathrm{~m}$ e $150 \mathrm{~m}$, condicionada pela morfologia de superfície e pelo substrato rochoso, representado pelos basaltos da Formação Serra Geral. A amplitude das variações sazonais no nível do lençol freático situa-se entre 2 e $4 \mathrm{~m}$, verificadas em poços de observação entre 1973 e 1976.

Ainda segundo DAEE (1976) o Aqǘ́fero Bauru é considerado como moderadamente permeável, em razão do teor relativamente elevado de material argiloso e siltoso. Os valores de transmissividade variam de $10 \mathrm{~m}^{2} / \mathrm{d}$ a $100 \mathrm{~m}^{2} / \mathrm{d}$, com média de $35 \mathrm{~m}^{2} / \mathrm{d}$, e porosidade efetiva entre $5 \%$ e $15 \%$. Coeficientes de armazenamento entre $10^{-3}$ e $10^{-5}$ indicam, localmente, condições de semiconfinamento a confinamento. Tais características hidráulicas resultam em vazões nos poços consideradas pequenas, com médias entre $12 \mathrm{e}$ $13 \mathrm{~m}^{3} / \mathrm{h}$, porém de grande importância em razão de sua extensa distribuição no Estado e facilidade de captação por poços relativamente rasos ( 75 a $125 \mathrm{~m}$ de profundidade).

ARID et al. (1970) estimaram a reserva permanente do Aqüífero Bauru na bacia hidrogeológica de São José do Rio Preto em 40 bilhões de $\mathrm{m}^{3}$, com volume disponível de cerca de 25 a 30 bilhões de $\mathrm{m}^{3}$.

BARCHA (1997) salientou que há uma espessa cobertura de solos coluvionais arenosos recobrindo o aqǘfero, ocorrendo circulação subterrânea, mais próxima à superfície, vinda dos interflúvios para os vales dos rios. Porém, numa profundidade maior, o fluxo se dá de N-NE para S-SW. 


\subsubsection{Geomorfologia}

O Planalto Ocidental Paulista é a zona de revelo onde está situada a área de estudo do presente trabalho, como observou BARCHA (1980). Nesta região existe uma topografia suave, com relevo ondulado relativamente uniforme, apresentando baixos espigões, em faixas longas e estreitas, principalmente nos divisores topográficos das bacias.

São basicamente dois os sistemas de relevo existentes na região estudada, como apresentado na Figura 14. As definições apresentadas a seguir provêm de IPT (1981b).

Nas colinas amplas predominam interflúvios com área superior a $4 \mathrm{~km}^{2}$, topos extensos e aplainados e vertentes com perfis retilíneos a convexos. Geralmente, a drenagem é de baixa densidade e apresenta padrão subdendrítico. Os vales apresentam planícies aluviais interiores restritas, podendo ocorrer, eventualmente, lagoas perenes ou intermitentes.

Nas áreas com relevo de colinas médias predominam interflúvios com áreas de 1 a 4 $\mathrm{km}^{2}$, de topos aplainados, drenagem de média a baixa densidade, padrão sub-retangular e vales abertos a fechados. As vertentes mostram perfis retilíneos a convexos, com ocorrência de planícies aluviais interiores restritas, podendo ocorrer lagoas perenes ou intermitentes.

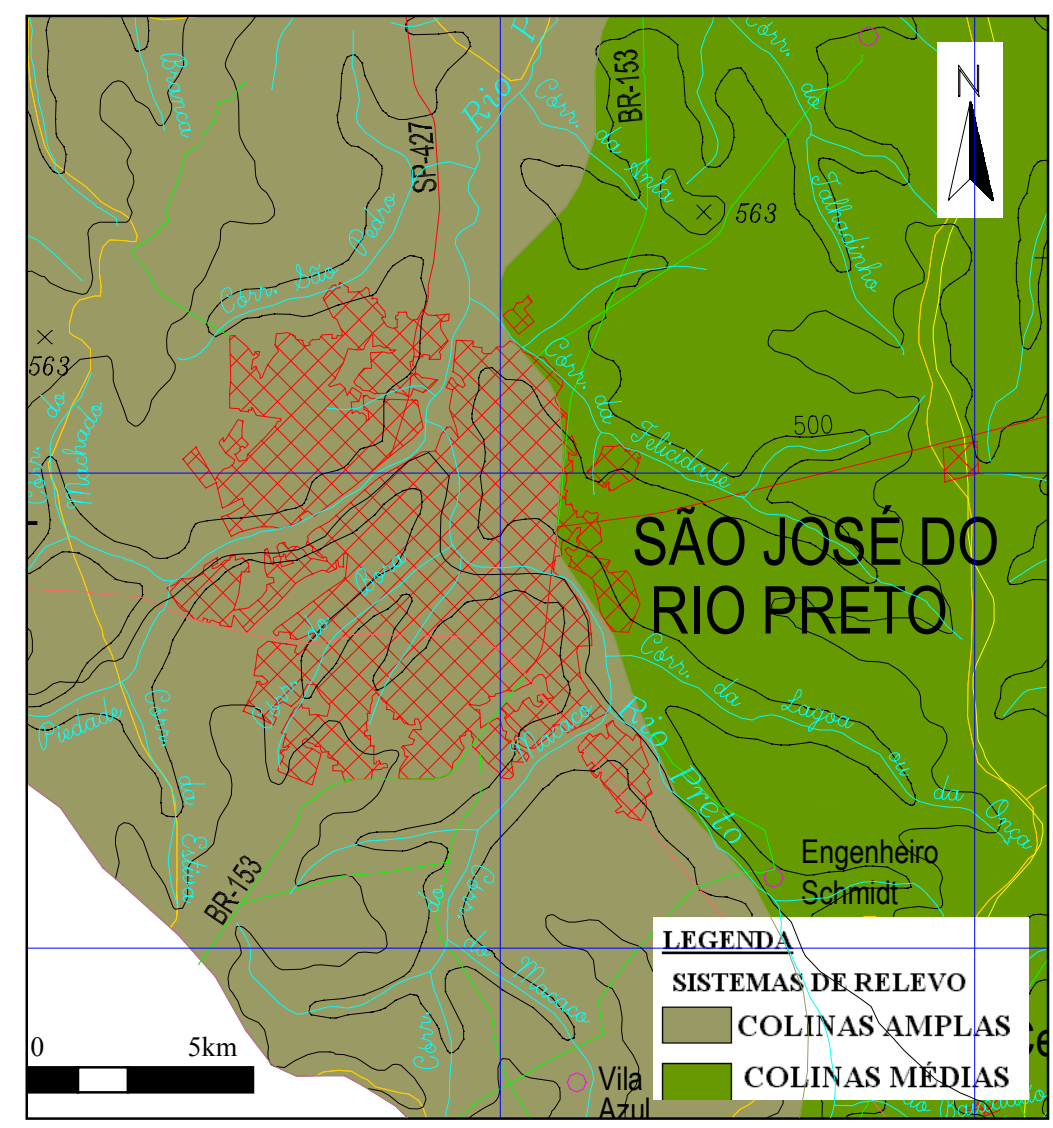

FIGURA 14 - Geomorfologia da região de estudo. Fonte: Modificado de DAEE (2000). 
As declividades que predominam na região são baixas, geralmente menores que $15 \%$. Tal condição torna-se positiva quanto à captação e possível infiltração da água das chuvas, fazendo com que o aqüífero se reabasteça em razão do pequeno gradiente topográfico que inibe o escoamento superficial, como afirma BARCHA (1980).

O sistema de drenagem é organizado na maior parte por rios conseqüentes (drenam no mesmo rumo do mergulho das camadas geológicas). $\mathrm{O}$ arranjo da rede de drenagem apresenta sugestões de capturas, como, por exemplo, Rio Preto (na área urbana de São José do Rio Preto), que, de sentido nitidamente noroeste, mudam seus cursos para norte, sugerindo a transferência de suas águas, em tempos passados.

\subsubsection{Pedologia e uso do solo}

Os solos são, em sua grande maioria, arenosos e advindos da decomposição da Formação Bauru. Segundo BARCHA (1980), a composição granulométrica é predominantemente arenosa, com $\pm 70 \%$ de areia e aproximadamente $30 \%$ de silte-argila.

Segundo VIEIRA (1988), os solos Podzolizados são bem desenvolvidos, bem drenados e normalmente ácidos. Quando distróficos, a fertilidade natural é baixa, porém, os eutróficos caracterizam-se por uma fertilidade natural média e alta. Nas áreas de ocorrência desse solo nota-se, também, uma predominância muito grande de relevos movimentados, principalmente caracterizados por colinas médias e morrotes com alta densidade de drenagem.

A Figura 15 mostra que há predominância do Solo Latosolo Vermelho Amarelo Podzolizado, A, textura media, além do Podzólico Vermelho Amarelo, A moderado, textura arenosa/média fraco.

Na Figura 16 evidencia-se o uso do solo na região de São José do Rio Preto, verificando-se a extensão das atividades de pecuária (pastagens) e a reduzida parcela da cobertura vegetal nativa (ARID, 1966), além das pequenas áreas destinadas às atividades agrícolas, principalmente relacionadas à citricultura. Verifica-se, ainda, a área urbanizada, a qual teve expansão na direção norte. 


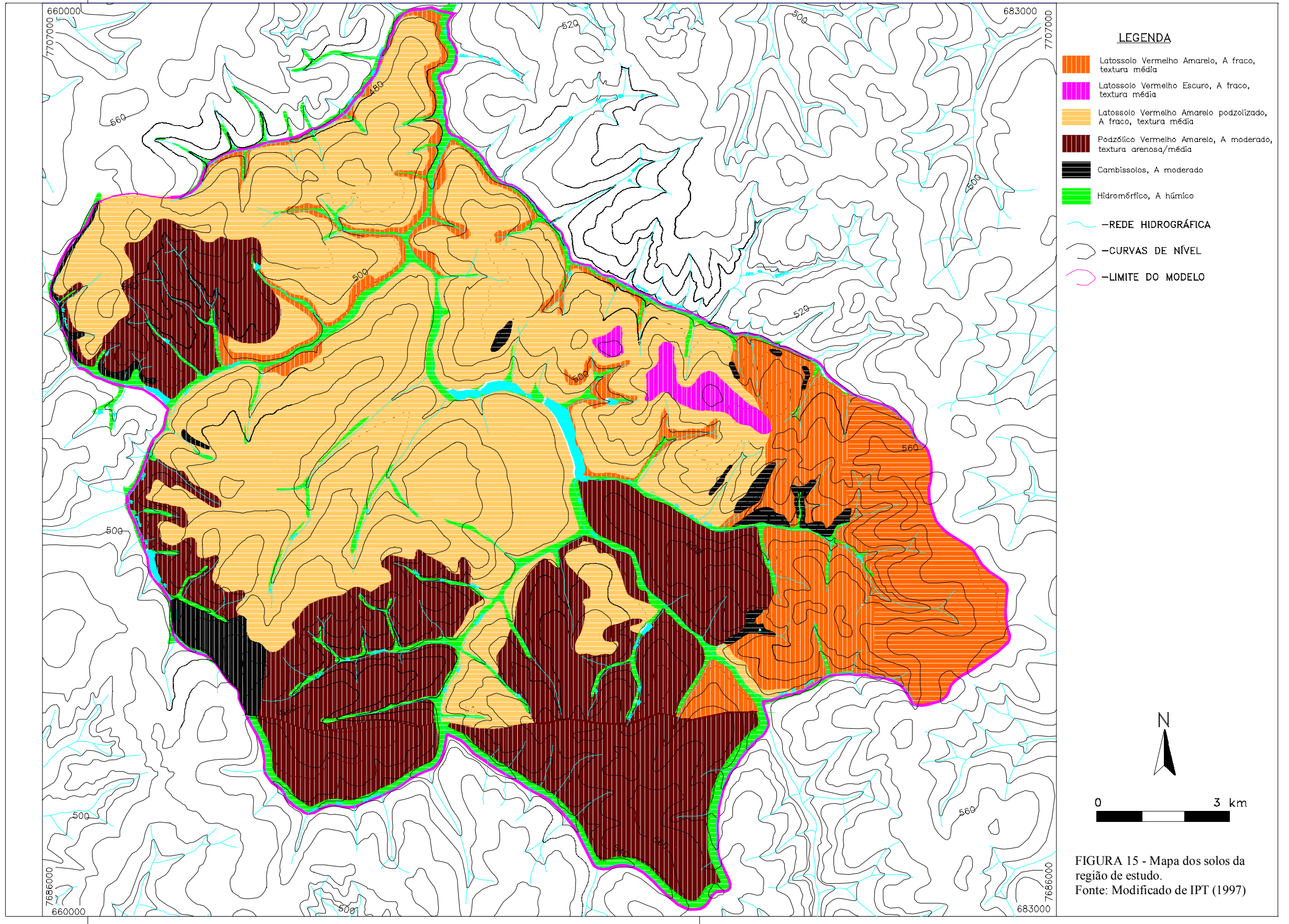




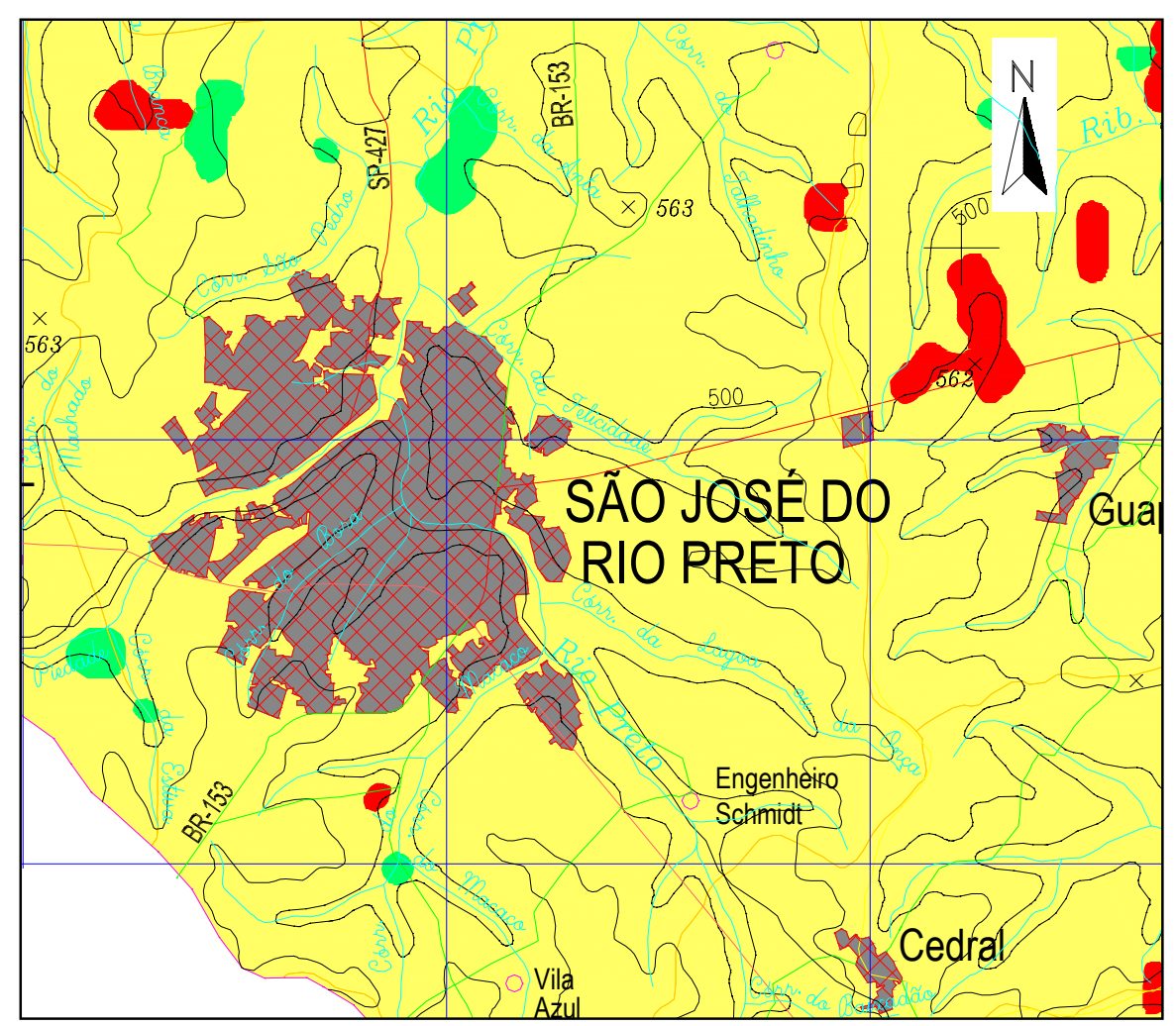

LEGENDA

USO DO SOLO

$\square$ COBERTURA VEGETAL NATIVA

ÁREA URBANA

$\square$ PASTAGENS

ATIVIDADES AGRÍCOLAS

FIGURA 16 - Mapa de uso do solo na região. Fonte: Modificado de DAEE (2000). 


\subsubsection{Características climáticas}

O clima no município de São José do Rio Preto apresenta-se bastante homogêneo, sendo considerados dois tipos climáticos, segundo a classificação de KÖEPPEN. O tropical úmido com inverno seco $(A w)$, predominante em $60 \%$ do município, e o quente úmido com estação seca, com verão quente e inverno não muito frio (subtropical) ( $C w a$ ), na parte sul da região, segundo DAEE (2000).

O comportamento térmico na região, no período de 1996 a 2000, apresentou temperatura média variando de 20,4 a $28,03^{\circ} \mathrm{C}$, enquanto a temperatura média mínima chegou a $13,41^{\circ} \mathrm{C}$ no mês de julho, com média máxima de $33,79^{\circ} \mathrm{C}$ em fevereiro. A Tabela 2 (anexo I) mostra os dados de temperatura coletados no posto meteorológico da Coordenadoria de Assistência Técnica Integral (CATI), Escritório de Desenvolvimento Rural de São José do Rio Preto (EDR-SJRP).

O município conta com dois postos pluviométricos, um mantido pela EDR e outro pelo DAEE. A pluviometria na região apresenta distribuição de chuvas não homogênea, com forte concentração de outubro a março e déficit pluviométrico de abril a setembro. A Tabela 3 (anexo I) apresenta os dados pluviométricos do município, com totais anuais variando de 1090,7 mm a 1928,4 mm ao ano. A precipitação média está em torno de $1300 \mathrm{~mm} / \mathrm{ano}$.

O comportamento heterogêneo da precipitação afeta a recarga natural do aqüífero, como cita BARCHA (1980).

O balanço hídrico pode se tornar deficitário com a sazonalidade da precipitação associada às elevadas temperaturas da região, como apresentaram ARID et al. (1970). Com isso criam-se condições para um aumento da evapotranspiração, com consumo rápido das reservas do solo, a partir do mês de abril. Esses fatores afetam o suprimento das reservas subterrâneas, porém não comprometem o abastecimento do aqüífero, afetando apenas o nível estático da região.

A evapotranspiração média real registrada na região é da ordem de $1000 \mathrm{~mm} / \mathrm{ano}$, o que, em média, garante um excedente de água no solo, que recarregará o aqüífero.

\subsubsection{Fluviometria}

O município de São José do Rio Preto conta com a estação fluviométrica de Ipiguá mantida pelo DAEE, com prefixo 6B-011, nas coordenadas $20^{\circ} 37^{\prime} 43^{\prime}$ ' de latitude e $49^{\circ}$ 21'18" de longitude. A estação se encontra no Rio Preto e abrange uma área de $576 \mathrm{~km}^{2}$. O posto funciona desde 1985, porém apresenta muitas falhas de dados. 
A Figura 17(A) apresenta a seção transversal do curso d'água onde se encontra o posto fluviométrico e a Figura 17(B) mostra a curva-chave para o período de 18/10/1998 a 31/3/1999. Ambas foram retiradas do site do Sistema Integrado de Gerenciamento de Recursos Hídricos do Estado de São Paulo (http://www.sigrh.sp.gov.br/sigrh/ basecon/bancodedados/flu/flu.htm).

(A)

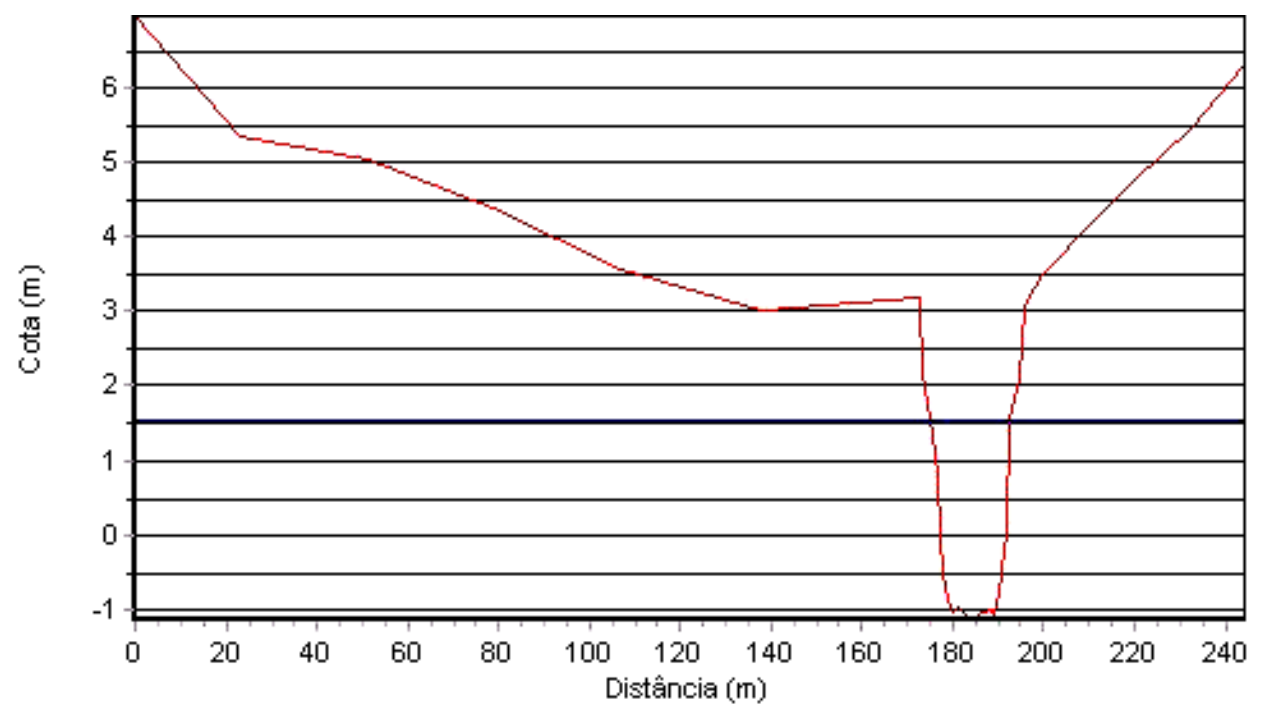

(B)

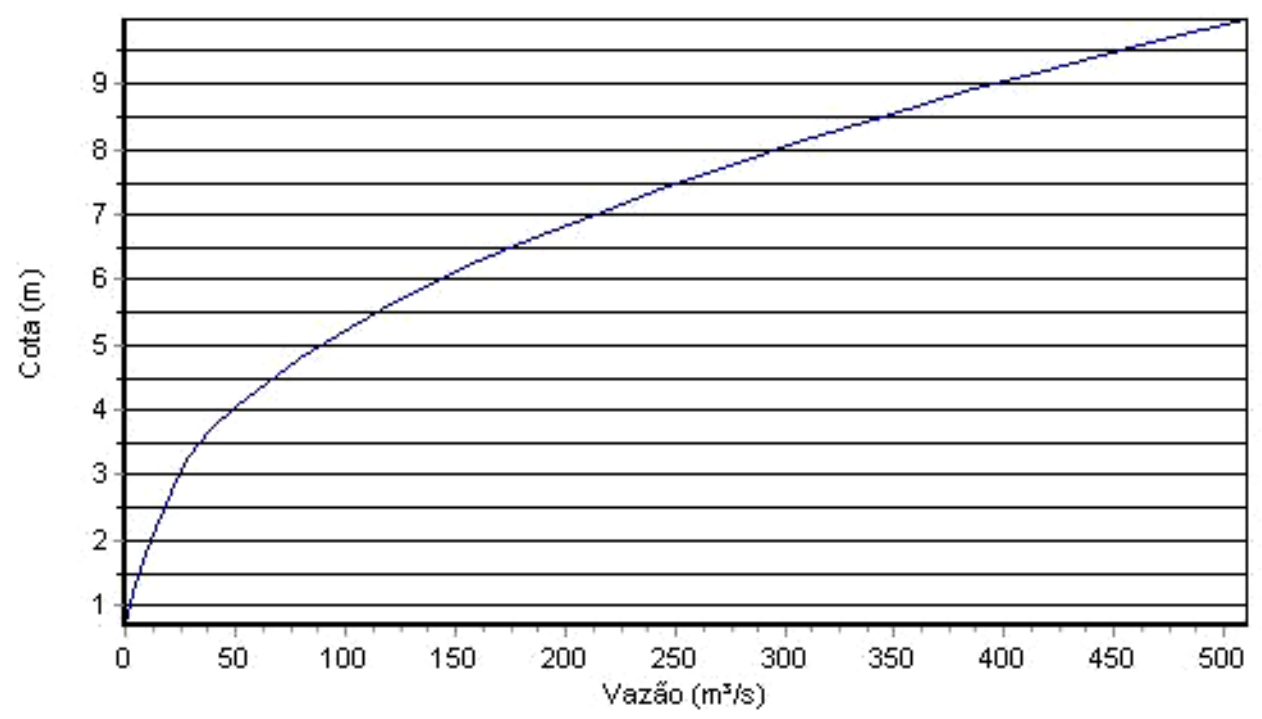

FIGURA 17 - (A) Seção transversal; (B) curva-chave do posto 6B-011. 
A Figura 18 apresenta um gráfico de vazões mensais de 1992, em que se pode observar a variação das vazões máxima, média e mínima nesse período. A vazão média anual para esse ano foi de $8,08 \mathrm{~m}^{3} / \mathrm{s}$, com os maiores valores de vazão ocorrendo entre janeiro e maio.

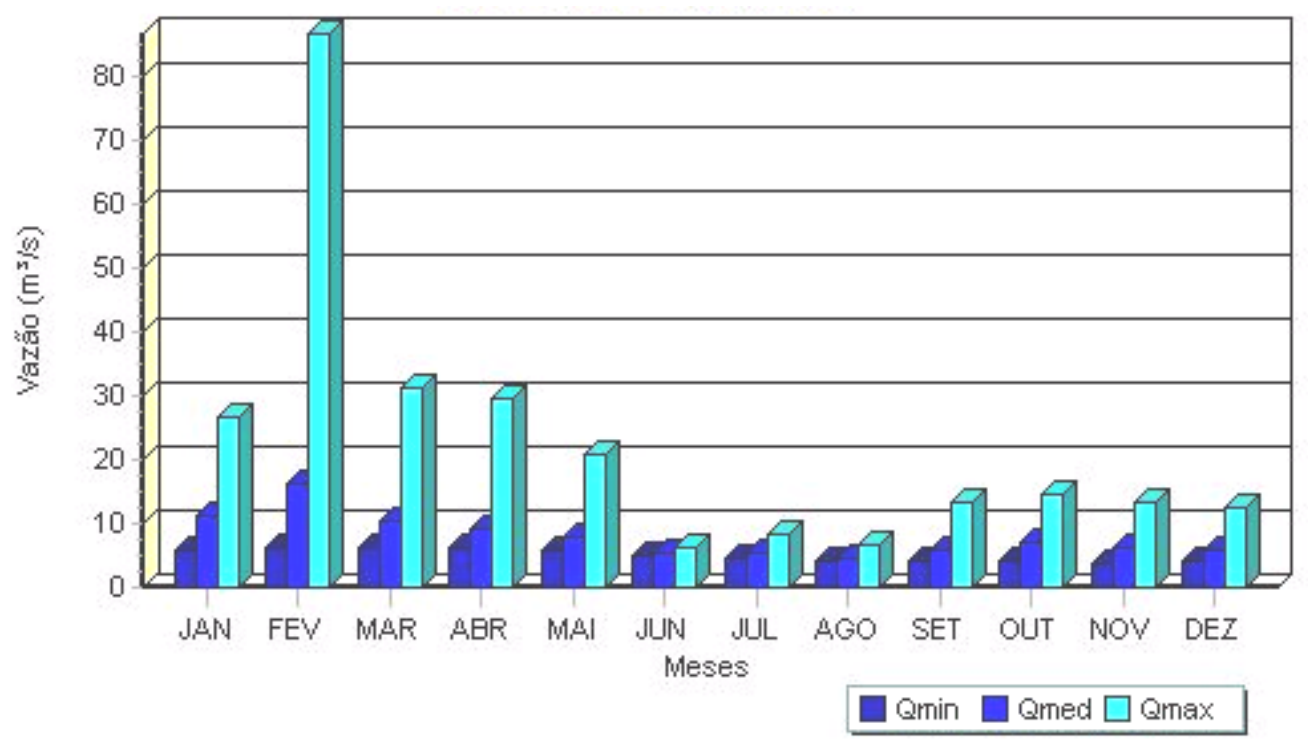

FIGURA 18 - Distribuição de vazões (m³/s) para o Rio Preto em 1992.

Na Figura 19 pode-se verificar a rede hidrográfica da área de estudo, destacando-se as barragens artificiais localizadas na área urbana, as quais foram avaliadas no presente estudo.

\subsection{Catalogação dos poços existentes}

Existem catalogados aproximadamente 600 poços que produzem água do Aqüífero Bauru, em São José do Rio Preto. As informações contendo detalhes construtivos e a produção dos poços estão distribuídas em três bases de dados: o DAEE de Araraquara, que gerencia todas as outorgas para perfuração e uso da água subterrânea, o CD-ROM do relatório Zero da Bacia do Turvo/Grande - BTG, que possui um arquivo de poços perfurados antes da obrigatoriedade da outorga, e o Sistema Autônomo de Água e Esgoto da cidade de São José do Rio Preto - SeMAE, que atualmente gerencia a coleta e distribuição da água subterrânea.

Nos Anexos 2, 3 e 4 estão sistematizados os dados referentes a cada um desses catálogos. Com base nesse material, após uma busca minuciosa nos órgãos competentes, foi elaborado o mapa da distribuição de poços apresentado na Figura 20.

Os perfis de detalhamento construtivo de poços catalogados no DAEE de Araraquara foram avaliados, mas infelizmente apenas $10 \%$ dos poços apresentam essa informação. 


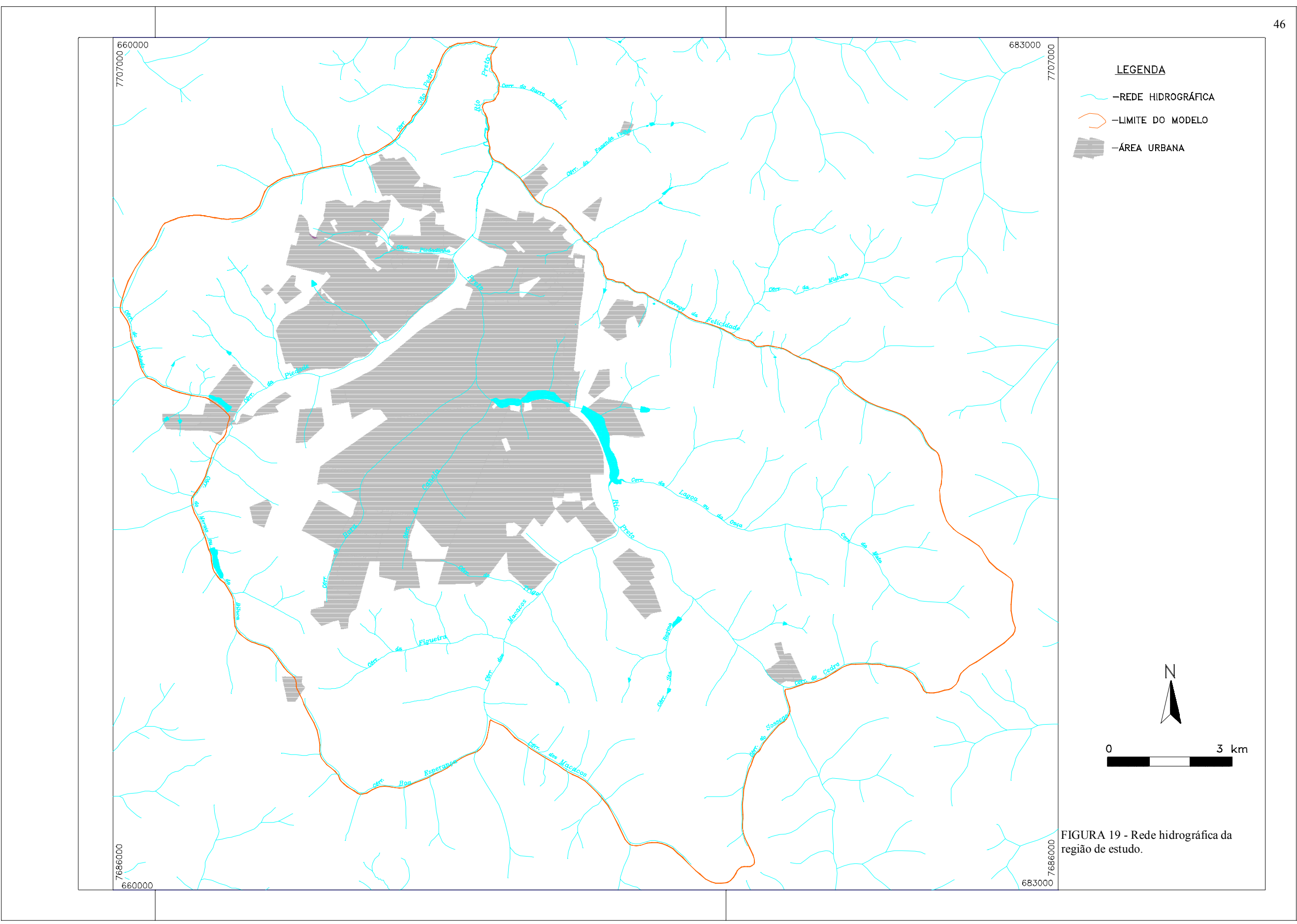




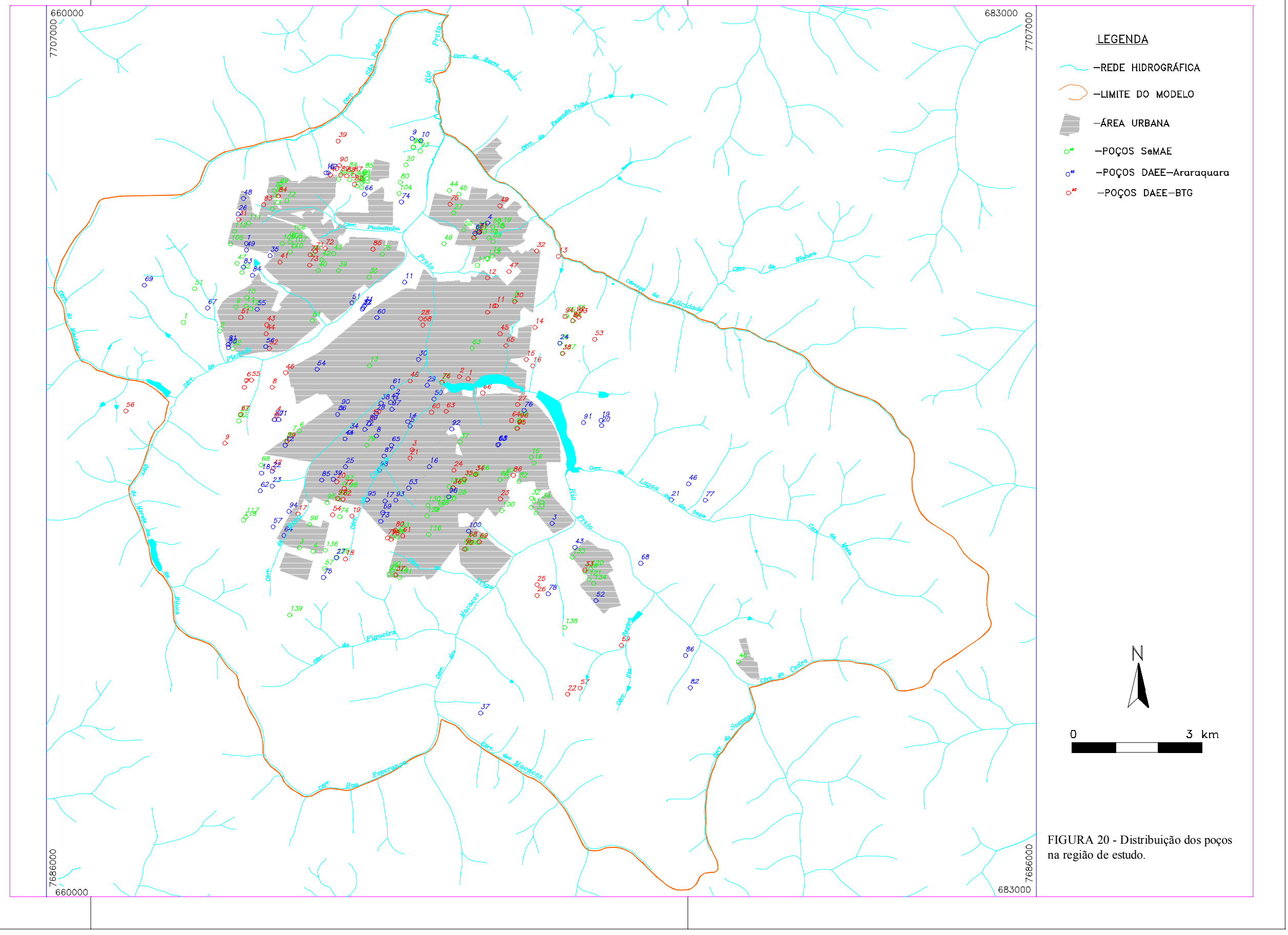




\subsection{Concepção do modelo}

Nesta etapa todos os dados que descrevem a área de estudo foram organizados e sistematizados de forma que pudessem ser aplicados a um modelo numérico e, assim, mostrar o comportamento do fluxo da água subterrânea. Esta conceituação ajudou a determinar o modelo que mais se aproxima da realidade e o tipo de programa computacional a ser usado para solucionar o problema em questão.

Algumas questões devem ser respondidas antes da tomada de decisão:

1. Os dados hidrometeorológicos são adequados para descrever as condições do local de estudo? Sim, pois existem registros de um período de 20 anos (precipitação), o que corrobora os dados necessários para o balanço hídrico.

2. O fluxo pode ser caracterizado em uma, duas ou três dimensões? Por se tratar de um aqüífero livre, de grande extensão, optou-se pela construção de um modelo bidimensional. Apesar da grande concentração de poços, consideraram-se válidas as hipóteses de Dupuit (Dupuit, 1863). Dessa forma, pode-se reduzir o esforço computacional e viabilizar a calibração do modelo no prazo disponível.

3. O sistema aqüífero é constituído por quantos aqüíferos? O fluxo vertical existente entre eles é considerável? O aqüífero Bauru foi considerado um pacote único, pois não se tem com precisão os níveis de cada Formação que compõe o Grupo e não se considerou a percolação profunda pelas possíveis fissuras no basalto subjacente.

4. A recarga é proveniente da precipitação ou do escoamento de rios, drenos, lagos ou reservatórios que interagem com o aqüífero? A precipitação é a principal fonte de recarga através da infiltração em zonas não impermeabilizadas.

5. A água subterrânea deixa o sistema pelo escoamento para um rio ou lago, pelo fluxo para um dreno ou pela extração da água por poços? Os rios e a exploração de água pelos poços drenam em parte o manancial subterrâneo. A malha fluvial tem comportamento efluente e influente. A água drenada do aqüífero em regiões rurais é transportada pelo sistema fluvial, abastecendo o aqüífero nas áreas centrais, através da infiltração no leito de rios e lagos.

6. As características hidrogeológicas e geológicas do aqüífero variam espacialmente ou permanecem relativamente uniformes em toda a área de estudo? Foram consideradas variações espaciais da condutividade hidráulica e da recarga, em razão das características geológicas e geomorfológicas da área de estudo.

7. As condições de contorno foram bem definidas, estão dentro do perímetro do domínio do modelo e de acordo com a base hidrogeológica? As condições de contorno foram 
definidas com base na malha fluvial, presente na área de estudo e por analogia com a área de drenagem da bacia hidrográfica.

8. As condições de fluxo variam ou não com o tempo? O fluxo foi considerado permanente.

Após a caracterização da área de estudo, o desenvolvimento do modelo conceitual requer a escolha de um programa computacional. O modelo selecionado deve ser capaz de simular as condições encontradas no local. No presente trabalho foi utilizado um programa baseado no Método das Elementos Finitos (SICK100), em razão da versatilidade deste e de sua aplicabilidade em situações complexas (SCHMID et al., 1992).

\subsubsection{Determinação das fronteiras}

Definido o objetivo do modelo, isto é, a avaliar o fluxo da água subterrânea na área urbana da cidade de São José do Rio Preto, e de posse dos mapas planialtimétricos da região, pode-se arbitrar a fronteira do domínio a ser modelado. Como primeiro passo, para a tomada de decisão, foram verificadas as possíveis evidências físicas que interagissem com o fluxo da água subterrânea. Assim, os córregos que cercam a área urbana também foram considerados como fronteiras, assim como os divisores topográficos entre eles. Esses elementos geográficos são fáceis de identificar espacialmente e permitem definir condições de contorno consistentes.

Os limites do modelo foram escolhidos de forma a considerar todos os elementos físicos e geológicos que possam interferir no fluxo de águas subterrâneas.

Outro ponto a ser observado é que a área de interesse principal (neste caso, a zona urbana central da cidade de São José do Rio Preto) está localizada suficientemente distante das fronteiras, de forma a minimizar o impacto de erros na definição das condições de contorno.

\subsubsection{Determinação das condições de contorno}

Já definida a fronteira estabelecem-se as condições de contorno, as quais reproduzem a interação do domínio (região) a ser modelado com o meio que o circunda. As condições de contorno permitem (viabilizam) a determinação de uma única solução para a formulação matemática proposta. Portanto, são de fundamental importância para a modelagem, uma vez que acarretam graves erros na solução do problema, conduzindo, em alguns casos, a uma solução desprovida de significado físico prático. 
Partindo do pressuposto de contorno físico, consideraram-se todos os cursos d'água superficiais existentes na fronteira como tendo uma conexão direta com o aqüífero Bauru e, conseqüentemente, uma carga hidráulica específica conhecida. Foram tomados os valores da cota topográfica de todos os córregos fronteiriços em vários pontos ao longo do contorno do domínio. Neste caso, a condição do ponto de vista matemático foi a condição de Dirichlet, com carga conhecida.

Visto que os cursos d'água superficiais não fecham totalmente o contorno do domínio, os divisores topográficos foram utilizados como contorno e considerados como linhas de fluxo nulo. Nessa aproximação supõe-se que os divisores de água subterrânea acompanham os divisores de águas superficiais. Tal condição de fluxo especificado impõe uma condição de Neuman.

Vale salientar que a opção por contornos físicos para representar os condições de contorno é recomendada por CABRAL \& DEMÉTRIO (2000), que também salientam a necessidade de conhecer ao menos uma das cargas hidráulicas no contorno, a fim de que o sistema de equações resultante da aproximação numérica das equações governantes não seja matematicamente indeterminado.

\subsubsection{Geração da malha}

A escolha da malha é fundamental para uma boa solução numérica de um problema de fluxo, como o de São José do Rio Preto. Deve-se ter em mente que o problema de geração da malha tem de ser abordado considerando a fronteira da região definida para o estudo e nas características físicas internas do problema.

A construção do modelo, utilizando os recursos do pacote SICK100, consistiu basicamente em 3 etapas: definição da estrutura hidrogeológica, geração da malha e atribuição de parâmetros físicos.

A definição da estrutura hidrogeológica consiste na indicação dos limites do modelo, dos principais cursos e acumulações de águas superficiais (rios e lagos), dos pontos de captação (poços) e dos limites geológicos eventualmente conhecidos. Esses elementos estruturais são representados por pontos com coordenadas georreferenciadas, estabelecendo os principais contornos do modelo.

Para geração da malha, o programa dispõe de algoritmos específicos. Inicialmente, são gerados nós sobre os pontos estruturais especificados previamente. Na etapa seguinte, são gerados nós internos ao modelo, paralelos aos nós estruturais. Essa técnica facilita a posterior geração de elementos. Finalmente, é gerada uma nuvem de nós regularmente espaçados nas áreas interiores do modelo, com distância especificada pelo usuário. Para o 
presente modelo, a distância máxima entre os nós foi de $300 \mathrm{~m}$. Com a finalidade de reproduzir os intensos gradientes que ocorrem nas proximidades dos poços, foi especificado para essas situações um refinamento de malha (espaçamento exponencial entre nós). A partir do poço, a distância radial da primeira série de nós foi de $40 \mathrm{~m}$, crescendo até $320 \mathrm{~m}$. Em razão da proximidade entre os poços no centro da cidade, alguns nós gerados exponencialmente encontram-se muito próximos. Nessas situações foi realizada uma correção manual. Os nós são, então, automaticamente conectados, gerando uma malha nãoestruturada de elementos finitos. Segundo FORTUNA (2000), esse tipo de malha é o mais aconselhável na ausência de regularidade na disposição dos pontos e em situações que apresentem domínios com geometrias complexas. Essa classe de malhas é também não uniforme, o que facilitou seu ajuste ao domínio da região de estudo. Dessa forma, gerou-se uma malha com 17433 nós e 27970 elementos, como apresentado na Figura 21. Um detalhe da zona de maior concentração de poços entre as coordenadas (664000,7690000) e (668000,7696000) é apresentado na Figura 22.

Os parâmetros físicos foram atribuídos ao modelo utilizando os recursos do préprocessador. Esses parâmetros podem ser atribuídos pontualmente (por exemplo, vazão de poços), linearmente (carga hidráulica ao longo de rios) ou espacialmente (zonas de condutividade hidráulica ou taxa de recarga conhecida).

\subsubsection{Determinação dos parâmetros geométricos}

Neste item foram avaliadas as cotas de topo e de base do aqüífero Bauru na região de estudo, de acordo com dados fornecidos pelas firmas perfuradoras de poços ao DAEE e de perfis construtivos divulgados pelo próprio DAEE no relatório ZERO da Bacia do Turvo/Grande.

Tendo por base os dados coletados, foi gerada, utilizado a técnica de krigagem, uma malha de isovalores da base do aqüífero Bauru, para que se pudesse definir o limite inferior do modelo a ser construído. Esse mapa de base permite, também, estimar a espessura da formação em todo o domínio estudado por meio da superposição com o mapa topológico.

\subsubsection{Parâmetros de entrada}

Os primeiros dados de entrada inseridos foram as cargas hidráulicas de todos os cursos d'água e barragens localizados na fronteira e no domínio da região de estudo. Tais valores foram obtidos a partir do mapa topográfico. 


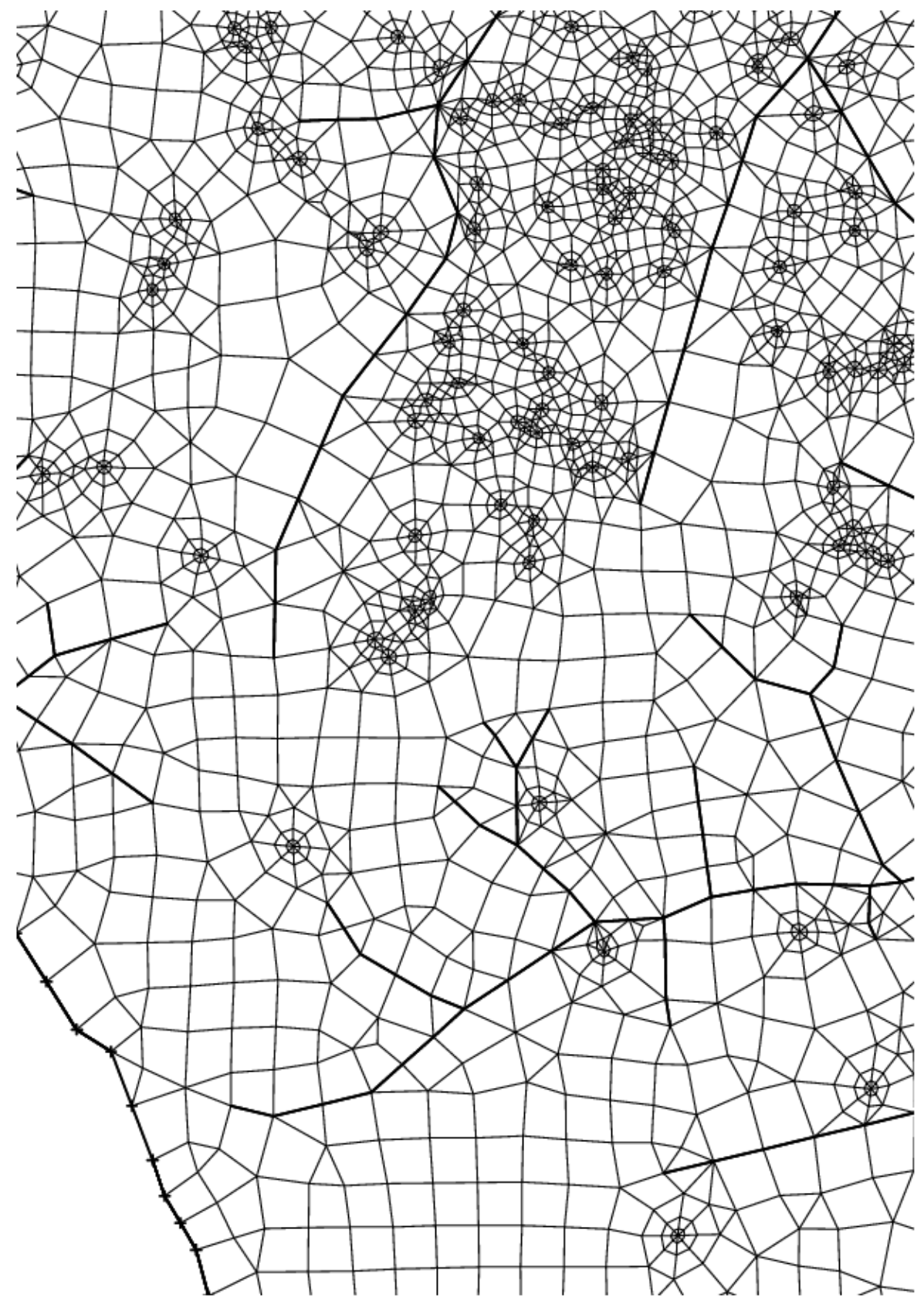

FIGURA 22 - Detalhe da malha na região central do modelo. 
Em seguida, foram incluídos os poços relacionados nos órgãos responsáveis (SeMAE e DAEE); vale salientar que foram considerados apenas os poços catalogados e que apresentavam valores de vazão, pois em muitos casos estão disponíveis somente os valores das coordenadas dos poços. Para as regiões mais altas da área, foi considerado fluxo nulo, sendo considerado o divisor topográfico das bacias.

Vários autores, como PORTO (1992) e RIGHETTO (1998) salientam a importância de verificar as características do tipo de solo, com atenção voltada principalmente para o grupo hidrológico do solo, verificando o teor de argila deste. Outros fatores relevantes são o tipo de uso e tratamento dado ao solo e a declividade.

Neste aspecto a interferência da urbanização é crucial, pois quanto mais adensada a população, maior a impermeabilização e, conseqüentemente, ocorre redução da recarga do aqüífero, principalmente se este for livre, como o aqüífero Bauru.

A declividade acentuada aumenta a velocidade de fluxo, diminuindo, assim, a taxa de infiltração do solo, tendo maior influência em solos argilosos.

Considerando os aspectos já citados, principalmente a taxa de ocupação urbana, foram analisadas as possíveis diferenças existentes na área de estudo no que diz respeito à recarga do aqüífero, sendo definidas quatro sub-regiões. A maior região é a área que circunda a parte urbanizada, com ocupação de solo baseada em pastagens e plantações que absorvem a água de chuva de maneira mais efetiva. Por essa razão, o coeficiente de recarga para a água de chuva foi de $468 \mathrm{~mm} / \mathrm{ano}$.

A área urbana foi subdividida em 3 setores: centro da cidade, periferia e zona alta (Figura 23). A área central da cidade foi considerada uma região bastante impermeabilizada, com solo compactado e relevo suave. A combinação desses fatores levou à definição de uma taxa de recarga de $300 \mathrm{~mm} /$ ano (23\% da precipitação média anual de $1300 \mathrm{~mm}$ ). Já a periferia, por apresentar menor densidade demográfica e grau de impermeabilização do solo menos intenso, teve taxa de recarga estimada em $364 \mathrm{~mm} /$ ano ( $28 \%$ da precipitação total). A zona mais alta da cidade apresenta declividade acentuada na região mais densamente povoada e impermeabilizada. Assim, para o último setor, considerou-se que $195 \mathrm{~mm} /$ ano ( $15 \%$ da chuva anual) recarrega o aqüífero.

A definição da condutividade hidráulica consistiu no maior problema na construção do modelo. Por se tratar da apresentação de um ferramental de gerenciamento, não se tinha a ambição de responder a todas as perguntas relativas ao funcionamento real do Aqüífero Bauru em São José do Rio Preto. A simplificação mais importante consiste no tratamento do sistema em regime permanente. 


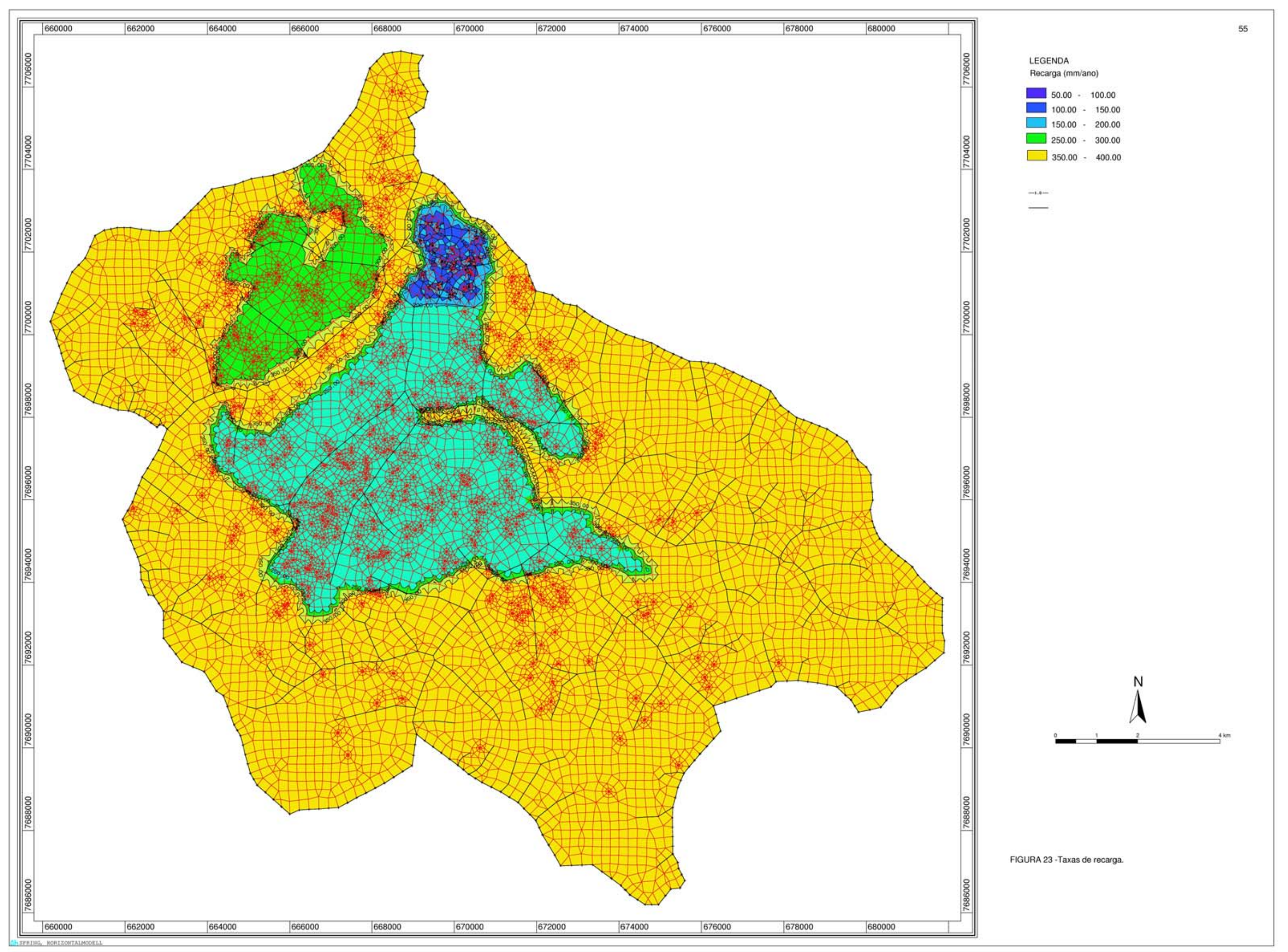


Efetivamente, é de conhecimento geral que o aqǘfero sofre rebaixamento contínuo de níveis estáticos e dinâmicos, em razão da exploração excessiva. Essa característica é eminentemente transiente. No entanto, o volume e a qualidades dos dados disponíveis não permitiram a construção do modelo transiente calibrável, que reproduzisse de maneira correta o rebaixamento observado anualmente. Dessa forma, optou-se pela construção de um modelo que funcionasse em regime permanente, indicando o comportamento geral do sistema e as direções principais de fluxo. Essa simplificação provoca discrepâncias entre os valores de condutividade hidráulica reais (observados em testes de bombeamento) e os valores utilizados no modelo. Para que o sistema atinja a convergência numérica com as taxas de recarga e as condições de contorno especificadas, é necessário que a condutividade hidráulica adotada seja maior que a condutividade efetiva da região. Caso contrário, em regime permanente, a simulação numérica apresentaria zonas com espessura nula ou próxima a zero, notadamente nas regiões centrais (mais estressadas hidraulicamente). Esse resultado indica a situação real a que deve chegar o Aqǘfero Bauru em São José do Rio Preto, caso não sejam adotadas medidas de proteção e recuperação dos níveis estáticos. Para um modelo transiente, que consiga avaliar o rebaixamento anual, são necessários mais dados e levantamentos de campo voltados especificamente para a construção do modelo. No entanto, essas atividades não constituem o escopo do trabalho.

A segunda fonte de discrepância é dada pelo fato de que os dados de transmissividade disponíveis foram obtidos em testes de bombeamento realizados com poços parcialmente penetrantes. Os valores obtidos desta forma são menores que os reais, uma vez que há componentes de fluxo vertical que impedem que a espessura saturada participe do fluxo. Em conseqüência, o rebaixamento observado nos poços é maior do que o que seria em um poço totalmente penetrante. Na mesma linha de raciocínio, as camadas mais profundas do Aqüífero Bauru apresentam partículas de maior diâmetro, consistindo nas camadas mais permeáveis. Essas camadas não contribuem diretamente no teste de bombeamento, resultando em transmissividades menores que as condições reais do aqüífero.

Tendo em vista essas considerações, adotou-se para a maior parte do modelo uma condutividade hidráulica de $13 \times 10^{-6} \mathrm{~m} / \mathrm{s}$, apesar de serem conhecidos valores médios de testes de bombeamento da ordem de $3 \times 10^{-6} \mathrm{~m} / \mathrm{s}$. Em termos de transmissividade hidráulica, o valor adotado equivale a aproximadamente $110 \mathrm{~m}^{2} / \mathrm{d}$, encontrando-se, portanto, um valor médio para as transmissividades de $20 \mathrm{~m}^{2} / \mathrm{d}$ a $220 \mathrm{~m}^{2} / \mathrm{d}$, normalmente citadas para o Aqǘf́fero Bauru (BARCHA, 1998).

A Figura 24 apresenta a distribuição da condutividade hidráulica na região de estudo. Neste caso, ocorre uma diferença de valores e de ordem de grandeza entre duas regiões 
apontadas no presente trabalho. A primeira é a formação Rio do Peixe, segundo FERNANDES (1998), presente na região central, como mostra a Figura 12 (mapa geológico), e corresponde às unidades litoestratigráficas $\mathrm{Ka}_{1}$ a $\mathrm{Ka}_{4}$ e parte da $\mathrm{Ka}_{5}$ da Formação Adamantina. A condutividade hidráulica estabelecida para a formação Rio do Peixe foi de $13 \times 10^{-6} \mathrm{~m} / \mathrm{s}$. A segunda formação que aparece superficialmente é a Fm. São José do Rio Preto, que circunda a primeira formação citada, com condutividade média de $2,5 \times 10^{-6} \mathrm{~m} / \mathrm{s}$. de acordo com o mapa do DAEE, apresenta-se externamente à região de São José do Rio Preto, margeando pelo lado oriental os limites da área de estudo. No âmbito deste trabalho, com base em resultados de testes de bombeamento que indicam transmissividade da ordem de $15-20 \mathrm{~m}^{2} /$ dia na zona mais alta da cidade, optou-se pela extensão dessa formação até a confluência do Rio Preto com o Córrego da Felicidade, de acordo com as Figuras 19 e 24.

Dados de vazão de todos os poços catalogados foram introduzidos no modelo com o objetivo de avaliar o comportamento deste durante a retirada de $3000 \mathrm{~m}^{3} / \mathrm{h}$ do Aqǘfero Bauru. De acordo com BARCHA (1988), há aproximadamente 3500 poços não catalogados, que produzem em média $2500 \mathrm{~m}^{3} / \mathrm{h}$. Por outro lado, estimativas do SeMAE (2000) indicam que $40 \%$ do volume de água disponibilizado diariamente na rede de distribuição é perdido por vazamentos. Essa vazão perdida corresponde a aproximadamente $2500 \mathrm{~m}^{3} / \mathrm{h}$. Neste trabalho considerou-se que esses dois componentes (perdas e ganhos) estão em equilíbrio.

As represas do centro da cidade (Figura 25) foram construídas como bacias de acumulação e captação para o abastecimento público. A primeira delas, localizada a jusante do sistema de acumulação (Figura 25b), data da década de 60 e a mais recente, localizada a montante (Figura 25c), foi construída nos anos 80. A foto aérea de alta resolução, apresentada na Figura 26, comprova o alto grau de assoreamento da represa mais antiga. 


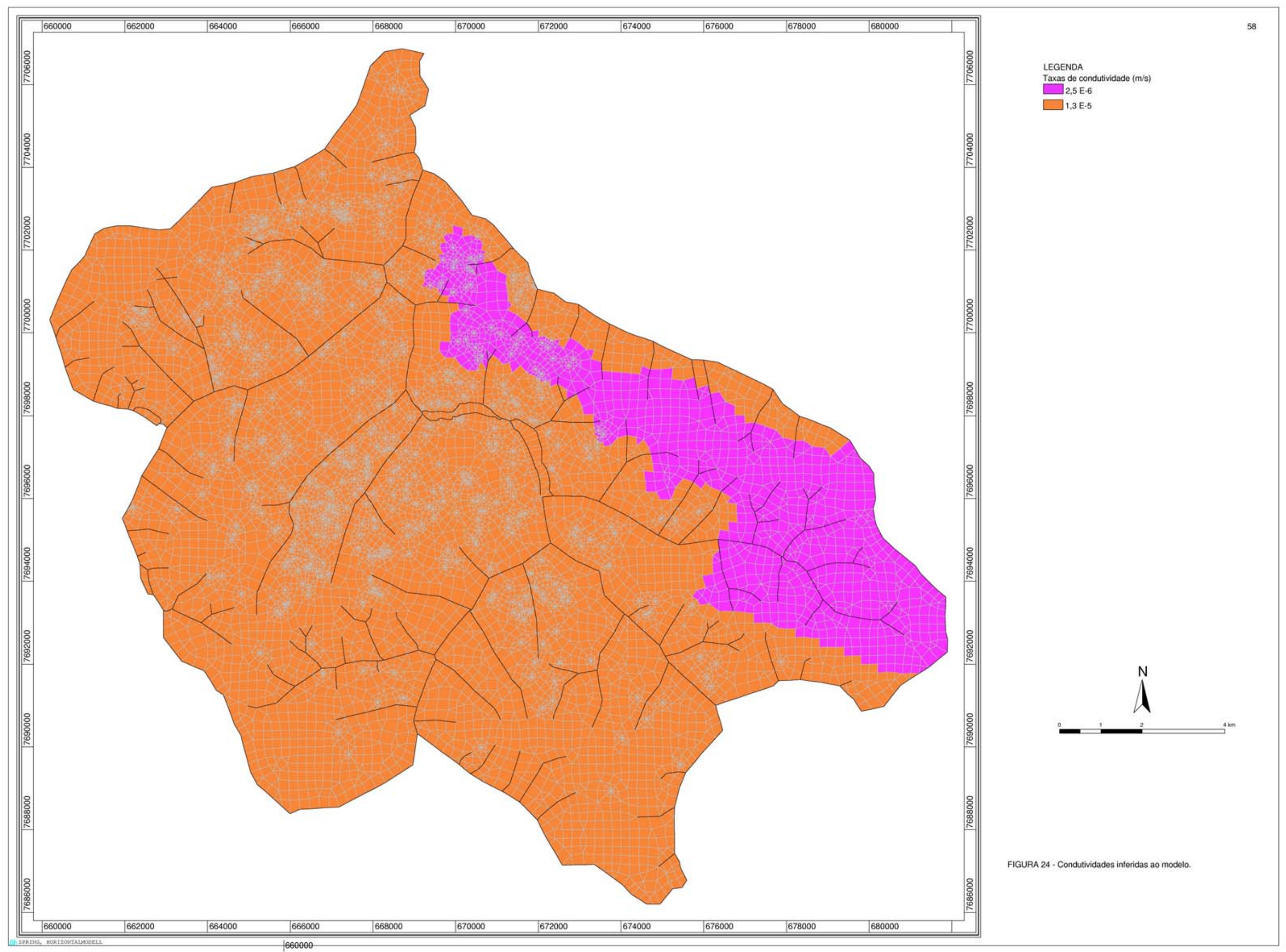




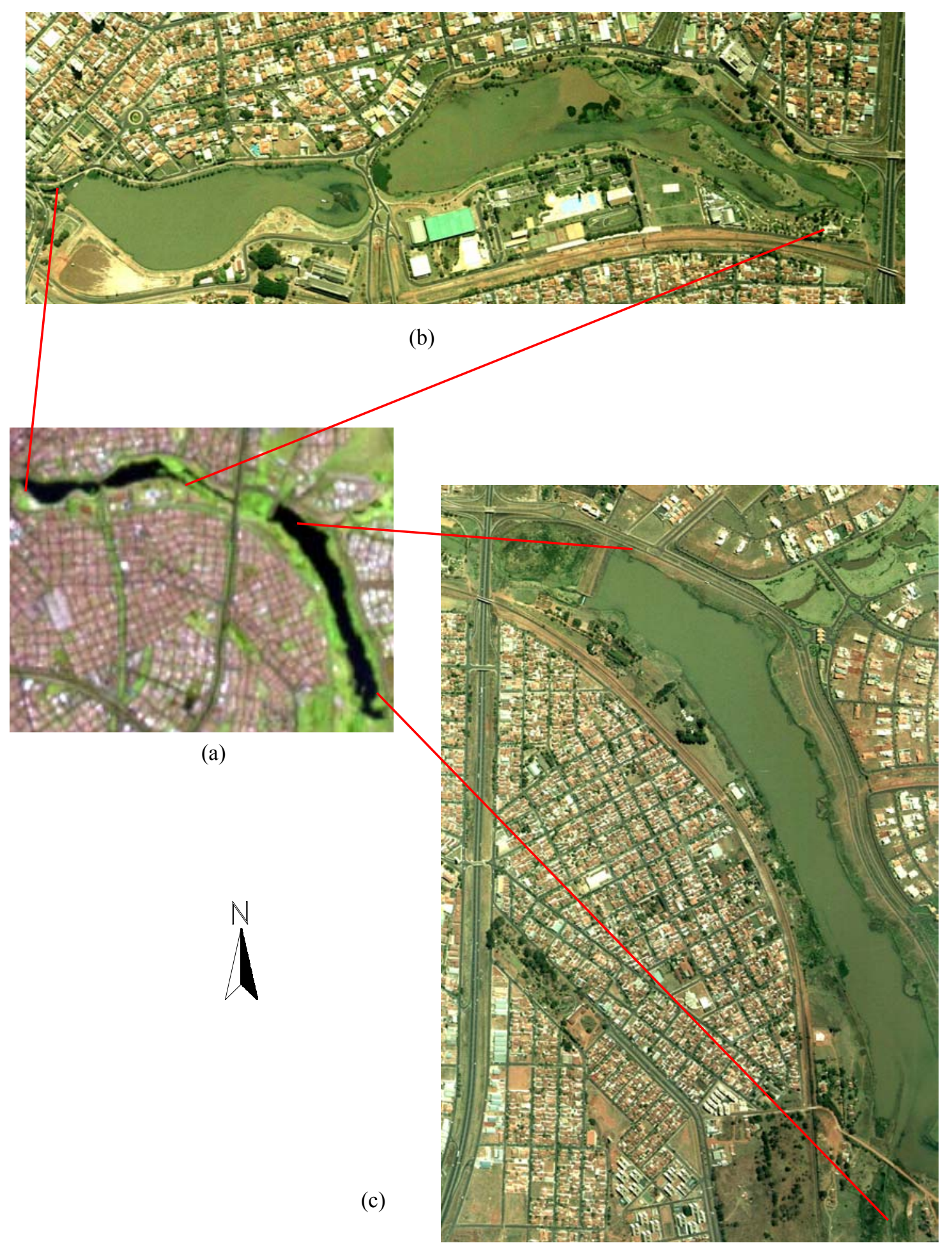

FIGURA 25 - (a) Foto de satélite das duas represas; (b) foto aérea mostrando represa assoreada (anos 60); (c) foto aérea mostrando represa nova (anos 80). Fonte: Pref. Municipal de São José do Rio Preto. (sem escala) 


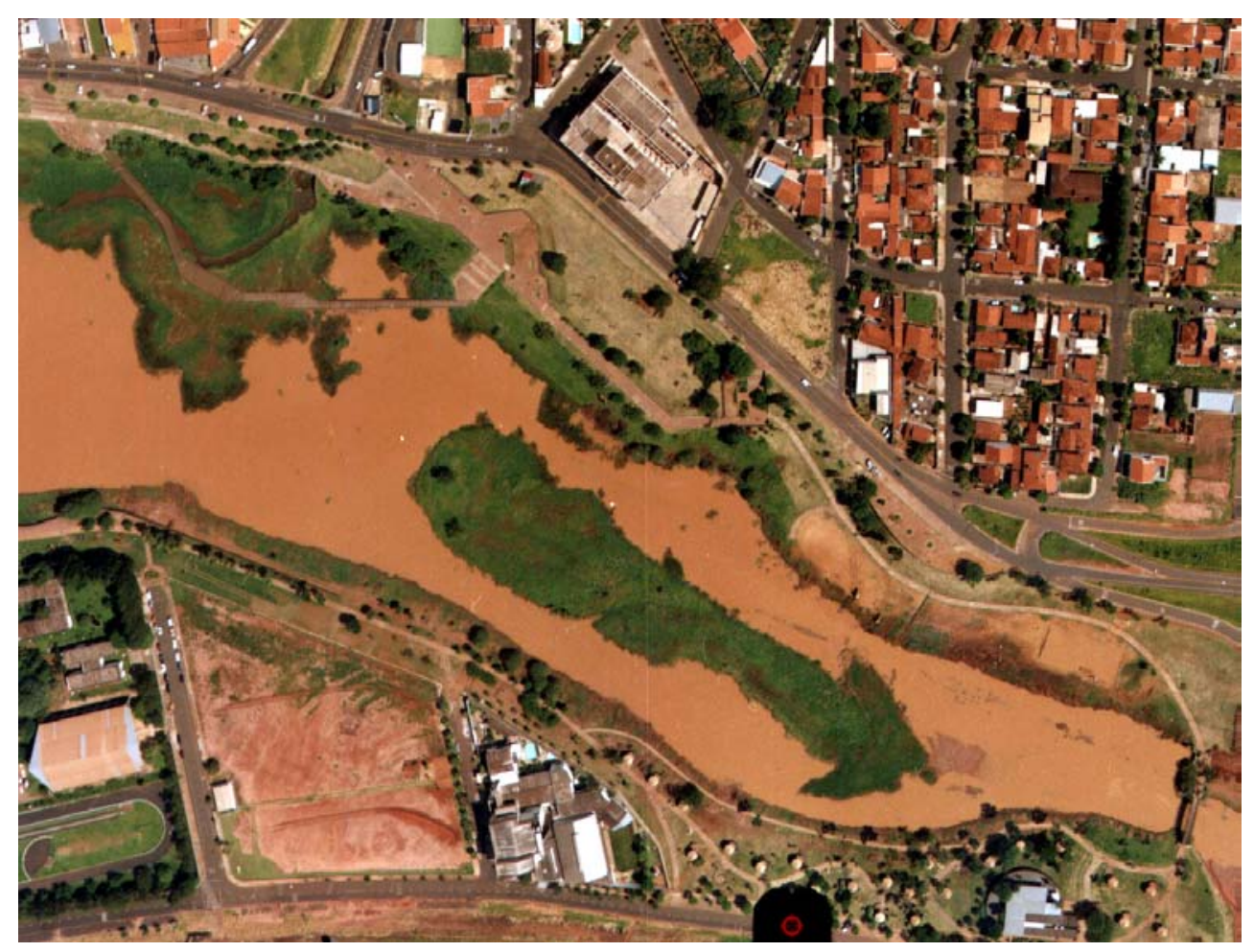

FIGURA 26 - Foto aérea mostrando detalhe do assoreamento ocorrido na represa. Fonte: Prefeitura de São José do Rio Preto.

O assoreamento mostrado nas imagens suscitou a hipótese de colmatação do leito do lago, em decorrência da compactação do sedimento. A ação prolongada do peso da água e a deposição de sedimentos finos provocam minimização de condutividade hidráulica do leito do lago, como citam CARVALHO (1994) e ANDERSON \&WOESSNER (1992). Assim, o reservatório mais antigo foi considerado sem conexão hidráulica direta com o aqüífero. Essa condição impede a infiltração e recarga do aqüífero nessa área.

Para a represa mais nova considerou-se conexão hidráulica completa entre lago e aqǘfero. Conseqüentemente, o lago deve atuar como uma recarga artificial do aqüífero. Essa condição deve ser verificada, por meio de um balanço de massa, levando em consideração as vazões drenadas nas cabeceiras dos rios que alimentam o lago. 


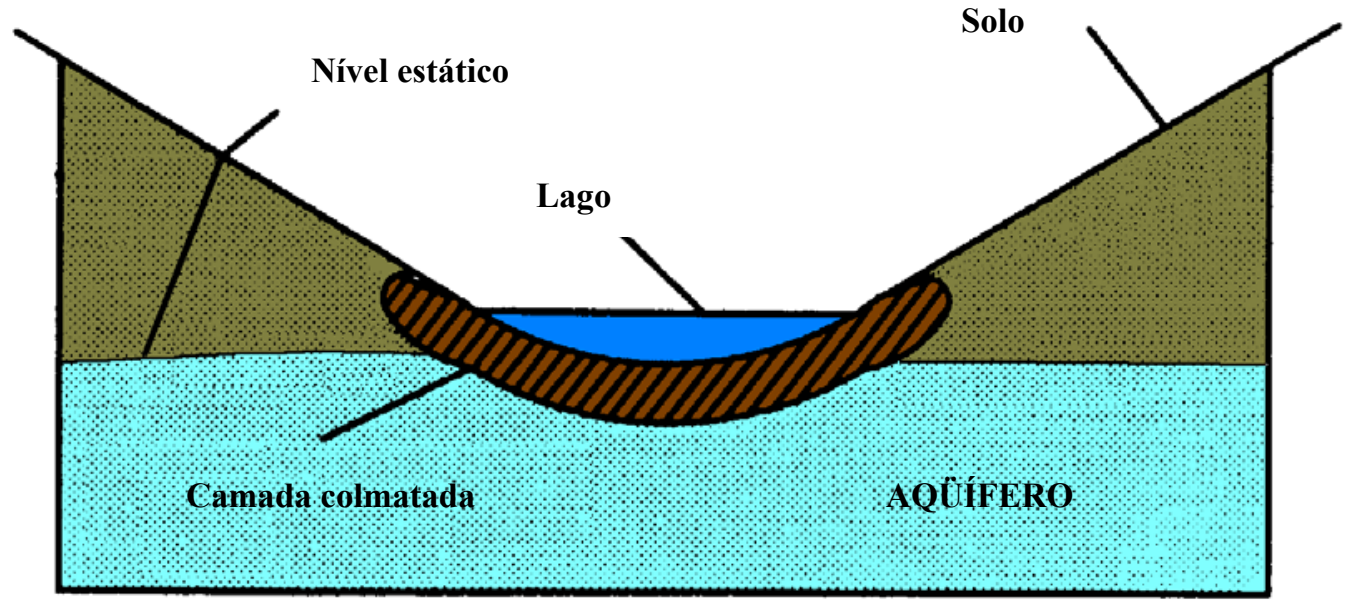

FIGURA 27 - Esquema da hipótese sobre a colmatação do leito do lago. Fonte: Modificado de ANDERSON \&WOESSNER (1992). 


\subsection{Balanço hídrico}

O balanço hídrico para determinada bacia pode ser dado pela relação

$P-R-G-E=\Delta s$,

em que

$$
\begin{aligned}
& P=\text { precipitação; } \\
& R=\text { escoamento superficial; } \\
& G=\text { escoamento subterrâneo; } \\
& E=\text { evapotranspiração; e } \\
& \Delta s=\text { armazenamento. }
\end{aligned}
$$

Para o presente modelo, foi considerada a precipitação média sobre a área de estudo da ordem de $1300 \mathrm{~mm} / \mathrm{ano}$, dado este corroborado pelos valores médios de chuva na região, de 1972 a 2000, levantados no SIGRH e na Coordenadoria de Assistência Técnica Integral - CATI, Escritório de Desenvolvimento Rural de São José do Rio Preto - EDR/SJRP, da Secretaria de Agricultura e Abastecimento. Assim, como a extensão da área é de aproximadamente $227,8 \mathrm{~km}^{2}$, o volume médio precipitado estimado foi de $296 \times 10^{6} \mathrm{~m}^{3} / \mathrm{a}$.

De acordo com os dados de vazão do posto fluviométrico, localizado na bacia Rio Preto, estimou-se o escoamento médio de base da área de estudo em $3,9 \mathrm{~m}^{3} / \mathrm{s}$ ou, aproximadamente, $123 \times 10^{6} \mathrm{~m}^{3} /$ a. Para chegar ao valor de $3,9 \mathrm{~m}^{3} / \mathrm{s}$ foi considerada uma vazão média anual de $8 \mathrm{~m}^{3} / \mathrm{s}$ para o período de medição existente no posto fluviométrico, que tem uma área de drenagem de $576 \mathrm{~km}^{2}$. Para a área de estudo, considerou-se a vazão proporcional à área de influência do modelo $\left(227,8 \mathrm{~km}^{2}\right)$.

O escoamento subterrâneo contempla, normalmente, as contribuições subsuperficiais provenientes de aqǘf́eros adjacentes. Neste estudo, o modelo foi delimitado acompanhando os divisores de águas subterrâneas, não recebendo, portanto, contribuições laterais. No entanto, o sistema de abastecimento de São José do Rio Preto é baseado, em parte, na captação de poços tubulares localizados no Aqüífero Botucatu, subjacente à Formação Serra Geral, considerada, para efeitos deste modelo, impermeável. De acordo com o SeMAE, os poços de captação do Aqüífero Botucatu exploram uma vazão média de 2245 $\mathrm{m}^{3} / \mathrm{h}$. Este valor anualizado corresponde a $20 \times 10^{6} \mathrm{~m}^{3} / \mathrm{a}$. O volume de água adentra $\mathrm{o}$ sistema, através da rede de distribuição de abastecimento urbano, sendo posteriormente drenado para fora da bacia pelo sistema de canais pluviais.

A evapotranspiração real relatada para a região de estudo pelo DAEE (1976) varia de 500 a $1000 \mathrm{~mm} / \mathrm{a}$. Para trabalhar a favor da segurança, o valor considerado para o balanço 
hídrico foi o mais alto. Assim, garante-se que, se o balanço for positivo, haverá sempre a garantia de vazão no curso superficial (Rio Preto). Considerando-se a área de estudo, a evapotranspiração corresponde a uma perda de $228 \times 10^{6} \mathrm{~m}^{3} / \mathrm{a}$.

Substituindo esses valores na equação do balanço hídrico, obtém-se

$$
\begin{aligned}
& \Delta \mathrm{s}=296 \times 10^{6}-123 \times 10^{6}+20 \times 10^{6}-228 \times 10^{6} \\
& \Delta \mathrm{s}=-35 \times 10^{6} \mathrm{~m}^{3} / \mathrm{a} .
\end{aligned}
$$

Esse valor absoluto representa a deficiência hídrica do sistema de abastecimento de São José do Rio Preto. Dividindo a deficiência pela área de influência do modelo, obtém-se uma deficiência anual de aproximadamente $0,15 \mathrm{~m} / \mathrm{a}$. Essa estimativa pode ser vista como a taxa de rebaixamento anual prevista para o Aqúífero Bauru na região de São José do Rio Preto. Considerando as espessuras da zona saturada disponíveis atualmente, pode-se prever que, sem medidas de proteção que preservem as reservas permanentes, as gerações futuras serão confrontadas com sérios problemas para a captação de água potável. 


\section{RESULTADOS E DISCUSSÃO}

A partir do modelo numérico construído com os dados representativos do sistema aqüífero, foram obtidos resultados relativos ao potencial hidráulico do aqüífero, aos níveis dinâmicos, à espessura da zona saturada e às velocidades.

Foram compostos, ainda, dois cenários, com hipóteses relacionadas ao comportamento hidráulico do modelo, avaliados a fim de tentar vislumbrar como o aqüífero reagiria em situação de stress.

Os resultados obtidos para cada um dos parâmetros estudados são descritos detalhadamente nos itens a seguir.

\subsection{Ajuste do modelo base}

O modelo base foi ajustado por tentativas, a fim de adequar as entradas do modelo aos possíveis resultados esperados, uma vez que já se tinha um conhecimento prévio da distribuição de cargas hidráulicas na região de estudo. Nesse processo buscou-se calibrar o modelo de forma determinística, fundamentando as decisões em critérios de plausibilidade hidrogeológica.

\subsubsection{Cargas hidráulicas}

O mapa de carga hidráulica gerado pelo modelo (Figura 28) evidenciou a drenagem de água, do aqüífero para os rios, nas regiões mais altas da área estudada, e a recarga nas regiões centrais da cidade de São José do Rio Preto. Esse resultado comprova a superexplotação do Aqüífero Bauru na região central do município.

Sob condições normais de uso, a água disponível para exploração em poços de água subterrânea infiltra no subsolo e percola subsuperficialmente até o filtro dos poços. Nesse processo, em razão do longo tempo de permanência no solo, a água passa por um processo de purificação. A situação de São José do Rio Preto indica que o sistema superficial (rios e lagos) é o principal responsável pelo transporte do volume de água necessário na região 
central da cidade. Em conseqüência, o tempo de permanência da água no subsolo é muito mais curto, não permitindo um processo completo de purificação.

A qualidade final da água bombeada não é mais afetada, em razão dos processos de diluição, tendo em vista as perdas que ocorrem na rede de distribuição oficial.

A carga obtida numericamente variou de $560 \mathrm{~m}$, nas cabeceiras, a $410 \mathrm{~m}$, no centro da cidade, onde a retirada de água subterrânea é intensa, em função da alta concentração de poços. A proximidade dos poços resulta em fenômeno de interferência de cones de rebaixamento. Como conseqüência, a energia essencial para a elevação da água é desnecessariamente alta.

A região denominada "zona alta" da área urbana também apresentou cargas próximas a $410 \mathrm{~m}$. Neste caso, a carga hidráulica reduzida está relacionada não apenas à demanda, mas também à condutividade hidráulica assumida para a região, que é de $2,5 \times 10^{-6} \mathrm{~m} / \mathrm{s}$. A baixa taxa de recarga também contribuiu para isso.

Foi detectada tendência de aumento de carga nas regiões sudeste, sul, sudoeste e noroeste da área de estudo, acompanhando a topografia da região. Assim, a área estudada funciona como um acumulador, havendo no centro desta uma retirada substancial que interfere na reserva ativa do Aqǘfero Bauru.

Uma vez que o crescimento da cidade, hoje, parece estar se direcionando para a região sul, pressupõe-se que, se houver controle do excesso de impermeabilização e racionalização da retirada de água, não deverá haver problemas com o suprimento de água nos novos loteamentos que estão surgindo na região.

Os menores valores apresentados para o potencial hidráulico calculado estão na região situada entre os córregos Borá e Canela, faixa compreendida entre as avenidas Alberto Andaló e Bady Bassit. Neste caso, tais valores ocorreram devido à exploração excessiva da água subterrânea. Os dois córregos que atravessam a zona central da cidade, de acordo com o SeMAE, encontram-se canalizados e impermeabilizados em praticamente toda sua extensão. Essa situação não permite a recarga do aqüífero através do leito dos rios.

Em função da direção do fluxo, de sul-sudeste para noroeste, a água captada nas regiões que apresentam maior coeficiente de recarga não chega integralmente à zona central, de maior demanda, pois é capturada por poços existentes a montante da mesma.

A partir do exposto, torna-se evidente que, pela quantidade de poços existentes na região central e pelas condições hidrogeológicas presentes, não se deveria perfurar nenhum outro poço na zona com potencial variando de $470 \mathrm{~m}$ a $410 \mathrm{~m}$, pois isso implicaria comprometimento dos poços existentes em termos de produção e aumento do consumo de energia, sendo necessário redimensionamento das bombas existentes. 


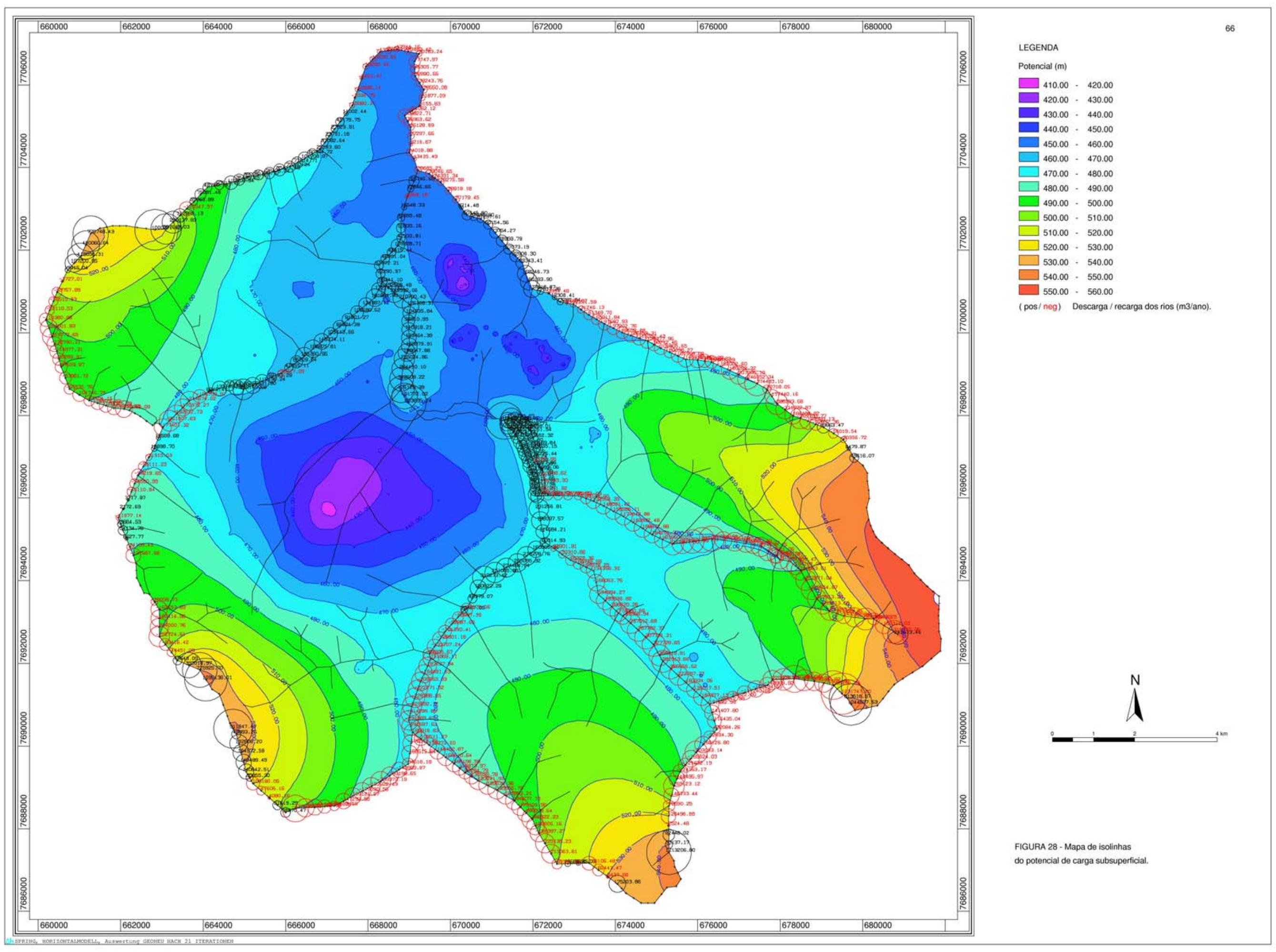




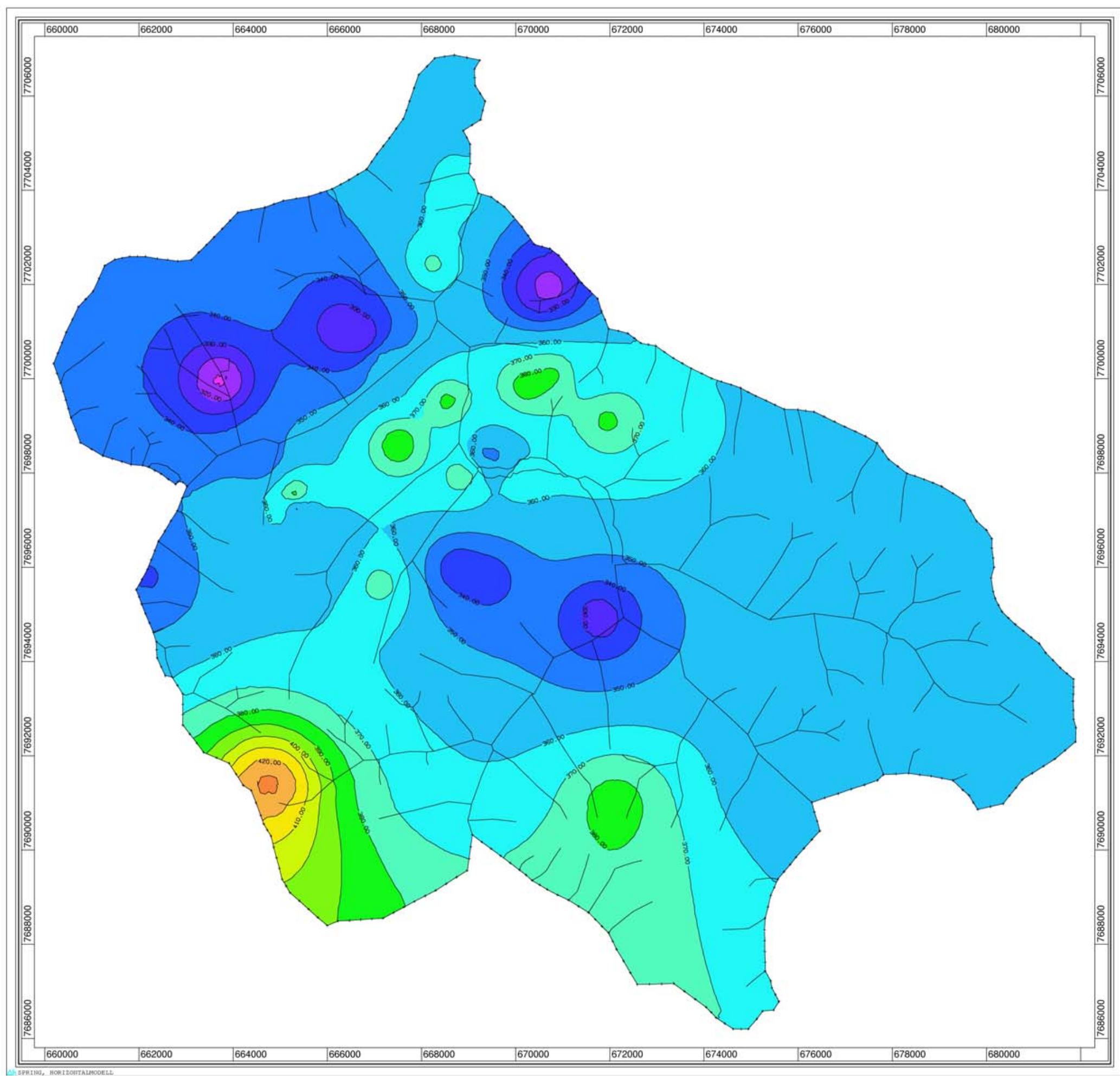

LEGENDA

Profundidade ( $m$ )

$300.00 \cdot 310.00$

$310.00-320.00$

$320.00-330.00$

- $34000-35000$

四 350.00 - 3500

$360.00-370.00$

$\square 370.00$ - 380.00

$\square 380.00$ - 390.00

$\square 390.00$ - 400.00

400.00 - 410.00

410.00
-420.00

$\square+43000-440$

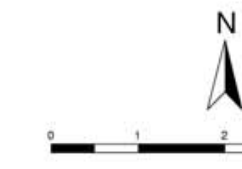

$\Lambda$

isovalores do

topo da Fm. Serra Geral. 


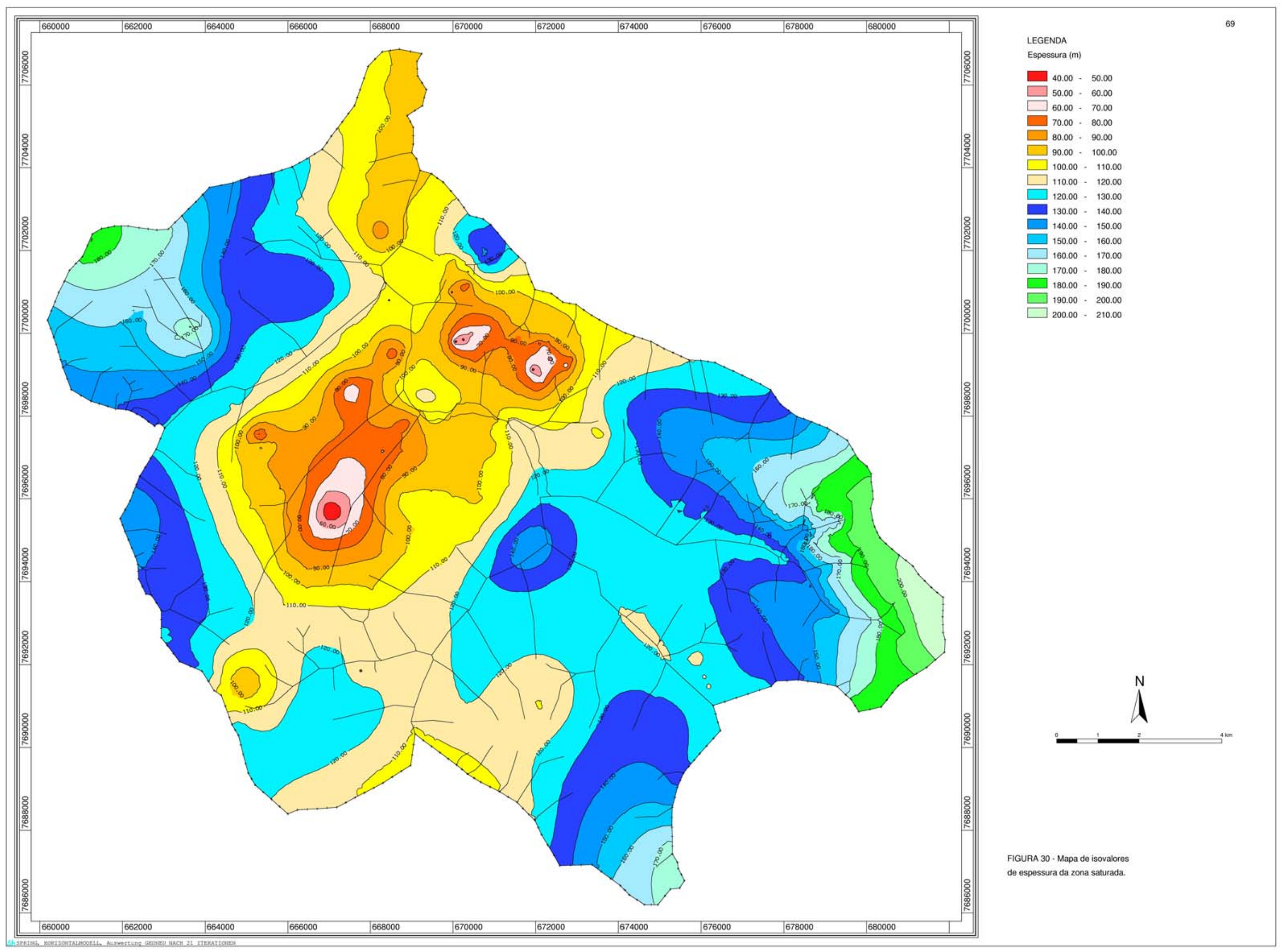


Já nas regiões de maior concentração populacional e que apresentam, conseqüentemente, maior número de poços, o comprometimento da recarga transitória e da recarga ativa é notado, uma vez que os estudos comprovaram uma queda significativa dos níveis estáticos quando comparados dados da década de 70 com dados da década de $90 . \mathrm{Na}$ Figura 31 são apresentados mapas de isovalores de níveis estáticos gerados a partir de dados de poços perfurados na década de 70 .

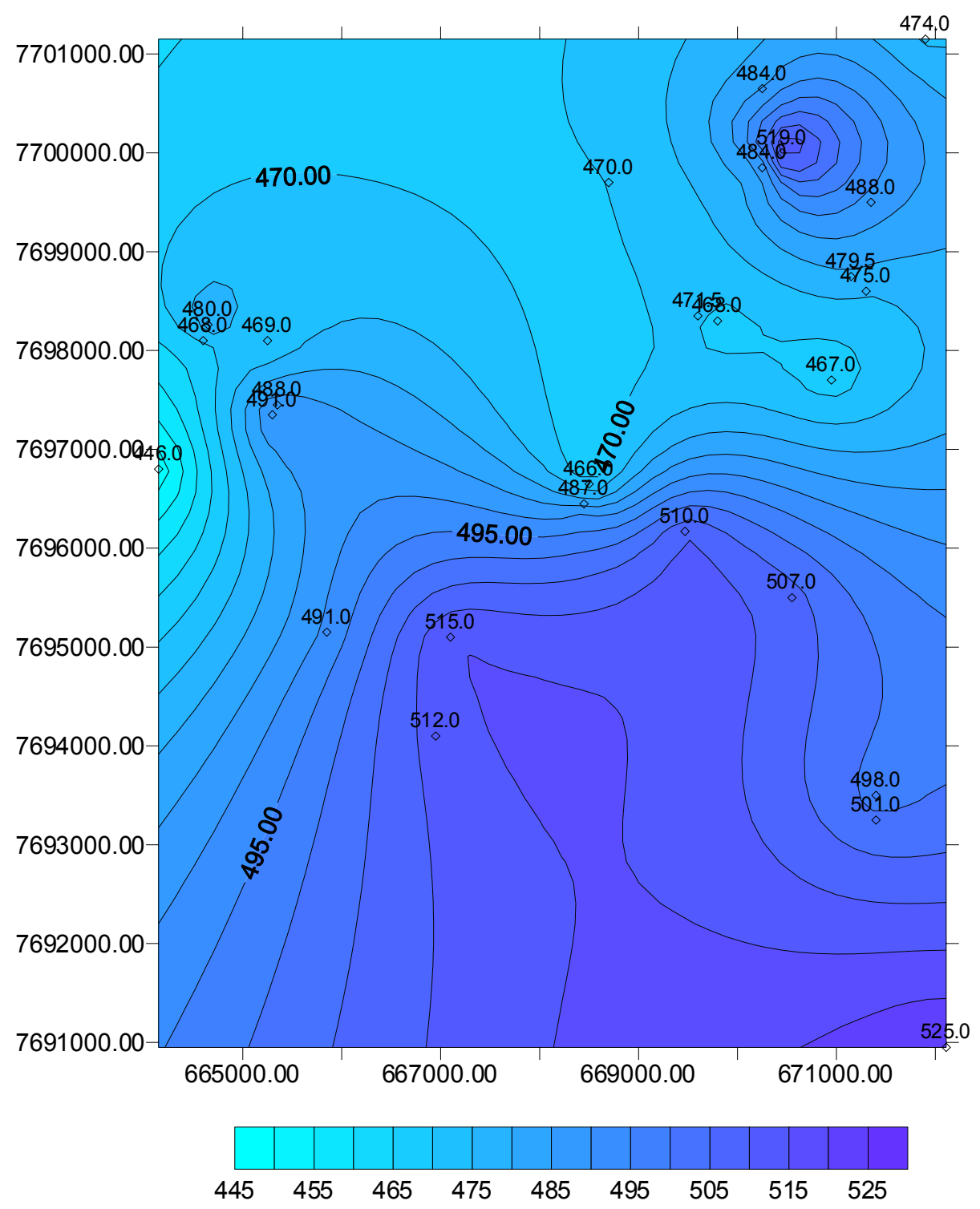

Figura 31 - Níveis estáticos estimados para a década de 70.

Na Figura 32 foram utilizados dados de poços mais recentes (década de 90). Esses mapas foram gerados por meio de krigagem simples, tendo por base os dados de níveis 
estáticos dos poços catalogados no DAEE e disponíveis no Relatório Zero da Bacia do Turvo/Grande. O reflexo se dá, principalmente, em alguns poços, que eram jorrantes nos anos 70 e hoje apresentam nível estático a mais de $10 \mathrm{~m}$ de profundidade. Em média, pode ser visualizado, por meio da comparação dessas figuras, um rebaixamento de $20 \mathrm{~m}$ nos níveis estáticos. Esse rebaixamento indica um déficit hídrico, provocado pela excessiva exploração do aqüífero.

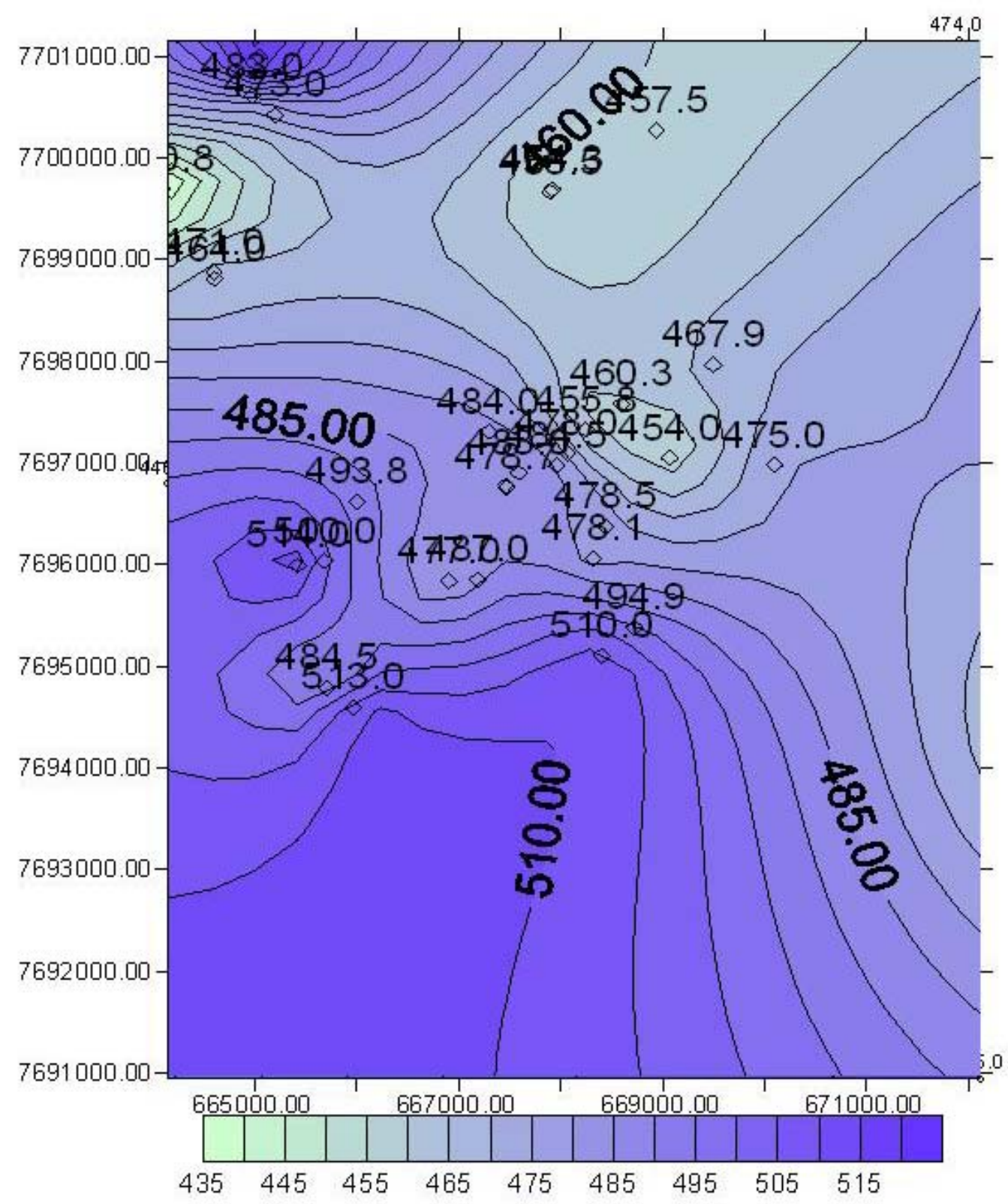

FIGURA 32 - Níveis estáticos gerados por krigagem para a década de 90. 


\subsubsection{Estimativa do nível dinâmico}

Os níveis dinâmicos calculados para a região de São José do Rio Preto atingiram 130m de profundidade, conforme apresentado na Figura 33. Em razão do excesso de poços e da interferência dos cones de depressão, há elevada proximidade entre as curvas de isovalores na região central e no conjunto de poços localizado na zona alta da cidade.

Os valores negativos encontrados são reflexo da baixa densidade de informações sobre os níveis, nas regiões mais distantes do centro, em direção ao sudeste.

Para um bom desempenho do presente modelo, seria necessário obter dados de campo, com testes de bombeamento de todos os poços catalogados; prática que não é comumente adotada por empresas perfuradoras, por onerar a construção de poços contratados.

Com base nesse mapa, pode-se estimar a profundidade de perfuração necessária para atingir o nível estático em novos poços. Evidentemente, deve-se evitar essas regiões com nível dinâmico muito profundo, pois além de indicarem superexploração, os custos de elevação de água serão proibitivos.

\subsubsection{Velocidade}

A velocidade média do Aqüífero Bauru na região de estudo foi estimada pelo modelo como sendo de 96,32 m/ano, considerando as condições de contorno físico do domínio e toda a complexidade existente em razão das contribuições internas de córregos e da quantidade elevada de poços de bombeamento na região. O gráfico com os vetores de velocidade é apresentado na Figura 34.

A distribuição de velocidades é homogênea. Nas proximidades dos poços pode-se observar velocidades mais elevadas. 


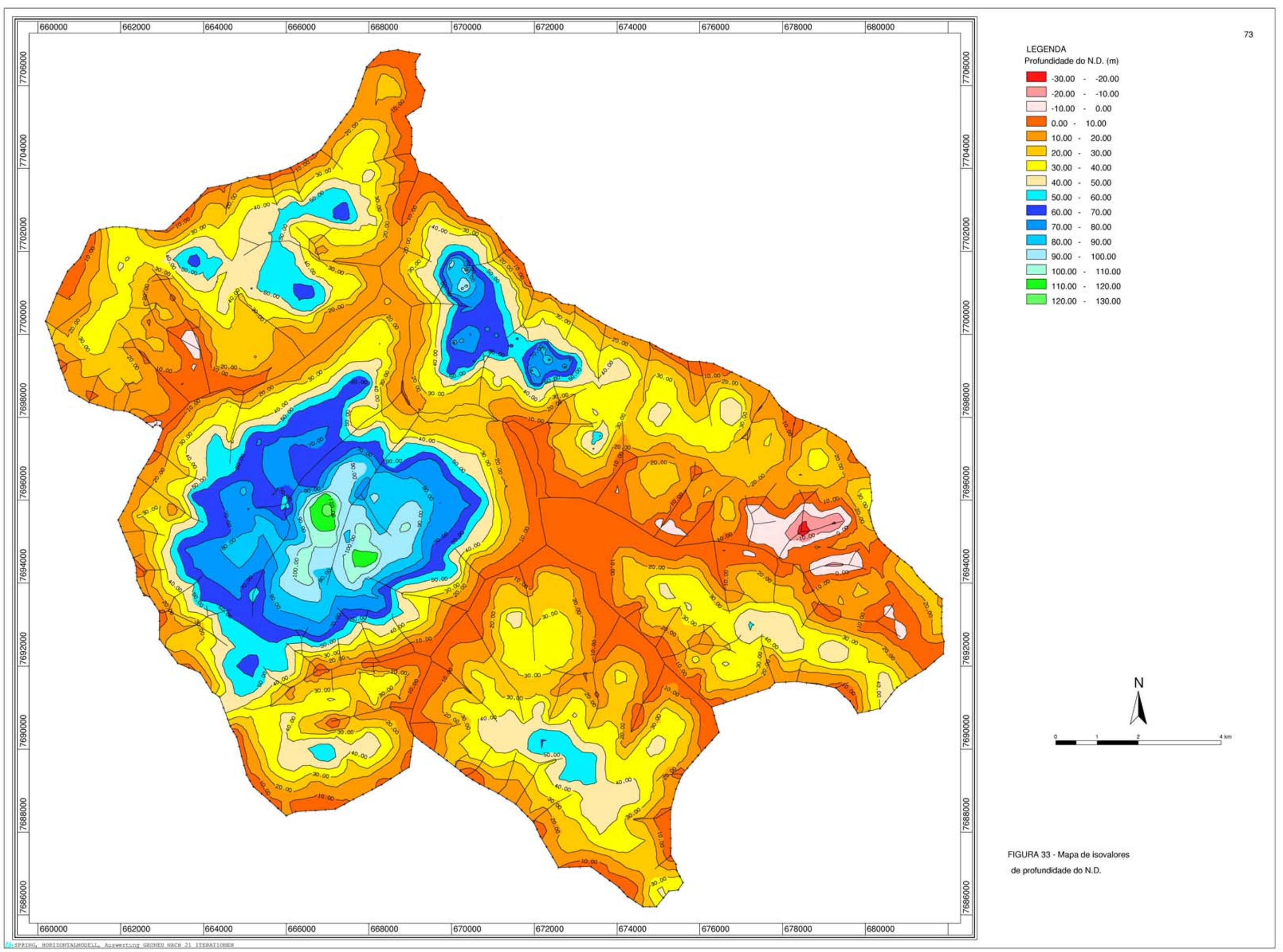




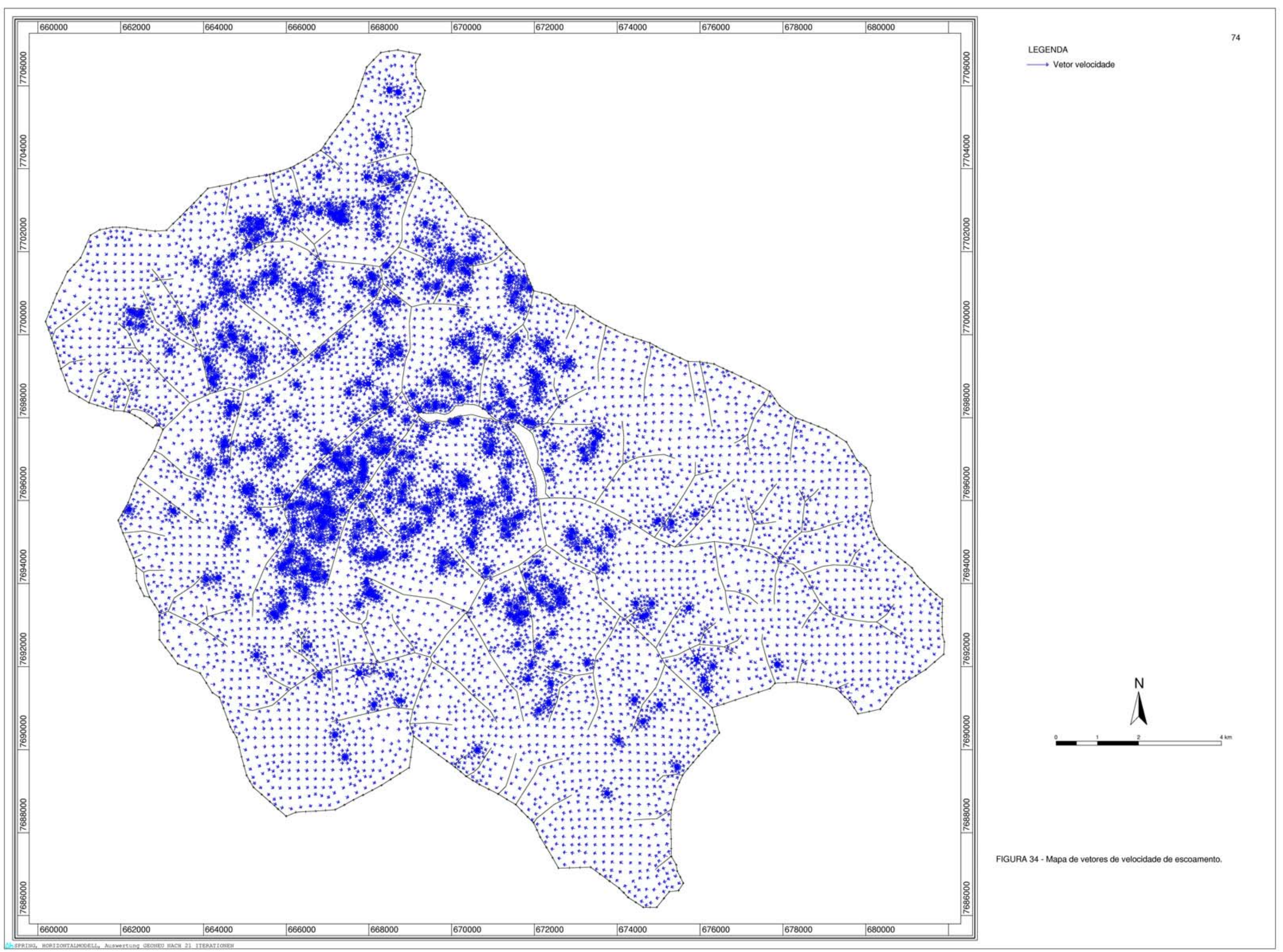




\subsection{Análise de cenários}

Admitindo que o modelo base reproduz razoavelmente a situação hidrogeológica atual em São José do Rio Preto, pode-se desenvolver cenários de comportamento futuro, em função de mudanças climáticas ou evolução urbana no município.

Nesse sentido, foram verificadas duas hipóteses em relação ao comportamento hidráulico do modelo. Foram inseridos no sistema fatores de stress, ou seja, novas conjunturas que podem afetar a resposta do ferramental desenvolvido para a análise do Aqüífero Bauru.

A escolha dos cenários procurou levar em conta as diretrizes de crescimento da cidade de São José do Rio Preto, estipuladas pelos órgão competentes. A análise dos dados hidrológicos da região de estudo, principalmente no que tange à recarga pela infiltração do volume precipitado, indica a necessidade de redução dos valores de taxa de infiltração, uma vez que os dados de chuva analisados apresentam valores muito abaixo da média para a região, como $966 \mathrm{~mm}$ no ano de 1954, segundo ARID et al. (1970). Este valor equivale a $74 \%$ da média precipitada anualmente na região.

\subsubsection{Ampliação da área urbanizada}

No primeiro diagnóstico efetuado no presente trabalho, foram inseridas duas novas aglomerações urbanas, a primeira localizada na região noroeste, entre o Córrego da Piedade e o Córrego São Pedro, e a segunda, na região sul, entre o Rio Preto e o Córrego dos Macacos. Essas áreas podem ser visualizadas na Figura 35, que apresenta as taxas de recarga correspondentes. Para as novas áreas, optou-se pela utilização de uma taxa de recarga de $65 \mathrm{~mm} / \mathrm{a}$, refletindo uma possível urbanização altamente densa e grande impermeabilização da área. Esse valor foi escolhido de forma a avaliar um cenário desfavorável do ponto de vista hídrico, representado por uma situação extrema de impermeabilização.

As mudanças de potencial hidráulico ocasionadas na área de estudo, apresentadas na Figura 36, não ocorreram de forma muito intensa onde já havia grande quantidade de poços produtores (centro da cidade). No entanto, nas áreas diretamente subjacentes, onde houve a retirada da contribuição de recarga, foi observada redução de 10 m no nível dinâmico. Essa redução é representada pelo deslocamento da isolinha de potencial de $480 \mathrm{~m}$ para a posição em que se encontrava anteriormente a isolinha de $490 \mathrm{~m}$. Comportamento análogo pode ser observado para as linhas de isovalores de $490 \mathrm{~m}$ e $500 \mathrm{~m}$. 
Isso ocorreu mais acentuadamente na área sul, com inversão de parte da interação do Rio Preto com o aqüífero, passando de efluente para influente, e com o aumento do trecho influente do Córrego dos Macacos. Isto poderia ocasionar uma diminuição do fluxo da água superficial de ambos os cursos d'água para a reserva existente na lagoa a jusante, com possível comprometimento do abastecimento público.

Analisando-se o mapa de espessuras da zona saturada (Figura 37), verifica-se que a inclusão de nova área urbana na região sul causou redução de $10 \mathrm{~m}$ a $20 \mathrm{~m}$ em toda a área a montante da região. A instituição de nova área a noroeste, por sua vez, levou a uma diminuição menos abrangente da espessura da zona saturada, o que poderia, entretanto, ter reflexos sobre os poços mais próximos a esta nova área.

Diante do exposto, constatou-se que, para os dados coletados e inferidos no presente trabalho, não haveria mudanças substanciais de comportamento hidráulico em relação à atual situação observada em São José do Rio Preto, no que tange às direções de fluxo no sistema. No sistema modelado com esse cenário houve modificação no nível dinâmico, principalmente onde as novas áreas urbanas foram inseridas, com queda média de $10 \mathrm{~m}$ em cada uma das regiões estudadas.

Em relação à água superficial, entretanto, haveria redução do fluxo de base do Rio Preto antes da chegada à primeira represa que abastece a população da cidade. 


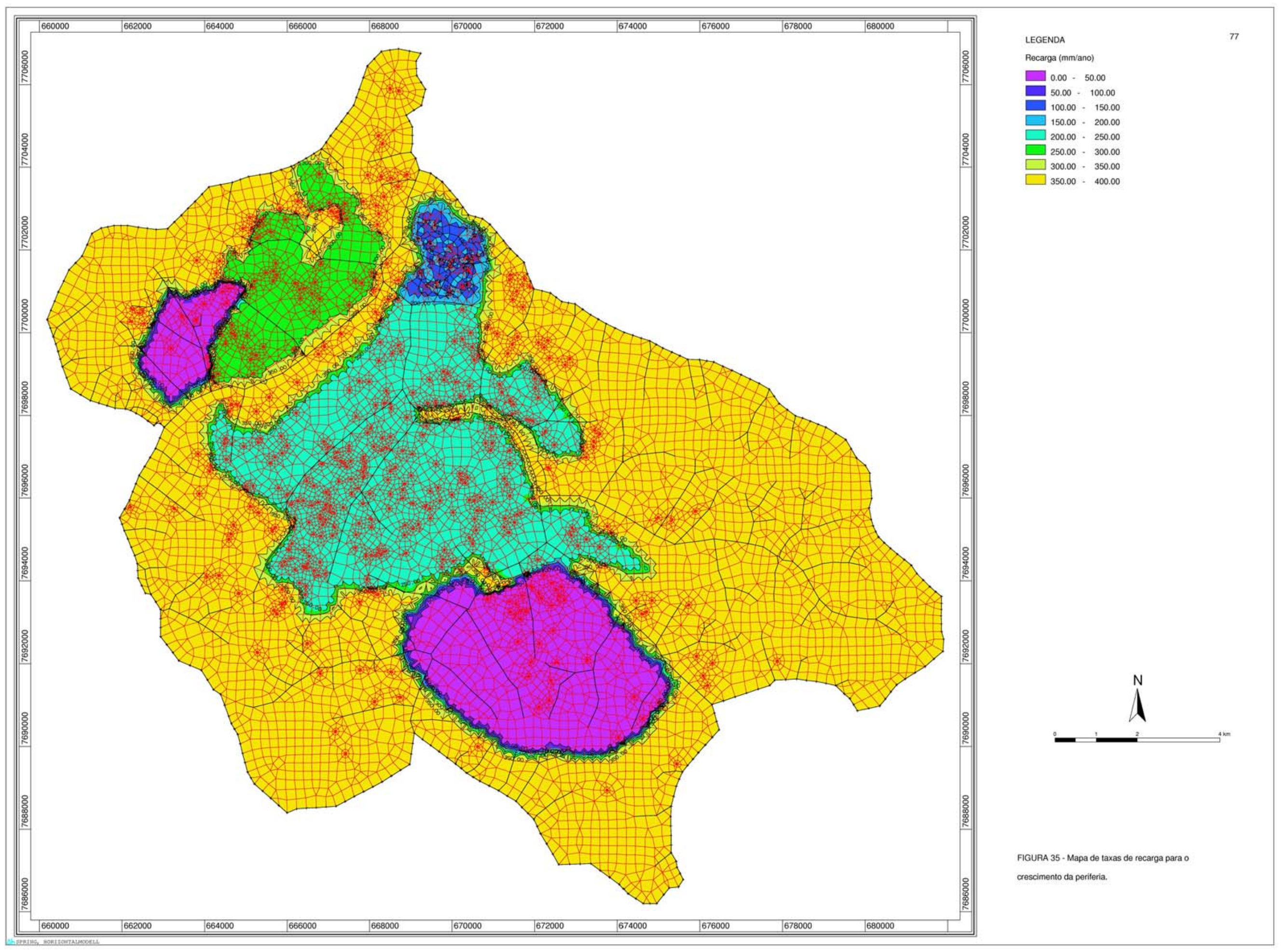




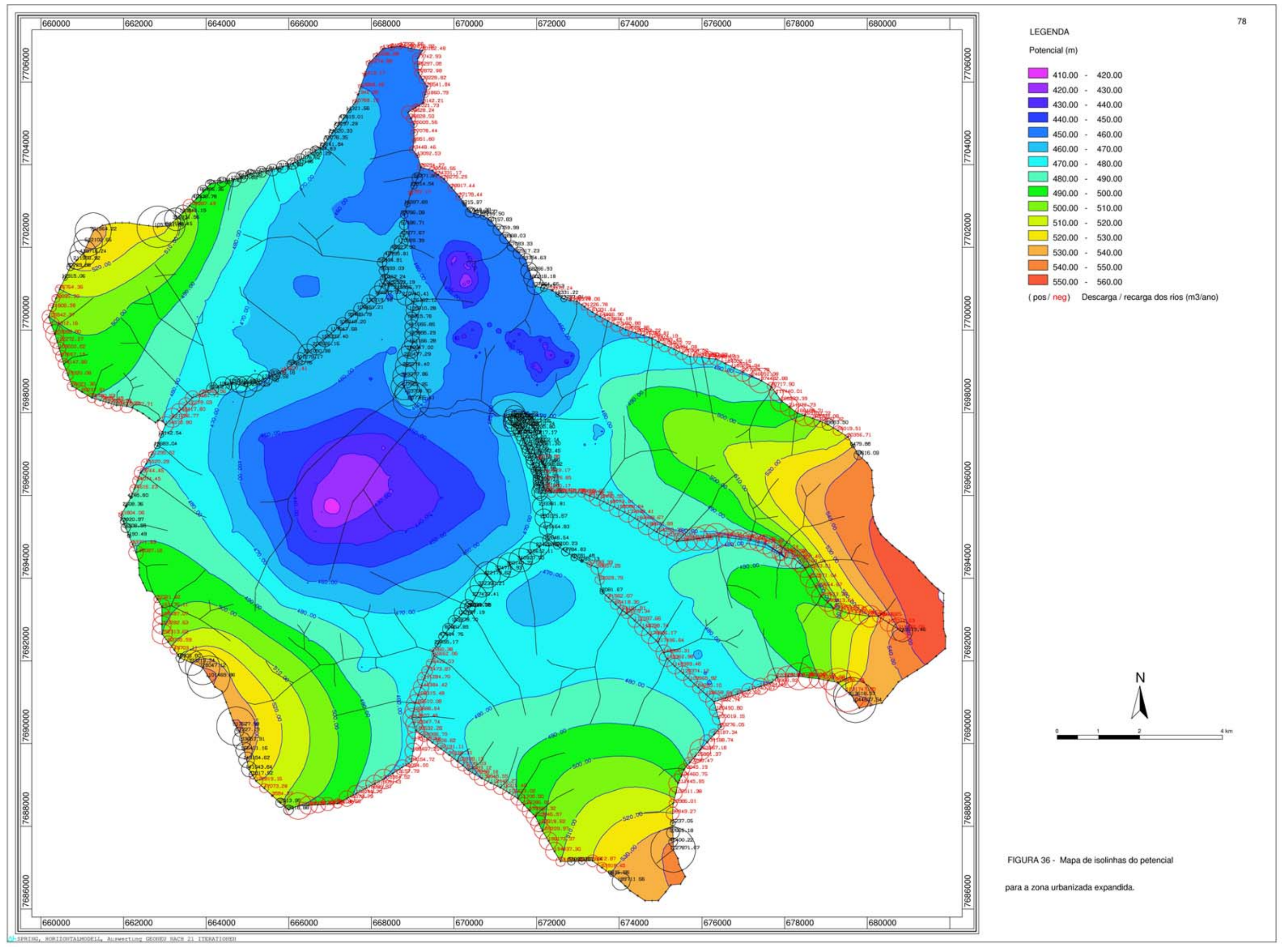




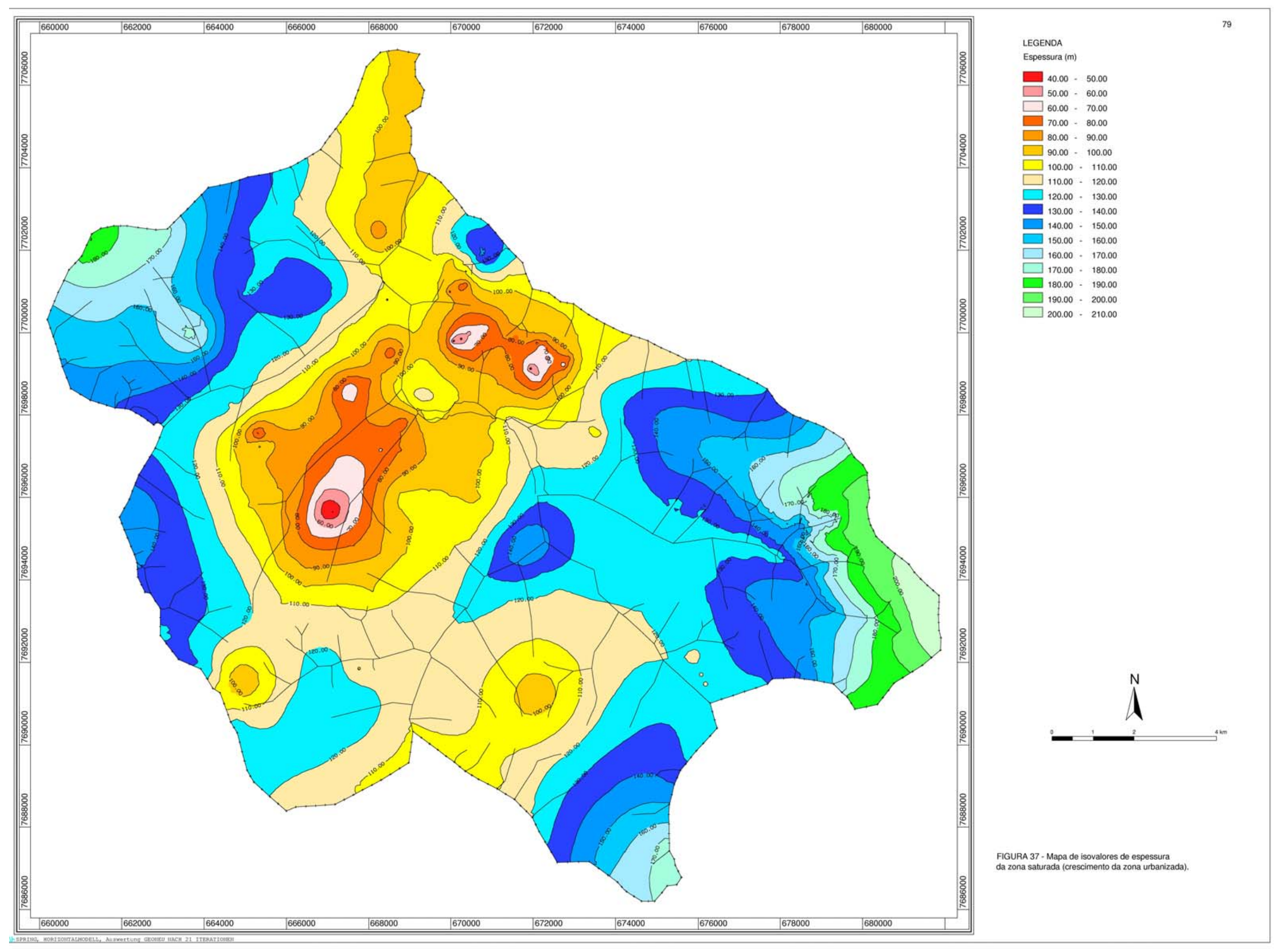




\subsubsection{Redução de precipitação}

Um segundo cenário foi criado para verificar a influência da redução da precipitação sobre o comportamento do aqǘfero. Na Figura 38 podem ser visualizadas as taxas de infiltração adotadas nesse modelo.

Foi considerada redução de apenas $10 \%$ do volume total precipitado, com diminuição das taxas de recarga em todas as áreas da região de estudo. Mesmo havendo dados com valores de precipitação $30 \%$ menores que a média anual estimada, tal simulação não foi possível, pois caso fosse reduzida a recarga nesse percentual, em regime permanente de escoamento, o aqüífero sofreria uma redução expressiva da espessura saturada, conduzindo à sua depleção completa em algumas regiões centrais. Numericamente, isso se traduz em problemas de convergência no cálculo iterativo da espessura saturada (modelo não-linear de Dupuit). Nesse caso, a simulação seria possível apenas em regime transiente. Essa alternativa não foi avaliada, uma vez que o modelo apresenta ainda deficiências que somente poderão ser eliminadas por meio de levantamentos específicos de campo.

Para o cenário estudado, o comportamento do potencial hidráulico do aqǘfero sofreu grandes modificações, tendo a área central apresentado valores de carga hidráulica inferiores a 410 m (Figura 39). Observou-se também, para a parte alta da cidade, redução para níveis abaixo do inferido quando utilizado o valor total da precipitação. Mesmo o potencial hidráulico da região sudeste, anteriormente mais abrangente, foi reduzido. Mudanças menos significativas ocorreram nas regiões sul e sudoeste, porém o mais grave problema ocorreu na zona central da cidade.

O reflexo sobre a espessura da zona saturada (Figura 40) também foi mais forte na área central da cidade, passando de $50 \mathrm{~m}$ para níveis abaixo de $40 \mathrm{~m}$, mostrando que o controle da quantidade de poços é um fator decisivo para manter o equilíbrio do sistema. No geral, a espessura da zona saturada diminuiu $10 \mathrm{~m}$ em toda a região de estudo e $20 \mathrm{~m}$ na região central.

Os reflexos da diminuição de potencial hidráulico e espessura da zona saturada poderão ser vistos no futuro. Tendo sido consumida toda a recarga transitória (explotável) e grande parte da reserva ativa, a reserva permanente será comprometida, uma vez que os poços precisarão ser perfurados numa profundidade cada vez maior para atender às demandas da população e de outros usos consuntivos.

Em relação à profundidade do nível dinâmico (Figura 41), a queda ocorreu mais acentuadamente na área central, passando de um nível máximo de $110 \mathrm{~m}$ para valores acima de $120 \mathrm{~m}$. O decaimento dos níveis d'água, principalmente na área central, poderá levar a região mais densamente povoada da cidade de São José do Rio Preto a um colapso. 


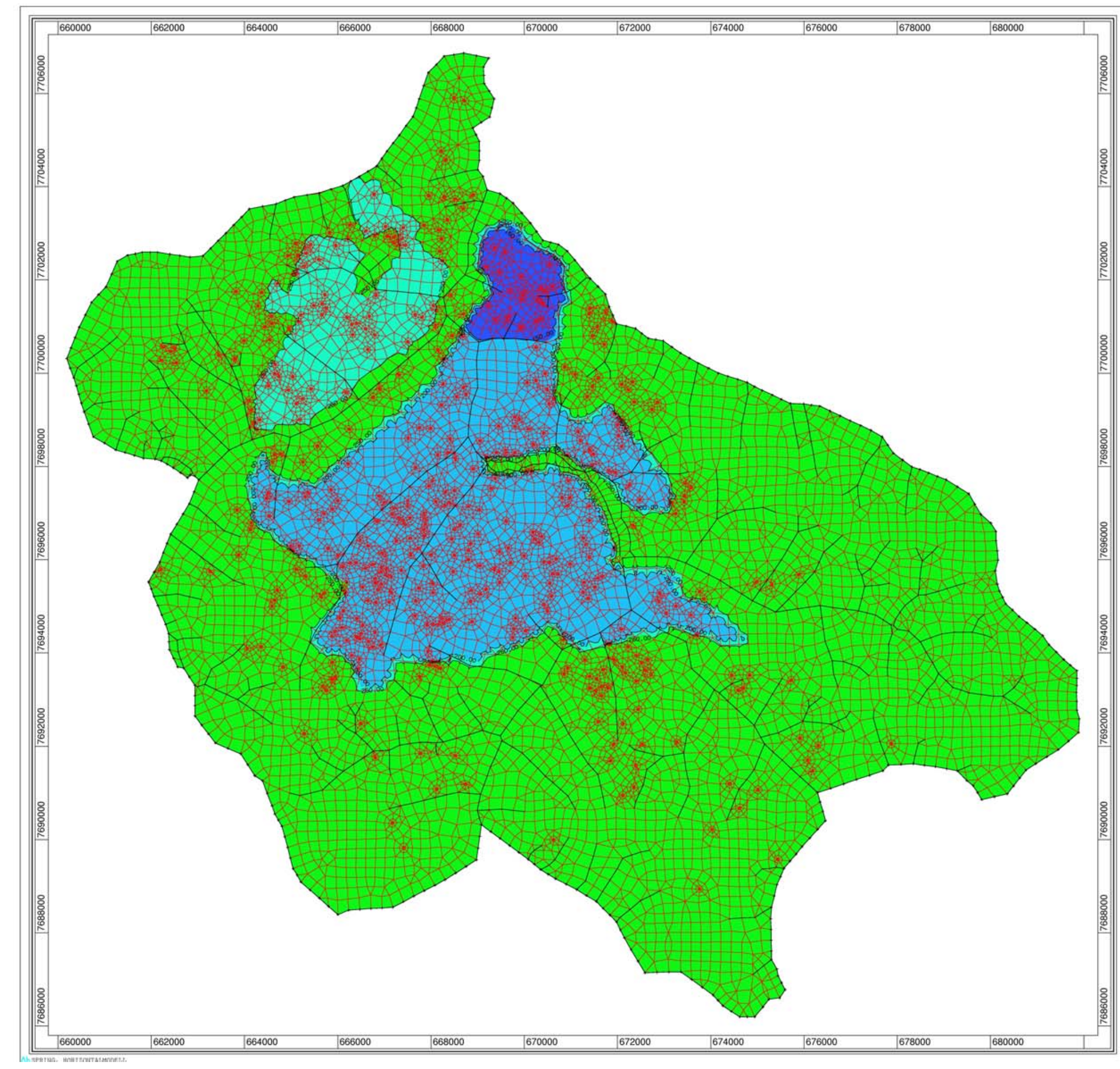

LEGENDA

Recarga (mm/ano)

$50.00-100.00$

$100.00-150.00$

150.00 - 200.00

$200.00-250.00$

$250.00-300.00$

(

81

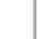

GURA 38 - Mapa das taxas de recarga

(chuva reduzida).

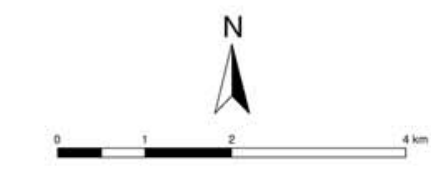




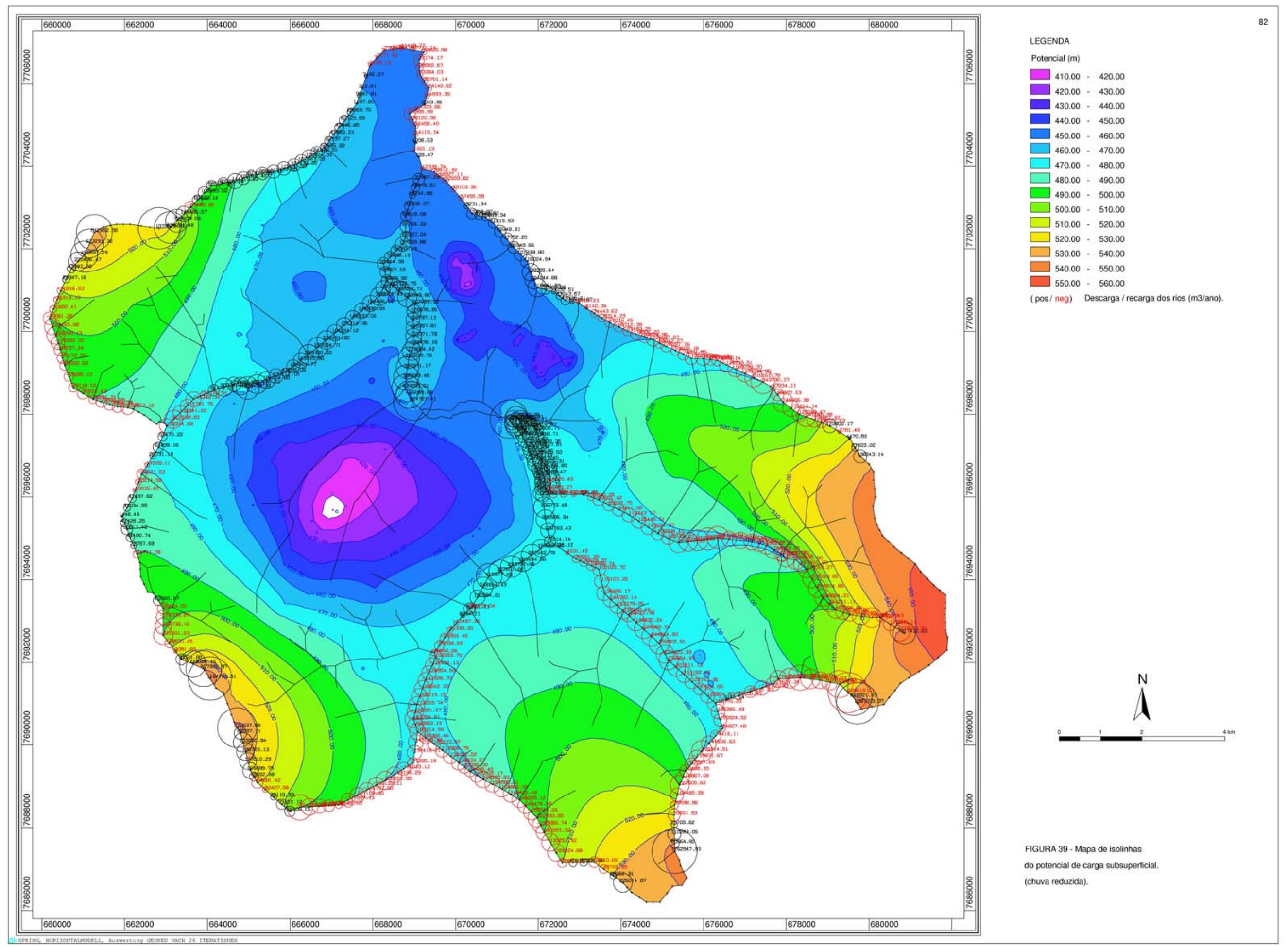




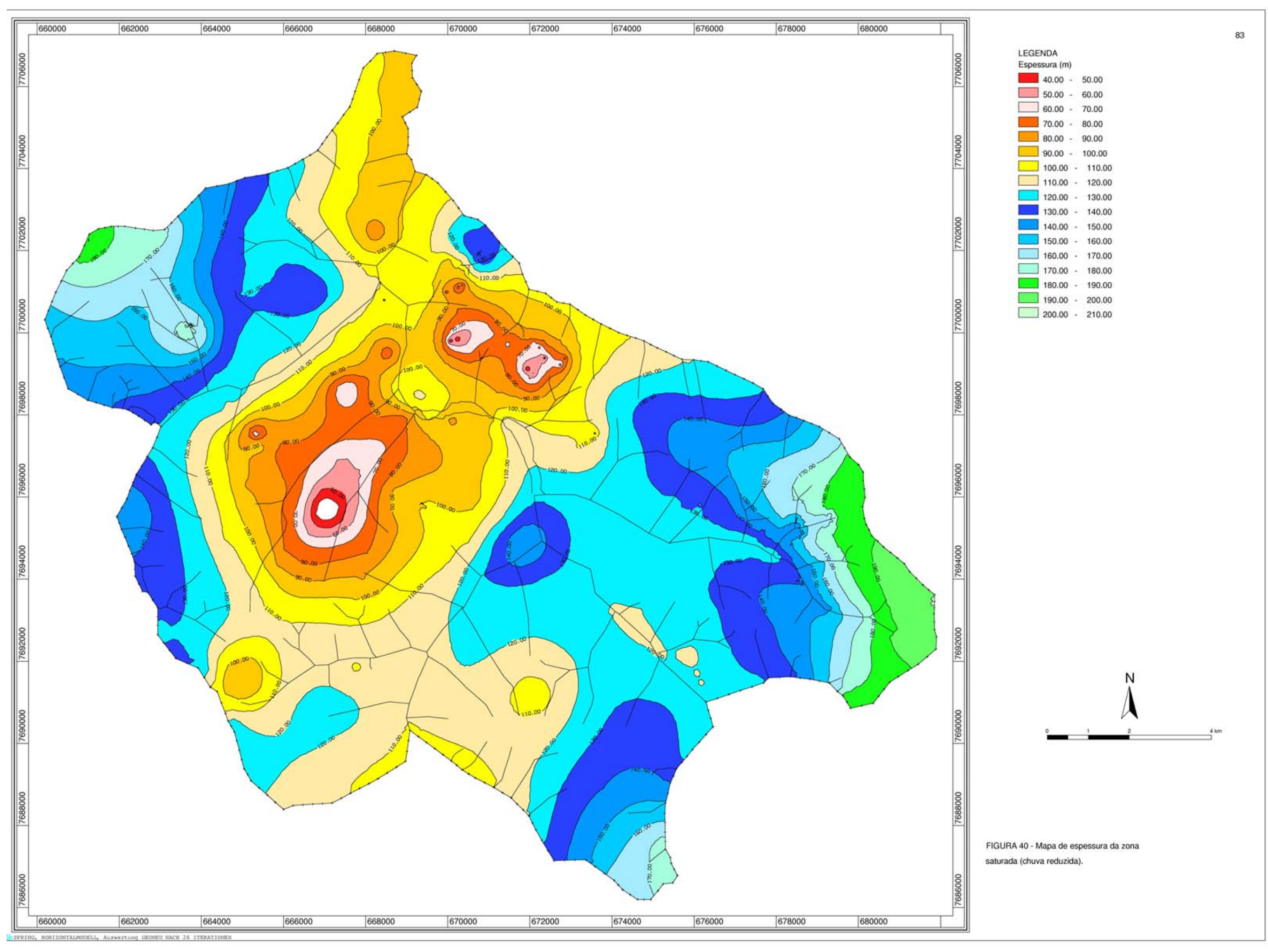




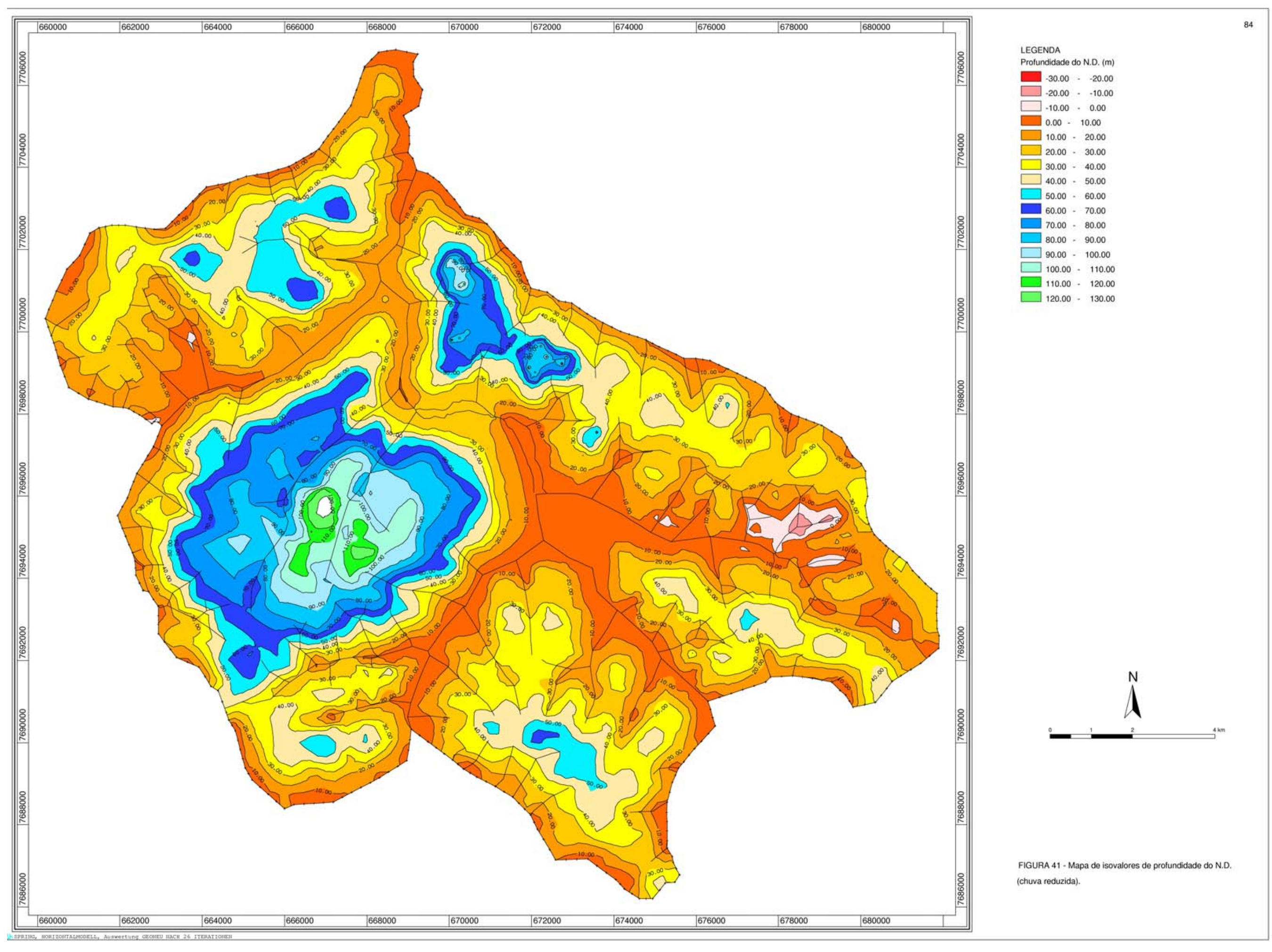




\section{Conclusões e recomendações}

A crescente utilização de mananciais subterrâneos para o abastecimento público torna a modelação numérica do fluxo de água subterrânea uma ferramenta imprescindível na tomada de decisões relativas ao gerenciamento desse recurso hídrico. Nesse contexto, o meio acadêmico representa o ambiente ideal para o desenvolvimento e avaliação de ferramentas e metodologias adequadas ao gerenciamento de águas subterrâneas, sob a ótica específica de problemas com características nacionais.

Neste trabalho foi desenvolvida uma metodologia de gerenciamento, visando a sua possível sistematização e utilização pelos órgãos gestores dos recursos hídricos subterrâneos. O ferramental desenvolvido enfocou a descrição, a catalogação e a extrapolação dos dados necessários à representação de todas as características físicas e hidrogeológicas da área de estudo, visando à definição de um modelo conceitual de fluxo. Posteriormente foi sistematizada a disponibilização em formato adequado à sua utilização no ambiente de trabalho do pacote SICK100, desenvolvido na Faculdade de Engenharia Civil da Ruhr-Universität Bochum. Esse pacote computacional, baseado no Método de Elementos Finitos, permite a construção de modelos de fluxo de alta complexidade, sendo executado sob plataforma LINUX.

A área urbana da cidade de São José do Rio Preto, abastecida principalmente por poços tubulares que captam água do Aqüífero Bauru, foi selecionada para a aplicação prática da metodologia desenvolvida. A região tem mais de 400 poços produtores cadastrados e 3500 poços clandestinos, que retiram aproximadamente $5000 \mathrm{~m}^{3} / \mathrm{h}$ do aqüífero livre. Com base nessas informações e dados climáticos regionais, foi construído um modelo numérico, que permitiu simular toda a complexidade hidrogeológica da região. Foram feitos também prognósticos para dois cenários distintos: um com diminuição da precipitação e outro com o aumento da área urbanizada e conseqüente impermeabilização. Os reflexos dessas duas hipóteses na dinâmica atual foram avaliados, sendo possível notar um colapso do sistema de captação, na região central da cidade, caso um dos prognósticos venha a ocorrer.

O modelo proposto, com base em dados cadastrados, sem envolver ensaios de campo, mostrou-se exeqüível para as simulações propostas e servirá como ferramenta para futuras avaliações do comportamento e do gerenciamento do Aqǘfero Bauru. Havia necessidade da construção de um modelo para a região, um vez que, desde o início da década de 90 , vêm sendo feitos alertas quanto à diminuição do nível estático dos poços na região, em razão do uso descontrolado do manancial subterrâneo. A proposição de um modelo de gerenciamento para o Aqüífero Bauru, capaz de reproduzir sua complexidade e 
suas peculiaridades dentro do sistema hidrogeológico, pode ser considerado um avanço no campo da modelação regional.

A sistematização efetuada para a confecção do modelo, com a busca e a avaliação de todos os dados relacionados à região de estudo e ao aqüífero a ela pertencente darão aos órgãos gestores condições de direcionar um uso mais sustentável do Aqüífero Bauru na região urbana de São José do Rio Preto.

As visualizações do comportamento do modelo quanto à carga hidráulica, os níveis dinâmicos e a espessura da zona saturada aparecem como parte da contribuição do presente trabalho ao setor de gestão da água subterrânea, para que se possa inferir a respeito do comportamento hidráulico do modelo desenvolvido. $\mathrm{O}$ ferramental desenvolvido demonstrou ser útil ao gerenciamento de recursos hídricos, tendo incrementado o conhecimento das condições do fluxo na região.

O balanço hídrico realizado para a bacia considerada indica uma deficiência hídrica considerável no sistema de abastecimento. Essa constatação corrobora e justifica o rebaixamento de níveis estáticos e dinâmicos observados no Aqüífero Bauru, conforme relatado no Plano Estadual de Recursos Hídricos (1990).

Vale salientar que o modelo criado é uma ferramenta que deve ser continuamente reciclada, no que tange aos dados de entrada e às características hidrogeológicas da região, de forma a desenvolver previsões cada vez mais acuradas e realistas. O monitoramento do aqǘfero, principalmente das cargas hidráulicas, é crucial para que se possa ajustar o modelo de maneira eficaz às constantes mudanças das condições hídricas do sistema.

A partir de dados atualizados, pode-se em trabalhos futuros, estudar o comportamento do aqüífero em regime transiente. Para esse fim, recomenda-se a realização de testes de bombeamento em pontos específicos da área de estudo, cobrindo de maneira representativa as possíveis diferentes formações presentes em São José do Rio Preto. 


\section{REFERÊNCIAS BIBLIOGRÁFICAS}

ALBERTSON, P.E.; HENNINGTON, G.W. (1996). Groundwater analysis using a Geographic Information System following finite-difference and-element techniques, Eigineering Geology, 42, p. 167-173.

ANDERSON; WOESSNER (1992). Applied grounwater modeling: simulation of flow and advective transport. Academic Press, Inc. 383 p.

ARID, F.M.; CASTRO, P.R.M., BARCHA, S.F. (1970). Estudos hidrogeológicos no município de São José do Rio Preto, SP. Bol. Soc. Bras. Geol., v. 19, n. 1, p. 43-69.

BARCHA, S.F. (1980). Aspectos geológicos e províncias hidrogeológicas da Formação Baru na região norte-ocidental do Estado de São Paulo. São José do Rio Preto. 209p. Tese (Livre Docência - Área de Geociências) - Departamento de Geociências, Instituto de Biociências, Letras e Ciências Exatas de São José do Rio Preto, Unesp.

BARCHA, S.F. (1985). Condicionamento geológico da água subterrânea em São José do Rio Preto, SP. Geociências, v. 4, p. 57-68.

BARCHA, S.F. (1997). Urbanização e impacto sobre aqüíferos, In: CONGRESSO BRASILEIRO DE RECURSOS HÍDRICOS, 12. 1997. Anais. Vitória, vol. 3, p. 683687.

BARCHA, S.F. (1998). Água e abastecimento urbano em São José do Rio Preto, SP. In: CONGRESSO BRASILEIRO DE ÁGUAS SUBTERRÂNEAS, 10. 1998. Anais. São Paulo, ABAS, CD-ROM.

BEAR, J. (1979). Hydraulics of groundwater. New York, McGraw-Hill Book Co. 
BEAR, J.; VERRUIJT, A. (1994). Modeling groundwater flow and pollution. Dordrecht. D. Reidel Plublishing Company.

BRODIE, R.S. (1999). Integrating GIS and RDBMS technologies during construction of a regional groundwater model. Environmental Modelling \& Software, v. 14, p. 119-128.

CABRAL, J.J.S.; SANTOS, S.M.; MONTENEGRO, S.M.G.L.; DEMETRIO, J.G.A.; CIRILO, J.A.; FILHO, J.M.; SANTOS, A.C.; MONTENEGRO, A.A.A. (1999). Ferramentas para o gerenciamento integrado dos aqǘ́feros da região metropolitana de Recife. In: SIMPÓSIO BRASILEIRO DE RECURSOS HÍDRICOS, 13. Belo Horizonte, 1999. Anais. Belo Horizonte, ABRH. CD-ROM.

CARRERA, J. (1988). State of the art of the inverse problem applied to the flow and solute transport equations. In: CUSTODIO, E; GURGUI, A.; LOBO FERREIRA, J.P. Groundwater, flow and quality modeling. NATO ASI Series, Series c, v. 224, p. 549583.

CARRERA, J.; NEUMAN, S.P. (1986). Estimation of aquifer parameters under transient and steady state conditions: 1. Maximum likelihood method incorporating prior information. Water Resources Research, v. 22, n. 2, p. 199-210, February.

CERTES, A.; MARSILY, G. de. (1991). Application of the pilot point method to identification of aquifer tansmissivities. Advances in Water Resources, v. 14, n. 5, p. 284-300.

COMPANHIA DE TECNOLOGIA DE SANEAMENTO AMBIENTAL - CETESB (1997a). Uso das águas subterrâneas para o abastecimento público no Estado de São Paulo. São Paulo, 48p.

COMPANHIA DE TECNOLOGIA DE SANEAMENTO AMBIENTAL - CETESB. (1997b). Relatório de qualidade das águas subterrâneas do Estado de São Paulo - 1997. São Paulo, 106p. (Série Relatórios)

CLEARY, R. (1989). Águas subterrâneas. In: RAMOS, F. et al. Engenharia hidrológica. Coleção ABRH de Recursos Hídricos, v. 2. 1ª ed. Rio de Janeiro, Editora da UFRJ, Cap. 5. p. 293-404. 
CLIFTON, P.M.; NEUMAN, S.P. (1982). Effects of kriging and inverse modeling on conditional simulation of Avra Valley aquifer in southern Arizona. Water Resources Research, v. 18, n. 4, p. 1215-1234, August.

COOLEY, R.L. (1977). A method of estimating parameters and assessing reliability for models of steady state groundwater flow 1 . Theory and numerical properties. Water Resources Research, v. 13, n. 2, p. 318-324, April.

COOLEY, R.L. (1982). Incorporation of prior information on parameters into nonlinear regression groundwater flow models 1. Theory. Water Resources Research, v. 18, n. 4, p. 965-976, August.

COOLEY, R.L.; KONIKOW, L.F.; NAFF, R.L. (1986). Nonlinear regression groundwater flow modeling of deep regional aquifer system. Water Resources Research, v. 22, n. 13, p. $1759-1778$, December.

DEPARTAMENTO DE ÁGUAS E ENERGIA ELÉTRICA - DAEE. (1976). Estudo das águas subterrâneas. Regiões administrativas 7, 8 e 9 (Bauru, São José do Rio Preto e Araçatuba). São Paulo, 3 vol.

DEPARTAMENTO DE ÁGUAS E ENERGIA ELÉTRICA - DAEE (1999). Água subterrânea: uma riqueza de São Paulo. Revista águas e energia, p. 75-80. Abril 1999.

DEPARTAMENTO DE ÁGUAS E ENERGIA ELÉTRICA - DAEE (2000). Relatório de Situação dos Recursos Hídricos. Secretaria de Recursos Hídricos Saneamento e Obras, Governo do Estado de São Paulo. CD-ROM.

DELHOME, J.P. (1978). Kriging in the hydrosciences. Advances in Water Resources, v. 1, n. 5, p. 251-266.

DOHERTY, J. (1994). PEST - Model Independent Parameter Estimation, Watermark Numerical Computing. First Version.

DRISCOLL, F. G. (1986). Groundwater and wells. Johnson Screens, 1089p. 
ENGEL, B.A.; NAVULUR, K.C.S. (1999). The role of geographical information systems in groundwater engineering. In: DELLEUR, J.W. (ed.). The handbook of groundwater engineering. CRC Press, Cap. 21, p. 21/1-20/40.

FEITOSA, F.A.C; MANUEL FILHO, J. (2000). Hidrogeologia: conceitos e aplicações. Recife, CPRM, 392p.

FERNANDES, L.A. (1998). Estratigrafia e evolução geológica da parte oriental da Bacia Bauru (Ks, Brasil). São Paulo, 215p. Tese (Doutorado) - Programa de pós-graduação em Geologia Sedimentar, Instituto de Geociências, USP, São Paulo.

FORTUNA, A. O. (2000). Técnicas computacionais para dinâmica dos fluídos: conceitos básicos e aplicações. EDUSP, São Paulo. 426p.

GELHAR, L.W. (1993). Stochastic subsurface hydrology. New Jersey, Prentice Hall, Cap. 6, p. 341-347. Geostatistical approach to the inverse problem.

GOGU, R.C.; CARABIAN G.; HALLET, V. (2001). GIS - based hydrogeological databases and groundwater modeling. Hydrogeology Journal, v. 9, p. 555-569.

HANTUSH, M.S. (1964). Hydraulics of well. In: CHOW, V.T. (ed.). Advances in hydroscience . New York, Academic Press, p. 281-432.

HARBAUGH, A.W.; McDONALD, M.G. (1996). User's documentation for MODFLOW96, an update to the U.S. Geological Survey modular finite-difference ground-water flow model: U.S. Geological Survey Open-File Report 96-485.

HAITJEMA, H.M. (1995). Analytic element modeling of groundwater flow. London/ San Diego, Academic Press.

INSTITUTO DE PESQUISAS TECNOLÓGICAS DO ESTADO DE SÃO PAULO - IPT. (1981a). Mapa Geológico do Estado de São Paulo. Escala 1:500.000. São Paulo. 2v. (IPT. Monografias, 6. Publicação, 1 184). 
INSTITUTO DE PESQUISAS TECNOLÓGICAS DO ESTADO DE SÃO PAULO - IPT. (1981b). Mapa Geomorfológico do Estado de São Paulo. Escala 1:1.000.000. São Paulo. 2v. (IPT. Monografias, 5. Publicação, 1 183).

ISAAKS, E.H.; SRIVASTAVA, R.N. (1989). Applied geostatistics. New York, Oxford University, 561p.

KITANIDIS, P.K. (1999). Geostatistics: interpolation and inverse problems. In: DELLEUR, J.W. (ed.). The handbook of groundwater engineering. CRC Press, Cap. 12.

KOHNKE, M.W. (2001). Análise da sensibilidade no modelamento de fluxo e tranporte de águas subterâneas. Boletim Informativo da Associação Brasileira de Água Subterrânea. n. 116. p. 17. Julho.

KONIKOW, L.F.; REILLY T.E. (1999). Groundwater Modeling. In: DELLEUR, J.W. (ed.) The handbook of groundwater engineering. CRC Press, Cap. 20, p. 20/1-20/40.

KRESIC, N. (1997). Quantitative solutions in hydrogeology and groundwater modeling. Boca Raton, Florida, CRC Press.

LANDIM, P.M.B. (1998). Análise estatística de dados geológicos. São Paulo, Fundação Editora da UNESP.

LARABI, A., De SMEDT, F. (1997). Numerical solution of 3D groundwater flow involving free boundaries by a fixed finite element method. Journal of Hydrology, v. 201, p. 161182.

LAZARIM, H.A.; LOUREIRO, C.O. (2000). Modelagem hidrogeológica computacional do sistema de fluxo de águas subterrâneas no bairro Jardim Canadá - Quadrilátero Ferrífero, Nova Lima, MG. In: CONGRESSO MUNDIAL INTEGRADO DE ÁGUAS SUBTERRÂNEAS. 1., Fortaleza, 2000. Anais. Fortaleza, ABAS. CD-ROM.

LEAP, D.I. (1999). Geological occurrence of groundwater. In: DELLEUR, J.W. (ed.). The handbook of groundwater engineering. CRC Press. Cap. 1. p. 1/1-1/52. 
LIMA, A.A. (2000). Estudo do lencol freatico e avaliacao hidrogeologica do aquifero Bauru na area urbana do municipio de São Jose do Rio Preto - SP. Trabalho de graduação. Instituto de Geociencias e Ciencias Exatas. UNESP - Rio Claro.63p.

MARSILY, G. de. (1986). Quantitative hydrogeology. . San Diego, .Academic Press

MATSUZAKI, S.S. (1998). Aplicação de modelo computacional de escoamento de água subterrânea no lixão de São Carlos. São Carlos. 113p. Dissertação (Mestrado) - Escola de Engenharia de São Carlos, Universidade de São Paulo.

McDONALD, M.C.; HARBAUGH, A.W. (1988). A modular three-dimensional finitedifference ground-water flow model: U.S. Geological Survey Techniques of WaterResources Investigations, book 6, chap. A1.

MENDES, C.A.B.; CIRILO, J.A. (2001). Geoprocessamento em recursos hídricos: princípios, integração e aplicação. Coleção geoprocessamento, v.1, Associação Brasileira de Recursos Hídricos, Porto Alegre, RS.

MENDONÇA et al. (1999). Simulação do cone de rebaixamento do poço 4-BO-01-PE na Chapada do Araripe utilizando o MODFLOW. In: SIMPÓSIO BRASILEIRO DE RECURSOS HÍDRICOS, 13., Belo Horizonte, 1999. Anais. Belo Horizonte, ABRH. CD-ROM.

MENDONÇA et al. (2001). Modelagem matemática dos aqüíferos da Chapada do Araripe. In: SIMPÓSIO BRASILEIRO DE RECURSOS HÍDRICOS, 14., Aracaju, 1999. Anais. Aracaju, ABRH. CD-ROM.

MICHIGAN (2002). Reports of Department of Environmental Qualit. State of MiciganUSA. http//:www.deq.state.mi.us/erd/gwater.

NEUMAN, S.P.; YAKOWITZ, S. (1979). A statistical approach to the inverse problem of aquifer hydrology 1. Theory. Water Resources Research, v. 15, n. 4, p. $845-860$, August. 
NOBRE, M.M.M.; NOBRE, R.C.M. (2001). Caracterização hidrogeológica para o uso racional e proteção dos mananciais subterrâneos em Maceió, AL. Revista Brasileira de Recursos Hídricos, v. 6, n. 5, p. 7-20, Jan/Mar.

OLSTHOORN, T.N. (1999). A comparative review of analytic and finite difference models used at the Amsterdam Water Supply. Journal of Hydrology, v. 226, p. 139-143.

POLLOCK, D.W. (1994). User's guide for MODPATH/MODPATH-PLOT, version 3: a particle tracking post-processing package for MODFLOW, the U.S. Geological Survey finite-difference groundwater flow model: U.S. Geological Survey Open-File Report 94$464,234 \mathrm{p}$.

RAYNE, T.W.; BRADBURY, K.R.; MULDOON, M.A. (2001). Delineation of capture zones for municipal wells in fractured dolomite, Sturgeon Bay, Wisconsin, USA. Hydrogeology Journal, v. 9, p. 432-450.

REBOUÇAS, A.C. (1999). Águas Subterrâneas. In: Águas Doces no Brasil: capital ecológico, uso e conservação. Escrituras Editora, São Paulo. Cap. 4, p117-151.

SCHMID, G.; OBERMANN, P.; BRAESS, D. et al. (1992), SICK100 Berechnung von stationären und instationären Grundwasserströmungen und Stofftransport. Programmbeschreibung. Arbeitsgruppe Grundwassermodellierung, Ruhr-Universität Bochum, Germany.

SUN, N.Z. (1994). Inverse problems in groundwater modeling. Norwell, MA. Dordrecht, Kluwer Academic Publishers.

USGS (1997). Modeling grounwater flow with MODFLOW and related programs. U. S. Geological Survey. USGS Fact Sheet. FS 121-97.

VAN DER HEIJE, P. et al. (1985). Groundwater management: the use of numerical models. American Geophysical Union. Washington, DC. $2^{\text {nd }}$. ed. (Water Resources Monograph 5)

VIEIRA, L.S. (1988). Manual da ciência do solo, com ênfase aos solos tropicais. São Paulo, Ed. Agronômica Ceres, 464p. 
VIESSMAN, W.; LEWIS, G.L. (1996). Introduction to hydrology. 4. ed., 759p. Harper Collins, New York.,

VIVES, L.; CAMPOS, H.; CANDELA, L.; GUARRACINO, L. (2000). Premodelo de flujo del Acuifero Guarani, In: JOINT WORLD CONGRESS ON GROUNDWATER, 1., Fortaleza, CE, CD-ROM.

YEH, W.W-G. (1986). Review of parameter identification procedures in groundwater hydrology: the inverse problem. Water Resources Research, v. 22, n. 2, p. 95-108, February.

YEH, W.W-G. (1975). Aquifer parameter identification. Journal of the Hydraulics. Division, v. 9. p. 1 197-209, Sept.

WANG, H.F.; ANDERSON, M.P. (1982). Introduction to groundwater modeling: finite difference and element methods. San Diego, Academic Press.

WINSTON, R.B. (1999). MODFLOW - related freeware and shareware resources on the internet. Computers \& Geosciences, v. 25, p. 377-382.

ZIMMERMAN, D.A. et al. (1998). A comparison of seven geostatistically based inverse approaches to estimate transmissivities for modeling advective transport by groundwater flow. Water Resources Research, v.34, n.6, p. 1373-1413, June. 
ANEXOS 
ANEXO 1 - Dados de temperatura da região de estudo 
ANEXO 1 - Temperatura - São José do Rio Preto, Médias de 1996 a 2000. Fonte: Secretaria de Agricultura e Abastecimento. Coordenadoria de Assistência Técnica Integral - CATI. Escritório de Desenvolvimento Rural de São José do Rio Preto - EDR - SJRP.

\begin{tabular}{|c|c|c|c|c|c|c|c|c|c|c|c|c|c|c|c|c|c|c|}
\hline \multirow{2}{*}{ MÊS } & \multicolumn{3}{|c|}{1996} & \multicolumn{3}{|c|}{1997} & \multicolumn{3}{|c|}{1998} & \multicolumn{3}{|c|}{19999} & \multicolumn{3}{|c|}{$\begin{array}{llll}2 & 0 & 0 & 0\end{array}$} & \multicolumn{3}{|c|}{ M É D I A } \\
\hline & MÁX & MÍN & MÉD & MÁX & MÍN & "MÉD & MÁX & MíN & MÉD & IÁX & MíN & "MÉD & MÁX & MÍN & MÉD & MÁX & MÍN & MÉD \\
\hline JAN &, 87 & & & s. & & & 5,68 & & 1,60 & 3,62 & & & 33,22 & & & 33,39 & 22,01 & 27,70 \\
\hline MAR & 2,70 & 21,83 & 27,30 & T, & 20,65 & 27,26 & 34,00 & 22,16 & 28,08 & 33,87 & 21,55 & 27,71 & 31,96 & 20,96 & 20,70 & 33,28 & 21,43 & 27,36 \\
\hline ABR & 1,90 & 20,23 & 26,06 & 30,93 & $11,0 J$ & 24,98 & 32,43 & 19,96 & 26,19 & 32,63 & 18,17 & 25,40 & 32,27 & 18,70 & 25,40 & 32,08 & 19,21 & 25,62 \\
\hline MAI & 8,58 & 16,64 & 22,61 & 2,01 & $10,4 J$ & 22,06 & 27,45 & 21,33 & 15,22 & 28,94 & 14,45 & 21,70 & 22,65 & 15,06 & $21,0 J$ & 28,25 & 16,78 & 20,68 \\
\hline JUL & 27,64 & 12,35 & 19,99 & 28,70 & 14,29 & 21,50 & 30,13 & 13,48 & 21,86 & 30,42 & 16,10 & 23,26 & 26,32 & 10,87 & 18,59 & 28,64 & 13,41 & 21,03 \\
\hline AGO & 31,96 & 16,38 & 24,17 & 30,71 & 14,80 & 22,75 & 29,54 & 16,83 & 23,19 & 32,13 & 15,06 & 23,60 & 30,61 & 15,71 & 23,16 & 30,99 & 15,75 & 23,37 \\
\hline SET & 31,10 & 18,13 & 24,61 & 34,84 & 19,00 & 26,92 & 32,17 & 18,30 & 25,34 & 33,03 & 17,97 & 25,50 & 30,87 & 17,83 & 24,35 & 32,40 & 18,24 & 25,33 \\
\hline OUT & 32,51 & 20,37 & 26,44 & 34,58 & 20,30 & 27,44 & 32,92 & 19,39 & 25,96 & 34,55 & 19,13 & 26,84 & 37,10 & 21,35 & 29,23 & 34,33 & 20,10 & 27,18 \\
\hline NOV & 31,16 & 20,90 & 26,03 & 34,20 & 22,10 & 28,15 & 34,27 & 19,57 & 26,92 & 33,50 & 18,73 & 26,12 & 32,90 & 20,67 & 26,78 & 33,20 & 20,39 & 26,80 \\
\hline
\end{tabular}


ANEXO 2 - Dados de pluviometria para a região de estudo 


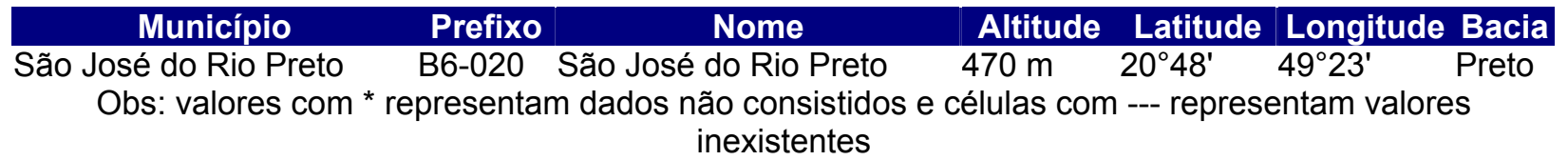

\begin{tabular}{|c|c|c|c|c|c|c|c|c|c|c|c|c|}
\hline \multicolumn{13}{|c|}{ CHUVA MENSAL (mm) } \\
\hline Ano & Jan & Fev & Mar & Abr & Mai & Jun & Jul & Ago & Set & Out & Nov & Dez \\
\hline 941 & $49,2^{*}$ & $100,2^{*}$ & $121,6^{*}$ & $82,1^{*}$ & $0,0^{*}$ & $0,0^{*}$ & $57,1^{*}$ & 3,0 * & $155,8^{*}$ & $55,4^{*}$ & $181,0^{*}$ & $130,7^{*}$ \\
\hline 942 & $72,4^{*}$ & $7,1^{*}$ & $123,4^{*}$ & $204,0^{*}$ & $59,0^{*}$ & $0,0^{*}$ & $0,0^{*}$ & $0,0^{*}$ & $76,0^{*}$ & $22,6^{*}$ & & $81,0^{*}$ \\
\hline 943 & $48,9^{*}$ & $95,4^{*}$ & $91,1^{*}$ & 29,0 * & $22,0^{*}$ & $30,0^{*}$ & $0,0^{*}$ & $0,0^{*}$ & & $53,2^{*}$ & & $57,0^{*}$ \\
\hline 944 & $44,0^{*}$ & $99,0^{*}$ & $74,0^{*}$ & $53,0^{*}$ & $0,0^{*}$ & $0,0^{*}$ & $0,0^{*}$ & $0,0^{*}$ & $0,0^{*}$ & & & \\
\hline 945 & $85,5^{*}$ & $92,8^{*}$ & & $6,0^{*}$ & $0,0^{*}$ & $0,0^{*}$ & $30,6^{*}$ & $0,0^{*}$ & $8,4^{*}$ & & & $3,3^{*}$ \\
\hline 946 & 90, & 29, & -- & $3,0^{*}$ & $0,0^{*}$ & $4,2^{*}$ & 54, & & & & & $212,3^{*}$ \\
\hline 947 & $19,7^{*}$ & 207,6 & $168,1^{*}$ & 0 , & $64,0^{*}$ & $0,0^{*}$ & $0,0^{*}$ & 66 , & & & & $17,8^{*}$ \\
\hline 948 & $20,2^{*}$ & $230, \varepsilon$ & --- & $25,3^{*}$ & $19,5^{*}$ & $0,0^{*}$ & $9,0^{*}$ & 26 & & & & \\
\hline 49 & $287,3^{*}$ & $90,0^{*}$ & $36,2^{*}$ & $40,8^{*}$ & $55,7^{*}$ & $0,0^{*}$ & $0,0^{*}$ & $0,0^{*}$ & $9,8^{*}$ & & & \\
\hline 950 & $45,4^{*}$ & $155,0^{*}$ & $156,7^{*}$ & $20,1^{*}$ & $0,0^{*}$ & $5,3^{*}$ & $0,0^{*}$ & $0,0^{*}$ & $0,0^{*}$ & & & $8,4^{*}$ \\
\hline 951 & $537,3^{*}$ & $07,1^{*}$ & $191,0 *$ & $58,1^{*}$ & $26,4^{*}$ & $11,3^{*}$ & $0,0^{*}$ & $8,0^{*}$ & $0,0^{*}$ & & & $28,0^{*}$ \\
\hline 952 & & $37,0^{*}$ & $184,3^{*}$ & $11,0^{*}$ & $0,0^{*}$ & $94,0^{*}$ & $0,0^{*}$ & & & & & \\
\hline 5 & & & $129,7^{*}$ & & 5 & 9 & 32, & & & & & \\
\hline 5 & & 77, & $94,3^{*}$ & $63,0^{*}$ & $373,3^{*}$ & $2,9^{*}$ & & & & & & $5,0^{*}$ \\
\hline 95 & 6 & 48 & $64,7^{*}$ & $23,0^{*}$ & $4,6^{*}$ & $1,3^{*}$ & $0,0^{*}$ & 37, & & & & --- \\
\hline 1956 & $78,3^{*}$ & $152,1^{*}$ & $38,8^{*}$ & $125,4^{*}$ & $169,7^{*}$ & $101,0^{*}$ & $24,6^{*}$ & & & $6,0^{*}$ & & $21,2^{*}$ \\
\hline 957 & $31,2^{*}$ & $34,7^{*}$ & $14,6^{*}$ & $27,0^{*}$ & $2,0^{*}$ & $2,0^{*}$ & $111,4^{*}$ & $98,3^{*}$ & & $79,8^{*}$ & & -- \\
\hline 958 & --- & $121,7^{*}$ & $02,1^{*}$ & $59,6^{*}$ & $143,8^{*}$ & $77,0^{*}$ & $1,4^{*}$ & $1,2^{*}$ & & & & $72,1^{*}$ \\
\hline 959 & $44,9^{*}$ & & 7,0 * & $83,0^{*}$ & & $7,0^{*}$ & $0,0^{*}$ & & & & & $104,6^{*}$ \\
\hline & & * & & & 52 & & 0, & & & & & $3,5^{\star}$ \\
\hline 61 & & & |* & $115,7^{*}$ & 25 , & & 0,0 & & $2,4^{*}$ & & & $96,9^{*}$ \\
\hline 62 & 26 & & 170 & 6 & 18 & $9 ?$ & $2,3^{*}$ & $3,1^{*}$ & $187,0^{*}$ & $8,7^{*}$ & $9,7^{*}$ & $266,0^{*}$ \\
\hline 963 & $07,8^{*}$ & & & $31,5^{*}$ & $0,0^{*}$ & & --- & --- & --- & --- & --- & $83,1^{*}$ \\
\hline 1964 & $46,9^{*}$ & & $2,4^{*}$ & -- & $107,6^{*}$ &, $7^{*}$ & $14,7^{*}$ & 3, & & --- & --- & -- \\
\hline 1965 & $0,5^{*}$ & & $6,5^{*}$ & $16,0^{*}$ & 2 & $3^{*}$ & $t, 1^{*}$ & 4 & & & & $40,1^{*}$ \\
\hline 966 & $34,6^{*}$ & & $72,4^{*}$ & $24,4^{*}$ & & & & & & & & \\
\hline & & & --- & & & & $2^{*}$ & & & & & $6,8^{\prime}$ \\
\hline & & & $76,7^{*}$ & & & & & & & & & \\
\hline 160 & & & 52,0 & & & & & & & & & \\
\hline 17 & & & & & & & & & & & & \\
\hline & & & 77,1 & 9,3 & 1 & & 5 & & & & 3,2 & 281,6 \\
\hline 17 & 34,5 & 337,0 & 106,6 & 33,7 & 104,5 & 0,0 & 79,8 & 44,7 & 5,9 & & 128,6 & 117,4 \\
\hline 197 & 181,2 & 126,0 & 131,2 & 59,8 & 49,0 & 9 & 17,6 & & 24,4 & & 4,3 & 302,2 \\
\hline 1974 & 376,3 & & 279,2 & 93,6 & 21,9 & 46,3 & & & & & & 288,2 \\
\hline 197 & & & & & & & 23,3 & & & & & 197,2 \\
\hline 1976 & & & & & & & 37,1 & 137,2 & & & & 271,8 \\
\hline 197 & 225 & & & 125 & & & & & & & & \\
\hline & & & & 2,1 & 138,5 & 17,7 & 2,4 & & & & & 403,8 \\
\hline & & & 112,6 & 126,6 & 59,9 & 0,0 & 26 & & & & & 322,9 \\
\hline 198 & & & & 64,8 & 8,4 & 37,5 & 0,0 & 3 & 73,3 & & 139,7 & 293,2 \\
\hline & 53,9 & 4,0 & 97,4 & 4,8 & 7,4 & 38,9 & 0,0 & 0,9 & 4,2 & 157,1 & 88,7 & 90,5 \\
\hline
\end{tabular}




\begin{tabular}{|c|c|c|c|c|c|c|c|c|c|c|c|c|}
\hline & & & & & $\mathbf{V}$ & AE & L & Im) & & & & \\
\hline Ano & Jan & Fev & Mar & Abr & Mai & Jun & Jul & Ago & Set & Out & Nov & Dez \\
\hline 1982 & 166,0 & 304,5 & 373,5 & 28,4 & --- & 17,6 & 7,2 & --- & 23,0 & 159,5 & 88,0 & 225 \\
\hline 1983 & 514,6 & 239,6 & 350,6 & 189,0 & 138,2 & 26,2 & --- & 0,0 & 192,4 & 148,5 & 105,2 & 334,9 \\
\hline 1984 & 129,9 & 53,1 & 197,9 & 197,5 & 46,8 & 0,0 & 0,8 & 72,3 & 84,9 & 57,4 & 108,6 & 210 \\
\hline 1985 & 277,8 & 78,7 & 140,4 & 230,0 & 30,7 & 9,9 & 14,7 & 12,3 & 20,2 & 23,8 & 171,4 & \\
\hline 1986 & 188,3 & 215,4 & 260,7 & 53,9 & 90,8 & 1,0 & 29,9 & 100,1 & 8,0 & 82,3 & 92,4 & 275 \\
\hline 1987 & 246,3 & 139,6 & 77,7 & 88,6 & 59,0 & 2,7 & --- & 7,1 & 115,8 & 114,1 & 271,7 & 13 \\
\hline 1988 & 259,2 & --- & 183,7 & 114,1 & 41,9 & 4,4 & 0,0 & --- & 0,5 & 182,7 & --- & 231 \\
\hline 1989 & 302,3 & --- & 169,8 & --- & 5,5 & --- & --- & --- & -- & 54,5 & --- & \\
\hline 1990 & --- & --- & 359,6 & 95,2 & --- & --- & --- & --- & --- & --- & --- & \\
\hline 1991 & 409,4 & --- & --- & --- & --- & 9,9 & --- & --- & --- & --- & 152,0 & 22 \\
\hline 1992 & $193,0^{*}$ & --- & $192,9^{*}$ & $102,2^{*}$ & $81,3^{*}$ & $0,0^{*}$ & $20,1^{*}$ & $15,2^{*}$ & $80,3^{*}$ & --- & $106,9^{*}$ & $120,1^{*}$ \\
\hline 1993 & $164,9^{*}$ & $167,1^{*}$ & $103,9^{*}$ & $141,2^{*}$ & $28,7^{*}$ & $59,9^{*}$ & $1,3^{*}$ & $32,2^{*}$ & $58,5^{*}$ & $41,5^{*}$ & $98,9^{*}$ & $240,1^{*}$ \\
\hline 1994 & $490,5^{\star}$ & $194,7^{*}$ & $74,1^{*}$ & $110,2^{*}$ & $17,7^{*}$ & $15,9^{*}$ & $18,7^{*}$ & $0,0^{*}$ & $1,0^{*}$ & $99,4^{*}$ & $108,6^{*}$ & $276,1^{*}$ \\
\hline 1995 & $175,2^{*}$ & $513,7^{*}$ & $189,6^{*}$ & $113,6^{*}$ & $28,2^{*}$ & $25,6^{*}$ & $14,8^{*}$ & $0,1^{*}$ & $26,9^{*}$ & $78,0^{*}$ & $162,3^{*}$ & $287,3^{*}$ \\
\hline 1996 & $213,3^{*}$ & $151,8^{*}$ & $152,7^{*}$ & $100,4^{*}$ & $106,7^{*}$ & $20,9^{*}$ & $0,3^{*}$ & $3,7^{*}$ & $90,9^{*}$ & $69,3^{*}$ & $236,2^{*}$ & $160,3^{*}$ \\
\hline 1997 & $457,6^{*}$ & $109,2^{*}$ & $104,5^{*}$ & $94,0 *$ & $50,8^{*}$ & $165,3^{*}$ & $10,1^{*}$ & $0,0^{*}$ & $33,3^{*}$ & $54,6^{*}$ & $342,7^{*}$ & $227,6^{*}$ \\
\hline 1998 & $193,1^{*}$ & $172,9^{*}$ & $338,7^{*}$ & $64,3^{*}$ & $95,1^{*}$ & $2,1^{*}$ & $0,0^{*}$ & $93,2^{*}$ & $44,1^{*}$ & $218,9^{*}$ & $101,9^{*}$ & $373,6^{*}$ \\
\hline 1999 & $303,8^{*}$ & $381,3^{*}$ & $236,3^{*}$ & $52,7^{*}$ & $37,0^{*}$ & $38,4^{*}$ & $7,5^{*}$ & $0,0^{*}$ & $55,7^{*}$ & $51,2^{*}$ & $72,8^{*}$ & $168,4^{*}$ \\
\hline 2000 & $273,5^{*}$ & $285,3^{*}$ & $228,8^{*}$ & $0,6^{*}$ & $1,7^{*}$ & $0,0^{*}$ & $37,5^{*}$ & --- & --- & --- & --- & \\
\hline
\end{tabular}


ANEXO 3 - Dados referentes aos poços registrados no DAEE - Araraquara 


\begin{tabular}{|c|c|c|c|c|c|c|c|c|c|c|}
\hline \multirow{2}{*}{$\begin{array}{c}\text { Poço } \\
\mathrm{N}^{\circ} \\
\end{array}$} & \multirow[t]{2}{*}{ Identificação } & \multirow[t]{2}{*}{ Endereço } & \multicolumn{2}{|c|}{ Coordenadas UTM } & \multirow{2}{*}{$\begin{array}{r}\text { Novas Cotas } \\
\text { Terreno(m) }\end{array}$} & \multirow{2}{*}{$\begin{array}{c}\text { Nível } \\
\text { Estático(m) }\end{array}$} & \multirow{2}{*}{$\begin{array}{c}\text { Nível } \\
\text { Dinâmico(m) }\end{array}$} & \multirow{2}{*}{$\begin{array}{c}\text { Cota } \\
\text { N.D.(m) }\end{array}$} & \multirow{2}{*}{\begin{tabular}{|c|} 
Cota \\
N.E. $(\mathrm{m})$
\end{tabular}} & \multirow{2}{*}{$\begin{array}{c}\text { Data } \\
\text { Construção }\end{array}$} \\
\hline & & & E-W $(m)$ & $\mathrm{N}-\mathrm{S}(\mathrm{m})$ & & & & & & \\
\hline 1 & Pref. Mun.- PM & ???? & 664650,0 & 77701450,0 & $?$ & ? & $?$ & $?$ & & $?$ \\
\hline 2 & Condominio Edificio Van Gogh & Rua Rubião Junior, 2714 & 668110,0 & 7697855,0 & 487 & 12,00 & 36,00 & 451 & 475 & ? \\
\hline 3 & Carrefour Rio Preto & Av. Tancredo Neves, 900 & 671750,0 & 7694930,0 & 480 & 43,53 & 68,74 & 411 & 436 & $?$ \\
\hline 4 & Sóquimica Loratórios Ltda. & Rua Jaguaré, 95 ou 55 & 670250,0 & 7701930,0 & 510 & 27,00 & 42,00 & 468 & 483 & $?$ \\
\hline 5 & HABBIB'S & Av. Alberto Andaló, 3554 & 668450,0 & 7697200,0 & 488 & 26,05 & 38,00 & 450 & 462 & 29.08 .98 \\
\hline 6 & Pref.Mun. - Jardim Seyon & R. Jordão da Silva c/ Neusa A.C. Garcia & 669960,0 & 7701690,0 & 512 & $?$ & $?$ & $?$ & $?$ & $?$ \\
\hline 7 & Pref.Mun.-Pq. Jaguaré & Entre Av. Jaguaré e Danilo Galeazzi & 670050,0 & 7701720,0 & 514 & 58,76 & 89,00 & 425 & 455 & $?$ \\
\hline 9 & Pref.Mun.-Conj. Habit. SJRP-G & Rua $2 \mathrm{c} / \mathrm{Av} . \mathrm{A}$ & 668500,0 & 7703900,0 & 490 & $?$ & $?$ & $?$ & $?$ & 16.06 .98 \\
\hline 10 & Pref.Mun.-Conj. Habit. SJRP-G & Rua 8 c/ Rua 15 & 668700,0 & 7703850,0 & 478 & 34,25 & 103,75 & 374 & 444 & 17.07 .98 \\
\hline 11 & SES -SENAT & Av. Linhão $\mathrm{s} / \mathrm{n}^{\circ}$ & 668325,0 & 7700550,0 & 484 & 12,45 & 36,43 & 448 & 472 & 13.03 .99 \\
\hline 12 & Antonio Claudio Fachin & R. Antônio F. Bilar, 150 & 665550,0 & 7696750,0 & 527 & 18,25 & 26,00 & 501 & 509 & 02.12 .98 \\
\hline 13 & Nunes Ferreira \& Cia. Ltda. Posto Petrobrás- CEDRAL & Rod. Washington Luís km 422-670m & 678950,0 & 7685300,0 & 545 & 32,00 & 58,50 & 487 & 513 & 28.05 .99 \\
\hline 14 & Cond. Edificio Palazzo Angelino Bassan & Rua Saldanho Marinho, 3332 & 668400,0 & 7697300,0 & 496 & 22,10 & 64,10 & 432 & 474 & $?$ \\
\hline 15 & Pref.Mun. - Creche Mun. Jd. Sto Antonio & R.Proj. 44, esq. R. Proj.17 & 666500,0 & 7703100,0 & 516 & 20,00 & 48,00 & 468 & 496 & $?$ \\
\hline 16 & $\begin{array}{l}\text { Jaime Nicola Cornachioni } \\
\end{array}$ & R. José Chain Elias, 271 & 668900,0 & 7696250,0 & 480 & 19,00 & 31,00 & 449 & 461 & $?$ \\
\hline 17 & Fernando Antonio Jorge & R. Antônio Pinheiro, 455 & 667870,0 & 7695450,0 & 528 & 12,30 & 25,05 & 503 & 516 & $?$ \\
\hline 19 & Residencial Damha I & Rod. SJRP - Eng. Schimidt, km 1.5 & 672890,0 & 7697330,0 & $?$ & 34,11 & 115,40 & $?$ & $?$ & 24.05 .99 \\
\hline 20 & Residencial Jardins & Rod. SJRP - Eng. Schimidt, km 2.0 & 672900,0 & 7697210,0 & $?$ & 30,97 & 112,25 & $?$ & $?$ & 24.05 .99 \\
\hline 21 & Maria Neudes Bonalume Viana & Estrada Mun. Eng. Schimidt, km 2.5 & 674520,0 & 7695480,0 & 486 & 8,50 & $?$ & $?$ & 478 & $?$ \\
\hline 22 & Pronadar - Escola de Natação S/C Ltda. & R. Paulo Roberto Resende, 351 & 665250,0 & 7696150,0 & 522 & 22,00 & 54,00 & 468 & 500 & 17.06 .99 \\
\hline 23 & Nilza Helena Silva Montoro & R. Antônio Evaristo Cabrera, 630 & 665250,0 & 7695800,0 & $?$ & 13,00 & 27,00 & $?$ & $?$ & $?$ \\
\hline 24 & Damha Urbanizadora e Constutora Ltda. & Rod. Estadual SP 425, km 1.5 & 671930,0 & 7699130,0 & 521,5 & 44,58 & 105,71 & 416 & 477 & 28.07 .99 \\
\hline 25 & Condomínio Edifício Strauss & R. Agostinho Silva Ganança, s/ $\mathrm{n}^{\circ}$ & 666950,0 & 7696250,0 & 516 & 16,00 & 32,00 & 484 & 500 & $?$ \\
\hline 26 & Adelino Lopes de Souza & R. $02, n^{\circ} 653$ & 664460,0 & 7702140,0 & 541 & 10,00 & 15,00 & 526 & 531 & $?$ \\
\hline 27 & Pref.Mun. -/Jd das Vivendas & Pça Francisco Fernando Alonso & 666740,0 & 7694130,0 & 550 & 68,00 & 172,00 & 378 & 482 & $?$ \\
\hline 28 & Condominio Edificio Paloma & R. Martinho Gonçalves, 2785 & 667670,0 & 7697490,0 & 480 & 24,20 & 39,40 & 441 & 456 & 13.08 .99 \\
\hline 29 & EMER - Emp. Mun. Estação Rodoviária & Praça Paul Harris, $\mathrm{s} / \mathrm{n}^{\mathrm{o}}$ & 668850,0 & 7698150,0 & 479 & 11,13 & 31,95 & 447 & 468 & 26.07 .99 \\
\hline 30 & Cond. Quinta da Boa Vista & R. Luiz Antônio da Silveira, 786 & 668650,0 & 7698750,0 & $?$ & $?$ & $?$ & $?$ & $?$ & $?$ \\
\hline 31 & Da Granja Agroindustrial Ltda. & R. João Mesquita, 767 & 667390,0 & 7700000,0 & 478 & 28,60 & 97,72 & 380 & 449 & $?$ \\
\hline 32 & Da Granja Agroindustrial Ltda. & R. João Mesquita, 767 & 667360,0 & 7699950,0 & 478,5 & 24,20 & 58,30 & 420 & 454 & 01.05 .99 \\
\hline 33 & Da Granja Agroindustrial Ltda. & R. João Mesquita, 767 & 667340,0 & 7699920,0 & 479 & 23,50 & 61,10 & 418 & 456 & 25.04 .99 \\
\hline 34 & Cond. Edifício Paraty & R. Luiz Vaz de Camões, 2500 & 667050,0 & 7697050,0 & 500 & 17,00 & 37,89 & 462 & 483 & 27.07 .98 \\
\hline 35 & Belmiro Castilho & R. Dom José Joaquim Gonçalves, 794 & 665200,0 & 7701170,0 & $?$ & $?$ & $?$ & $?$ & $?$ & $?$ \\
\hline 36 & Condominio Ed. Sào Marino & R. Cel. Spinola de Castro, 4841 & 666770,0 & 7697470,0 & 506 & 22,00 & 44,22 & 462 & 484 & 07.10 .98 \\
\hline
\end{tabular}




\begin{tabular}{|c|c|c|c|c|c|c|c|c|c|c|}
\hline \multirow{2}{*}{$\begin{array}{c}\text { Poço } \\
\mathrm{N}^{\mathrm{o}} \\
\end{array}$} & \multirow[t]{2}{*}{ Identificação } & \multirow[t]{2}{*}{ Endereço } & \multicolumn{2}{|c|}{ Coordenadas UTM } & \multirow{2}{*}{$\begin{array}{r}\text { Novas Cotas } \\
\text { Terreno(m) }\end{array}$} & \multirow{2}{*}{$\begin{array}{c}\text { Nível } \\
\text { Estático(m) }\end{array}$} & \multirow{2}{*}{\begin{tabular}{||c||} 
Nível \\
Dinâmico(m)
\end{tabular}} & \multirow{2}{*}{$\begin{array}{c}\text { Cota } \\
\text { N.D. }(\mathrm{m})\end{array}$} & \multirow{2}{*}{\begin{tabular}{|c||} 
Cota \\
N.E. $(\mathrm{m})$ \\
\end{tabular}} & \multirow{2}{*}{$\begin{array}{c}\text { Data } \\
\text { Construçã }\end{array}$} \\
\hline & & & $\mathrm{E}-\mathrm{W}(\mathrm{m})$ & $\mathrm{N}-\mathrm{S}(\mathrm{m})$ & & & & & & \\
\hline 38 & 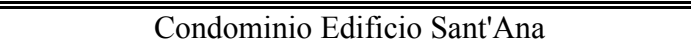 & R. Imperial, 66 & 667780,0 & 76997730,0 & 480 & 10,00 & 23,59 & (256 & 470 & ? \\
\hline 39 & A Riopretana - Cond. Monte Castelo & R. Enjoras Vampre, quadra E & 666670,0 & 7695960,0 & 520 & 33,00 & 45,00 & 475 & 487 & 14.07 .99 \\
\hline 40 & José Theophilo Fleury Neto - MIRASSOL & Prol. Av. Marginal Fepasa, $\mathrm{s} / \mathrm{n}^{\circ}$ & 656900,0 & 7696550,0 & 556 & 55,00 & 121,15 & 435 & 501 & $?$ \\
\hline 41 & Carlos Roberto Guerzi & Chácara & 670800,0 & 7686150,0 & 560 & $?$ & $?$ & $?$ & $?$ & $?$ \\
\hline 42 & Pref.Mun. - UBS - Jd Santo Antonio & R. Ida Daglia Vime Polachini, 580 & 666550,0 & 7703100,0 & 516 & 22,00 & 41,00 & 475 & 494 & $?$ \\
\hline 43 & A Riopretana - Parque Res. Cambuí & R. Odilon Amadeu, $\mathrm{s} / \mathrm{n}^{\mathrm{o}}$ & 672280,0 & 7694370,0 & 490 & 33,00 & 50,00 & 440 & 457 & 10.10 .99 \\
\hline 44 & Condominio Edificio Suiça & R. Suécia c/ R. Projetada & 666940,0 & 7696900,0 & 495 & 16,30 & 26,56 & 468 & 479 & 13.12 .99 \\
\hline 45 & Francisco de Oliveira & Fazenda Talhados & 675300,0 & 7704250,0 & 530 & 13,00 & 32,00 & 498 & 517 & $?$ \\
\hline 46 & João Roberto Fuzari & Est. Vic. SJRP/ Eng. Schimidt & 674920,0 & 7695850,0 & 500 & 18,00 & 29,00 & 471 & 482 & $?$ \\
\hline 47 & Curso Oswaldo Cruz S/C Ltda.-COC-Rio Preto & R. Benjamin Constant, 3463 & 668000,0 & 7697750,0 & 480 & 19,70 & 42,20 & 438 & 460 & 23.03 .00 \\
\hline 48 & Paulo César Bonfim & R. 1, quadra $B, n^{\circ} 96$ & 664579,0 & 7702500,0 & 532 & 35,00 & 45,00 & 487 & 497 & 04.08 .99 \\
\hline 49 & Associação de Pais e Mestres Prof. Riscieri Berto & R. Mário Valadão Furquim, 931 & 664650,0 & 7701300,0 & 539 & 8,40 & 25,70 & 513 & 531 & 20.04 .00 \\
\hline 50 & Edificio Antonio Antunes & R. Prudente de Moraes, 3299 & 669010,0 & 7697830,0 & 480 & 18,00 & 28,00 & 452 & 462 & $?$ \\
\hline 51 & Auto Posto Escala I Ltda. & Av. Ernani P. Domingues, 1810 & 667100,0 & 7700070,0 & 480 & 8,00 & 30,00 & 450 & 472 & $?$ \\
\hline 52 & Concreband - Engenharia de Concreto Ltda. & Av. Percy Gandini, 1985 & 672770,0 & 7693130,0 & 508 & 10,00 & 30,00 & 478 & 498 & $?$ \\
\hline 53 & Victor Miguel Bastos Andrade e Outros & R. Toríbio Arroyo Valério, Q- 02,1000 & 668420,0 & 7695750,0 & 522 & 16,00 & 38,00 & 484 & 506 & $?$ \\
\hline 54 & Mini Mercado Jd Congonhas Ltda. - Alvaro Mendes & Av. João Bernardino S. Ribeiro,1000 & 666290,0 & 7698520,0 & $?$ & 19,50 & 36,00 & $?$ & $?$ & $?$ \\
\hline 55 & Lavanderia Delave Ltda. & Av. Fortunato E. Vetorazzo, 1350 & 664900,0 & 7699920,0 & 513 & 10,00 & 34,00 & 479 & 503 & $?$ \\
\hline 56 & Ginez Angelo Gasques & R. Sinsei Toma, 336 & 665100,0 & 7699050,0 & 495 & 15,00 & 30,00 & 465 & 480 & $?$ \\
\hline 57 & Tarraf Construtora Ltda. & R. Jamil B. Cury, c/ R. Aniz Buchala & 665270,0 & 7694850,0 & 504 & 19,50 & 48,06 & 456 & 485 & 15.05 .00 \\
\hline 58 & Aniloel Melchiori & R. Alberto Naffah, 121 & 670510,0 & 7696770,0 & 520 & 28,00 & $?$ & $?$ & 492 & $?$ \\
\hline 59 & Ecco - Teraoka Engenharia Ltda. & R. Demétrio Elias Madi, 534 & 667820,0 & 7695180,0 & 530 & 20,00 & 41,85 & 488 & 510 & 25.04 .00 \\
\hline 60 & Condominio Edificio San Martin & R. Cel. Spinola de Castro, 4061 & 667680,0 & 7699725,0 & 513 & 18,00 & 28,00 & 485 & 495 & $?$ \\
\hline 61 & Ass. de Pais e Mestres-EMEF-Prof. Ezequiel Ramos & Praça Carlos Gomes, 938 & 668040,0 & 7698100,0 & 480 & 15,00 & 30,00 & 450 & 465 & $?$ \\
\hline 62 & Gerson Luiz Osório Vilela & R. Joaquim Fernandes Diniz, 100 & 664970,0 & 7695690,0 & 530 & 10,00 & 30,00 & 500 & 520 & $?$ \\
\hline 63 & Marlucy Miyeko Habasaki & R. Alberto Naffah, 80 & 670490,0 & 7696760,0 & 520 & 15,00 & 35,00 & 485 & 505 & $?$ \\
\hline 64 & Braile Biomédica Ind., Com. e Representações S/A & Av. Juscelino Kubtischek, 3101 & 665520,0 & 7694650,0 & 530 & 17,00 & 36,00 & 494 & 513 & 27.05 .00 \\
\hline 65 & Amélia Shizuko Morita Kawano & Travessa dos Guaranis, 56 & 668020,0 & 7696750,0 & 487 & 10,00 & 30,00 & 457 & 477 & $?$ \\
\hline 66 & Cem Empreendimentos Imobiliários Ltda. & Lot. Alto das Andorinhas & 667390,0 & 7702600,0 & 520 & 41,00 & 111,29 & 409 & 479 & 08.02 .99 \\
\hline 67 & Carlos de Marqui e outros & Rua 14 com Rua 11 & 663750,0 & 7699950,0 & 500 & 69,21 & 101,24 & 399 & 431 & 08.11 .99 \\
\hline 68 & Maria Rosa Tasinafo & Rua Proj. 2 - Quadra G-Lote 7 & 673810,0 & 7694000,0 & 490 & 20,00 & 36,00 & 454 & 470 & $?$ \\
\hline 69 & Consórcio Urbaniz. Vetorasso & Lot. Nato Vetorasso & 662280,0 & 7700480,0 & 542 & 43,60 & 108,32 & 434 & 498 & 27.06 .00 \\
\hline 70 & Spaipa S/A Ind. Bras. Bebidas & Rua Francisco Curi,65 & 665300,0 & 7697350,0 & 520 & 76,00 & 108,00 & 412 & 444 & $?$ \\
\hline 71 & Spaipa S/A Ind. Bras. Bebidas & Rua Francisco Curi,65 & 665400,0 & 7697350,0 & 520 & 79,00 & 119,00 & 401 & 441 & $?$ \\
\hline 72 & Condominio Edificio Itajai & R. Cel. Spínola de Castro, 4568 & 667400,0 & 7697120,0 & 504 & 19,50 & 41,35 & 463 & 485 & 08.09 .98 \\
\hline 73 & Cond. Moraes do Sul & R. Paulo Vidali, 245 & 667770,0 & 7694980,0 & 540 & $?$ & $?$ & $?$ & $?$ & $?$ \\
\hline 74 & Zaia Tarraf Emprendimentos Imob. Ltda. & Lot. Parque Juriti & 668250,0 & 7702420,0 & 500 & 41,30 & 115,64 & 384 & 459 & 29.06 .00 \\
\hline 75 & Rodobens Adm. e Promo. Ltda.(Cond Green Palm) & BR153 e Av. Anísio Haddad & 666440,0 & 7693670,0 & $?$ & $?$ & $?$ & $?$ & $?$ & 01.02 .01 \\
\hline
\end{tabular}




\begin{tabular}{|c|c|c|c|c|c|c|c|c|c|c|}
\hline \multirow{2}{*}{$\begin{array}{c}\text { Poço } \\
\mathrm{N}^{\mathrm{o}} \\
\end{array}$} & \multirow[t]{2}{*}{ Identificação } & \multirow[t]{2}{*}{ Endereço } & \multicolumn{2}{|c|}{ Coordenadas UTM } & \multirow{2}{*}{\begin{tabular}{|r|} 
Novas Cotas \\
Terreno(m) \\
\end{tabular}} & \multirow{2}{*}{$\begin{array}{c}\text { Nível } \\
\text { Estático(m) } \\
\end{array}$} & \multirow{2}{*}{\begin{tabular}{|c|} 
Nível \\
Dinâmico(m)
\end{tabular}} & \multirow{2}{*}{$\begin{array}{c}\text { Cota } \\
\text { N.D.(m) } \\
\end{array}$} & \multirow{2}{*}{\begin{tabular}{|c||} 
Cota \\
N.E. $(\mathrm{m})$ \\
\end{tabular}} & \multirow{2}{*}{$\begin{array}{c}\text { Data } \\
\text { Construção } \\
\end{array}$} \\
\hline & & & E-W $(m)$ & $\mathrm{N}-\mathrm{S}(\mathrm{m})$ & & & & & & \\
\hline 76 & MARMOART- Marmores e Granitos São Jorge Ltda. & Av. Lineu de Alcântara Gil, 245 & 671100,0 & 7697560,0 & 4990 & 28,00 & \begin{tabular}{|c|}
$?$ \\
\end{tabular} & $?$ & \begin{tabular}{|l|}
462 \\
\end{tabular} & ? \\
\hline 77 & Ana Maria Lombardi (Cond. Bela Vista III) & R. Nove, 208 & 675310,0 & 7695470,0 & 530 & 15,00 & 35,00 & 495 & 515 & $?$ \\
\hline 78 & Lourival Jesus de Carvalho & Rua 7,148 & 671660,0 & 7693290,0 & 500 & 20,00 & 35,00 & 465 & 480 & $?$ \\
\hline 79 & \begin{tabular}{|l||} 
Pref.Mun. SJRP - Residencial Santa Ana \\
\end{tabular} & Marginal ao Corrégo da Felicidade & 669850,0 & 7704300,0 & 490 & 31,50 & 77,00 & 413 & 459 & 19.12 .00 \\
\hline 80 & Toulose Construtora (Residencial Rio das Flores) POÇO 3 & Quadra C lotes 01 e 02 & 664230,0 & 7699030,0 & 487 & 23,00 & 41,00 & 446 & 464 & 11.07 .00 \\
\hline 81 & Toulose Construtora (Residencial Rio das Flores) POÇO 4 & Quadra C lotes 01 e 02 & 664226,0 & 7699099,0 & 489 & 18,00 & 43,76 & 445 & 471 & 12.06 .00 \\
\hline 82 & \begin{tabular}{|c||} 
Aparecida Carreira Okubara \\
\end{tabular} & Rua 1, Quadra B, Lote 08 & 674960,0 & 7691100,0 & 504 & 20,00 & 32,00 & 472 & 484 & $?$ \\
\hline 83 & arraf Construtora Ltda.(Conj. Hab. Villa Borghesi) Poço & Prolong. Av Fortunato E. Vetorazzo & 664580,0 & 7700900,0 & 532 & 49,00 & 96,90 & 435 & 483 & 25.05 .98 \\
\hline 84 & arraf Construtora Ltda.(Conj. Hab. Villa Borghesi) Poço & Prolong. Av Fortunato E. Vetorazzo & 664790,0 & 7700710,0 & 520 & 47,00 & 85,00 & 435 & 473 & 27.05 .99 \\
\hline 85 & \begin{tabular}{|l|l|} 
Buck Enga e Comércio - Cond. Edfício Sol \\
\end{tabular} & Rua José Urias Forte, 244 & 666400,0 & 7695940,0 & 525 & 48,00 & 58,12 & 467 & 477 & 20.10 .00 \\
\hline 86 & Valter Aparecido Parisi & Rua Proj. 2 - Quadra G - Lote 32 & 674850,0 & 7691850,0 & 520 & 6,00 & 12,00 & 508 & 514 & $?$ \\
\hline 87 & ACCOR - Adm. de Hotéis Ecônomicos no Brasil S/A & Av. Artur Nonato, 4193 & 667850,0 & 7696500,0 & 496 & 17,55 & 43,47 & 453 & 478 & 02.03 .01 \\
\hline 88 & Paulo de Jesus Barbosa (Sítio 22 de abril) & Est. Munc. Vila Azul/ Eng $^{\circ}$ Schimidt & 670690,0 & 7686540,0 & 565 & 28,00 & 47,00 & 518 & 537 & $?$ \\
\hline 89 & Cond. Edif. Residencial Porto Príncipe & R. Cel. Spinola de Castro, 4235 & 667500,0 & 7697250,0 & 503 & 25,00 & 50,00 & 453 & 478 & 23.09 .99 \\
\hline 90 & Francisco Frederico de Luca & VERIFICAR & 666850,0 & 7697620,0 & 528 & & $?$ & $?$ & 528 & $?$ \\
\hline 91 & Residencial Damha & Av. Nadma Damha, km 1.5 & 672480,0 & 7697280,0 & 498,35 & 22,20 & 89,77 & 409 & 476 & 20.12 .99 \\
\hline 92 & Atacadão Dist. Com. E Indústria Ltda. & Rua Machado de Assis, 279 & 669420,0 & 7697130,0 & 502 & 27,00 & 42,40 & 460 & 475 & 28.05 .01 \\
\hline 93 & Calio \& Rossi Enga . Comércio Ltda. & Rua Don Afonso Henrique, 901 & 668120,0 & 7695470,0 & 520 & 25,10 & 36,95 & 483 & 495 & 20.10 .99 \\
\hline 94 & Okada \& Ribeiro Ltda. & Av. Juscelino Kubtischek, 1476 & 665640,0 & 7695210,0 & 524 & 36,00 & 45,00 & 479 & 488 & $?$ \\
\hline 95 & Escola Infantil Arte Manha & R. Gilberto Lopes da Silva, 1940 & 667460,0 & 7695480,0 & $?$ & 18,00 & 45,00 & $?$ & $?$ & $?$ \\
\hline 96 & APM. da Esc. 1 Grau Prof ${ }^{a}$.Zulmira da Silva Salles & Rua Olavo Guimarães Corrêa & 669350,0 & 7695550,0 & 554 & 15,00 & 30,00 & 524 & 539 & $?$ \\
\hline 97 & Cond. Edf. Residencial Humaitá & R. Cel. Spinola de Castro, 4235 & 668030,0 & 7697590,0 & 498 & $?$ & $?$ & $?$ & $?$ & \\
\hline 98 & GEPÊ - Empreendimento de Hotelaria Ltda. & Av. José Munia, 5200 & 667740,0 & 7696170,0 & 492 & 13,92 & 32,76 & 459 & 478 & 23.02 .00 \\
\hline 99 & Lucia Carolina P. Pandin (Chac. Bela Vista) MIRASSOL & Rua Proj. A - Quadra A - Lote 24 & 658480,0 & 7696810,0 & 560 & 30,00 & $?$ & $?$ & 530 & $?$ \\
\hline 100 & \begin{tabular}{|l|} 
Flavina Lavanderia Ltda. \\
\end{tabular} & Av. Floriano André Cabrera, 1427 & 669810,0 & 7694750,0 & 520 & 33,00 & 49,00 & 471 & 487 & $?$ \\
\hline
\end{tabular}


ANEXO 4 - Dados referentes aos poços registrados no SeMAE - São José do Rio Preto 


\begin{tabular}{|c|c|c|c|c|c|c|c|c|c|c|c|}
\hline \multirow{2}{*}{$\begin{array}{l}\mathbf{N}^{\circ} \\
\text { UND } \\
\end{array}$} & \multirow{2}{*}{$\begin{array}{c}\text { No } \\
\text { Poços }\end{array}$} & \multirow[t]{2}{*}{ Quad. } & \multicolumn{2}{|c|}{ Coordenadas UTM } & \multirow{2}{*}{$\begin{array}{l}\text { Bauru } \\
\text { Botucatu }\end{array}$} & \multirow[b]{2}{*}{ Cadastro dos poços NOVO DAE } & \multirow{2}{*}{$\frac{\text { Bairro/local }}{\text { em São José do Rio Preto (BAUF }}$} & \multirow{2}{*}{$\begin{array}{c}\text { Instalação } \\
\text { Data de }\end{array}$} & \multirow{2}{*}{$\frac{\mathrm{m}}{\text { Profund }}$} & \multirow{2}{*}{$\begin{array}{l}\mathrm{m} \\
\mathrm{NE}\end{array}$} & \multirow{2}{*}{$\frac{m}{N D}$} \\
\hline & & & E-W (m) & $\mathrm{N}-\mathrm{S}(\mathrm{m})$ & & & & & & & \\
\hline 1 & DAE-119 & 21 & 663182.40 & 7699616.00 & ATIVO & Rua projetada $\mathrm{n}^{\circ} 4$ & Antonieta & & & & \\
\hline 2 & DAE-120 & 21 & 664032.57 & 7699412.95 & ATIVO & Entre as Ruas Proj. 07 e Proj. A & Antonieta & & & & \\
\hline 3 & DAE-60 & 50 & 665879.49 & 7694364.39 & ATIVO & Rua Rio Paranapanema em frente ao $\mathrm{n}^{\circ} 400 \mathrm{x} \mathrm{c}$ & Aclimação & $23 / 3 / 2001$ & 54 & & \\
\hline 4 & DAE-61 & 51 & 666198.73 & 7694278.91 & ATIVO & Rua Rio Paranapanema x rua Anísio Haddad G & Aclimação & 12/8/1996 & 99 & & \\
\hline 5 & DAE-04 & 19 & 670869.99 & 7700141.39 & ATIVO & Av. N. Sra. da Paz x rua Beny Roqueti (reserv./A & Alto Alegre & 13/2/1995 & & & \\
\hline 6 & DAE-62 & 34 & 665880.15 & 7697085.86 & ATIVO & Rua José M. Casaca x rua Alemanha, próximo & Alto Rio Preto & $31 / 5 / 1996$ & 169 & 53 & 78 \\
\hline 7 & DAE-63 & 40 & 665704.95 & 7696999.99 & ATIVO & Av. Jesus Vila Nova Vidal x rua José Anísio log & Alto Rio Preto & 6/10/1998 & 183 & 55 & 87 \\
\hline 8 & DAE-64 & 40 & 665584.55 & 7696848.43 & ATIVO & Rua José Anísio logo x rua Felipe Gataz, próxin & Maria Cândida & 10/12/1996 & 108 & & \\
\hline 9 & DAE-99A & 22 & 664408.00 & 7699973.00 & ATIVO & r. Carolina S. Coelho esq. Com Av. Eribelto Mar & Anna Angelica & $15 / 7 / 2000$ & 151,3 & 33,7 & 64,75 \\
\hline 10 & DAE-97 & 16 & 664659.58 & 7700191.11 & ATIVO & Rua Rogério Cevizzi x rua Benedito T. de Olivei & Belo Horizonte (CECAP) & $5 / 8 / 1997$ & & & \\
\hline 11 & DAE-98 & 22 & 664643.80 & 7699997.11 & ATIVO & Av. Fortunato Vetorazzo $x$ av. Eribelto M. Reino & Belo Horizonte (CECAP) & $24 / 11 / 2000$ & 92 & & \\
\hline 12 & DAE-99 & 22 & 664749.64 & 7699932.31 & ATIVO & Av. B $\times$ av. Fortunato Vetorazzo, em frente à rua & Belo Horizonte (CECAP) & 23/10/1998 & & & \\
\hline 13 & DAE-02 & 29 & 667508.93 & 7698608.72 & ATIVO & Rua Marechal Deodoro x rua Campos Salles & Boa Vista & 16/3/1999 & 72 & & \\
\hline 14 & DAE-95 & 14 & 670364.35 & 7701167.32 & ATIVO & Rua Antônio Munia x rua José Rambaielo & Bosque & $14 / 11 / 1990$ & & & \\
\hline 15 & DAE-39 & 43 & 671265.72 & 7696471.80 & ATIVO & Rua Francisco Sizenando, n_ 276 (mercearia/a & CAIC & $19 / 1 / 2000$ & 120 & & \\
\hline 16 & DAE-40 & 43 & & & ATIVO & Rua Benedito Duarte, em frente a $n_{-}^{0} 241$, entre & CAIC & 21/7/1993 & & & \\
\hline 17 & DAE-41 & 43 & 671325.69 & 7696337.01 & ATIVO & Rua Proj n $n^{\circ} 0$ (entre os lotes 9 e 10 ) & CAIC & $21 / 6 / 2000$ & 138 & & \\
\hline 18 & DAE-187 & 55 & & & ATIVO & Rua Odilon Amadeu esq. Com prolongamento $\mathrm{d}$ & Cambui & & & & \\
\hline 19 & DAE-81 & 14 & 670278.22 & 7701579.61 & ATIVO & Rua Bechara Hage x rua Antonio Sbioge & Castelinho do Bosque & $22 / 8 / 2000$ & & & \\
\hline 20 & DAE-82 & 14 & 670440.57 & 7701728.21 & ATIVO & Rua Bechara Hage x rua L. J. Nascimento & Castelinho do Bosque & $22 / 8 / 2000$ & 96 & & \\
\hline 21 & DAE-83 & 14 & 670602.43 & 7701857.75 & ATIVO & Rua Bechara Hage, em frente ao $n_{-}^{\circ} 1140 \times$ rua & Castelinho do Bosque & $22 / 8 / 2000$ & & & \\
\hline 22 & DAE-123 & 03 & 668355.81 & 7703285.89 & ATIVO & Rua proj. 05 esquina com a Rua proj. 04 & Centenário da Emancipação & 13/4/1999 & 132 & 50,5 & 86 \\
\hline 23 & DAE-01 & 30 & 669190.96 & 7698210.88 & ATIVO & Rua São Paulo x Av Philadelpho G. Neto ( BEB & Centro (ETA) & 8/12/1998 & 78 & & \\
\hline 24 & DAE-160 & A & & & STAND BY & Rua projetada D x Rua Proj. 30 & Cidadania & & & & \\
\hline 25 & DAE-159 & $\mathrm{E}$ & & & ATIVO & Rua proj. $n^{\circ}-09$ esquina com a Rua proj. $n^{0}-31$ & Cidadania & & & & \\
\hline 26 & DAE-150 & 34 & 664473.74 & 7697317.14 & ATIVO & Cidade das Crianças, cerca de $100 \mathrm{~m}$ da entrad, & Cidade da Crianças & 27/7/1999 & 120 & & \\
\hline 27 & DAE-149 & 34 & 664504.87 & 7697449.06 & ATIVO & Cidade das Crianças, em frente à av. Daniel A. & Cidade das Crianças & $1 / 7 / 1997$ & 166 & 54 & 85 \\
\hline 28 & DAE-158 & 52 & & & ATIVO & Rua Prof. Narinha N. Verdenaski esquina com & Cidade Jardim & $30 / 10 / 2000$ & 150 & 47 & 110 \\
\hline 29 & DAE-42 & 52 & 669771.84 & 7694518.20 & ATIVO & Rua Sílvio Colombo x rua 29 x rua 13 , próximo & Cidade Jardim & 21/8/1998 & 165 & 65 & 96 \\
\hline 30 & DAE-43 & 53 & 670027.19 & 7694478.36 & ATIVO & Rua Rajide Jamal x rua Sílvio Colombo, em frer & Cidade Jardim & 21/8/1998 & 126 & 45 & 58 \\
\hline 31 & DAE-44 & 52 & 669749.72 & 7694336.36 & ATIVO & Canteiro interno da av. 1 (sob linhão CPFL) x ru & Cidade Jardim & 29/5/2001 & 163 & 49 & 107 \\
\hline 32 & DAE-84 & 08 & 669465.53 & 7702167.34 & ATIVO & Rua Jaguaré s/n após 758 & Clementina & $25 / 10 / 2000$ & 84 & & \\
\hline 33 & DAE-94 & 04 & 670622.91 & 7703316.14 & ATIVO & Rua Antonio Buzzini x rua E & Conj. Res. São J Rio Preto I & 26/2/1997 & 72 & & \\
\hline 34 & DAE-93 & 04 & 670676.40 & 7703585.95 & ATIVO & Rua 1 x rua 7 (reservatório) & Conj. Res. São J. Rio Preto I & 10/11/2000 & 102 & & \\
\hline 35 & DAE-96 & 17 & 667496.71 & 7700667.68 & ATIVO & Av. Mirassolândia, entre as ruas Santa Paula e & Costa do Sol & 11/11/1999 & 96 & & \\
\hline 36 & DAE-36 & 48 & 671265.15 & 7695301.89 & ATIVO & Rua Proj. A, entre as ruas José Rossi e José Jo & Cristo Rei & 14/9/1998 & 102 & & \\
\hline
\end{tabular}




\begin{tabular}{|c|c|c|c|c|c|c|c|c|c|c|c|}
\hline \multirow{2}{*}{$\begin{array}{l}\mathrm{N}^{\circ} \\
\text { UND }\end{array}$} & \multirow{2}{*}{$\begin{array}{c}\text { No } \\
\text { Poços }\end{array}$} & \multirow[t]{2}{*}{ Quad. } & \multicolumn{2}{|c|}{ Coordenadas UTM } & \multirow{2}{*}{$\begin{array}{c}\text { Bauru } \\
\text { Botucatu }\end{array}$} & \multirow[b]{2}{*}{ Cadastro dos poços NOVO DAE } & \multirow{2}{*}{$\frac{\text { Bairro/local }}{\text { em São José do Rio Preto (BAUF }}$} & \multirow{2}{*}{$\begin{array}{c}\text { Instalação } \\
\text { Data de }\end{array}$} & \multirow{2}{*}{$\frac{\text { m }}{\text { Profund }}$} & \multirow{2}{*}{$\begin{array}{l}\mathrm{m} \\
\mathrm{NE}\end{array}$} & \multirow{2}{*}{$\frac{m}{N D}$} \\
\hline & & & E-W (m) & $\mathrm{N}-\mathrm{S}(\mathrm{m})$ & & & & & & & \\
\hline 37 & DAE-37 & 48 & 671275.92 & 7695512.58 & ATIVO & R. José Cury, próx. à r. Projetada A, em frente a & Cristo Rei & 22/10/1998 & 108 & & \\
\hline 38 & DAE-38 & 48 & 671380.53 & 7695174.10 & ATIVO & Rua Projetada B, entre as ruas José Rossi e Jo: & Cristo Rei & $19 / 12 / 2000$ & 102 & & \\
\hline 39 & DAE-203 & 48 & 671514.00 & 7695426.00 & PERFURANDd & Rua Projetada A x Rua José a Filho ( NOVO) & Cristo Rei & & & & \\
\hline 40 & DAE-201 & & & & ATIVO & CTR 055 São Manoel S/N ao lado do Praia Clu & Ch.de Recreio Felicidade & & & & \\
\hline 41 & DAE-89 & 26 & 672087.17 & 7699760.91 & ATIVO & Rua Ataliba Caldas (em frente ao $\left.n_{-}^{0} 150\right) \times$ rua & Deocleciano & $25 / 8 / 2000$ & 120 & 51 & 112 \\
\hline 42 & DAE-92C & 26 & & & ATIVO & Rua João José Lucania Fernandes n59 & Deocleciano & 17/5/1997 & 124 & 37 & 51 \\
\hline 43 & DAE-90 & 26 & 672318.98 & 7699812.54 & ATIVO & Rua Saad Madrum $x$ Av B em frete ao $n^{0} 14 \quad(M$ & Deocleciano & 4/3/1996 & 120 & 36 & 86 \\
\hline 44 & DAE-05 & 42 & 669613.07 & 7696827.75 & ATIVO & Av. América, entre as ruas da Imprensa e Padre & Diniz & $26 / 3 / 2001$ & & & \\
\hline 45 & DAE-198 & 07 & 667211.00 & 7702790.00 & ATIVO & Rua proj. 10 esq. Com Rua Manoel Del' $\operatorname{Arco}(A$ & Dist. Adail Vetorazzo & $2 / 8 / 2000$ & 167 & 35,1 & 79,45 \\
\hline 46 & DAE-204 & & & & STAND BY & Rua projetada $06 \mathrm{x}$ com Av. projetada n 08 (áre & Dist. Ulysses Guimarães & $23 / 4 / 2001$ & 120 & 58,37 & 128,77 \\
\hline 47 & DAE-16 & 17 & 666787.71 & 7700823.18 & ATIVO & Rua Jales ( Estadio Municipal Eldorado / Centr & Eldorado & $2 / 3 / 2000$ & 21 & & \\
\hline 48 & DAE-17 & 17 & 666319.99 & 7700826.11 & ATIVO & Praça cercada, entre as ruas Estrela d'Oeste e & Eldorado & 10/5/1996 & 147 & 59 & 86 \\
\hline 49 & DAE-18 & 12 & 666195.40 & 7701202.33 & ATIVO & R. Três Lagoas, entre os $n_{-}^{0 s} 3741 / 3761$, entre a & Eldorado & $1 / 5 / 2001$ & 170 & 69 & 114 \\
\hline 50 & DAE-19 & 12 & 666401.88 & 7701078.64 & ATIVO & Rua Jales, entre as ruas Indiaporã e Antonio MA & Eldorado & $15 / 12 / 1997$ & 162 & 80 & 94 \\
\hline 51 & DAE-20 & 12 & 666673.02 & 7701217.54 & ATIVO & Praça e ponto de ônibus, entre av. Mirassolândi| & Eldorado & 2/5/1996 & 156 & 44 & 105 \\
\hline 52 & DAE-87 & 08 & 669363.16 & 7702689.66 & ATIVO & Rua 25 de Janeiro $x$ rua Hormínio de Oliveira & Elmaz & DISPONIVEL & & & \\
\hline 53 & DAE-88 & 08 & 669583.51 & 7702602.15 & ATIVO & Rua Antonio G. Lourenço, em frente ao $n_{-}^{\circ} 1436$ & Elmaz & 21/7/1992 & & & \\
\hline 54 & DAE-48 & 65 & & & ATIVO & Rodovia Engenheiro Schmidt & Schmidt & 18/4/1996 & 78 & & \\
\hline 55 & DAE-49 & 65 & 676080.02 & 7691707.10 & ATIVO & Rua Coutinho Cavalcante ( junto a caixa ) & Schmidt & 21/4/1999 & 120 & & \\
\hline 56 & DAE-128 & 16 & 664431.57 & 7700992.24 & ATIVO & Rua Arquimedes esquina com Av. Beolchi & ETEMP & $10 / 11 / 2000$ & 120 & & \\
\hline 57 & DAE-165 & 04 & 671100.00 & 7704060.00 & ATIVO & Rua Projetada $n^{\circ}-01$ esquina com a Rua Pro & Felicidade & $16 / 6 / 2000$ & 90 & 38 & 84 \\
\hline 58 & DAE-100 & 13 & 669236.52 & 7701448.85 & ATIVO & Rua Projetada- $03 \times$ Av. Antonio Marques dos S & Flores I & & & & \\
\hline 59 & DAE-101 & 13 & 669697.98 & 7701770.89 & ATIVO & Rua Maria A Santana $\times$ Cesar Pupim & Flores II & 15/4/1994 & & & \\
\hline 60 & DAE-144 & 15 & 663445.03 & 7700398.67 & ATIVO & Rua Sebastião Ortega Egea SN & Gabriela & & 120 & & \\
\hline 61 & DAE-127 & 16 & & & DESATIVADO & Rua Prof. Jaime Moore S/N esquina com a Rua & Gisete & 11/9/1999 & 120 & 36 & 110 \\
\hline 62 & DAE-202 & 16 & 664543.71 & 7700775.71 & ATIVO & Rua Prof. Jaime Moore $S / N$ esquina com a Rua & Gisete & & & & \\
\hline 63 & DAE-45 & 52 & 668230.79 & 7694739.21 & ATIVO & Rua 15 x Rua Abraão Thomé (praça ao lado do & Higienópolis & 29/8/1995 & 126 & & \\
\hline 64 & DAE-46 & 52 & 668040.35 & 7694618.70 & ATIVO & Rua Luiz Spíndola Castro (trecho sem asfalto), & Higienópolis & $12 / 4 / 2001$ & 126 & & \\
\hline 65 & DAE-47 & 52 & 668154.62 & 7694611.81 & ATIVO & Rua Feres Kfouri x rua 15 & Higienópolis & $12 / 2 / 2001$ & 160 & 62 & 94 \\
\hline 66 & DAE-102 & 14 & 670027.31 & 7701758.19 & ATIVO & Rua Jaguaré $x$ av. Danilo Galeazzi (fabrica de & Jaguaré & 8/10/1995 & 108 & 59 & 100 \\
\hline 67 & DAE-78 & 56 & 666466.98 & 7693877.47 & ATIVO & Rua Carlos R. de Oliveira Junto ao reservatório & Jd. Vivendas & $23 / 10 / 2000$ & 174 & 68 & 172 \\
\hline 68 & DAE-186 & 06 & & & ATIVO & Rua proj. 06 ärea institucional -02 (em frente ao & Jardim Colorado & & & & \\
\hline 69 & DAE-26 & 14 & 670369.53 & 7701838.26 & ATIVO & Rua Sebastião Borges $\mathrm{x}$ rua José Leite Anabon & João Paulo II & 17/8/1998 & 144 & & \\
\hline 70 & DAE-29 & 14 & 670380.86 & 7701503.27 & ATIVO & Rua Frederico de Freitas $x$ rua Alberto Batistela & João Paulo II & $8 / 2 / 2001$ & & & \\
\hline 71 & DAE-53 & 37 & 670982.52 & 7697331.45 & ATIVO & Marginal/BR-153, em frente ao n_- 4546 , entre as & Judas Tadeu & $18 / 6 / 1996$ & 142 & 30 & 50 \\
\hline 72 & DAE-54 & 37 & 670929.85 & 7697156.21 & ATIVO & Rua Casa Blanca x rua José Bonifácio, em frent & Judas Tadeu & 4/10/1997 & 135 & 29 & 69 \\
\hline
\end{tabular}




\begin{tabular}{|c|c|c|c|c|c|c|c|c|c|c|c|}
\hline \multirow{2}{*}{$\frac{\mathbf{N}^{\circ}}{\text { UND }}$} & \multirow{2}{*}{$\begin{array}{l}\text { No } \\
\text { Poços }\end{array}$} & \multirow[t]{2}{*}{ Quad. } & \multicolumn{2}{|c|}{ Coordenadas UTM } & \multirow{2}{*}{$\begin{array}{l}\text { Bauru } \\
\text { Botucatu }\end{array}$} & \multirow[b]{2}{*}{ Cadastro dos poços NOVO DAE } & Bairro/local & \multirow{2}{*}{$\begin{array}{c}\text { Instalação } \\
\text { Data de }\end{array}$} & \multirow{2}{*}{$\frac{m}{\text { Profund }}$} & \multirow{2}{*}{$\begin{array}{l}\mathrm{m} \\
\mathrm{NE}\end{array}$} & \multirow{2}{*}{$\frac{m}{\mathrm{ND}}$} \\
\hline & & & $E-W(m)$ & $\mathrm{N}-\mathrm{S}(\mathrm{m})$ & & & São José do Rio Preto (BAUF & & & & \\
\hline 73 & DAE-109 & 28 & 664326.90 & 7699000.47 & ATIVO & Rua Jamil Kfouri x rua José Ribeiro & Macedo Teles I & & & & \\
\hline 74 & DAE-110 & 28 & & & ATIVO & Rua Santa Paula esq com Rua José Ribeiro & Macedo Teles I & 20/4/1999 & 66 & & \\
\hline 75 & DAE-03 & 24 & 669892.53 & 7699013.94 & ATIVO & Rua São Paulo x rua Visconde de Porto Seguro & Maceno & $1 / 2 / 1999$ & 90 & & \\
\hline 76 & DAE-85 & 07 & 667328.12 & 7702869.77 & ATIVO & Rua Wagner C. Pereira, junto à caixa d'água & Manoel del Arco & 15/11/1995 & 160 & 60 & 123 \\
\hline 77 & DAE-86 & 07 & 667326.85 & 7702755.28 & ATIVo & Rua Wagner C.Pereira $x$ rua Manoel del Arco, & Manoel del Arco & $28 / 11 / 2000$ & 160 & & 114 \\
\hline 78 & DAE-67 & 48 & 670541.06 & 7695949.33 & ATIVo & R. Theotonio Monteiro de Barros $\mathrm{F}_{-}^{0} \mathrm{x}$ av. Gov. & Mansur Daud & & & & \\
\hline 79 & DAE-68 & 43 & 670684.59 & 7696019.11 & ATIVO & Av. Aniloel Nazareth (Marginal), em frente à ag. & Mansur Daud & & & & \\
\hline 80 & DAE-103 & 40 & 664990.54 & 7696292.28 & ATIVO & \begin{tabular}{|l|} 
Rua 17, nos fundos da Concretex \\
\end{tabular} & Maracanã & $17 / 7 / 2000$ & 120 & & \\
\hline 81 & DAE-157 & 40 & & & ATIVO & Av. da Luz esquina com Rua Paulo Menezeli & Maracanã & $24 / 2 / 2000$ & 140 & 67 & 110,21 \\
\hline 82 & DAE-156 & 35 & & & ATIVO & Av. Jesus Vila Nova Vilanova Vidal $x$ com Rua & Maria Candida & $3 / 5 / 2000$ & 145 & 66,5 & 134,98 \\
\hline 83 & DAE-104 & 06 & 665423.18 & 7702761.54 & ATIVO & Rua Alexandre Magnum x rua Almirante Taman & Maria Lúcia & 20/6/1994 & & & \\
\hline 84 & DAE-105 & 06 & 665296.42 & 7702686.73 & ATIVo & Rua Padre Manoel Bernardes seq com Alexar & Maria Lúcia & 9/12/1996 & 120 & & \\
\hline 85 & DAE-106 & 06 & 665324.00 & 7702568.03 & ATIVO & Rua Manoel Bernardes, em frente ao $n_{-}^{0} 1180 \times$ & Maria Lúcia & $4 / 8 / 2000$ & 140 & & \\
\hline 86 & DAE-107 & 06 & 665590.51 & 7702451.77 & ATIVO & Rua Almirante Tamandaré x rua 19 de Março & Maria Lúcia & $20 / 12 / 1997$ & 120 & & \\
\hline 87 & DAE-108 & 06 & 665258.10 & 7702261.54 & ATIVO & Rua 19 de Março, entre as ruas 510 e 511 & Maria Lúcia & $14 / 3 / 1997$ & & & \\
\hline 88 & DAE-69 & 46 & 666819.33 & 7695083.66 & ATIVO & Rua Raul Silva x rua Lino Braile & Morumbi & $23 / 9 / 2000$ & 108 & & \\
\hline 89 & DAE-111 & 12 & 667807.70 & 7701203.27 & ATIVO & Rua Paschoal Decrescenzo x rua 3, próximo a & Paraiso & $20 / 12 / 1989$ & & & \\
\hline 90 & DAE-73 & 26 & 671934.69 & 7699127.28 & ATIVO & Marginal a Rod. Assis Chateaubriand & Parque São Miguel & & & & \\
\hline 91 & DAE-70 & 46 & 66188.10 & 7695528.55 & ATIVO & Rua Joaquim Pires, $n_{-}^{\circ} 766$, em frente ao Rio $\operatorname{Pr}$ & Pinheiros & $12 / 8 / 1997$ & 54 & & \\
\hline 92 & DAE-112 & 02 & 667846.99 & 7703174,32 & ATIVo & Rua Evaristo Cabral esquina c/ Rua Oscar F. Pf & Planalto & 18/2/1995 & & & \\
\hline 93 & DAE-15 & 41 & 667447.83 & 7696754.61 & ATIVO & Praça Aldo Tonelli, entre as ruas Bernardino de & Redentora & $20 / 9 / 1999$ & 102 & & \\
\hline 94 & DAE-131 & 08 & 668225.83 & 7702877.98 & ATIVO & Av. Domingos Falavina esquina c/ Av. proj. 02 & Renascer & $4 / 5 / 2000$ & 52 & & \\
\hline 95 & DAE-133 & 23 & 666181.32 & 7699658.48 & ATIVO & Rua Maria de Almeida Caputti esquina c/ Rua N & Renata Tarraf & $3 / 12 / 1998$ & 84 & & \\
\hline 96 & DAE-66 & 43 & & & ATIVO & Rua Montteiro Lobato com Rua Adelardo Cesa & Romano Calil & $1 / 12 / 2000$ & 147 & & 146 \\
\hline 97 & DAE-65 & 48 & 670981.33 & 7695910.62 & ATIVO & Rua Monteiro Lobato, a cerca de $200 \mathrm{~m}$ da rua & Romano Calil & $30 / 3 / 2001$ & 66 & & \\
\hline 98 & DAE-91 & 26 & 672230.63 & 7699648.53 & ATIVO & ao lado do "reservatório" (UBS - Unidade Básica & S. Deocleciano & $6 / 11 / 2000$ & 99 & & \\
\hline 99 & DAE-30 & 02 & 667023.03 & 7703142.28 & ATIVO & \begin{tabular}{|l|l} 
Rua $31 \mathrm{x}$ rua 55, em frente ao $\mathrm{n}_{-}^{\circ} 170$ \\
\end{tabular} & Santo Antonio & & & & \\
\hline 100 & DAE-31 & 02 & 667397.74 & 7703124.88 & ATIVO & Rua $55 \mathrm{x}$ rua 24 , em frente a um ginásio de esp & Santo Antonio & 13/8/1998 & 120 & & \\
\hline 101 & DAE-32 & 07 & 666792.97 & 7702951.70 & ATIVo & Praça, entre as ruas 21,52 e 53 (a casa de forç & Santo Antonio & $18 / 3 / 1998$ & 120 & & \\
\hline 102 & DAE-33 & 07 & 667050.24 & 7702942.00 & ATIVo & Rua 50, em frente ao $n_{-}^{\circ} 362$ (a casa de força dd & Santo Antonio & $12 / 8 / 1998$ & 120 & & \\
\hline 103 & DAE-34 & 07 & 667210.44 & 7702922.59 & ATIVo & Rua 50 , em frente ao no 212 , entre as ruas $26 \mathrm{e}$ & Santo Antonio & $18 / 12 / 2000$ & 148 & 50 & 116 \\
\hline 104 & DAE-35 & 07 & 667328.72 & 7702963.40 & ATIVO & \begin{tabular}{|l|} 
Rua 25 , em frente ao $n_{-}^{\circ} 101$, no mesmo \\
terreno do poco/reservatóric
\end{tabular} & Santo Antonio & $28 / 3 / 2001$ & 120 & & \\
\hline 105 & DAE-92A & 20 & & & ATIVO & Sào Deocleciano III ( Rua Brassolat entre as Ru & São Deocleciano III & & 114 & & 80 \\
\hline 106 & DAE-92B & 20 & & & ATIVO & Sào Deocleciano III ( Rua "C" s/n x João Canizz & São Deocleciano III & & 108 & & 101,1 \\
\hline 107 & DAE-51 & 57 & 668032.63 & 7693836.17 & ATIVO & Rua Gianino Kaiser, $n_{-}^{\circ} 990$ (praça com campo & São Francisco & $10 / 10 / 1994$ & 108 & & \\
\hline
\end{tabular}




\begin{tabular}{|c|c|c|c|c|c|c|c|c|c|c|c|}
\hline $\mathbf{N}^{\circ}$ & $\mathbf{N}^{\circ}$ & Quad. & Coordenadas & & Bauru & Endereço & Bairro/local & Instalação & $\mathbf{m}$ & $\mathbf{m}$ & $\mathbf{m}$ \\
\hline UND & Poços & & E-W (m) & N-S (m) & Botucatu & Cadastro dos poços NOVO DAE & em São José do Rio Preto (BAUF & Data de & Profund & NE & ND \\
\hline 108 & DAE-52 & 57 & 667961.30 & 7693746.34 & ATIVO & Rua Gianino Kaiser, $n_{-}^{\circ} 1080 \times$ Rua Valdir de $C_{-}$ & São Francisco & $22 / 11 / 2000$ & 96 & & \\
\hline 109 & DAE-135 & 03 & 668521.90 & 7703696.54 & ATIVO & Rua Proj n² esquina com Av. A & São José do Rio Preto F/G & 24/9/1998 & 114 & 36,3 & 110,3 \\
\hline 110 & DAE-136 & 03 & 668688.17 & 7703606.82 & ATIVO & Rua Proj n8 esquina com a Rua Proj. 15 & São José do Rio Preto F/G & $1 / 8 / 2000$ & 108 & 34,3 & 96,6 \\
\hline 111 & DAE-196 & 03 & 668526.00 & 7703700.00 & ATIVO & Aréa Institucional entre as Ruas Heitor de Souz: & São José do Rio Preto F/G & $3 / 9 / 2000$ & 110 & 22,6 & 58,95 \\
\hline 112 & DAE-139 & 46 & 666523.72 & 7695415.21 & ATIVO & Av.Anísio Haddad, atrás do rest. Chopim, em fre & São Manoel & $10 / 8 / 1995$ & 126 & & \\
\hline 113 & DAE-140 & 51 & 666116.80 & 7694908.50 & ATIVO & Rua Rio Juquiá, entre as ruas Rio Solimões e R & Aclimação & $9 / 6 / 1998$ & 120 & & \\
\hline 114 & DAE-141 & 46 & 666934.24 & 7695843.81 & ATIVO & Rua Antonio de Godoi x rua Joaquim Barbeiro & São Manoel & $1 / 10 / 1996$ & 114 & & \\
\hline 115 & DAE-142 & 46 & 667031.41 & 7695680.28 & ATIVO & Rua Sinésio de Melo x com Rua Raul Silva, den & São Manoel & $14 / 2 / 1995$ & 120 & & \\
\hline 116 & DAE-138 & 46 & 666799.94 & 7695498.42 & ATIVO & Av. Francisco C. Oliveira x rua Antonio de Godd & São Manoel/Ch. Municipal & 19/1/1999 & 120 & 59 & 89 \\
\hline 117 & DAE-71 & 48 & 670583.00 & 7695226.00 & ATIVO & Rua Dr. João Tajara da Silva / quadra 04 esqui & São Marcos & $12 / 2 / 2001$ & 142 & 44,58 & 105,71 \\
\hline 118 & DAE-72 & 53 & 669749.72 & 7694336.36 & ATIVO & Rua Adélia Munis esquina com Av. Paulo de Oli & São Marcos & & & & \\
\hline 119 & DAE-50 & 65 & & & ATIVO & Rua José Ensina, s/n_o & Schmidt & 17/11/1997 & 108 & & \\
\hline 120 & DAE-115 & 13 & 669962.50 & 7701679.49 & ATIVO & Av. Jaguaré, entre as ruas Neusa A. de C. Gard & Seyon & $23 / 8 / 2000$ & 114 & & \\
\hline 121 & DAE-116 & 13 & 669943.33 & 7701579.76 & ATIVO & Praça, entre as ruas Jordão Marques da Silva, 1 & Seyon & $12 / 12 / 1997$ & 120 & & \\
\hline 122 & DAE-134 & 08 & 668196.95 & 7702614.56 & ATIVO & Av. Falavina, na saída para Mirassolândia, próx & Simões & $15 / 2 / 2001$ & & & \\
\hline 123 & DAE-118 & 11 & 664284.96 & 7701442.26 & ATIVO & Rua 1_ de Março (parte sem pavimentação, ao & Solo Sagrado II & $8 / 9 / 1995$ & & & \\
\hline 124 & DAE-21 & 11 & 665725.18 & 7701678.39 & ATIVO & Rua Maria E. Ferreira x Rua José Bossa & Solo Sagrado & 12/9/1989 & & & \\
\hline 125 & DAE-22 & 11 & 665754.05 & 7701397.10 & ATIVO & $\begin{array}{l}\begin{array}{l}\text { Rua Manoel C. Branco } x \text { rua D. José I. } \\
\text { Golçalves }\end{array} \\
\end{array}$ & Solo Sagrado & $13 / 12 / 2000$ & 120 & & \\
\hline 126 & DAE-23 & 11 & 665660.00 & 7701488.73 & ATIVO & Rua Manoel C. Branco, ao lado do reservatório & Solo Sagrado & $7 / 12 / 2000$ & 132 & 70 & \\
\hline 127 & DAE-24 & 11 & 665482.84 & 7701453.65 & ATIVO & Rua Maria E. Ferreira x rua Beatriz Conceição & Solo Sagrado & 10/5/2001 & & & \\
\hline 128 & DAE-25 & 11 & 665667.63 & 7701253.07 & ATIVO & Rua D. José I. Gonçalves x rua Beatriz Conceiç & Solo Sagrado & $21 / 2 / 2000$ & 120 & & \\
\hline 129 & DAE-80 & 11 & 664700.76 & 7701924.69 & ATIVO & Av.S.J.Rio Preto x rua Padre Santo Marini & Solo Sagrado & $22 / 2 / 2000$ & 78 & & \\
\hline 130 & DAE-117 & 11 & 664370.52 & 7701738.21 & ATIVO & Rua 10 de Abril x Rua Projetada nove (junto a c & Solo Sagrado II & $26 / 10 / 2000$ & 126 & & \\
\hline 131 & DAE-113 & 18 & 670013.76 & 7700943.61 & ATIVO & Rua Miguel Scarpeli, s/n em fr. Ao $n^{\circ} 170$ & Sta. Rosa I & & & & \\
\hline 132 & DAE-114 & 14 & 670252.40 & 7701106.63 & ATIVO & Rua José Rombaiolo esq com Rua M. Tambu & Sta. Rosa II & 23/8/1994 & & & \\
\hline 133 & DAE-137 & $\mathbf{T}$ & 67737.72 & 7709178.33 & ATIVO & Rua Capitão Delmiro x rua Ezequiel Pinto & Talhados & $10 / 2 / 2000$ & 54 & & \\
\hline 134 & DAE-74 & 52 & 668883.36 & 7694670.19 & ATIVO & Av.Getúlio Vargas, próximo à rua Maria Cury e & Tangará & $5 / 12 / 2000$ & 120 & & \\
\hline 135 & DAE-75 & 45 & 664635.81 & 7695085.35 & ATIVO & Rua Joaquim Fernandes Diniz $\mathrm{x}$ rua Vicente de & Tarraf - II & 18/8/1998 & 120 & & \\
\hline 136 & DAE-76 & 50 & 664586.54 & 7695007.91 & ATIVO & Rua Joaquim F. Diniz, próximo à rua Vicente de & Tarraf - II & $24 / 8 / 1998$ & 96 & & \\
\hline 137 & DAE-56 & 59 & 672513.36 & 7693796.96 & ATIVO & Rua Maria C. Volpe, entre rua Maria Molinari x $r$ & Toninho & $3 / 8 / 2000$ & 109 & 54 & 75 \\
\hline 138 & DAE-57 & 59 & 672649.61 & 7693863.77 & ATIVO & Rua Maria C. Volpe (ex-rua 2), entre as ruas Oli & Toninho & $20 / 8 / 1999$ & 120 & & \\
\hline 139 & DAE-58 & 59 & 672604.93 & 7693627.72 & ATIVO & Rua Antonio Lopes (ex-rua 5) x rua Maria C.Vol & Toninho & 16/4/1996 & 114 & & \\
\hline 140 & DAE-06 & 47 & 669358.58 & 7695788.31 & ATIVO & R. Centenário, em frente ao n¹514, entre as ru & Urano & $26 / 8 / 1996$ & & & \\
\hline 141 & DAE-07 & 47 & 669459.57 & 7695750.53 & ATIVO & Av. Potirendaba $x$ av. Vivendas $x$ rua Padre A. & Urano & & & & \\
\hline 142 & DAE-08 & 47 & 669715.15 & 7695935.93 & ATIVO & Av. Vivendas $x$ av. São Vitor & Urano & & & & \\
\hline
\end{tabular}




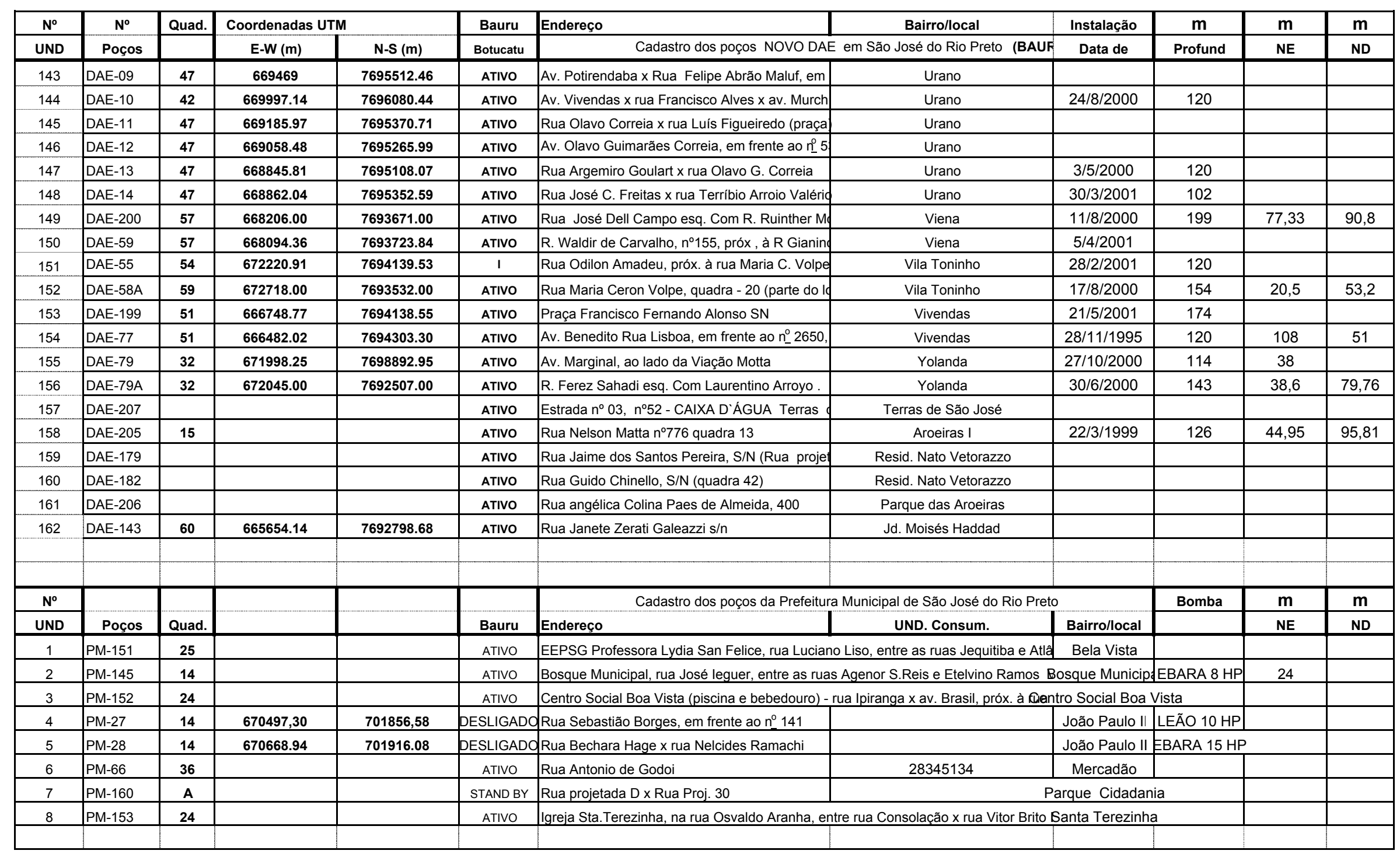


ANEXO 5 - Dados referentes aos poços registrados no DAEE - BTG 


\begin{tabular}{|c|c|c|c|c|c|c|c|c|c|c|c|c|c|c|}
\hline PoçoI & & Endereço & Uso & Proprietário & Atividade & Ano & Coordena & das UTM & Cota do te & Prof. & Vazão & $\mathrm{NE}$ & ND & Perfil litoestratigráfico \\
\hline $\mathrm{N}^{\mathrm{L}}$ & DAEE & & & & & Const & $-W$ & $\mathrm{~N}-\mathrm{S}$ & & $(\mathrm{m})$ & $(\mathrm{m} 3 / \mathrm{h})$ & (m) & $(\mathrm{m})$ & \\
\hline 1 & 789 & Cerâmica São José & Privado & Maurício Trigo Cia. & Doméstico & 1971 & 670.110 & 7.699 .950 & 515 & 100 & 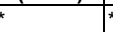 & & & 0-100 Bauru \\
\hline 2 & 790 & Praça São Sebastião, B. Talhado & Público & Prefeitura Municipal & Público & 1969 & 677.750 & 7.709 .150 & 519 & 110 & $12^{*}$ & & * & $0-110$ Bauru \\
\hline 3 & 791 & Barreiro & Privado & Santo Vironi & Doméstico & \begin{tabular}{|c|}
1972 \\
\end{tabular} & 666.700 & 7.706 .820 & 510 & 101 & $10 *$ & & & 0-101 Bauru \\
\hline 4 & 792 & Chácara Madalena & Privado & Valdemar M. Rodrigues & Doméstico & 1974 & 667.800 & 7.708 .070 & 510 & 108 & $13^{*}$ & & & Sem descrição \\
\hline 5 & 793 & Chácara & Privado & Siriaco I. Brunchi & Doméstico & & 668.000 & 7.708 .350 & 510 & & $4^{*}$ & & & Sem descrição \\
\hline 6 & 794 & Estância São Judas Tadeu & Privado & \begin{tabular}{|l|} 
Willian Ralid \\
\end{tabular} & Doméstico & & 673.350 & 7.710 .120 & 455 & & $9^{*}$ & & & Sem descrição \\
\hline 7 & 795 & Fazenda Santa Isabel & Privado & Alceu C. Machado & Doméstico & & 671.600 & 7.709 .100 & 485 & 62 & $9^{*}$ & & & $0-62$ Bauru \\
\hline 8 & 796 & Sítio São Jorge & Privado & Silvio Macedo & Doméstico & & 672.250 & 7.708 .520 & 505 & & 12 & & & Sem descrição \\
\hline 9 & 797 & Sítio São Miguel & Privado & Miguel Kfouri & Doméstico & 1969 & 672.850 & 7.708 .470 & 510 & & $+x$ & & & Sem descrição \\
\hline 10 & 798 & Fazenda Santa Herminia & Privado & Faiçal Romano Calil & Doméstico & 1974 & 673.650 & 7.706 .120 & 545 & 102 & $6^{*}$ & & & 0-102 Bauru \\
\hline 11 & 799 & Auto Posto 52 & Privado & Auto Posto 52 Ltda. & Doméstico & 1970 & 673.150 & 7.707 .070 & 530 & 120 & $5^{*}$ & & & 0-120 Bauru \\
\hline 12 & 800 & Chácara Pandin & Privado & João Lopes Pandin & Doméstico & & 672.150 & 7.705 .650 & 530 & 110 & $6^{*}$ & & & 0-110 Bauru \\
\hline 13 & 801 & Sítio Alto Alegre & Privado & E. João Gossin & Doméstico & & 673.250 & 7.705 .650 & 530 & 83 & $9^{*}$ & & * & Sem descrição \\
\hline 14 & 802 & Rodovia São José do Rio Preto & Privado & Antônio Pimenta & Doméstico & & 674.470 & 7.705 .870 & 560 & & 5 & & & Sem descrição \\
\hline 15 & 803 & Av. Duque de Caxias, 395 & Privado & Wisnan Gabriel & Doméstico & 1975 & 669.600 & 7.698 .250 & 470 & 80 & $13 *$ & & & $0-80$ Bauru \\
\hline 16 & 804 & Av. Duque de Caxias, 597 & Privado & Dr. Orestes R. dos Santos & Doméstico & 1975 & 669.800 & 7.698 .300 & 470 & 117 & 13 & 2 & * & 0-116,9 Bauru; 116,9-117 Basalto \\
\hline 17 & 805 & Rua do Trevo & Privado & Dr. Ítalo Buzzola & Doméstico & 1975 & 669.600 & 7.698 .350 & 480 & 118 & 20 & 8,5 & & $0-118$ Bauru \\
\hline 18 & 806 & Av. das Hortêcias & Privado & \begin{tabular}{|l|} 
José P. Constantin \\
\end{tabular} & Doméstico & 1974 & 669.800 & 7.698 .350 & 480 & 80 & 14 & & & $0-80$ Bauru \\
\hline 19 & 807 & Rua dos Lírios, Av das Hortências & Privado & Guilherme de La Cruz Corc & Doméstico & 1975 & 669.950 & 7.698 .450 & 480 & 117 & $x$ & & * & 0-117 Bauru \\
\hline 20 & 808 & Av. Marginal, 5020 & Privado & Cirasa (Agência Nova) & Industrial & 1973 & 668.500 & 7.696 .650 & 490 & 102 & 12 & 24 & & 0-102 Bauru \\
\hline 21 & 809 & Av. Duque de Caxias - Centro Esportivo & Público & Prefeitura Municipal & Público & 1974 & 670.050 & 7.697 .950 & 470 & 114 & 25 & & & 0-102 Bauru; 102-114 Basalto \\
\hline 22 & 810 & Rua São Paulo / Duque de Caxias & Público & Prefeitura Municipal & Público & 1974 & 669.400 & 7.698 .300 & 470 & 150 & $30 *$ & & & 0-140 Bauru: $140-150$ Basalto \\
\hline 23 & 811 & Prolongamneto da Av. 1 / Rua José Degu & Público & Prefeitura Municipal & Público & 1973 & 671.400 & 7.701 .400 & 482 & & $30^{\circ}$ & & & Sem descrição \\
\hline 24 & 812 & Jardim Eldorado & Público & Prefeitura Municipal & Público & 1975 & 666.300 & 7.701 .050 & 518 & 209,2 & $80^{*}$ & & & 0-199,8 Bauru; 199,8-209,2 Basalto \\
\hline$\frac{24}{25}$ & 813 & Jardim Eldorado & Público & Prefeitura Municipal & Público & 1972 & $\frac{000.000}{66.800}$ & 7.700 .850 & 510 & \begin{tabular}{|r|r|}
20,2 \\
192 \\
\end{tabular} & $366^{*}$ & & * & 0-191,9 Bauru; 191,9-192 Basalto \\
\hline 26 & 814 & Chácara Tranqüilidade & Privado & Maria A.Vieira & Doméstico & 1972 & 668.100 & 7.701 .350 & 470 & 60 & $5^{*}$ & & & $0-60$ Bauru \\
\hline 27 & 815 & São José do Rio Preto & Privado & Olga de Oliveira & Doméstico & & 668.360 & 7.702 .200 & 485 & 80 & 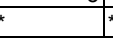 & & & $0-80$ Bauru \\
\hline 28 & 816 & Eng. Schmidt, Rua Dr. Coutinho, 447 & Público & Prefeitura Municipal & Público & 1973 & 676.150 & 7.691 .550 & 510 & 115 & $60^{*}$ & & * & 0-115 Bauru \\
\hline 29 & 817 & Rua Francisca Curti & Privado & Refrigerantes Rio Preto & Doméstico & 1972 & 665.350 & 7.697 .450 & 519 & 170 & 49 & 31 & & 0-114 Bauru; 114-170 Basalto \\
\hline 30 & 818 & Boa Vista & Público & Prefeitura Municipal & \begin{tabular}{|l|} 
Público \\
\end{tabular} & 1971 & 667.500 & 7.698 .600 & 530 & 145 & $45^{*}$ & & & 0-17 Bauru; $137-145$ Basalto \\
\hline 31 & 819 & Distrito Industrial, Av. Principal - quadra 6 & Privado & Mattos Cia. & Industrial & 1971 & 665.300 & 7.697 .350 & 525 & 108 & 27 & 34 & & 0-108 Bauru \\
\hline 32 & 820 & Distrito Industrial & Privado & Sedas Shoee Batac & Industrial & 1974 & $\frac{0.000}{664.650}$ & 7.698 .260 & 503 & 160 & 79 & 23 & & 0-159,9 Bauru; $159,9-160$ Basalto \\
\hline 33 & 821 & Distrito Industrial & Privado & Companhia Saad do Brasil & Industrial & 1972 & 664.600 & 7.698 .100 & 485 & 103 & 12 & 17 & 27,19 & 0-103 Bauru \\
\hline 34 & 822 & Distrito Industrial & Privado & Sanbra & Industrial & 1970 & 665.250 & 7.698 .100 & 485 & 102 & 10 & 16 & & 0-102 Bauru \\
\hline 35 & 823 & Via Washington Luís, Km 442 & Público & \begin{tabular}{|l|} 
Instituto Penal Agricola \\
\end{tabular} & Público & 1966 & $\frac{0.250}{663.350}$ & 7.695 .850 & 505 & 120 & 12 & & & $0-120$ Bauru \\
\hline 36 & 824 & Via Washington Luís, Km 442 & Privado & Instituto Penal Agrícola & Doméstico & 1960 & 662.200 & 7.695 .800 & 475 & 136 & $20 *$ & & * & 0-135,9 Bauru; 135,9-136 Basalto \\
\hline 37 & 825 & Via Washington Luiss, Km 442 & Público & CATI & \begin{tabular}{|l|l|} 
Público \\
\end{tabular} & 1972 & 664.150 & 7.696 .800 & 478 & 101 & 14 & 32 & & $0-101$ Bauru \\
\hline 38 & 826 & Rua Nossa Senhora da Paz, 525 & Privado & Auto Posto Parati & Doméstico & 1975 & 670.400 & 7.699 .600 & 510 & 65 & & & & $0-65$ Bauru \\
\hline 39 & 827 & Rua Nossa Senhora da Paz & Privado & Auto Posto Bosque & Doméstico & 1973 & 671.350 & 7.700 .850 & 510 & 70 & & & & 0-70 Bauru \\
\hline 40 & 828 & Via BR 153 - Km 59 & Privado & Terraf. (Ver. SCANIA) & Doméstico & 1969 & 671.700 & 7.700 .750 & 490 & 150 & & & & Sem descrição \\
\hline 41 & 829 & Via BR $153-$ Km 59 & Privado & D.N.E.R & Doméstico & 1967 & 671.250 & 7.699 .900 & 519 & & & & & Sem descrição \\
\hline 42 & 830 & Via BR $153-$ Km 59 & Privado & Lion & Doméstico & 1967 & 671.600 & 7.700 .100 & 519 & 157 & * & & & 0-156,9 Bauru; 156,9-157 Basalto \\
\hline 43 & 831 & Chácara Maquinha & Privado & Domingos Sofredini & Doméstico & 1960 & 671.850 & 7.700 .550 & 485 & 56 & $15^{*}$ & & & $0--56$ Bauru \\
\hline 44 & 832 & Rua Benil Rofueti & Privado & Pedro José Carvalho & Doméstico & 1965 & 670.650 & 7.700 .050 & 520 & 90 & & & & 0-90 Bauru \\
\hline 45 & 833 & Av. Feliciano Salles, 1650 & Privado & João Martins & Doméstico & 1974 & 665.050 & 7.698 .050 & 485 & 70 & $x^{*}$ & & & 0-70 Bauru \\
\hline 46 & 834 & Rua Cristovão Colombo, 1374 & Privado & Antenor Vieira da Silva & \begin{tabular}{|l|} 
Irrigação \\
\end{tabular} & 1975 & 670.250 & 7.699 .850 & 514 & 125 & 14 & 30 & & 0-124,9 Bauru, $124,9-125$ Basalto \\
\hline 47 & 835 & Rua 15, Número 10 & Privado & Celso Volpe & Doméstico & 1972 & 670.450 & 7.700 .000 & 519 & 112 & & Jorrante & & $0-112$ Bauru \\
\hline$\frac{41}{48}$ & 836 & Rua Nossa Senhora da Paz & Privado & Lemar Ltda. & \begin{tabular}{|l|l|l|l|l} 
Industrial \\
\end{tabular} & 1974 & $\frac{0.400}{670.250}$ & 7.700 .650 & 510 & 81 & $\frac{12}{6}$ & 26 & & 0-18 ?; 18-81 Bauru \\
\hline 49 & 837 & Rua Nossa Senhora da Paz, 298 & Privado & Geodisel & Doméstico & 1975 & 670.250 & 7.700 .660 & 510 & 98 & 5 * & & 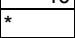 & $0-48$ ?; 48-98 Bauru \\
\hline 50 & 838 & Via BR $153-$ Km 58 & Privado & Sebo Sol Ltda. & \begin{tabular}{|l|} 
Industrial \\
\end{tabular} & 1972 & 671.750 & 7.701 .300 & 480 & 86 & $20^{*}$ & & & Sem descrição \\
\hline 51 & 839 & Chácara São José & Privado & Dr. João T. da Silva & Doméstico & 1973 & 671.900 & 7.701 .150 & 480 & 102 & 12 & 6 & & $0-102$ Bauru \\
\hline 52 & 840 & Av. Romeu Strarr & Privado & Refrigerantes Pia & \begin{tabular}{|l|} 
Industrial \\
\end{tabular} & 1964 & 668.350 & 7.696 .500 & & & 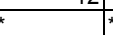 & & & Sem descrição \\
\hline 53 & 841 & Rodovia São Joaquim da Barra & Privado & Rede Globo & Doméstico & 1972 & 672.000 & 7.698 .950 & 522 & 90 & $6^{*} \times$ & & & 0-90 Bauru \\
\hline 54 & 842 & Indústria de Compressores PEG & Privado & Paulo Edair Gazola & Industrial & 1975 & 671.350 & 7.699 .500 & 519 & 75 & 4 & 31 & & 0-75 Bauru \\
\hline 55 & 843 & Via SP $425-\mathrm{km} 1$ & Privado & Pavimentadora Riqueza & Doméstico & 1969 & 672.100 & 7.699 .150 & 522 & 110 & & & & $0-110$ Bauru \\
\hline 56 & 844 & Av. Dr. Fernando Costa (Trevo) & Privado & Posto Brasília & Doméstico & 1951 & 671.150 & 7.698 .750 & 502 & 60 & 10 & 22,5 & & $0-60$ Bauru \\
\hline 57 & 845 & Rua Fernando Pierre & Privado & Transportadora H Ltda. & Doméstico & 1973 & 671.300 & 7.698 .600 & 500 & 105 & 12 & & & 0-105 Bauru \\
\hline
\end{tabular}




\begin{tabular}{|c|c|c|c|c|c|c|c|c|c|c|c|c|c|c|}
\hline \multirow{3}{*}{\multicolumn{2}{|c|}{\begin{tabular}{|l|l|} 
Poço & $\mathbf{N}^{\circ}$ \\
$\mathbf{N}^{\circ}$ & DAEE \\
\end{tabular}}} & \multirow{3}{*}{\begin{tabular}{|l|} 
Endereço \\
Via SP 425 - km 143
\end{tabular}} & \multirow{3}{*}{\begin{tabular}{|l|} 
Uso \\
Privado \\
\end{tabular}} & \multirow{3}{*}{\begin{tabular}{|l|} 
Proprietário \\
Bebidad Dunorte \\
\end{tabular}} & \multirow{3}{*}{\begin{tabular}{|l|} 
Atividade \\
Industrial \\
\end{tabular}} & \multirow{2}{*}{\multicolumn{3}{|c|}{\begin{tabular}{|l|l|l|} 
Ano & Coordenadas UTM \\
Const $E-W$ & N-S \\
\end{tabular}}} & \multicolumn{2}{|c|}{ Cota do te Prof. } & \multirow{2}{*}{$\begin{array}{l}\text { Vazão } \\
(\mathrm{m} 3 / \mathrm{h}) \\
\end{array}$} & \multirow{2}{*}{$\frac{\mathrm{NE}}{(\mathrm{m})}$} & \multirow{2}{*}{$\begin{array}{l}\mathrm{ND} \\
(\mathrm{m}) \\
\end{array}$} & \multirow[t]{2}{*}{$\begin{array}{l}\text { Perfil litoestratigráfico } \\
\end{array}$} \\
\hline & & & & & & & & & & (m) & & & & \\
\hline & & & & & & 1973 & 671.600 & 7.698 .800 & 498 & $88 * x$ & & & & $0-88$ Bauru \\
\hline 59 & 847 & Via SP $425-\mathrm{Km} 183$ & Privado & Jaime Vindes B. Puno & Doméstico & 1973 & 673.450 & 7.699 .200 & 499 & $855^{*}$ & * & & * & 0-85 Bauru \\
\hline 60 & 848 & Granja Felicidade & Privado & Walter Damiani & Doméstico & 1975 & 675.200 & 7.699 .100 & 465 & $80^{*}$ & * & & & 0-79,9 Bauru; 79.90-80 Basalto \\
\hline 61 & 849 & Fazenda Titio & Privado & Liberato Cezário Castro & Doméstico & 1975 & 675.150 & 7.699 .600 & 470 & 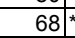 & * & & * & $0-68$ Bauru \\
\hline 62 & 850 & Sítio Monte Alto & Privado & Hermes Negrelli & Doméstico $^{*}$ & & 679.400 & 7.699 .600 & 570 & 100 & $8^{* \text { * }}$ & & * & $0-100$ Bauru \\
\hline 63 & 851 & Chácara Rancho Regina & Privado & Domingos Monia & \begin{tabular}{|l|} 
Doméstico \\
\end{tabular} & \begin{tabular}{|c|}
1972 \\
\end{tabular} & 665.750 & 7.693 .200 & 570 & 90 & $6^{*}$ & & & 0-90 Bauru \\
\hline 64 & 852 & Estância Paraíso & Privado & Aldemar Micale & Doméstico & 1972 & 665.850 & 7.693 .350 & 570 & $100 *$ & * & & * & 0-100 Bauru \\
\hline 65 & 853 & Av. Faria Lima (Chácara Primavera) & Privado & Dr. Alin Atikes & \begin{tabular}{|l|} 
Doméstico \\
\end{tabular} & 1968 & 666.250 & 7.693 .750 & 575 & $100^{*}$ & * & & & 0-100 Bauru \\
\hline 66 & 854 & Av. Faria Lima (Chácara Jolina) & Privado & Dr. Jorge Zaid & Doméstico & 1969 & 666.300 & 7.693 .950 & 575 & 106 & $12^{*}$ & & & 0-106 Bauru \\
\hline 67 & 855 & Av. Faria Lima (Fazenda Santa Helena) & Privado & Dr. P. César Custi & Doméstico & 1971 & 665.650 & 7.694 .300 & 550 & $72{ }^{*}$ & * & & * & 0-72 Bauru \\
\hline 68 & 856 & Fazenda Santa Helena (BR 153) & Privado & Francisco Fernandes & Doméstico & 1955 & 666.650 & 7.694 .250 & 575 & 100 & $6^{*}$ & & & $0-100$ Bauru \\
\hline 69 & 857 & Av. Faria Lima & Público & Presídio de menores & \begin{tabular}{|l|l|l|l|l|l|} 
Público \\
\end{tabular} & 1972 & 665.850 & 7.695 .150 & 515 & $90 *$ & & 24 & & $0-90$ Bauru \\
\hline 70 & 858 & Av. Faria Lima & Público & Lar do menor & Público & 1961 & 666.100 & 7.694 .800 & 540 & $487^{*}$ & ${ }^{*}$ & & * & Sem descrição \\
\hline 71 & 859 & Av. Faria Lima & Público & Rio Preto Esporte Club & Público & 1964 & 666.100 & 7.695 .350 & 520 & 124 & $10^{*}$ & & & 0-124 Bauru \\
\hline 72 & 860 & Rua Raul Silva & Privado & Bispado de Rio Pardo & Doméstico & 1975 & 667.150 & 7.695 .300 & 520 & 100 & $10^{*}$ & & & 0-100 Bauru \\
\hline 73 & 861 & Rua Raul Silva (Garagem municipal) & Público & Prefeitura Municipal & \begin{tabular}{|l|l} 
Público \\
\end{tabular} & 1974 & 667.100 & 7.695 .650 & 525 & 150 & $40^{*}$ & & * & 0-149,9 Bauru; $149,9-150$ Basalto \\
\hline 74 & 862 & Rua Raul Silva - Clube Recreativo & Privado & Assistência odontológica R & Doméstico & 1974 & 666.950 & 7.694 .100 & 540 & 124 & 9 & 28 & & $0-18$ ?; 18-124 Bauru \\
\hline 75 & 863 & Rua Raul (Chácara Minicipal) & Privado & Liga de combate a tubercul & \begin{tabular}{|l|} 
Doméstico \\
\end{tabular} & 1965 & 666.700 & 7.695 .100 & 550 & & * & & & Sem descrição \\
\hline 76 & 864 & Av. Faria Lima & Privado & Centro de Professorado & Doméstico & 1971 & 666.550 & 7.695 .150 & 545 & $139 *$ & * & & & 0-139 Bauru \\
\hline 77 & 865 & Rua Raul Silva & Privado & Faculdade de Odontologia & Doméstico & 1974 & 667.100 & 7.695 .100 & 535 & 102 & 11 & 20 & & $0-102$ Bauru \\
\hline 78 & 866 & Av. Faria Lima, 5928 & Privado & Auto Posto Universitário & Doméstico & 1971 & 666.800 & 7.695 .600 & 535 & 139 & $20^{*}$ & & & 0-139 Bauru \\
\hline 79 & 867 & Rua Raul Silva (Club Recreativo) & Privado & Sindicato dos Comerciários & Doméstico & \begin{tabular}{|c|}
1975 \\
\end{tabular} & 666.100 & 7.695 .850 & 525 & 108 & $9^{*}$ & & & 0-108 Bauru \\
\hline 80 & 868 & Rua Raul Silva, 1863 & Privado & APAE & \begin{tabular}{|l|} 
Doméstico \\
\end{tabular} & \begin{tabular}{|l|}
1967 \\
\end{tabular} & 666.150 & 7.696 .100 & 525 & $100^{*}$ & * & & & 0-100 Bauru \\
\hline 81 & 869 & Av. Faria Lima. 5622 & Privado & Instituto de Neurologia & \begin{tabular}{|l|} 
Doméstico \\
\end{tabular} & 1974 & 666.750 & 7.695 .900 & 525 & 100 & 8 & $33^{*}$ & & 0-100 Bauru \\
\hline 82 & 870 & Av. Faria Lima & Público & Hospital de Base & \begin{tabular}{|l|l} 
Público \\
\end{tabular} & 1951 & 666.950 & 7.696 .150 & 520 & 120 & $18^{*}$ & & & $0-120$ Bauru \\
\hline 83 & 871 & Rua Jair Mil Homens & Privado & Lourival Costa & \begin{tabular}{|l|} 
Doméstico \\
\end{tabular} & \begin{tabular}{|c|}
1975 \\
\end{tabular} & 667.250 & 7.696 .400 & 520 & 80 & $6^{*}$ & & & $0-80$ Bauru \\
\hline 84 & 872 & Rua Francisco Cal, 78 & Privado & Victor B. N. Cruz & \begin{tabular}{|l|l|} 
Doméstico \\
\end{tabular} & 1974 & 667.150 & 7.696 .350 & 520 & $60 *$ & * & & & $0-60$ Bauru \\
\hline 85 & 873 & Estância São José & Privado & C. Cocenza & Doméstico & 1966 & 664.750 & 7.691 .400 & 550 & $1177^{*}$ & * & & & 0-116,9 Bauru; 116,9-117 Basalto \\
\hline 86 & 874 & Posto Cocenza & Privado & José Cocenza Neto & Doméstico & \begin{tabular}{|l|}
1974 \\
\end{tabular} & 664.900 & 7.691 .350 & 550 & $113^{*}$ & * & & & 0-113 Bauru \\
\hline 87 & 875 & Rua Antônio de Godoy, 4944 & Privado & Antônio Del Campo & \begin{tabular}{|l|} 
Doméstico \\
\end{tabular} & 1975 & 667.400 & 7.696 .250 & 520 & $90 *$ & * & & & 0-90 Bauru \\
\hline 88 & 876 & Rua Raul Silva, s/n & Privado & Nilton Biaisi & Doméstico & 1975 & 667.350 & 7.696 .150 & 520 & $80^{*} \times$ & & & & 0-80 Bauru \\
\hline 89 & 877 & Rua Antônio de Godoy & Privado & Minerva Jales & Doméstico & 1973 & 667.200 & 7.696 .150 & 525 & & * & & & Sem descrição \\
\hline 90 & 878 & Rua Raul Silva, 333 & Privado & Dr. José Garcia Filho & Doméstico & 1975 & 667.850 & 7.696 .650 & 500 & 80 & $12^{*}$ & & & 0-80 Bauru \\
\hline 91 & 879 & Av Faria Lima, 4948 & Privado & Posto Rio Preto & Doméstico & 1950 & 667.150 & 7.696 .550 & 510 & $100^{*}$ & & & & 0-100 Bauru \\
\hline 92 & 880 & Rua Ondina, 700 & Privado & \begin{tabular}{|l|l} 
Sevom \\
\end{tabular} & Doméstico & 1960 & 666.350 & 7.696 .600 & 510 & $80 \times$ & * & & & Sem descrição \\
\hline 93 & 881 & Rua Luiz de Camões, 3150 & Público & Hosp. Beneficência Portugu| & Público & 1966 & 667.550 & 7.696 .700 & 505 & $132^{*}$ & * & & & 0-132 Bauru \\
\hline 94 & 882 & Rua Bernardino de Campos & Privado & João Bassit & Doméstico & 1975 & 668.100 & 7.697 .250 & 500 & 117 & $12^{*}$ & & & 0-117 Bauru \\
\hline 95 & 883 & Rua Capião José Marta, 1380 & Privado & Pandini Cia. & \begin{tabular}{|l|} 
Industrial \\
\end{tabular} & \begin{tabular}{|c|}
1973 \\
\end{tabular} & 669.200 & 7.695 .450 & 540 & $110^{*}$ & * & & * & $0-110$ Bauru \\
\hline 96 & 884 & Av. Romeu Shazzi, 117 & Privado & Circular Santa Luzia & Doméstico & 1973 & 668.450 & 7.696 .450 & 505 & 102 & 10 & 18 & 30 & 0-102 Bauru \\
\hline 97 & 885 & Rua Santa Maria, 875 & Privado & \begin{tabular}{|l|} 
Souza Cia Ltda. \\
\end{tabular} & Doméstico & 1971 & 668.550 & 7.699 .500 & 505 & 120 & $60^{*}$ & & & 0-119,9 Bauru; $119,9-120$ Basalto \\
\hline 98 & 886 & Av. Alberto Andalo & Privado & Rio Preto Automóvel Club & \begin{tabular}{|l|} 
Doméstico \\
\end{tabular} & \begin{tabular}{|c|}
1947 \\
\end{tabular} & 668.900 & 7.697 .950 & 485 & 104 & $18^{*}$ & & * & 0-103,9 Bauru; 103,9-104 Basalto \\
\hline 99 & 887 & Rod. SP 310 (Club Campo) & Privado & Rio Preto Automóvel Club & Doméstico & \begin{tabular}{|l|}
1974 \\
\end{tabular} & 672.110 & 7.690 .950 & 540 & 120 & 12 & $15^{*}$ & & $0-120$ Bauru \\
\hline 100 & 888 & Rua José Bonifácio, s/n & Privado & Comunidade São Judas Ta & Doméstico & 1965 & 670.850 & 7.697 .050 & 510 & $100 *$ & & & & 0-100 Bauru \\
\hline 101 & 889 & Rua machado de Assis, 201 & Privado & \begin{tabular}{|l|l} 
América de Rio Preto \\
\end{tabular} & \begin{tabular}{|l|l|} 
Doméstico \\
\end{tabular} & 1974 & 669.400 & 7.697 .150 & 510 & $120^{*}$ & & & & $0-120$ Bauru \\
\hline 102 & 890 & Rua João Mesquita, 2831 & Privado & Palestra Esporte Club & Doméstico & 1974 & 668.850 & 7.696 .350 & 490 & 102 & $22^{*}$ & & & 0-102 Bauru \\
\hline 103 & 891 & Rua Pedro Amaral, 3438 & Privado & \begin{tabular}{|l|l} 
Expresso Itamarati \\
\end{tabular} & Doméstico $^{*}$ & & 668.800 & 7.696 .000 & 485 & 154 & $10^{*}$ & & & 0-153,9 Bauru; 153,9-154 Basalto \\
\hline 104 & 892 & Av. Duque de Caxias, 3756 & Privado & Assoc.dos Func.Público Mu & Doméstico & 1972 & 669.550 & 7.697 .950 & 485 & $127 *$ & * & & & 0-127 Bauru \\
\hline 105 & 893 & Rua Capitão Faustino de Almeida, s/n & Privado & \begin{tabular}{|l|l} 
Frigorifico Bordon \\
\end{tabular} & Industrial & 1960 & 667.550 & 7.700 .050 & 460 & $90 *$ & & & & 0-90 Bauru \\
\hline 106 & 894 & Rua Capitão Faustino de Almeida, s/n & Privado & Frigorífico Bordon & Industrial & 1970 & 667.650 & 7.700 .150 & 466 & $80^{*}$ & * & & & $0-80$ Bauru \\
\hline 107 & 895 & Rua Capitão Faustino de Almeida, s/n & Privado & Frigorífico Bordon & Industrial & 1966 & 667.800 & 7.700 .200 & 525 & $130 *$ & & & & $0-130$ Bauru \\
\hline 108 & 896 & Rua João Mesquita, 676 & Privado & Fábrica de Salame Rio Pre & Industrial & 1973 & 667.400 & 7.699 .950 & 525 & $80 *$ & & & & 0-80 Bauru \\
\hline 109 & 897 & Rua do Rosário & Privado & Frigorifico Santa Cruz & Industrial & 1967 & 668.150 & 7.700 .500 & 525 & 120 & $18^{*}$ & & & $0-120$ Bauru \\
\hline 110 & 898 & Chácara Bonanza & Privado & Irene do Vale Martins & Doméstico & 1975 & 667.650 & 7.700 .700 & 505 & & * & & & Sem descrição \\
\hline 111 & 899 & Rua do Rosário, 1000 & Privado & Curtume Falavilla & \begin{tabular}{|l|} 
Industrial \\
\end{tabular} & 1964 & 668.450 & 7.700 .800 & 525 & 100 & $100^{*}$ & & & 0-100 Bauru \\
\hline 112 & 900 & Rua Oswaldo Cruz, 2905 & Privado & \begin{tabular}{|l|} 
César Filho \\
\end{tabular} & Doméstico & \begin{tabular}{|l|}
1974 \\
\end{tabular} & 666.650 & 7.696 .300 & 535 & 116 & $13^{*}$ & & & Sem descrição \\
\hline 113 & 901 & Av. Major Leoterro, s/n & Privado & Lott João Bassit & Doméstico & \begin{tabular}{|l|}
1965 \\
\end{tabular} & 671.400 & 7.696 .850 & 500 & 100 & $12^{*}$ & & & 0-100 Bauru \\
\hline & 902 & Rua Soraye - Jd. Soraia & Privado & Antenor Marchim & Doméstico & \begin{tabular}{|c|}
1967 \\
\end{tabular} & 671.400 & 7.697 .150 & & & & & & 0-80 Bauru \\
\hline
\end{tabular}




\begin{tabular}{|c|c|c|c|c|c|c|c|c|c|c|c|c|c|c|}
\hline \multicolumn{2}{|c|}{\begin{tabular}{l|l|l|l} 
Poço & $N^{\circ}$ \\
\end{tabular}} & \multirow{3}{*}{\begin{tabular}{|l|} 
Endereço \\
Rua 2, número 203
\end{tabular}} & \multirow{3}{*}{\begin{tabular}{|l|} 
Uso \\
Privado \\
\end{tabular}} & \multirow{3}{*}{\begin{tabular}{|l} 
Proprietário \\
Miguel e Kalil \\
\end{tabular}} & \multirow{2}{*}{ Atividade } & \multirow{2}{*}{\multicolumn{3}{|c|}{ Ano Coordenadas UTM }} & \multicolumn{2}{|c|}{\begin{tabular}{|l|l} 
Cota do te & Prof. \\
\end{tabular}} & \multirow{2}{*}{$\begin{array}{l}\text { Vazão } \\
\text { (m3/h) }\end{array}$} & \multirow{2}{*}{$\begin{array}{ll}\mathrm{NE} \\
(\mathrm{m})\end{array}$} & \multirow{2}{*}{$\begin{array}{l}\mathrm{ND} \\
(\mathrm{m})\end{array}$} & \multirow[t]{2}{*}{ Perfil litoestratigráfico } \\
\hline $\mathrm{N}^{0}$ & DAEE & & & & & & & & & (m) & & & & \\
\hline 115 & 903 & & & & & 1957 & 671.200 & 7.696 .450 & 510 & $107 *$ & $x^{*}$ & & & 0-107 Bauru \\
\hline 116 & 904 & Rua dos Agostinianos & Privado & Colégio São José & \begin{tabular}{|l|} 
Doméstico \\
\end{tabular} & 1961 & 669.650 & 7.696 .250 & 520 & 118 & $10^{*}$ & & * & 0-118 Bauru \\
\hline 117 & 905 & Rua Barão de Cotegipe, 89 & Privado & J. Alves Veríssimo & Doméstico & 1966 & 669.300 & 7.697 .800 & 480 & $1188^{*}$ & , & & $t$ & $0-118$ Bauru \\
\hline 118 & 906 & Praça Paul,11 & Privado & FEPASA & Doméstico & 1945 & 669.000 & 7.698 .000 & 480 & * & * & & & Sem descrição \\
\hline 119 & 907 & Av. Duque de Caxias, 3428 & Privado & Cia. Saad do Brasil & Doméstico & & 669.250 & 7.696 .000 & 480 & $x^{*}$ & 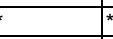 & & * & Sem descrição \\
\hline 120 & 908 & Rua Rubião, 3609 & Privado & Colégio Santo André & Doméstico & 1951 & 668.650 & 7.697 .100 & 495 & $76^{*}$ & * & & & 0-76 Bauru \\
\hline 121 & 909 & Rua Cândido Carreiro, 665 & Público & Casa de Saúde N. S. das C & GPúblico & 1960 & 668.950 & 7.697 .850 & 485 & $50 *$ & * & & * & 0-50 Bauru \\
\hline 122 & 910 & Rua Bernardino de Campos, 3128 & Privado & \begin{tabular}{|l|} 
Hotel Metrópole \\
\end{tabular} & Doméstico & 1975 & 668.300 & 7.697 .450 & 500 & 96 & $6^{* *}$ & & * & 0-96 Bauru \\
\hline 123 & 911 & Rod. SP 310 & Público & D.E.R & Público & 1973 & 670.550 & 7.695 .500 & 535 & 125 & 7 & 28 & & 0-125 Bauru \\
\hline 124 & 912 & Rod SP $310 \mathrm{Km} 433$ & Privado & Irmãos Folchini & Doméstico & 1972 & 672.170 & 7.693 .570 & 512 & 99 & $7^{*}$ & & & 0-99 Bauru \\
\hline 125 & 913 & Rod. Washington Luiz, Km 433,5 & Privado & W. Canhedo & Doméstico & 1974 & 672.400 & 7.693 .400 & 512 & 100 & $9^{*}$ & & * & 0-100 Bauru \\
\hline 126 & 914 & Praça Herrich Nordatz & Privado & Rio Preto Motor & Doméstico & 1965 & 669.470 & 7.696 .170 & 525 & 120 & 15 & 15 & & $0-125$ Bauru \\
\hline 127 & 915 & Rod. Washington Luiz, Km 433 & Privado & Sergio Salvador e Cia Ltda & a. Doméstico & 1974 & 672.800 & 7.693 .500 & 495 & $833^{*}$ & * & & * & $0-83$ Bauru \\
\hline 128 & 916 & Chácara Santa Filomena (V. Toninho) & Privado & Raimundo C. P. Carvalho & Doméstico & 1974 & 672.400 & 7.693 .950 & 502 & 85 & $66^{*}$ & & * & $0-85$ Bauru \\
\hline 129 & 917 & Chácara Nossa Senhora da Paz-Rod SP 310 & Privado & M. Loudes Benicazza & Doméstico & 1971 & 672.650 & 7.693 .750 & 503 & 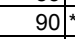 & * & & & 0-90 Bauru \\
\hline 130 & 918 & Rua 2 & Privado & Centro Social Vila Toninho & Doméstico & 1973 & 672.650 & 7.693 .650 & 503 & $80 *$ & * & & * & $0-80$ Bauru \\
\hline 131 & 919 & Chácara das Orquídeas & Privado & Rafael e João Dias & Doméstico & 1972 & 672.050 & 7.693 .250 & 510 & $98^{*}$ & * & & * & 0-98 Bauru \\
\hline 132 & 920 & Rua Coronel Spinola,5661 & Privado & Soc. Méd. Cirurgiões de S. & Doméstico & 1970 & 666.100 & 7.696 .000 & 500 & $86{ }^{*}$ & & & & $0-86$ Bauru \\
\hline$\frac{133}{133}$ & 921 & Rua Jardim, 2073 & Privado & José da Silva S.E & Doméstico & 1965 & 668.150 & 7.696 .550 & 495 & 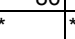 & * & & * & Sem descrição \\
\hline 134 & 922 & Rodovia Washington Luiz - Km 433 & Privado & Indústria Prellinson & \begin{tabular}{|l|} 
Industrial \\
\end{tabular} & 1971 & 671.750 & 7.693 .650 & 490 & 113 & $166^{*}$ & & & $0-113$ Bauru \\
\hline 135 & 923 & Rodovia SP $310-$ Km 435 & Privado & Liquigas & Doméstico & 1973 & 671.800 & 7.694 .200 & 485 & 88 & $8^{*}$ & & & 0-88 Bauru \\
\hline 136 & 924 & Rodovia SP $310-\mathrm{Km} 433$ & Privado & Bem-Hur & Doméstico & 1973 & 671.800 & 7.694 .000 & 485 & $100 *$ & * & & * & $0-100$ Bauru \\
\hline 137 & 925 & Av. Bady Bassit, 4870 & Privado & \begin{tabular}{|l|l|} 
Clínica Imagem \\
\end{tabular} & \begin{tabular}{|l|} 
Doméstico \\
\end{tabular} & 1975 & 667.100 & 7.697 .300 & 480 & $100 \times$ & & & & $0-100$ Bauru \\
\hline 138 & 926 & Chácara São Judas Tadeu & Privado & Seba Nassif Ardams & \begin{tabular}{|l|} 
Doméstico \\
\end{tabular} & 1975 & 671.600 & 7.693 .750 & 495 & $100 *$ & & & * & $0-100$ Bauru \\
\hline 139 & 927 & Sítio São Miguel & Privado & \begin{tabular}{|l} 
Miguel Kfouri \\
\end{tabular} & Doméstico & \begin{tabular}{|c|c|}
1970 \\
\end{tabular} & 671.400 & 7.093 .1500 & 520 & 102 & 13 & 22 & & $0-102$ Bauru \\
\hline 140 & 928 & Rua Antônio de Godoy & Privado & Ariovaldo de Castro & Doméstico & 1974 & 671.400 & 7.693 .250 & 522 & 80 & 4 & 21 & & $0-80$ Bauru \\
\hline 141 & 929 & Chácara Xodó & Privado & Joaquim Estrela & Doméstico & 1974 & 672.100 & 7.693 .700 & 500 & 110 & $8^{*}$ & & & 0-110 Bauru \\
\hline 142 & 930 & Rodovia Sp 310 - Km 433 & Privado & Severo Marchesoni & Doméstico & 1974 & 671.650 & 7.694 .250 & 480 & $120 *$ & * & & * & 0-120 Bauru \\
\hline$\frac{143}{143}$ & 931 & Rodovia SP $310-$ Km 433 & Privado & Ernesto Strazzi & Doméstico & 1970 & 670.850 & 7.693 .550 & 500 & 100 & $10^{*}$ & & & $0-100$ Bauru \\
\hline 144 & 932 & Chácara Santa Isabel & Privado & Antônio Conte & Doméstico & 1974 & 667.750 & 7.693 .500 & 495 & 85 & $10^{*}$ & & & 0-85 Bauru \\
\hline 145 & 933 & Chácara Jockey Club & Privado & Wandir Gandolfi & Doméstico & 1973 & 671.550 & 7.693 .450 & 500 & 90 & $12^{*}$ & & * & 0-90 Bauru \\
\hline 146 & 934 & Rua Marechal Deodoro, 1439 & Privado & José Carlos & Doméstico & & 671.050 & 7.693 .750 & 505 & * & * & & & Sem descrição \\
\hline 147 & 935 & Chácara Carmina & Privado & Rubens Palka & Doméstico & 1971 & 671.850 & 7.693 .850 & 480 & 105 & $10^{*}$ & & & 0-105 Bauru \\
\hline 148 & 936 & Chácara São Marcos & Privado & Joaquim Fernandes & Doméstico & 1973 & 671.750 & 7.693 .850 & 490 & $1477^{*}$ & & & * & 0-147 Bauru \\
\hline 149 & 937 & Chácara Fábio Adriano & Privado & Dr. Miguel G. B. lopes & \begin{tabular}{|l|} 
Doméstico \\
\end{tabular} & 1967 & 671.800 & 7.693 .250 & 500 & 85 & $5^{*}$ & & & 0-85 Bauru \\
\hline 150 & 938 & Rua Santos Dumont, 382 & Privado & Paulo Edair Gazola & Doméstico & 1975 & 669.550 & 7.697 .450 & 500 & $88 * x$ & & & & $0-88$ Bauru \\
\hline 151 & 939 & Rua Santos Dumont, 365 & Privado & Fortunato Gazzole & Doméstico & 1966 & 669.500 & 7.697 .600 & 490 & $70^{*}$ & & & * & 0-70 Bauru \\
\hline 152 & 940 & Rua Jorge Tiririca, 3515 & Privado & Sebastião Tavares & Doméstico & 1973 & 668.800 & 7.697 .500 & 490 & $105 *$ & & & & 0-105 Bauru \\
\hline 153 & 941 & Rua Franco Carneiro, 266 & Privado & Dr. Vicente F. Júlio & Doméstico & 1970 & 668.700 & 7.697 .500 & 480 & $60 *$ & & & & $0-60$ Bauru \\
\hline 154 & 942 & Fazenda Santo Isidoro, BR 153, Km 68 & Privado & Sebastião e Pereira & Doméstico & 1971 & 668.750 & 7.697 .450 & 480 & $120 *$ & & & * & 0-120 Bauru \\
\hline 155 & 943 & Av. Alberto Andalo, 3220 & Privado & Condomínio Edifício Rio Br & r. Doméstico & 1974 & 668.500 & 7.696 .100 & 485 & 103 & $188^{*}$ & & & 0-103 Bauru \\
\hline 156 & 944 & Rua XV, 3333 & Privado & Condomínio Edifício Ana A & AlDoméstico & \begin{tabular}{|c|c|}
1975 \\
\end{tabular} & 668.300 & 7.697 .150 & 485 & 118 & $55^{*}$ & & & $0-118$ Bauru \\
\hline 157 & 945 & Rua Antônio de Godoy, 4473 & Privado & Ariobaldo K. de Castro & Doméstico & 1974 & 667.850 & 7.696 .900 & 505 & 80 & $4^{*}$ & & * & 0-80 Bauru \\
\hline 158 & 946 & Granja Santo Antônio & Privado & Antônio Fernandes & \begin{tabular}{|l|} 
Doméstico \\
\end{tabular} & 1969 & 672.450 & 7.692 .800 & 525 & 80 & $6^{*}$ & & & $0-80$ Bauru \\
\hline 159 & 947 & Estância Fazendinha & Privado & Benedito Vargas & Doméstico * & & 672.100 & 7.691 .700 & 535 & 150 & $5 *$ & & & 0-150 Bauru \\
\hline 160 & 948 & Av. Bady Bassit / Paqueta & Privado & Auto Posto Buzzini & Doméstico & 1972 & 667.800 & 7.697 .100 & 505 & $70 *$ & & & & 0-70 Bauru \\
\hline 161 & 949 & Av. Bady Bassit & Privado & Auto Posto Homsi Ltda. & Doméstico & 1975 & 667.550 & 7.696 .900 & 510 & 60 & $10^{*}$ & & & $0-60$ Bauru \\
\hline 162 & 950 & Av. Alberto Andalo, 4005 & Privado & Antônio P. Carneiro - Lava & Doméstico & \begin{tabular}{|l|}
1971 \\
1971
\end{tabular} & 667.400 & 7.696 .850 & 510 & 80 & $15^{*}$ & & & $0-80$ Bauru \\
\hline 163 & 951 & Rua Cristovão Colombo, 2265 & Privado & FFCL São J. R. Preto & Doméstico & 1970 & 670.050 & 7.699 .800 & 505 & & & & * & Sem descrição \\
\hline 164 & 952 & BR $153-\mathrm{Km} 65$ & Público & CESP & \begin{tabular}{|l|l|} 
Público \\
\end{tabular} & 1969 & 669.450 & 7.694 .500 & 535 & $150 * x$ & & & & $0-150$ Bauru \\
\hline 165 & 953 & Fazenda São José - Rod. 425, Km 192 & Privado & Jair Barbosa & Doméstico & \begin{tabular}{|c|}
1973 \\
\end{tabular} & 666.450 & 7.692 .500 & 550 & 100 & $13^{*}$ * & & & $0-100$ Bauru \\
\hline 166 & 954 & Chácara Daud & Privado & Espólio Daud & Doméstico & 1950 & 670.400 & 7.696 .550 & 518 & & & & * & Sem descrição \\
\hline 167 & 955 & Rodovia 153, Km 62,5 & Privado & CAIC & \begin{tabular}{|l|} 
Doméstico \\
\end{tabular} & 1965 & 671.150 & 7.696 .700 & 520 & $150 * x$ & & & * & $0-150$ Bauru \\
\hline 168 & 956 & Av. Nossa Senhora da Paz, 967 & Privado & Pissolatti e Cia Ltda. & Doméstico* & & 670.100 & 7.699 .350 & 510 & & * & & * & Sem descrição \\
\hline 169 & 957 & Rua Presidente Kenedy & Privado & Oswaldo Del Machio & \begin{tabular}{|l|} 
Doméstico \\
\end{tabular} & 1974 & 670.950 & 7.697 .700 & 480 & 81 & 7 & 13 & & $0-81$ Bauru \\
\hline 170 & 958 & Rua Filho Preste & Privado & \begin{tabular}{|l|l|} 
Wilson C. Filho \\
\end{tabular} & \begin{tabular}{|l|} 
Industrial \\
\end{tabular} & 1973 & 668.700 & 7.699 .700 & 482 & 102 & 8 & 12 & & 0-102 Bauru \\
\hline 171 & 959 & Rua dos expedicionários & Privado & Noberto Ramos & Doméstico & 1972 & 668.650 & 7.698 .750 & & & & & & $0-80$ Bauru \\
\hline
\end{tabular}




\begin{tabular}{|c|c|c|c|c|c|c|c|c|c|c|c|c|c|c|}
\hline Poçon & & Endereço & Uso & Proprietário & Atividade & Ano & oordenac & das UTM & Cota do te & Prof. & Vazão & $\mathrm{NE}$ & ND & Perfil litoestratigráfico \\
\hline \begin{tabular}{l|l}
$\mathbf{N}^{\circ}$ & $\mathrm{D}$ \\
\end{tabular} & DAEE & & & & & Const & $-W$ & $\mathrm{~N}-\mathrm{S}$ & & $(\mathrm{m})$ & $(\mathrm{m} 3 / \mathrm{h})$ & (m) & $(\mathrm{m})$ & \\
\hline 172 & 960 & Rua Sebastião, s/n & Não defin & João Ramos & Não definic & 1976 & 668.250 & 7.699 .250 & 500 & & & & & Sem descrição \\
\hline 173 & 961 & Chácara Ipê & Privado & Clovis Sabela & Doméstico & 1973 & 671.400 & 7.696 .050 & 500 & 105 & $12^{*}$ & & & $0-105$ Bauru \\
\hline 174 & 962 & Rua Boa Vista & Não Defin & Mário Henrique Pereira & Não Definiq & & 668.350 & 7.698 .300 & 480 & 90 & 4 * & & & 0-90 Bauru \\
\hline 175 & 963 & Chácara Maia (Rodovia Washington Luiz) & Privado & José Alves Menezes & Doméstico & 1971 & 664.050 & 7.694 .100 & 545 & 100 & $10^{*}$ & & & $0-100$ Bauru \\
\hline 176 & 964 & Chácara Boa Esperança & Privado & Mário T. Vieira & Doméstico & 1972 & 665.250 & 7.694 .150 & 540 & & * & & & Sem descrição \\
\hline 177 & 965 & Rodovia Washington Luiz, Km 429 & Privado & Auto Posto Texaco & Doméstico & 1969 & 674.550 & 7.690 .700 & 520 & 95 & $55^{*}$ & & & 0-95 Bauru \\
\hline 178 & 966 & Rodovia SP - $310, \mathrm{Km} 445$ & Privado & Monte Libano Clube & Doméstico & 1969 & 662.200 & 7.697 .500 & 504 & 70 & $20^{*}$ & & 33,74 & 0-70 Bauru \\
\hline 179 & 967 & Chácara Penal, Rodovia BR-153, Km 69 & Privado & Abel Silveira Mendes & Doméstico & 1964 & 663.750 & 7.690 .300 & 570 & 110 & $12^{*}$ & & & 0-110 Bauru \\
\hline 180 & 968 & Rua José Anisio Yoka / Rua Felipe Gataz (próximo ach & Público & Prefeitura Municipal & Público & & 665.590 & 7.696 .840 & & 182,9 & 34 & 54,98 & 87,1 & Sem descrição \\
\hline 181 & 969 & Rua Rio Paranapanema/Rua Anísio H. Gabriel & Público & Prefeitura Municipal & Público & & 666.200 & $7.694 .270^{*}$ & & & $20^{*}$ & & & Sem descrição \\
\hline 182 & 970 & Rua Rio Paranapanema / Rua Nadir Kenan (próximo & Público & Prefeitura Municipal & Público & & 665.910 & $7.694 .410^{*}$ & * & & $30^{*}$ & & & Sem descrição \\
\hline 183 & 971 & Av. N. S. da Paz / Rua Beny Roqueti & Público & Prefeitura Municipal & Público & & 670.880 & $7.700 .100 *$ & & & 9 & $40,7^{*}$ & & Sem descrição \\
\hline 184 & 972 & Av. Fortunato Vetorazzo / Av. Eribelto M. Reino & Público & Prefeitura Municipal & Público & & 664.430 & $7.700 .110^{*}$ & & & $15^{*}$ & & & Sem descrição \\
\hline 185 & 973 & Av. B/Fortunato Vetorazzo (em frente r. M.Q.J.Medeirf & Público & Prefeitura Municipal & Público & & 664.550 & $7.700 .060^{*}$ & * & & $16^{*}$ & & & Sem descrição \\
\hline 186 & 974 & Rua Rogério Cevizzi / Rua Benedito T. de Oliveira & Público & Prefeitura Municipal & Público & & 664.460 & $7.700 .320 *$ & & & 24 * & & & Sem descrição \\
\hline 187 & 975 & Av. Jesus Vila Nova Vidal / Rua José Anísio & Público & Prefeitura Municipal & Público & & 665.700 & $7.696 .990^{*}$ & & & $20^{*}$ & & & Sem descrição \\
\hline 188 & 976 & Rua Manoel C. Branco (ao lado do reservatório do bal & Público & Prefeitura Municipal & Público & 1989 & 665.420 & $7.701 .620^{*}$ & * & 190 & $22^{*}$ & & & 0-190 Bauru \\
\hline 189 & 977 & Rua Manoel C. Branco / Rua D. José I. Golçalves & Público & Prefeitura Municipal & Público & 1989 & 665.540 & $7.701 .510 *$ & & 180 & 24 * & & & $0-180$ Bauru \\
\hline 190 & 978 & Rua Maria E. Ferreira / Rua Beatriz Conceição & Público & Prefeitura Municipal & Público & & 665.270 & $7.701 .570 *$ & & & $20^{*}$ & & & Sem descrição \\
\hline 191 & 979 & Rua D. José I. Gonçalves / Rua Beatriz Conceição & Público & Prefeitura Municipal & Público & & 665.470 & $7.701 .3700^{*}$ & & & $16^{*}$ & & & Sem descrição \\
\hline 192 & 980 & Rua 1 de Março (ao lado de pasto - próx. à r. 10 de All & Público & Prefeitura Municipal & Público & & 664.060 & $7.701 .560 *$ & & & $15^{*}$ & & & Sem descrição \\
\hline 193 & 981 & Rua Maria E. Ferreira / Rua José Bossa & Público & Prefeitura Municipal & Público & & 665.540 & $7.701 .800 *$ & & & $18^{*}$ & & & Sem descrição \\
\hline 194 & 982 & Av.S. J. Rio Preto / R. P. Santo Marini & Público & Prefeitura Municipal & Público & 1995 & 664.470 & $7.702 .010^{*}$ & & 120 & 28 & 36 & 65 & Sem descrição \\
\hline 195 & 983 & R.Joaquim F. Diniz / R. Vicente de Paula Barbosa & Público & Prefeitura Municipal & Público & & 664.610 & $7.695 .110^{*}$ & & & $28^{*}$ & & & Sem descrição \\
\hline 196 & 984 & Bosque Municipal, r. José leguer & Público & Prefeitura Municipal & Público & 1973 & 671.390 & $7.701 .280 *$ & & & 22 & $21,5^{*}$ & & Sem descrição \\
\hline 197 & 985 & r. Joaquim F. Diniz (próx. à r. Vicente de Paula Barbo: & Público & Prefeitura Municipal & Público & & 664.540 & $7.695 .020^{*}$ & & & * & & & Sem descrição \\
\hline 198 & 986 & R. Maria C. Volpe (entre r. Olinda Roma/Osv.Santos) & Público & Prefeitura Municipal & Público & 1980 & 672.510 & $7.693 .840^{*}$ & & 109 & 25 & 54,37 & 75,13 & Sem descrição \\
\hline 199 & 987 & C.Comunitário - R. Maria C. Volpe & Público & Prefeitura Municipal & Público & & 672.280 & $7.694 .120 *$ & & & $8^{*}$ & & & Sem descrição \\
\hline 200 & 988 & R.Antonio Lopes/R. Maria C.Volpe & Público & Prefeitura Municipal & Público & & 672.590 & $7.693 .620^{*}$ & & & $14^{*}$ & & & Sem descrição \\
\hline 201 & 989 & Rua Centenário (em frente ao no 1514) & Público & Prefeitura Municipal & Público & 1975 & 669.350 & $7.695 .810^{*}$ & & & $18^{*}$ & & & Sem descrição \\
\hline 202 & 990 & Rua José C. Freitas / Rua Terríbio Arroio Valério & Público & Prefeitura Municipal & Público & & 668.870 & $7.695 .330 *$ & & & $24^{*}$ & & & Sem descrição \\
\hline 203 & 991 & Rua Argemiro Goulart / Rua Olavo G. Correia & Público & Prefeitura Municipal & Público & & 668.810 & $7.695 .100^{*}$ & & & $20^{*}$ & & * & Sem descrição \\
\hline 204 & 992 & Av. Vivendas / Rua Francisco Alves / Av. Murchid Hor I & Público & Prefeitura Municipal & Público & 1994 & 669.970 & 7.696 .070 & & 157 & 8 & 52 & 110 & Sem descrição \\
\hline 205 & 993 & Rua Benedito Duarte (em frente a no 241 ) & Público & Prefeitura Municipal & Público & & 671.330 & $7.696 .340 *$ & & & 10 * & & & Sem descrição \\
\hline 206 & 994 & Av. Vivendas / Av. São Vitor & Público & Prefeitura Municipal & Público & 1996 & 669.710 & $7.695 .960 *$ & & 172 & 12 & 49 & 110 & Sem descrição \\
\hline 207 & 995 & Av. Potirendaba/Av. Vivendas/R. Padre A. Vieira & Público & Prefeitura Municipal & Público & 1995 & 669.450 & 7.695 .760 & & 190 & 28 & 51 & 114 & Sem descrição \\
\hline 208 & 996 & Av. Potirendaba/R. Felipe A. Maluf (em frente a Shell) & Público & Prefeitura Municipal & Público & & 669.470 & 7.695 .500 & & & 40 * & & & Sem descrição \\
\hline 209 & 997 & Rua Olavo Correia / Rua Luís Figueiredo (praça) & Público & Prefeitura Municipal & Público & & 669.280 & 7.695 .440 & & & 14 * & & & Sem descrição \\
\hline 210 & 998 & Av. Olavo Guimarães Correia (em frente ao no 530) & Público & Prefeitura Municipal & Público & 1995 & 669.120 & 7.695 .290 & & 198 & $24^{*}$ & & & Sem descrição \\
\hline 211 & 999 & R. Waldir de Carvalho, 155 (praça dos IPT-85 e 86) & Público & Prefeitura Municipal & Público & & 668.120 & 7.693 .730 & & & 24 & 18 & 66 & Sem descrição \\
\hline 212 & 1000 & R. Carlos R. de Oliveira (próx. a escola - COOPEC) & Público & Prefeitura Municipal & Público & & 666.480 & $7.693 .930 *$ & & & & & & Sem descrição \\
\hline 213 & 1001 & Av. Benedito/R. Lisboa (em frente ao no 2650) & Público & Prefeitura Municipal & Público & & 666.490 & $7.694 .320^{*}$ & & & & & & Sem descrição \\
\hline 214 & 1002 & Av. Marginal (ao lado da Viação Motta) & Público & Prefeitura Municipal & Público & & 671.990 & 7.698 .890 & & & & 26 & 114 & Sem descrição \\
\hline 215 & 1003 & R. Francisco Sizenando, 276 & Público & Prefeitura Municipal & Público & & 671.280 & 7.696 .460 & & & $13^{*}$ & & & Sem descrição \\
\hline 216 & 1004 & & Público & Prefeitura Municipal & Público & & 669.180 & 7.701 .490 & & & & & & Sem descrição \\
\hline 217 & 1005 & Rua Projetada 3 & Público & Prefeitura Municipal & Público & & 669.180 & $7.701 .460 *$ & & & * & & & Sem descrição \\
\hline 218 & 1011 & Rua Bechara Hage / Rua L. J. Nascimento & Público & Prefeitura Municipal & Público & & 670.450 & $7.701 .730^{*}$ & & & $20^{*}$ & & & Sem descrição \\
\hline 219 & 1013 & R.Manoel del Arco / Rua 25 / Rua 54 & Público & Prefeitura Municipal & Público & 1996 & 667.150 & 7.703 .020 & & & & & & Sem descrição \\
\hline 220 & 1014 & Av. Projetada B1/R. Joaquim R. dos Santos (Creche NF & Público & Prefeitura Municipal & Público & & 669.260 & $7.701 .720^{*}$ & & & * & & & Sem descrição \\
\hline 221 & 1015 & Rua 6 / Rua 39 (Escola Profissionalizante) & Público & Prefeitura Municipal & Público & 1996 & 666.780 & $7.703 .840 *$ & & 100 & 7 & 32 & & $0-100$ Bauru \\
\hline 222 & 1016 & Av. S.J.R.Preto/R. Alberto Targas (Esc. Profission.) & Público & Prefeitura Municipal & Público & 1996 & 666.600 & 7.703 .050 & & 100 & 12 & 28 & & 0-100 Bauru \\
\hline 223 & 1017 & Praça, entre as Ruas 21,52 e 53 & Público & Prefeitura Municipal & Público & 1994 & 665.430 & $7.701 .020^{*}$ & & 162 & 18 & 49 & & Sem descrição \\
\hline 224 & 1018 & R. Odilon Amadeu (Centro Comunitário) & Público & Prefeitura Municipal & Público & & 672.210 & $7.694 .240 *$ & & & & & & Sem descrição \\
\hline 225 & 1019 & Av. da Luz/R. Dionísio Cardoso (unidade escolar) & Público & Prefeitura Municipal & Público & & 665.270 & 7.696 .210 & & & & $7,9^{*}$ & & Sem descrição \\
\hline 226 & 1020 & R.Proj. A/R. José Rossi/R. José Cury/R. Proj. B & Público & Prefeitura Municipal & Público & 1997 & 671.300 & 7.695 .280 & & & & & & Sem descrição \\
\hline 227 & 1021 & Rua Bechara Hage / Rua Antonio Sbioge & Público & Prefeitura Municipal & Público & & 670.290 & 7.701 .630 & & & $14^{*}$ & & & Sem descrição \\
\hline 228 & 1022 & Posto de Saúde (Av. F.Vetorazzo x Mte Aprazivel) & Público & Prefeitura Municipal & Público & & 665.120 & $7.699 .560 *$ & & & & $18^{*}$ * & & Sem descrição \\
\hline
\end{tabular}




\begin{tabular}{|c|c|c|c|c|c|c|c|c|c|c|c|c|c|}
\hline \multirow{2}{*}{\multicolumn{2}{|c|}{$\begin{array}{l}\text { Poço } N^{\circ} \\
N^{\circ} \text { DAEE }\end{array}$}} & \multirow{2}{*}{ Endereço } & \multirow{2}{*}{ Uso } & \multirow{2}{*}{ Proprietário } & \multirow{2}{*}{ Atividade } & \multirow{2}{*}{\multicolumn{3}{|c|}{\begin{tabular}{|l|l|} 
Ano & Coordenadas UTM \\
\end{tabular}}} & $\begin{array}{ll}\text { Cota do te } & \text { Prof. } \\
\end{array}$ & \multirow{2}{*}{$\frac{\text { Vazão }}{(\mathrm{m} 3 / \mathrm{h})}$} & \multirow{2}{*}{$\begin{array}{l}\text { NE } \\
(m) \\
\end{array}$} & \multirow{2}{*}{$\begin{array}{l}\mathrm{ND} \\
(\mathrm{m}) \\
\end{array}$} & \multirow{2}{*}{$\begin{array}{l}\text { Perfil litoestratigráfico } \\
\end{array}$} \\
\hline & & & & & & & & \begin{tabular}{|l|l}
$\mathrm{N}-\mathrm{S}$ & $\mathrm{l}$ \\
\end{tabular} & \begin{tabular}{|l|l|} 
& $(\mathbf{m})$ \\
\end{tabular} & & & & \\
\hline 229 & 1023 & Lar Beatriz Conceição & Público & Prefeitura Municipal & Público & & 665.980 & 7.700 .420 & & & & & Sem descrição \\
\hline 230 & 1024 & Rua Nelson Freitas, 805 & Privado & Condomínio Edifício Alabar & Doméstico & 1996 & 665.110 & 7.699 .350 & 100 & 10 & 34 & 46 & Sem descrição \\
\hline 231 & 1025 & Escola Laerte T. da Costa (Ruas Haiti x Bait Chalela) F & Público & \begin{tabular}{|l|l} 
Prefeitura Municipal \\
\end{tabular} & Público & 1996 & 670.540 & 7.699 .350 & 100 & 12 & 24 & 48 & 0-92 Bauru \\
\hline 232 & 1026 & Rua Pedro Góes / Rua Guiomar A. Kalil & Privado & Condomínio Elite's Parh & Doméstico & & 665.590 & 7.698 .220 & & & & & Sem descrição \\
\hline 233 & 1027 & Rua Santina Figliage Cecato, 450 & Privado & Condomínio Village Itália II & Doméstico & 1996 & 665.560 & 7.698 .440 & 110 & 14 & 30 & 44 & Sem descrição \\
\hline 234 & 1028 & BBILCE - UNESP - Campus S.J.Rio Preto & Público & \begin{tabular}{|l|l|l|} 
UNESP \\
\end{tabular} & Público & 1997 & 670.750 & 7.700 .800 & $150^{*}$ & & $48,84^{*}$ & & Sem descrição \\
\hline 235 & 1029 & Rua Tiradentes, 2640 & Privado & Edifício Roberto M. Honsi & Doméstico & & 668.450 & 7.698 .250 & 100 & 12 & 28 & 46 & Sem descrição \\
\hline 236 & 1030 & Rua Bechara Hage (em frente ao no 1140) & Público & Prefeitura Municipal & Público & & 670.610 & 7.701 .860 & & 20 & & & Sem descrição \\
\hline 237 & 1031 & Creche (entre as r. Fernando Pessoa e Fco. A. AndralF & Público & Prefeitura Municipal & Público & 1996 & 670.540 & 7.702 .330 & 100 & 8 & 42 & 62 & $0-100$ Bauru \\
\hline 238 & 1032 & Rua Carmelino G. Condessa, 650 & Privado & Condomínio Ulisses J. Cury & Doméstico & & 666.670 & 7.697 .070 & $100^{*}$ & & & & Sem descrição \\
\hline 239 & 1033 & Rua Benjamin Constant, 4050 & Privado & Condomínio Angra dos Reil & Doméstico & 1996 & 667.580 & 7.697 .380 & $100^{*}$ & & 30 & 44 & Sem descrição \\
\hline 240 & 1034 & EEPSS Maria G. Nora - Av. Antonio Pereira da Silva, & Público & \begin{tabular}{|l|l|} 
Prefeitura Municipal \\
\end{tabular} & Público & 1996 & 664.520 & 7.699 .730 & 100 & 10 & 41 & 55 & Sem descrição \\
\hline 241 & 1035 & Rua Nelson Freitas, 365 (próximo à Rua Santa Paula) & Privado & Condomínio Residencial Pi & Doméstico & 1996 & 665.180 & 7.699 .010 & 80 & 11 & 18 & 36 & Sem descrição \\
\hline 242 & 1036 & Rodovia SP 425, $\mathrm{km} 1,5$ & Privado & \begin{tabular}{|l|l|} 
Encalso Constr.Ltda. \\
\end{tabular} & Doméstico & 1996 & 672.740 & 7.699 .220 & 142 & 33 & 50 & 114 & Sem descrição \\
\hline 243 & 1037 & R. Lino Braile (entre as r. Ant. Godoi e Anísio Haddad F & Privado & Rio Preto Shopping Center & Doméstico & 1996 & 666.650 & 7.695 .130 & 202 & 34 & 42 & 130 & Sem descrição \\
\hline 244 & 1038 & Rua Isidoro Pupim, 2100 & Privado & Lécio Pneus (antigo Saad) & Doméstico & 1972 & 664.770 & 7.698 .270 & 103 & 12 & 17 & 27,19 & Sem descrição \\
\hline 245 & 1039 & Clube Monte Libano (próximo à divisa com Mirassol) & Privado & Clube Monte Libano & Doméstico & 1969 & 661.850 & 7.697 .550 & 110 & 6 & 37,1 & 38,42 & $0-110$ Bauru \\
\hline 246 & 1040 & Chácara Julião (a $2 \mathrm{~km}$ do Rio Preto Automóvel Clubef & Erivado & Marcos Cásar Julião & Doméstico & & 672.400 & 7.691 .090 & 150 & 5 & 37,27 & 47,85 & Sem descrição \\
\hline 247 & 1041 & Centro Social Boa Vista - Rua Ipiranga / Av. Brasil & Público & Prefeitura Municipal & Público & 1975 & 668.750 & 7.699 .550 & & 15 & $16^{*}$ & & Sem descrição \\
\hline 248 & 1042 & Rio Preto Automóvel Clube & Privado & Rio Preto Automóvel Clube & Doméstico & 1974 & 673.360 & 7.692 .090 & 120 & 13 & 13,8 & 26 & Sem descrição \\
\hline 249 & 1043 & Rua Jorge Tibiriçá, 3515 & Privado & Sebastião Tavares & Doméstico & 1973 & 668.950 & 7.697 .520 & 105 & & 14,35 * & & Sem descrição \\
\hline 250 & 1044 & Rua Otávio Pinto Cesar, 1400 & Público & DAEE & Público & 1980 & 668.280 & 7.694 .640 & 130 & 13 & 21,8 & 59,8 & 0-130 Bauru \\
\hline 251 & 1045 & Rua Raul Silva/Rua Fco. das Chagas Oliveira & Privado & Assoc. Odontol./S.J.R.P. & Doméstico & & 666.890 & 7.695 .490 & 124 & 9 & 12,35 & 40 & Sem descrição \\
\hline 252 & 1046 & Escola Cenobelina B. Seabra - Av. da Saudade & Público & Prefeitura Municipal & Público & & 669.290 & 7.697 .540 & & 12 & $30^{*}$ & & Sem descrição \\
\hline 253 & 1047 & EEPSS Jamil Kahuan - Praça Valparaíso, s/n & Público & Prefeitura Municipal & Público & & 670.810 & 7.697 .330 & 100 & 10 & $30^{*}$ & & Sem descrição \\
\hline 254 & 1048 & EEPSG Professora Lydia San Felice - R. Luciano LiscF & Público & Prefeitura Municipal & Público & & 670.680 & 7.699 .070 & 100 & & $30^{*}$ & & Sem descrição \\
\hline 255 & 1049 & Instituto Penal Agricola - IPA (futuro distrito industrial) $\mathrm{P}$ & Público & Prefeitura Municipal & Público & & 664.490 & 7.696 .320 & & & & & Sem descrição \\
\hline 256 & 1050 & Estacionamento do ginásio Antônio Natalone / SESI & Público & Prefeitura Municipal & Público & 1974 & 670.140 & 7.697 .970 & 114 & 20 & 1,2 & & 0-114 Bauru \\
\hline 257 & 1051 & Rua General Glicério, n. 3947 & Público & Secretaria da Educação & Público & & 667.670 & 7.697 .970 & & 8 & & & Sem descrição \\
\hline 258 & 1052 & Jardim Antonieta & Público & & Público & & 662.150 & 7.697 .450 & & 22 & & & Sem descrição \\
\hline 259 & 1053 & FG (2 vendas) & Público & & Público & & 668.500 & 7.705 .900 & & 22 & & & Sem descrição \\
\hline 260 & 1054 & \begin{tabular}{|l|l}
$F G(2$ vendas $)$ & $P$ \\
\end{tabular} & Público & & Público & & 668.700 & 7.705 .850 & & 25 & & & \\
\hline 261 & 1055 & Cidade das Crianças (em frente à Av. Daniel A. Freita & Público & Prefeitura Municipal & Público & & 664.520 & 7.697 .470 & 164 & 15 & 53,76 & 100,4 & 0-114 Bauru; 114-160 Basalto \\
\hline 262 & 1056 & Cidade das Crianças (cerca de $100 \mathrm{~m}$ da entrada) & Público & Prefeitura Municipal & Público & & 664.510 & 7.697 .310 & & $15^{\circ}$ & & & Sem descrição \\
\hline 263 & 1057 & Rua Sílvio Colombo (próximo à rodovia Marginal) & Público & Prefeitura Municipal & Público & & 669.810 & 7.694 .530 & 166,1 & 15 & 54,34 & 85 & Sem descrição \\
\hline 264 & 1058 & \begin{tabular}{|l|l} 
Rua Rajide Jamal / Rua Silvio Colombo \\
\end{tabular} & Público & Prefeitura Municipal & Público & & 670.060 & 7.694 .500 & 126 & 13 & 45,1 & 57,59 & Sem descrição \\
\hline 265 & 1059 & Canteiro interno da Av. 1/R. Marinha (próx. ao SOS g: $\mathrm{F}$ & Público & Prefeitura Municipal & Público & 1993 & 669.720 & 7.694 .330 & 163 & 13 & 49 & 107 & Sem descrição \\
\hline 266 & 1060 & Rua 25 de Janeiro (ex-Rua Subh Jamal) / Av. Jaguaré & Eúblico & Prefeitura Municipal & Público & & 669.180 & 7.702 .280 & & 14 & & & Sem descrição \\
\hline 267 & 1061 & \begin{tabular}{|l|l} 
Rua $1 /$ Rua 7 & F
\end{tabular} & Público & Prefeitura Municipal & Público & & 670.530 & 7.703 .800 & & 15 & & & Sem descrição \\
\hline 268 & 1062 & Rua Antonio Buzzini / Rua E & Público & Prefeitura Municipal & Público & & 670.500 & 7.703 .550 & & 13 & & & Sem descrição \\
\hline 269 & 1063 & Av. Mirassolândia - R. Santa Paula/R. Sebastião Fiuz:F & Público & Prefeitura Municipal & Público & & 667.300 & 7.700 .800 & & 26 & & & Sem descrição \\
\hline 270 & 1064 & Rua Proj. A (entre as r. José Rossi e José J. Cury) & Público & Prefeitura Municipal & Público & & 671.260 & 7.695 .300 & & 25 & & & Sem descrição \\
\hline 271 & 1065 & Rua José Cury, próximo à Rua Projetada A & Público & Prefeitura Municipal & Público & & 671.290 & 7.695 .320 & & $20^{\circ}$ & & & Sem descrição \\
\hline 272 & 1066 & Rua Projetada B, entre as Ruas José Rossi e José CLF & Lúblico & Prefeitura Municipal & Público & & 671.370 & 7.695 .170 & & 25 & & & Sem descrição \\
\hline 273 & 1067 & Av. América (entre r. da Imprensa e Padre J. Bento) & Público & Prefeitura Municipal & Público & & 669.630 & 7.696 .810 & & 24 & & & Sem descrição \\
\hline 274 & 1068 & Rua Jales/R. Indiaporã/R. Antonio Marmo & Público & Prefeitura Municipal & Público & & 666.250 & 7.701 .270 & 162,6 & 24 & 80 & 93,67 & Sem descrição \\
\hline 275 & 1069 & Secr. Mun. de Esportes - Av. Monte Aprazível / Rua JiF & Público & Prefeitura Municipal & Público & 1972 & 666.600 & 7.700 .950 & 192 & 32 & & & 0-192 Bauru \\
\hline 276 & 1070 & Praça - Av. Mirassolândia/R. Pereira Barreto & Público & Prefeitura Municipal & Público & & 666.480 & 7.701 .340 & 156,2 & 30 & 44 & 105 & Sem descrição \\
\hline 277 & 1071 & Praça - R. Estrela D'Oeste/Santana do Parnaíba & Público & Prefeitura Municipal & Público & & 666.120 & 7.700 .950 & 147,1 & 32 & 58,68 & 85,76 & Sem descrição \\
\hline 278 & 1072 & Rua Três Lagoas - $3741 / 3761$ & Público & Prefeitura Municipal & Público & 1992 & 666.130 & 7.701 .190 & 170 & 24 & 69,2 & 114,4 s & Sem descrição \\
\hline 279 & 1073 & Rua Antonio G. Lourenço (em frente ao no 1436) & Público & Prefeitura Municipal & Público & 1995 & 669.380 & 7.702 .370 & 120,6 & 22 & 28 & 72 & 0-120 Bauru/ Adamantina; $120-$ \\
\hline 280 & 1074 & Rua 25 de Janeiro / Rua Hormínio de Oliveira & Público & Prefeitura Municipal & Público & & 669.580 & 7.702 .620 & & 18 & & & Sem descrição \\
\hline 281 & 1075 & Av.Getúlio Vargas (próx. à escola João J. Sabino) & Público & Prefeitura Municipal & Público & & 668.870 & 7.694 .670 & & 18 & & & Sem descrição \\
\hline 282 & 1076 & Palácio das Águas, r. São Paulo/r. Filadelpho G. NetoF & Público & Prefeitura Municipal & Público & 1974 & 669.190 & 7.698 .220 & 150 & 17. & orrante & & 0-140 Bauru; $140-150$ Basalto \\
\hline 283 & 1077 & \begin{tabular}{|l|l} 
Garagem Municipal, R. Raul Silva, 2054 & F \\
\end{tabular} & Público & Prefeitura Municipal & Público & 1974 & 666.920 & 7.695 .740 & 150 & 15 & 12,4 * & & $0-150$ Bauru \\
\hline 284 & 1078 & Rua Feres Kfouri / Rua 15 & Público & Prefeitura Municipal & Público & 1980 & 668.010 & 7.694 .560 & 160 & 25 & 61,73 & 94,15 & 0-150 Bauru; $140-150$ Basalto \\
\hline 285 & 1079 & & Público & Prefeitura Municipal & Público & 1995 & 667.930 & 7.694 .590 & 170 & & & & \\
\hline
\end{tabular}




\begin{tabular}{|c|c|c|c|c|c|c|c|c|c|c|c|c|c|}
\hline \multicolumn{2}{|c|}{ Poço $N^{\circ}$} & \multirow{2}{*}{ Endereço } & \multirow[t]{2}{*}{ Uso } & \multirow[t]{2}{*}{ Proprietário } & \multirow{2}{*}{ Atividade } & \multicolumn{3}{|c|}{ Coordenadas UTM } & \begin{tabular}{|l|l} 
Cota do te & Prof. \\
\end{tabular} & \multirow{2}{*}{$\begin{array}{l}\text { Vazão } \\
(\mathrm{m} 3 / \mathrm{h}) \\
\end{array}$} & \multirow{2}{*}{$\begin{array}{l}\mathrm{NE} \\
(\mathrm{m}) \\
\end{array}$} & \multirow{2}{*}{$\begin{array}{l}\text { ND } \\
\text { (m) }\end{array}$} & \multirow[t]{2}{*}{ Perfil litoestratigráfico } \\
\hline $\mathrm{N}^{\circ}$ & DAEE & & & & & Const & E-W & N-S & \begin{tabular}{|l|l|} 
& $(\mathrm{m})$ \\
\end{tabular} & & & & \\
\hline 286 & 1080 & Rua 15 / Rua Abraão Thomé (praça ao lado do DAEE & Público & Prefeitura Municipal & Público & 1995 & 668.110 & 7.694 .770 & 156 & 16 & 58 & & 0-136 Adamantina; 136-156 Sto. Anastá \\
\hline 287 & 1081 & Rua Jaguaré / Av. Danilo Galeazzi & Público & Prefeitura Municipal & Público & & 670.060 & 7.701 .720 & 141,2 & 24 & 59 & 89 & Sem descrição \\
\hline 288 & 1082 & Rua Antônio Munia / Rua José Rambaielo & Público & Prefeitura Municipal & Público & & 670.360 & 7.701 .140 & & $25^{*}$ & & & Sem descrição \\
\hline 289 & 1083 & Rua Sebastião Borges / Rua José L. Anabone & Público & Prefeitura Municipal & Público & 1989 & 670.390 & 7.701 .820 & 180 & 26 * & & & $0-180$ Bauru \\
\hline 290 & 1084 & Rua Sebastião Borges (em frente ao no 141) & Público & Prefeitura Municipal & Público & 1989 & 670.480 & 7.701 .860 & 187,6 & $26^{*}$ & & & 0-187,6 Bauru \\
\hline 291 & 1085 & Rua Bechara Hage / Rua Nelcides Ramachi & Público & Prefeitura Municipal & Público & 1989 & 670.690 & 7.701 .940 & 189,7 & ${ }^{*}$ & & & 0-189,7 Bauru \\
\hline 292 & 1086 & Rua Frederico de Freitas / Rua Alberto Batistela & Público & Prefeitura Municipal & Público & & 670.390 & 7.701 .550 & * & 22 * & & & Sem descrição \\
\hline 293 & 1087 & Rua Jamil Kfouri / Rua José Ribeiro & Público & Prefeitura Municipal & Público & & 664.120 & 7.699 .100 & * & & & & Sem descrição \\
\hline 294 & 1088 & Rua São Paulo / Rua Visconde de Porto Seguro & Público & Prefeitura Municipal & Público & 1975 & 669.880 & 7.698 .990 & 180 & $25^{*}$ & & & Sem descrição \\
\hline 295 & 1089 & Rua Wagner C. Pereira (junto à caixa d'água) & Público & Prefeitura Municipal & Público & 1988 & 667.130 & 7.702 .980 & 180 & $177^{*}$ & & & Sem descrição \\
\hline 296 & 1090 & Rua Wagner C.Pereira / Rua Manoel del Arco & Público & Prefeitura Municipal & Público & 1992 & 667.160 & 7.702 .830 & 164,2 & & 65,49 & 95,88 & Sem descrição \\
\hline 297 & 1091 & R. Theotonio M. Barros Fo./ Av. Gov. Adhemar de Bal & Público & Prefeitura Municipal & Público & & 670.570 & 7.695 .960 & & $18^{*}$ & & & Sem descrição \\
\hline 298 & 1092 & Av. Aniloel Nazareth (em frente à do Banespa) & Público & Prefeitura Municipal & Público & & 670.700 & 7.696 .020 & * & $14^{*}$ & & * & Sem descrição \\
\hline 299 & 1093 & Rua 17 (nos fundos da Concretex) & Público & Prefeitura Municipal & Público & 1989 & 664.980 & 7.696 .290 & 190 & $15^{*}$ & & & $0-190$ Bauru \\
\hline 300 & 1094 & Rua Manoel Bernardes (em frente ao n.1180) & Público & Prefeitura Municipal & Público & & 665.180 & 7.702 .630 & & $18^{*}$ & & & Sem descrição \\
\hline 301 & 1095 & Rua Manoel Bernardes (em frente ao n. 1300) & Público & Prefeitura Municipal & Público & & 665.090 & 7.702 .790 & * & $15^{*}$ & & * & Sem descrição \\
\hline 302 & 1096 & Rua Alexandre Magnum / Rua Almirante Tamandaré & Público & Prefeitura Municipal & Público & & 665.230 & 7.702 .870 & & $18^{*}$ & & & Sem descrição \\
\hline 303 & 1097 & Rua 19 de Março (entre a Rua 510 e 511) & Público & Prefeitura Municipal & Público & 1994 & 665.050 & 7.702 .360 & 180 & 16 & 48 & 112 & Sem descrição \\
\hline 304 & 1098 & Rua Almirante Tamandaré / Rua 19 de Março & Público & Prefeitura Municipal & Público & 1995 & 665.390 & 7.702 .560 & 186,5 & 30 & 64 & 108 & Sem descrição \\
\hline 305 & 1099 & Rua Raul Silva / Rua Lino Braile & Público & Prefeitura Municipal & Público & & 666.840 & 7.695 .080 & & $25^{*}$ & & & Sem descrição \\
\hline 306 & 1100 & R. Paschoal Decrescenzo/ r. 3 (próx. ao posto de saú & Público & Prefeitura Municipal & Público & & 667.590 & 7.701 .320 & 106 & $18^{*}$ & & & 0-106 Bauru \\
\hline 307 & 1101 & Rua Joaquim Pires, n. 766 & Público & Prefeitura Municipal & Público & & 666.220 & 7.695 .540 & & $22^{*}$ & & & Sem descrição \\
\hline 308 & 1102 & Rua Evaristo F.Cabral / Rua Oscar Pastore & Público & Prefeitura Municipal & Público & & 667.640 & 7.703 .270 & & $20^{*}$ & & & Sem descrição \\
\hline 309 & 1103 & Rua São João / Rua Campos Salepraça Gandhi & Público & Prefeitura Municipal & Público & 1988 & 668.220 & 7.699 .320 & & $25^{*}$ & & & Sem descrição \\
\hline 310 & 1104 & Pça. Aldo Tonelli & Público & Prefeitura Municipal & Público & 1975 & 667.480 & 7.696 .740 & & $15^{*}$ & & & Sem descrição \\
\hline 311 & 1105 & R. Monteiro Lobato (200 m da r. Adelardo C. Barros) & Público & Prefeitura Municipal & Público & & 670.850 & 7.696 .050 & 100 & 18 & 22 & 35 & Sem descrição \\
\hline 312 & 1106 & Igreja Sta.Terezinha - Rua Osvaldo Aranha & Público & Prefeitura Municipal & Público & 1996 & 668.260 & 7.699 .770 & & $20^{*}$ & & & Sem descrição \\
\hline 313 & 1107 & Possivelmente junto ao poço IPT-56 & Público & Prefeitura Municipal & Público & & 667.100 & 7.702 .980 & & $15^{*}$ & & & Sem descrição \\
\hline 314 & 1108 & Rua 25 (em frente ao $\mathrm{n}^{\circ} 101$ ) & Público & Prefeitura Municipal & Público & 1992 & 667.140 & 7.703 .040 & 159,5 & 16 & 50 & 116 & Sem descrição \\
\hline 315 & 1109 & Rua 55 / Rua 24 (em frente ao ginásio de esportes) & Público & Prefeitura Municipal & Público & & 667.280 & 7.703 .360 & & $222^{*}$ & & & Sem descrição \\
\hline 316 & 1110 & Rua 50 , em frente ao n. 202 - Ruas 26 e 27 & Público & Prefeitura Municipal & Público & 1994 & 666.980 & 7.703 .030 & 162 & 20 & 49 & 110 & Sem descrição \\
\hline 317 & 1111 & Rua 50, em frente ao n. 362 & Público & Prefeitura Municipal & Público & 1994 & 666.840 & 7.703 .050 & 144 & 22 & 50 & 114 & Sem descrição \\
\hline 318 & 1112 & Rua 31 / Rua 55 (em frente ao $\left.n^{\circ} 170\right)$ & Público & Prefeitura Municipal & Público & 1995 & 666.810 & 7.703 .270 & 150 & 20 & 50,5 & 108 & Sem descrição \\
\hline 319 & 1113 & Rua Virgílio Dias/R. Sado Nadihum (Un. Bás.Saúde) & Público & Prefeitura Municipal & Público & 1994 & 672.230 & 7.699 .660 & 135 & 20 & $35^{*}$ & & 0-103 Adamantina; 103-133 Sto. Anastá \\
\hline 320 & 1114 & R. Virgílio de Castro/R. Maria Longhi (Un. Bás. Saúde & Público & Prefeitura Municipal & Público & & 672.310 & 7.699 .780 & 124,5 & 22 & 36,82 & 50,82 & Sem descrição \\
\hline 321 & 1115 & UBS (Unidade Básica de Saúde) & Público & Prefeitura Municipal & Público & & 672.370 & 7.699 .740 & 120 & 16 & 36,45 & 86,5 & Sem descrição \\
\hline 322 & 1116 & Rua Ataliba Caldas (em frente ao n.150) & Público & Prefeitura Municipal & Público & 1994 & 672.050 & 7.699 .750 & 135 & 16 & 51 & 112 & Sem descrição \\
\hline 323 & 1117 & Rua Gianino Kaiser, n.990 & Público & Prefeitura Municipal & Público & & 668.080 & 7.693 .830 & & 16 * & & & Sem descrição \\
\hline 324 & 1118 & Rua Gianino Kaiser, n.1080 & Público & Prefeitura Municipal & Público & & 668.000 & 7.693 .700 & & $15^{*}$ * & & & Sem descrição \\
\hline 325 & 1119 & Rua Casa Blanca / Rua José Bonifácio & Público & Prefeitura Municipal & Público & & 670.940 & 7.697 .140 & 171 & 18 & 18 & 102 & Sem descrição \\
\hline 326 & 1120 & Marginal/ BR-153 (em frente ao $\left.n^{\circ} 4546\right)$ & Público & \begin{tabular}{|l|l} 
Prefeitura Municipal \\
\end{tabular} & Público & & 671.000 & 7.697 .300 & 142,8 & 30 & 30 & 50,07 & Sem descrição \\
\hline 327 & 1121 & Av. Francisco C. Oliveira / Rua Antonio de Godoi & Público & Rio Preto Shopping Center & Público & & 666.770 & 7.695 .510 & 120 & 28 & 59 & 89 & Sem descrição \\
\hline 328 & 1122 & Av. Anisio Haddad (atrás do rest. Chopim) & Público & Prefeitura Municipal & Público & & 666.500 & 7.695 .440 & & 24 * & & & Sem descrição \\
\hline 329 & 1123 & Rua Rio Juquiá / Ruas Rio Solimões / Rua Rio Mamo| & Público & Prefeitura Municipal & Público & & 666.130 & 7.694 .930 & & $20^{*}$ & & & Sem descrição \\
\hline 330 & 1124 & Rua Antonio de Godoy / Rua Joaquim Barbeiro & Público & Prefeitura Municipal & Público & & 666.920 & 7.695 .820 & & $20^{*}$ & & & Sem descrição \\
\hline 331 & 1125 & Rua Sinésio de Melo / Rua Raul Silva (almoxarifado) & Público & Prefeitura Municipal & Público & & 667.010 & 7.695 .690 & & $188^{*}$ & & & Sem descrição \\
\hline 332 & 1126 & Praça, entre as R. Jordão M. da Silva e Nicolau Dumb & Público & Prefeitura Municipal & Público & & 669.930 & 7.701 .590 & & 26 & 42 & 104 & Sem descrição \\
\hline 333 & 1127 & Av. Jaguaré (r. Neusa A. de C. Garcia/Jordão M. da S & Público & Prefeitura Municipal & Público & & 669.970 & 7.701 .700 & & $28^{*}$ & & & \\
\hline 334 & 1128 & Av. Falavina (na saída para Mirassolândia) & Público & Prefeitura Municipal & Público & & 668.050 & 7.702 .770 & & $244^{*}$ & & & Sem descrição \\
\hline
\end{tabular}

